
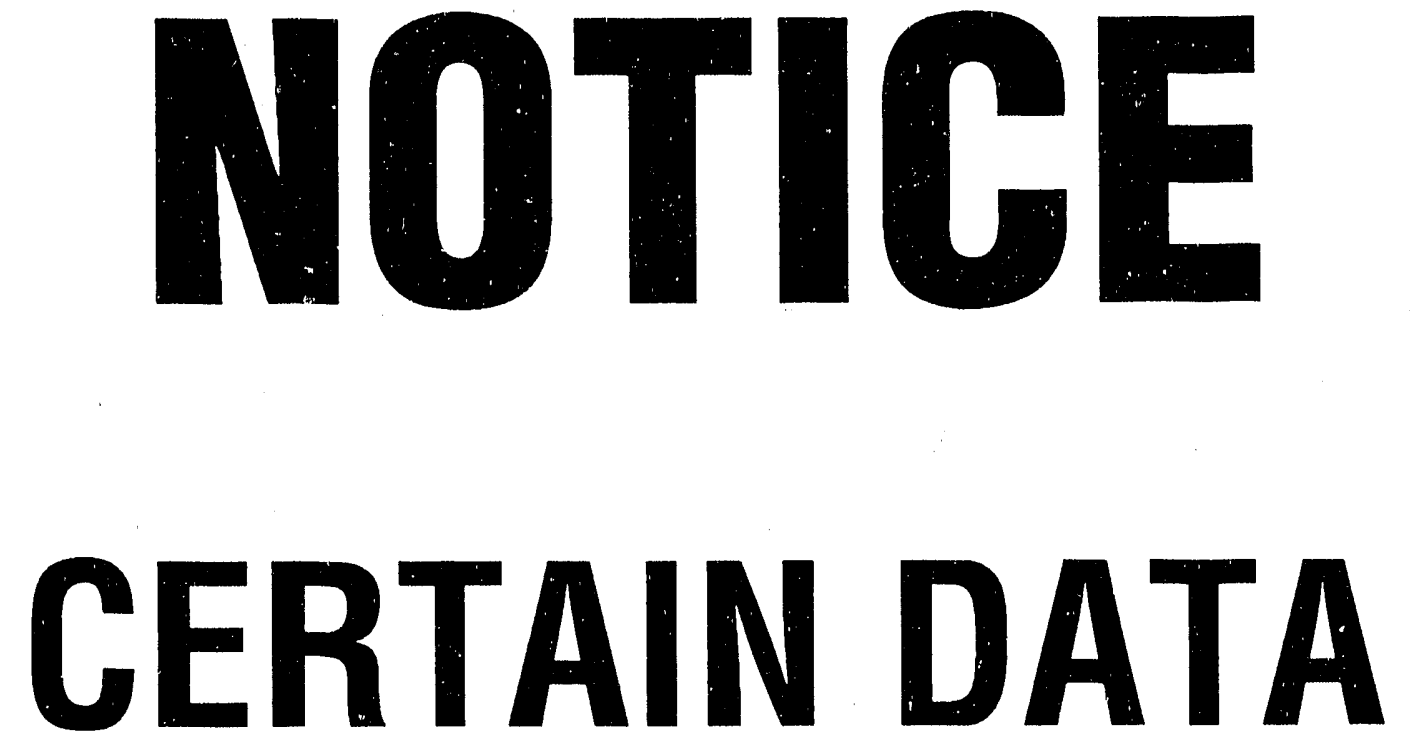

CONTAINED IN THIS
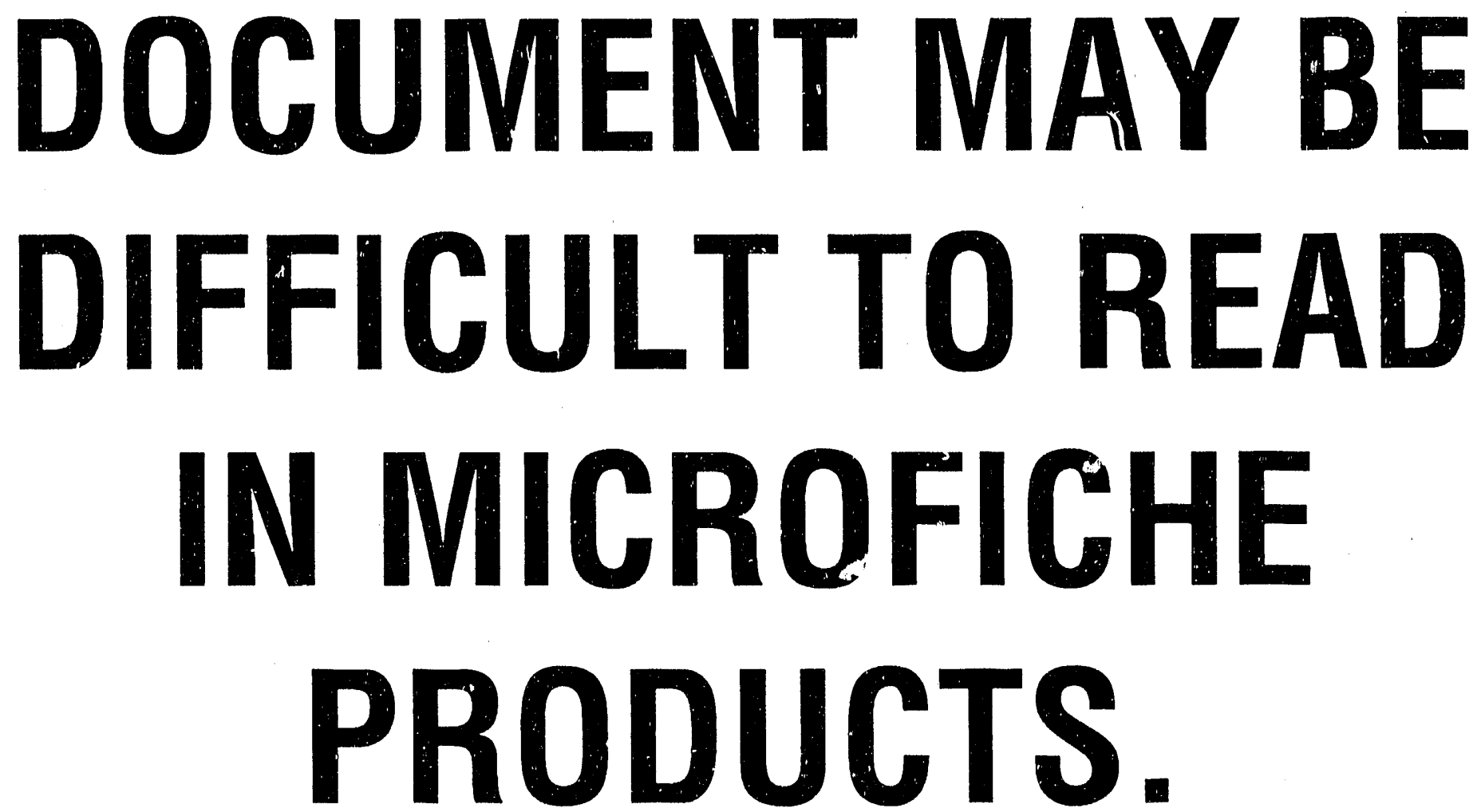


\title{
ENERGY EFFICIENT INDUSTRIALIZED HOUSING RESEARCH PROGRAM
}

\author{
VOLUME II \\ A PPENDICES \\ FY 1589 T'ASK REPORTS
}

CENTER FOR HOUSING IVNOUVATION

UNIVERSITY OF OREGON

AND

FLORIDA SOLAR ENERGY CENTER 


\section{AUTHORS}

\section{Center For Housing Innovation}

Rudy Berg

G.Z. Brown

Jerry Finrow

Ron Kellett

Margot McDonald

Barry McGinn

Pat Ryan

Tomoko Sekiguchi

\author{
Research Assistant \\ Project Director, Professor of Architecture \\ Principal Investigator, Professor of Architecture \\ Principal Investigator, Asst. Professor of Architecture \\ Research Assistant \\ Research Assistant \\ Research Assistant \\ Senior Research Assistant
}

\section{Florida Solar Eriergy Center}

Subrato Chandra

Ahmad K. Elshennawy

Philip Fairey

John Harrison

Lawreice Maxwell

Jim Roland

William Swar
Project Director, Directior of Research \& Development Dirision Assistant Professor, Department of Industrial Engineering, UCF Principal Investigator, Program Director ${ }_{v}$ R\&D Division Research Assistant

Senior Research Architect

Director, Testing \& Operation Division

Chairman \& Professor, Dept. of Industrial Engineering, UCF

iii. 


\section{STEERING COMMITTEE}

J. Wayne Beighle

Executive Vice President

The Charles Wayne Group

Daytona Beach, Forida

Don Carlson

Editor and Publisher

Automated Builder

Carpenteria, California

\section{Michael Dickens}

Manager, Advanced Design \& Development

GE Plastics

Pittsfield, Massachusetts

John Elizalde

Chief, Residential Program Branch

Bonneville Power Administration

Portland, Ortigon

Stan Floyd

Manager, Structural Materials

Corporate Research \& Engineering

Weyerhaeuser Company

Federal Way, Washington

Barbara Harwood

President

EBH Enterprises

Dallas, Texas

\section{United States Department of Energy}

Marvin Gorelick

Pioject Manager

Building Fnergy Research Division

U.S. Department of Energy

Washingtorn, D.C.
Larry Jordan

Manager, Manufactured Housing

Codes and Standards

Department of Community Affairs

Tallahassee, Florida

Mark Kelley

Energy Engincer

Acorn Structures

Acton, Massachusetts

Jon Nord

Senior Vice Presiden:

Fleetwood Enterprises

Riverside, California

Ed Sheets

Executive Director

851 Northwest Power Planning Council

Portland, Oregon

John Slayter

Director, Research \& Engineering Ryland Gmup

Columbia, Maryland

\section{Randy Chang}

Program. Manager

U.S. Department of Energy

Oakland, Caiifornia 


\section{INDUSTRY COSPONSORS AND COLLABORATORS}

Michael Tobin, Executive Director/V.P.

AFM - (R-Control)

Excelsior, Minnesota

Michael Busich, President

American Ingenuity

Melbourne, Florida

Kenneth Franklin, Project Leader

Dow Chemical

Granville, Ohio

Van Pope, Corporate Director of Operations

Phil Tanner, General Manager Haines City Plant

Fleetwood Industries

Michael J. Dickens, Manager

Advanced Design and Development

GE Plastics

Pittsfield, Massachusetts

vi. 


\section{ACKNOWLEDGEMENTS}

\section{Center for Housing Innovation}

$\begin{array}{ll}\text { Beth Holmes } & \text { Word Processing } \\ \text { Joyce Deters } & \text { Word Processing } \\ \text { Matt Meacham } & \text { Research, Ilustration, and Pasteup } \\ \text { Diane Fellows } & \text { Research, Ilustration, and Pasteup } \\ \text { Gunnar Huhbard } & \text { Research, Ilustration } \\ \text { Kimberly Kaufman } & \text { Illustration } \\ \text { Curt Wilson } & \text { Research and Ilustration } \\ \text { Marian Fincher } & \text { Librarian }\end{array}$

\section{Florida Solar Energy Center \\ and \\ Department of Industrial Engineering, UCF}

$\begin{array}{ll}\text { Robert Abernethy } & \text { Construction } \\ \text { Timothy Branson } & \text { Research } \\ \text { Bidyut Chakraborty } & \text { Computer } \\ \text { Mable Flumm } & \text { Word Processing } \\ \text { Alan Garent } & \text { Construction Leader } \\ \text { Elvis Gumbs } & \text { Instrumentation } \\ \text { Gloria Hill } & \text { Word Processing } \\ \text { Jeanette Holder } & \text { Word Processing } \\ \text { Lorenzo Young } & \text { Research } \\ \text { FSEC Graphics } & \text { Photo Pasteup } \\ \text { FSEC Library } & \text { Library Services } \\ \text { FSEC Testing \& Operations } & \text { Construction, Instrumentation }\end{array}$

vii. 


\section{CONTENTS}

VOLUME II

\section{TRIP REPORTS}

2. SOFTWARE BIBLIOGRAPHY

3. COST COMPARISON OF SWEDISH \& U.S. HOUSING

4. CONTACTS

5. LIBRARY

6. INDUSTRIALIZED HOUSING MANUFACTURING SYSTEMS ..Fleetwood

\section{VOLUME I}

1. ABSTRACT

2. INTRODUCTION

2.1 Research Context

2.2 Research Goals

2.3 Overview of FY \&9 Research

2.4 Project Team

2.5. Industry Participation

2.6 Project Funding

3. ANAL YSIS OF U.S. INDUSTRIALIZED HOUSING

3.1 Definitions and Characterisitics of Industrializing Housing

3.2 Statistics and Trends in Industrialized Housing

3.3 Field Observations of HUD Code, Modular and Panelized Housing Manufacturers

3.4 Case Study: Fleetwood Homes

3.5 Current Status of Energy Efficiency

3.6 U.S. and Foreign Building Codes

viii. 
4. ASSESSMENT OF FOREIGN TECHNOLOGY

4.1 Current Status of Design, Manufacturing, Marketing and installation in Industrialized Housing in Sweden

4.2 Current Status of Design, Manufacturing, Marketing and Installation in Industrialized Housing in Other Westem and Northern European Countries

4.3 Curreni Status of Design, Manufacturing, Marketing and Installation in Industrialized Housing in Japan

\section{ASSESSMENT OF INDUSTRIALIZATION APPLICATIONS}

3.1 Statistical Analysis of Industrialized Housing Production by Climate Zone

5.2 Climate Response of Industrialized Housing by Clinnate Region

5.3 Analysis of Domestic and Foreign Industrialized Housing Costs and Energy Performance

5.4 Towards 21 st Century Manufacturing: the GE Plastics Panelizing Plant for the Future

5.5 Emerging Componerits and Subsystems

6. COMPUTERIZED DESIGN AND EVALUATION TOOLS

6.1 Evaluation of Computerized Design Tools Used by Industrialized Housing Manufacturers

6.2 Analysis of the Energy Decision Making Process in Industrialized Housing

6.3 Prototypo-Design Tool - R-Control Panel

7. ASSESSMEITT OF ENERG Y PERFORMANCE OF BASELINE AND ADVANCED INDUSTRIALIZED HOUSING CONCEPTS

7.1 Side by Side House Comparisons

7.2 Artificial Sky

7.3 Wind Tunnel

\section{OBSERVATIONS AND RECOMMENDATIONS}

9. REFERENCES

ix. 


\section{TRIP REPORTS}




\section{TRIP REPORTS}

\section{UNITED STATES}

Palm Harbor Homes (ENERGMISER)

Bill Nolan, President, Orlando Homebuilders Assn.

Pease Company, Inc.

Benchmark Homes

Unibilt Industries

All American Homes, Inc.

Nationwide Homes

National Building Systems

Titan Manufacturing Co.

Ryland Homes

American Standard Building Systems

Cardinal Homes

Fleetwood Enterprises, Inc.

Acom Structures

Ryan Homes

MOD-U-KRAF Homes Inc.

Meadowood Industries

Western Insulfoam/R-Control Panels

DesCon '89 A/E/C Systems Conference

Fleetwood Enterprises, Housing Group

Automated Builder Magazine

Blazer Yndustries

Ryland Modular Homes

Ryland Construcjtion Systems (Panelized) Manufacturing Plant

"Modular Housing: The Trend for the 90 's" Conference

Advanced Building Systems

Key-Loc Hones (Division of Hodgson Houses Inc.)

National Association of Home Builders Annual Meeting
Plant City, Florida

Orlando, Florida

Hamilton, Ohio

Brookville, Ohio

Vandalia, Ohio

Decatur, Indiana

Martinsville, Virginia

Collinsville, Virginia

Orlando, Florida

Columbia, Maryland

Martinsville, Virginia

Williesburg, Virginia

Haianes City, Florida

Concord, Massachuserts

Plant City, Florida

Rocky Mount, Virginia

Lebanon, Oregon

Kent, Washington

Anaheim, California

Riverside, Califomia

Carpenteria, Califomia

Silverton, Oregon

New Windsor, Maryland

Columbia, Maryland

Penn State University

Bennington, Vermont

Suncook., New Hampshire

Atlanta, Georgia 


\section{SWEDEN}

Multifamily Project

Prefab Housing Project

Atrium Project

Housing Project

Apartments

Energy Efficient Multifamily Project

Multifamily Project

Bodbetjanten

SFC Housing Project

Lambohov. Project

Myresjofonster Plant

Myresjohus Plant

4 Plex

Gullringshus Plant

Hultsfreds - Hus

Will House

Burmek

Boro AB

Myresjohus Under Construction
Ingebo

Stockholm

Stockholm

Kejsaren, Stockholm

Sjukskoferskan, Shockholm

Konsolem

Skogsalmen, Stockholm

Stockholm

South Linkoping

Linkoping

Vetlanda

Vetlanda

Vetlanda

Gullringen

Hultsfred

Gullringen

Nassjo

Landsbro

Vetland

\section{DENMARK}

Architectural Museum and Bookstore

Copenhagen

Hosby Hus a/s

Juelsminde

Roslev Hus

Skive

Ebbeltoft Recreational Housing Community

Northeast of Aarhus

Housing Project

Energy Efticient Co-Housing Project

Byg and Bo Housing Exhibition Slite

Aarhus, Denmark

Fredrice

Tinggarden Housing Project

Holmeback Housing Project

Odense

Koge

Sun, Wind and Light Co. Housing Project

Herfloge

Tastrup Hof Development Area

Retrofit Housing Project

Koge

West of Copenhagen

Damgardscrealet Project

North of Copenhagen

Albertslund 
Sibelius - Parken Project

Urban Mixed Use Building

Martin Rubow et. al. Office

Vandkunsten Office

Norgards Plantage Project

Fuglsangpaken Forum

Graese Bakkeby

Modulbeton Plant

Torstorp

Skoven Interview
West Copenhagen

Copenhagen

Copenhagen

Copenhagen

Hesselbo

Copenhagen

Brondby

Copenhagen

Copenhagen

\section{JAPAN}

Kyoto University

Waseda University

*Meiji University

*Osaka City University

Misawa Homes Co. Ltd. Headquarters

Misawa Homes Co. Ltd. Plant

*Mitsui Home Company Limited

* Sekisui Chemical

* Sekisui House

* Building Center of Japan

*Building Research Institute

*Federation of Home Contractors

"Issiki Architects and Partners

*Housing Parks
Kyoto

Tokyo

Tokyo

Osaka

Tokyo

Nagoya

Tokyo

Tokyo, Hasuda

Tokyo, Koga, Osaka

Tokyo

Tsukuba

Tokyo

Tokyo

Tokyo

Shin-yurigaoka

Takaido

Hasuda

Koga

Osaka

Kusatsui

Nagoya

* Visits made, trip reports incomplete 
Energy Efficlent Industrialized Housing Project

IRIP REPORI

Fac1lity visited:

Palm Harbor homes (ENERGMISER)

605 S. Fromtace Rd.

Plant City, FL 33566

Visit Date:

octoter 17, 1989

(take exit 13 or 14 from $I-4$ )

Host:

Took the standard gulded plant tour which is offered routinely to the public

Project Staff: Subrato Chandra

Report Propared By: Sibrato Chandra

Company Profile

They are a HUD code manufacturer and the only one that I know of which emphasizes energy conservation as their top marketing tool. They have a neat "warning" sign in all theis model homes saying the buyer widl lose $\$ 7244$ in higher utility bills over the lifetime of the home if they bought from a competitor. They emphasize their better constriction quality over thelr competitors every step of the way from models to the plant tour. See attached materials describing the company.

Business Volume and staffing

? - million/year

500-700 homes/year

Design Siaf: ?

Production Stafs = ?

Administrative staff = ?

Sales Staff = quite a few, about 25 in their model center attached to the factory

Desian Procedure

$?$

Energy Design Decisions:

For many years, they have advertised thelr product as a high quality energy efficient manufactured home. The words Hud code and moblle home are never mentioned.

Automation and Computerization 
level is comparable to Benchmark homes

Products Manufactured

See attached

Raw Materlal and Inventory

Quite signiflcant. Huge plant. I would guess it at three weeks. Plant accomodates about 14 modules and throughput is 6 to 8 modules per day (one shift)

Manufacturing Methods

Plant was weld laid out with vertical spaces well utilized by hoists and cranes. Pneumatic hand tools. Level of manufacturing sophistication was close to better modular builders such as Benchmark. Some interesting features:

1. Frame gets a built in camber by welding so that when modules get built they are level.

2. Chassis painting is done holding chassis vertically to minimize space requirement. Minimal palnt overspray noted.

3. Carpet 18 field installed and so is drywall taping and finishing as an option.

4. Last manufaturing step is gassing each module with anhydrous ammonia for 12 hours to get rid of $90 x$ of the formaldehyde.

5. Varlous module shapes were in production at the same time.

Qual1ty Control

In general the quality control appeared to be superior. See attached materlals. They use white rather than yellow pine throughout. $2 \times 4$ construction with full top and bottom $2 \times 4$ plates. Good application of insulation in knee wall areas and over celiling. Uses $235 \mathrm{lb}$. shingle. vinyl siding is installed with room to move to prevent warping.

Each module goes thru a 16 step inspection procedure. 4 plant Inspectors.

\section{Energy Performance}

Should be quite superlor to standard HUD code homes. Comparable to modulars. See attached for specs. Heating and cooling equipment selection 18 upto the bulider/dealer.

\section{Comments}

IMPRESSIV for a HOD code hone. 


\section{Notes of Meeting with B111 Nolan}

\section{PSRC $10 / 29 / 89$ 10AM-NOOR}

At tendees: Chandra, Pajrey, Maxwe 11, Ro Iand, Swart

1. Nolan is enthusiastlc about our project and supports 1 t.

2. He 18 currently the ma1n peroon putting together the natlonal modular conetruction act. He do golng to ce cenator orehem next week about cosponeoring 1t. Graham, back in 1973 or to was the senate sponsor for the Plorida modular houeing act.

3. Nolan belloves the Hajlahan ctudy numbers on the tize of the industry. saye Carloon numbere are probably Inflated. Hallahen apparently has a good reputation as a market eurvey paraon.

4. The coliapse of cardinal is very bad for growth of the Industry. 1t might take modulare Ilve yeare to overcome the rlpple elsecte from Cardinal. Aside from the change in tax laws, Cardinal lailed because it was very inflexibje on denion. The $24 x$ 12 cardinal module size and lts $2: 12$ pltch was dictated by transportation requirements. That was the largest ize poasible without getting epecial road permite. Avaliablilty of $4 \times$ cheets was not a etrong iactor. As a matter of fact, in later atages cardinal used $8 \times 12$ sheets ( 300 lb. each) for flooring so that it had only two seams and consequently wuch lese probleme than floors with wore poame. 80* of Cardinal' bueinese was in rental undt conetruction. Single family was a very small market due to inflexiblilty of design. Cardinal alwaye had a flxed production echedulo to make a $t 1 x e d$ number of unite a year and ilwaye had a ready market for thom through the1r development eubeldiary. 
5. In general, 1 done right, rate of returs for manufacturers can be pretty high, 18\%-21* per year plus perks. So th1s is a lucratlve business and falrly simple to do. The reason $G M$ and Boeing have not gone into moblie home manufacturing is that they didnot have - home buldder mentality. That 1s to keep thinge low tech and simple. Ho also agreed with Philip' hypothesis that 1 t 1 e very diffleult to patent or otherwise protect a manufacturing procese or innovative idea in this buelness. That's why the big boye are not in $1 t$.

6. Home manufacturiag falls apart when there 18 too much flexiblidty. He cited two efforts in Plorida - one by continental homes in Halnos clt'y and enother by benchmark in Taldahaseee who tried to make modulare the way the customer wanted, and folded in one to two years

7. Operation Breakthrough had number of good effecte, For the flret time yeople saw that good homea (better than moblle) can be made in the factory. Secondly it spawned the extsting modular codee in $30+$ etates and therefore created the modular housing Industry. He agreed with PhIllp that we could make a case that operation breakthrough was a euccese.

B. Statewlde modular codes can be enforced at the local level 14 one is prepared to elght. Cardinal never, was stopped at the local level al though it had to engage the law a fow times to do It. Local zoning laws can keep the moblie homes out because they do not meet the natlonal codes (SBCCI, BOCA etc.).

Thoughte about Project

a. Saw the future (next ilve years) in larger componente. perhaps in wet core modules.

b. Thought induetry would be interested in dolng coet shared RAD where they get govt. to pay for about half the coete. Then we would toet the prototype products for performance.

c. Mentloned an 1dea a Texas prof had for operation breakthrough. Have PVC plpe Inetend of $2 \times 4$. Then uee the pipes an chases for wiring and plumbling. We should follow thio up with aE plastice. 


\title{
Energy Efficient Industrialized Housing Project
}

\section{TRIP REPORT}

\author{
Eacility visited: $\quad$ Pease Company, Inc. Visit Date: \\ 900 Laurel Ave. $\quad$ Sept. 15, 1989 \\ Hamilton, Ohio 45023-0001 \\ Host: \\ (E1.3) 867.3382 \\ Project Staff: Lawrence Maxwell, Subrato Chandra \\ (BSC Fall Plant Tour) \\ Report Prepared By Lawrence Maxwell
}

\section{Company Profile}

Pease Company has been a manufacturer and supplier of home building materials ever since it was established in 1893. The company began as a small wholesale sash and door company selling to retail lumber yards within the "horse and bugs" distance of its Cincinnati, Ohio, business.

Pease was one of the early manufacturers of pre-cut, or prefabricated homes in the country, and one of the first in the industry to utilize assembly-line production techniques to produce homes. The first Pease home, produced in 1939, was a one and one-half story Cape Cod called the "Peaseway" and was designed to be built in any of four variations. The homes business expanded rapidly and 1940, and the company moved its homes manufacturing to Hamilton, Ohio.

The advent of new materials and the desire for more flexibility in design brought about the development in 1950 of the "Pease-Fab System". This system allowed the home owner to customize the home to his individual taste.

In 1959, the company successfully directed the research and development of the EverStrait Door System. This warp-free, insulated and magnetically weatherstripped product was accepted so well that in 1966 a separate manufacturing division was formed. In 1982 , the division, with plants in Fairfield, Ohio, Denver, Colorado, and New Castle, Indiane, was spun-off and became Pesse Industries.

Today, Pease Company employs 260 people and manufacturers and distributes building products throughout Obio, Indiana, Kentucky

and Weat Virginia.

The company's package homes are designed for single-family and multi-family as well as for light commercial buildings. The are manufactured at the 360,000 s.f. plant in Hamilton, 
Ohio, with the capacity for producing and shipping 2,500 units a year.

Pease Company also sells a wide range of building products to the construction industry. There are four Pease Showrooms and Design Centers in the grealier Cincinnati area, Cheviot, Kenwood, Hamilton, and Sharonville. Full-sized displays exhibit the Pease Product Line, as well as providing full kitchen planners on staff.

The companies Hamilton, Obio plant appears to be a fairly old heavy industry type manufacturing complex, which Pease has acquired and is presently utilizing for both component, and panelization production as well as product storage.

Business Volume and Stafing

? - million/year

up to 2,500 homes/year

Design Staff $=8$

Production Staff $=\sim 150$

Administrative Staff $=-42$

Sales Staff $=-25$

\section{Desion Procedure}

Pease Company has a design staff which includes 2 registered Architects. The company has introduced AutoCad into the design process. The company continuously creates new single and multi-family housing units. Further, designs are accepted from builders and home buyers, if they can be effectively produced is the manufacturing plant. The design staff will review and revise a design as necessary to work in the factory production mode.

The designs created by the company are within the standard design types noted throughout the industry, i.e. capes, ranches, colonials, etc., as well as more contemporary, and larger custom homes.

\section{Eneroy Desion Decisions}

Energy related design decisions are based on requirements of the local energy codes where a home will be located. No additional design for passive energy strategies are incorporated into the homes. An energy efficiency upgrade package is available, which consists of increased insulation levels in the walls and ceiling.

\section{Automation and Computerization}

Pease Company utilizes AutoCad Sottware for design and drafting functions. Autocad is also utilized to prepare wall panel framing diagrams for the manufacturing plant. Materials takeofis and quantity control is not monitored or control by use of computers. Hewlett Packard computer hardware is usod to run the AutoCad drafting functions, with 8 stations 
operating. The computers are not networked, but are buffered for printing on a single printing device. Other software used is "The Plan" software package and Alpiwe Truss software and equipinent for truss configuration and production.

A larger networked computer system is utilized for corporate business functions, such as bookkeeping, inventory, and order processing and control.

The industrialized housing component of the company incorporates wall panel jigs and laser controlled automatic nailing bridges, roller bridges for panel movement, Alpine Truss rolling truss presses, automated vented soffit manufacturing equipment, automated stair stringer manufacturing equipment, and automatic wood finish trim routing equipment.

\section{Products Manufactured}

Pease is a manufacturer as well as a major distributor of building products selling lumber, building components, mill work, windows and doors, and kitchen and bath cabinetry.

The company has a door manufacturing company with several manufacturing plants around the country.

The industrialized housing portion of the company produces open wall panels for single and multi-family and light commercial construction. The company also produces pre-engineered roof and lloor trusses, and permanent wood foundation systems.

\section{Raw Material and Inventory}

As Pease Company is both a house panelizer operation we well as a components manuficturer, supplier, and retailer, the company maintains a large inventory, of materials and components. Approximately one half of the manufacturing plant is given over to inventory storage.

\section{Manufacturing Methods}

Pease incorporates cad generated wall framing configurations to the manufacturing plant. Initial cutting is performed with manually fed and positioned cutting equipment, and all measurements and markings for stud locations, openings, member identification, etc, is performed by hand and marker pen. Once individual members are cut and marked, they are sorted into bins for use on the assembly line. The panels are then configured on jig tables, with manual member selection from bins, and manual member placement and aligoment into the jig stops. Fastening of studs to plate and headers is accomplished with pneumatic nailing guns which are suspended from the ceiling on cables to eliminate the continuous lifting of the heavy guns used. The panels are shifted to the next station on a roller bridge, which requires only that the panel be pushed manually to the next station. Exterior sub-sheathing is manually placed on the wall panel and positioned, and tacked into position. An electric router is utilized to cut window and door openings out of the sheathing after placement but prior to full attachment of the sheathing to the panel. Then a laser guided automatic nailing bridge staples the sheathing to the panel. The panels are then loaded directly on to trucks for transport to the construction site. 


\section{Quality Control}

is open wall panels, and floor and panels are the product produced, jigs and automated nailing bridges are the main metbod of quality control. No additional QC personnel were noted, or additional QC measures observed.

\section{Eperoy Performance}

It is assumed that the energy performance of the homes constructed would be similar in nature to a site built hoves which is constructed with the same levels of insulation and building components incorporated into the finsl product. However, the ability to produce wall panels with closer tolerances, will likely provide a better constructed product which could belp increase the energy efficiency of the home.

\section{Comments}

Pease Company is possibly one of the largest companies in the business, with business interests in all facets of the construction of homes, from the production and distribution of materials and components, to the manufacture of panelized homes themselves. Numerous contributions to the construction industry as well as the industrialized housing has been brought about by the company. The potential for further contributions to quality, affordability, and energy efficiency exists within the structure of the company. 


\section{Enerey Efficient Industrialized Housing Project}

\section{TRIP REPORT}

$\begin{array}{lll}\text { Facility visited: } & \begin{array}{l}\text { Benchmark Homes, Inc. } \\ \text { 630 Hay Avenue }\end{array} & \text { Visit Date: } \\ & \text { Brookville, Obio } 45309 & \text { Sept. 13,1989 }\end{array}$

Host: $\quad$ George Kirby, Jr. (President)

(513) 833-4091

Project Staff: $\quad$ Lawrence Marwell, Subrato Chandra (BSC Fall Plant Tour)

Report Prepared ByLawrence Marwell

Company Profile

Benchmark Homes is a fully integrated building company which is one of the pioneers in the modular building industry. The company has been in the modular home building industry for 45 years. Benchmark homes builds single-family homes through the Benchmark builder dealer network. All bomes manufactured by Benchmark are transported, installed, and finished by Benchmark crews. The builder/dealers are responsible only for site and foundation work and the plumbing and electrical connections outside of the bome. The company utilizes sub-contractors inside the plant for all of the construction of their product.

Benchmark Communities, Inc. is another arm of the company which is involved in design, site planning, full approval processes, construction, and management of multi-family residential projects. The sume plant is utilized for both the single and multi-family modular units construction. The plant comprises 95,000 8.f.

Business Volume and Stafing

$$
\text { - million/year 750-1200 living units/year }
$$

$$
\begin{aligned}
& \text { Design Staff }=-6 \text { designers Production Staff }=175 \\
& +4 \text { engineers ( } 7 \text { on payroll and } 7
\end{aligned}
$$

Administrative Staff $=-40$

Bales Staff = 


\section{Design Procedure}

Benchmark Homes bas a complete design dept. with 6 designers and 4 engineers. All design work is accomplished in house. The company works both from standard plans for single family homes and custom designs for malti-family. A large portion of Benchmark's work is for multi-fainily projects, and the company will provide the complete package, from design of the units, to site design, engineering, and code approval. The company has designs ranging from fairly standard product, to very high quality designed projects. Much care is taken in the design and construction of the projects to avoid the look or indications that the product is modular in nature. It appears that once a project program is developed by Benchmark or by a separate client, the design staff is given the design leeway to produce what they feel is appropriate. However, much of the product is a variation on a theme which they have found to be successful. For exampie, a standard floor plan arrangement may be utilized, with slight modifications, and the exterior elevations changed to suit the specific project.

\section{Energy Desipg Decisions}

The energy design decisions appear to be made to meet cade requirements of the local where the project will be built. No specific enhancements beyond code minimums were noted in the design or construction of the single or multi-family units.

\section{Automation and Computerization}

Benchmark utilizes AutoCad for the design and drafting of their new projects. The system has been in operation for about one year. Presently the users are just becoming familiar enough with the system to be able to utilize it effectively. The hardware utilized is an Acer system with approximately 30 stations operating both the AutoCad as well as accounting and word processing operations through the use of an Ethernet networking setup.

"Low tech in plant, high tech in engineering" is how George Kirby describes Benchmark's approach to manufacturing. The plant does not incorporate any automation in its manufacturing operation. One of the reasons for the lack of automation is the fact that Benchmark utilizes all sub-contractors to perform the labor roles in the plant. The oubcontractors provide most all the tools ${ }^{+2}+\mathrm{ey}$ require for the performance of their work

\section{Products Manufactured}

Benchmark is a manufacturer of modular single and multi-family homes and apartment complexes. For the last five years, the company concentrated totally on multi-family rental and condominium complezes. This year the company is again producing single family homes, which comprises approximately 25\% of their production. The typical single or multi-family unit is approximately 1200 s.f. to 2600 s.f. The multi-family structures are buildings up to 3 stories in height. Single family are produced and sold to Benchmark builder/dealer network, multi-family are developed through Benchmark Communities. 


\section{Raw Material and Inventory}

Benchmark practices Just.In.Time (JT) inventory acquisition and control. All raw materials and component inventories are provided to the subcontractors on the production line. Asreements with materials and components suppliers are setup so that necessary materials arrive within one day of use. Due to JT, very little inventory is maintained on hand, reducing storage requirements, pilferage, and overbead cost.

\section{Manufacturing Methods}

Benchmark has a very low tech manufacturing operation. The company incorporates subcontractors for all the trades on the job. The subcontractors are actual field construction crews that bid for and work in the company's production plant. It is the subcontractors responsibility to add to or deduct from his crer as necessary to maintain the amount of manpower necessury to perform the work required. Simple jig tables are utilized for the framing of doors and walls. The rest of the production is directly related to similar site construction techniques.

\section{Quglity Control}

Quality Control sign off forms follows each module as it moves through the plant. The quality control inspectors are among the few people who are on the actual payroll of the company. They are required to sign off at each stage of work before it proceeds to the next step. The subcontractor does not gat paid until his work is Enished and approved.

Benchmark also installs the modules on the foundations and performs all finish work. If a discrepancy is discovered in a subcontractors work, the subcontractor responsible has a specific time period in which to rectify the deficiency or Benchmark crews will do the repairs and the subcontractor will be backcharged accordingly.

\section{Eneroy Performance}

The units designed by Benchmark do not incorporate any special energy efficiency design, and the units insulation, etc, are based on code requirements. However, the company does seal all top and bottom plates, and all receptacle boxes to reduce infiltration, and coupled with the tighter construction tolerances, is most likely producing a more energy efficient product then its site build counterpart.

\section{Comprents}

Benchmark is fully integrated company which is involved in every aspect of the single and multi-family development process. The business sense of the compeny is very impresaive. The integration of production, development, land planning, sarketing, property management, JT inventory management, and labor controls through subcontrectod labor, is vastly different from about every other Industrialized housing manufacturer visited. The company takes great pains to avoid the "modular" stigmen or the "M" word as they put it. In the design and manufacture of the homes, the company goes to lengths to eliminate the telltale signs of a modular unit such as a too thick marriage wall, or variations in the floor at the door opening in a marriage wall. Further, no mention is 
made to modular when going for zoning approval, or for marketing of the units. If the topic is brought up, they stress the quality control benefits and the cost benifits of the factory produced units.

To ensure the quality of their product, the company maintains their own erection and finishing crews, instead of leaving this aspect to the builder/dealer. They also make every effort to rectify any problem a home owuer may have within 2 days of the receipt of the complaint.

LM 


\section{Energy Efficient Industrialized Housing Project}

\section{TRIP REPORT}

Facility visited: Unibilt Industries, Inc. Vandalia, Obio

Visit Date:

Sept. 14,1989

Host: BSC Plant Tour

Proiect Staff: Lawrence Maxwell, Subrato Chandra (BSC Plant Tour)

Repert Prepared By Lawrence Maswell

\section{Company Profile:}

Unibilt Ind. is a privately held corporation (management owning $92 \%$ of company) which was incorporated in 1969. The senior management has been with the company since 1972. The company is a modular home manufacturer, which began pruduction in a 14,000 8.f. warehouse building. Presently, Unibilt's monufacturing facilities consist of 49,000 8.f. of production space, 24,500 s.f. of warehouse space, 4,500 s.f. of office space, and 2,300 s.f. of garage space, for a total of 80,300 s.f. on a 7 acre site. The company sells exclusively through a builder network, with $90 \%$ of the homes sold in the state of Ohio, with the other $10 \%$ going to Indiana, Kentucky and Tennessee. The product manufactured is singiefamily homes consisting of ranches, cape cods, and two story homes. The product selection is from over 100 standard plans.

Business Volume and Staffing

$$
\text { - million/year } 425 \text { homes/year }
$$

Design Staff = 1 Architect

Production Staff - 70 persons day shift2 draftsmen 30 persons night

Administrative Staff $=13$ Delivery crews $=10$ persons

Sales Staff $=4$ 


\section{Design Procedure}

Product design is based on perceived market desires. Input is also generated by the type of requests of the builders. Most new product design consists of revising existing standard plans through a method of "cut and paste". Where exasting plans are revised utilizing "white out" and pasting revisions over existing drawings then creating reproducible drawings with a "Xerox" machine.

When a completely new product is desired, the architect will develop the design based on input from marketing and administration.

\section{Eneroy Desion Decisions}

Unibilt Industries strives to market energy efficiency, and to this end, most of their product is constructed with energy upgrade packages. The desigas of the bomes themselves are not such that they attempt to derive beating or cooling from natural or passive means. However, the adage of "more is better" is utilized in selecting insulation levels for the homes. That is, the perceived impro"ements in energy efficiency, more than the actual cost optimized increases in insulation levels for example, are opted for by the home buyers. Interestingly, the home buyers are typically selecting improved energy efficiency over incressed amount of amenity or size house.

Unibilt is also providing Anderson Windows as a standard in all their homes, as it is felt that they provide the energy efficiency levels desired along with reduced inventory requirements of carrying only one grade of window. The same concept is utilized for doors, etc.

\section{Autcmation and Computerization}

The use of computerization at Unibilt is extremely limited. PC's are utilized for bookkeeping operations and for general business word processing. Computers are not utilized for design or drafting at all. As meritioned under design procedure, the method of "cut and paste" is utilized for revising plans for manufacturing. This operation would lend itself very well to a $\mathrm{CAD}$ application. No automation is incorporated into the manufacturing operation.

\section{Products Manufactured}

Unibilt Industries manufactures single family modular homes exclusively. Homes consist of ranches, capes, and two story units, from over 100 standard plans. The company currently produces 18 to 20 "floors" per week.

\section{Baw Material and Inventorr}

Raw material is stored in a warehouse separate from the manufacturing facility and was not available for viewing. The amount of materials stored or the rate of inventory turnover is unkonown. 


\section{Manufacturing Methods}

Unibilt constructs wall panel assemblies on RL Industries wall table jigs. Floor platforms are produced on jig tables, placed on roller assemblies and manually moved from station to station on tracks. The manufacturing process closely follows site construction techniques and sequences throughout the production process.

The manufacturing process is low tech in nature and resembles that seen at most plant. The emphasis is on utilizing relatively unskilled to semi-skilled labor in-lieu of autorastion or bigher technologies, or fewer higher skilled laborers.

\section{Quality Control}

Unibilt has one Quality Control inspector at the plant. The inspector will check each portion of the work before it is covered up by subsequent construction.

\section{Eneroy Performance}

The energy periormance of the typical Unibilt home is expected to be higher than that of a typical comparable home. The reason is due to the increased levels of insulation installed in the construction of the units as well as the tighter level of construction tolerances over a site built product. The homes are typical in other respects in that they do not incorporate any site specific designs or orientations nor do they incorporate any passive heating or cooling design strategies.

\section{Comments}

Unibilt is a typical modular home manufacturer, with a low tech approach to manufacturing. They a-e essentially site built under a roof utilizing the advantages of improved productivity through assembly line operation, volume purchasing, and protection from the elements during construction. The advantages of automation or computerization of the production process has not been explored or exploited in their operation.

The assembly line operation at the plant consists of a $L$ shaped configuration, with the turn occurring about $2 / 3$ of the way down the line. This requires each module to be lifted with jacks off of its rollers and then have rollers that move in the other direction placed under the unit. The modules move "sideways". down the first portion of the assembly line, and then after the switch, move "endwise" down the remainder of the line. At the end of the assembly line, the module is rolled out of the building and directly onto the back of a awaiting trailer to be transported to its final destination. 


\section{Energy Efficient Industrialized Housing Project}

\section{TRIP REPORT}

Facility visited: All American Homes, Inc. Decatur, Indiana
Visit Date:

Sept. 13,1989

Host: Mike

Research and Development

Project Staff: $\quad$ Lawrence Marwell (BSC Fall Plant Tour)

Report Prepared BriLawrence Maswell

\section{Company Profile}

All American Homes is a producer of modular homes. The company is presently operating in a new 142,000 8.f. plant which they began production in March 1, 1989. The company is producing approximately 3 homes or 6 "floors" per day. All American Homes are sold through builder/dealers in Ohio, Indiana, Michigan, Mlinois, Kentucky, and West Virginia.

The cosupany produces bomes from approximately 80 standard plans of their own, and does not produce any homes not from their plans.

Business Volume and Stafing

- million/year $\quad$-800 homes/year

Design Staff $=4 \quad$ Production Staff $=100+$

Administrative Staff $=35$

Sales Staff $=7$ 


\section{Design Procedure}

All American does not have a design staff, but rather a drafting department. Each year approximately 2 new models are developed. New models are created to provide a product similar to what is being built by site built contractors in the area. The balance of the work is modifications to existing designs.

\section{Eneroy Desizn Decisions:}

Energy decisions are hased on compliance with energy codes at the location where the final home is being built for. Exisencements to the basic energy includes changing the roof insulation from R-25 to R-40, changing walls from R-11 to R-19, and all homes receive Anderson Windows.

\section{Automation and Computerization}

The drafting department utilizes AutoCad Software on a IBM 286 and a Compaq 386. The computer is utilized to change and upgrade plans for production. No materials or inventory control or take-offs are performed on the computer. Production scheduling is performed manually, as well as all production procedures. Computers are utilized for bookkeeping functions as well as word processing.

\section{P:oducts Manufactured}

All American Homes produces all modular single family homes from a stock of approximately 80 standard plans. The mix consists of 864 s.f. to 2400 s.f. homes with the largest group being approximately 1.800 s.f. The floors are a standard $12^{\prime}$ or $13^{\prime}-6^{\prime \prime}$ wide 2 box or 4 box homes. The mix of homes is about $80 \% 2$ box, and $20 \% 4$ box configurations:

\section{Raw Material and Inventors}

All raw materials and inventory is kept under the same roof as the manufacturing operation. The manufacturing operation is in a linear configuration, with the manufacturing taking up half of the width of the building, and the sub-assembly (plumbing trees, etc,) down the middle of the building, and the materials storage running parallel to the manufacturing line and taking up about one third of the width of the building. Inventory turn around is approximately once a month, with a two week turn around desired A vast quantity of inventory is on hand at any given time, adding to overhead and carrying costs, along with storage costs.

\section{Manufacturing Methods}

Of the 142,000 s.f. for the entire plant, 135,000 s.f. is production and materials storage space, with approximately $2 / 3$ given to production, and $1 / 3$ given to materials storage. The production area consists of a $\mathrm{L}$ shaped configuration. In the lower leg of the $\mathrm{L}$, wall panals 
and floor platforms are constructed. Clary wall and floor jigs are utilized in assembly. An Alpine Truss machine is utilized to fabricate roof trusses. The wall and foors are then moved to the main assembly line by the use of overhead cranes, the floor is placed on trolley wheels, and the walls, roofs, and subsequent construction takes place. . Foam glue is used to aitach ceiling gypsum board to roof trusses, and the finished roof structure is placed on top of the assembled walls.

After the walls are erected, and the roof structure attached, the module moves down the assembly line. Plumbing and electrical lines are routed, interior syp. bd. is attached, and insulation in the exterior walls and roof is installed. Exterior wall sub-sheathing and roof decking is installed. Windows and doors are installed utilizing a split jamb system which allows installation of the door or window from one side and insertion of the other frame half from the nther. Doors and windows and frames are pre-finished at the component manufacturers prior to shipping to the modular plant. This eliminates several finishing steps as well as the need to use materials that will generate EPA scrutinized hazardous wastes. The construction practices utilized in the plant closely resemble field techniques for the balance of the work. No automation or special procedures or techniques were noted in the construction. At the end of the assembly line, the finished products are lifted off the trolley rollers by the use of motorized lift similar to what is used a marinas to lift boats out of the water. The lift straddles the module, straps are placed under the box, it is lifted off the trolleys and rolled outside and placed on concrete blocks until such times as it is to be loaded on a truck for shipment.

\section{Quality Control}

A quality control check list is attached to each module along with a copy of the floor plan for the module. The worker responsible for each portion of the work signs the shoet when his work is finished, the work is reviewed by a QC inspector and sizned off on wihen the work is considered acceptable.

\section{Eneroy Performance}

No special design consideration is given to the modules to allow for any passive heating or cooling strategies. The materials used and the tighter tolerances that were noted in the construction of the modules would help in producing a home that is more energy efficient than a similar standard house that was site built.

\section{Comments}

The All American Homes present manufacturing plant is new and in its first year of operation. The building and the configuration of the assembly line were created for the manufacturing of modular homes versus most plants visited that had developed their manufacturing operation in existing industrialized buildings that were deemed to be suitable for the purpose. The manufacturing operation does not deviate from the standard method of operation noted in other plants, ie. low tech,and low levels of automation, and high use of a low or semi-skilled labor force. 
A very large inventory of materials was on hand at the plant, and over $1 / 3$ of the entire plant floor space was used to store it.

The investment in plant facilities is among the largest seen at any plant visited, however, the investment in design staff and product design was very minimal. It appeared that much less than optimal study was put into rethinking the production process at the time the design of a new production facility took place. The company direction was to provide a product similar to what a typical builder was providing in the area, but to build it in a factory to benefit from the advantages inherent in that type of operation. The potential benefits of restarting a production process "from scratch" don't seem to have been explored or exploited in the creation of this new facility.

LM 


\section{Energy Efficient Industrialized Housing Project}

\section{TRIP REPORT}

Facility visited: Nationwide Homes

P.O. Box 5511

Visit Date: 1 June 1989

Martinsville, VA 24115

(revised $7 / 14 / 89$ )

Host: James Love, Production Manager

Project Staff: Jim Roland, Bill Swart, Ahmad Elshennawy

Report Prepared By: Jim Roland

\section{Company Profile}

Nationwide is a modular housing manufacturer producing 12 and 14 feet models. The company has two modular plants, and a separate building for components and storage. Nationwide sells through a dealer network.

Nationwide was recently purchased by senior plant management.

Business Volume and Staffing

- million/year

680 homes/year

Design Staff $=6$

Production Staff =

Administrative Staff =

Sales Staff =

Total staff is approximately 350

\section{Design Procedure}

They have a standard design for 37 homes. However, Nationwide, as all other manufacturers, pointed out that they are in the custom house business. They build what the market wants and designs for the individual buyer. A Vemacod system is used for design. I did not get to see the engineering office of this plant.

\section{Automation and Computerization}

No automation. Use computers for desing and costing. Computer system is not integrated with production. 


\section{Products Manufactured}

Mudular homes from 800 to 3000 square feet. They also assemble their own cabinets.

\section{Raw Material and Inventory}

Materials are stored inside. Quality appears good. There was no sophisticated inventory control.

\section{Manufacturing Methods}

Two manufacturing lines in separate plants for 12 foot and 14 foot models. They also assemble cabinets and doors. Much work by hand - more apparent waste than expected. Models are stick built under roof.

\section{Quality Control}

Reported to have Quality Control inspectors who report to General Management. Quality of contruction appeared good.

\section{Energy Performance}

Nationwide provides a standard energy package with features greater than that required by code and provided by some of the other modular builders. The standard package includes insulation values of R30, R13 and R19 in the attic, walls and floors respectively. Upgrades to R38 in the attic is offered. Foam hoard can also be added to the walls. The standard package includes double pane windows with storm windows as an option.

Heat is provided by baseboard electric heaters. If the customer desires a heat pump, the factory provides and opening and pre-wires the thermostat. The owner/local builder is responsible for the heat pump and installation.

Two grades of appliances (GE) are offered, but the difference is in finish and/or size not energy consumption.

The hot water heater is an electric, 50 gallon energy efficient unit.

A design committee consisting of three senior management persons make decisions on features to offer. When a customer requests, through a builder anythink different from standard or standard options, an engineering and production committee decide its feazibility and cost.

\section{Comments}




\section{Energy Efficient Industrialized Housing Project}

\section{TRIP REPORT}

Facility visited: National Building Systems P.O. Box 8578

Collinsville, VA 24078-8578
Visit Date: 1 June 1989

(text revised $7 / 12 / 89$ )

\section{Host: Don Peck}

Project Staff: Jim Roland, Bill Swart, Ahmad Elshennawy

Repert Prepared By: Jim Roland

\section{Company Profile}

National is a large panelized home builder (over 6000 bousing units per year) located in Lafayette, Indiana; Martinsville, Virginia; and Thomson, Georgia. Homes are sold to builders. Nationai uses a sales force (17 people). They are market driven. Almost every home is customized.

National recently reorganized, putting all engineering at the Martinsville plant. Business is $20 \%$ single family detached, $75 \%$ multi-family and $5 \%$ commercial.

\section{Business Volume and Staffing}

70 - million/year

Design Staff =

Administrative Staff =

Soles Staff $=17$

\section{Desion Procedure}

National offers design services or will build to other's plans. Although they have standard designs almost every unit is customized.

They build what the customer wants. They have a computerized materials take off and estimating system. They receive order for $15 \%$ of the estimates they do.

\section{Automation and Computerization}

No automation. National is progressive in use of computers. They use ICG software (walls), Merlin (trusses) and Advanced Construction Technology for estimating. Their ¿noo homes/year total

At this plarit 800

Production Staff $=120$ 
system will eventually control inventory. Computer produced tickets are used on the plant floor to specify all cutting and construction.

\section{Products Manufactured}

Open panels with or without exterior siding, with doors and windows, trusses, cabinets. Have ceased closed panel construction because of code problems.

\section{Raw Material and Inventory}

The computerized design system they are using will eventually also be used to control inventory. Part numbers are assigned now.

\section{Manufacturing Methods}

National has seven production lines at the Virginia plant. Cutters using radial arm saws cut and mark all pieces using computer generated instructions. Cut materials loaded on part costs and delivered to the lines.

\section{Quality Control}

Quality Control reports to general management. Final quality control, in this case, is more a function of the local builder.

\section{Energy Performance}

National builds what the customer wants. Their panels are not closed and contain no insulation.

\section{Comments}

National is operating in a very old plant in Martinsville. They had the most advanced computer usage of any of the plants we visited.

National can deliver a typical 3 bedroom, 2 bath house on one truckload. Their trucks have cranes for set-up and an air compressor for use by the builder in assembly of walls and roof.

The National plant is unionized. Average labor rate is $\$ 7.64$ per hour which is substantially higher than any other plant on the Virginia tour. At other plants the labor rates were $\$ 5.00$ to $\$ 6.00$ per hour.

National estimated materials cost to be $50 \%$ and labor 10 to $15 \%$ of total cost of house. 
Energy Efficient Industrialized Housing Project

\section{TRIP REPORT}

$\begin{array}{ll}\text { Facility visited: } & \text { Titan Manufacturing Co. } \\ & \text { 10901 Rhems Road } \\ & \text { Orlando, Florida 32821 }\end{array}$

Host: Mr. Tom Nelson, President (407) 851-8450

Project Staff: Lawrence Maxwell, Jim Roland

Report Prepared By Lawrence Maxwell
Visit Date:

March 2,1989

\section{Company Profile}

Titan Manufacturing $C_{0}$. is a producer of light gauge steel stud framed panelized housing components, which includes wall assemblies and roof trusses. The manufacturer is working on developing innovative panelized housing components and systems utilizing metal stud framing in lieu of wood stud framing. Currently, Titan Manufacturing has 22 patents or patents pending for various innovations developed for metal stud framed panelized construction.

Mr. Nelson is responsible (aided by an outside engineer), for the creation and development of the innovations that liave patents applied for or patents obtained.

Titan has been developing new stud shapes and forms for various portions of their work. The new shapes and forms are to facilitate the manufacturing and construction process. At the present time, Titan does not have the capability to form shapes that they utilize from roll steel, however, the company is involved in retooling to increase their manufacturing process as well as enable them to form the shapes they need, as they require them.

\section{Business Volume and Stafing}

.5 -million/year

Design Staff $=0$
60 homes/year

Production Staff $=6$

Administrative Staff $=1$

Sales Staff = 1 (Presently organizing sales staff)

\section{Desion Procedure}

At present, there is no in-house design work. All work is bid from outside home builders. 


\section{Energy Desion Decisions}

All work preformed by the company is to plans provided by outside contractors, as such, there is no energy related decisions made, but rather the panels manufactured are per the requirements of the builder.

\section{Automation and Computerization}

Computers are utilized for word processing and administrative functions only. The company is presently investigating computers for cost estimating, truss configuring, and structural analysis,

Robotic welding systems are being investigated for wall panel and truss member welding. Further, an auto-pnuematic screw driving system in-lieu-of welding is being investigated. The robotic welding system is by Hobart, Inc., and the auto-pneumatic screw system is by Kinnetix, Inc.

\section{Products Manufactured}

Open panel exterior and interior steel stud framed wall systems and steel stud framed roof trusses, for outside bome builders.

\section{Raw Material and Inventory}

Raw material consists of galvanized steel studs of various gauges and stud thicknesses. Material inventories are maintained and obtained on an as required basis.

\section{Manufacturing Methods}

Wall panels are constructed on company built jigs. Wall panels consist of various gauge steel studs which configured in the jig and then connections are made by welding. At the weld point, (the point where stud meets top or sill track), a continuous weld the length of the side of the stud is applied. Even though spot welding may be sufficient, the company provides full welds at each location. Truss members are formed on a plant fabricated metal brake. Then the individual truss members are arranged in a truss jig, (also in-plant built), and welded together. If any additional work is required on the panels, such as attachment of exterior sheathing or installation of windows, these operations are performed off to the side of the main assembly line area.

\section{Quality Control}

Quality control measures consist of the use of alignment jigs and fixtures to insure plumb and square panels, and the insistence that all welds be full welds versus spot welds.

\section{Enerby Performance}

The plant provides to the buyer what the buyer has specified as all work is based on designs brought into the plant. However, as the plant can provide wall framing such as 
6" framing for less cost than $2 \times 4$ wood framing, many clients opt for the greater thickness which allows for increased wall insulation capabilities. Further, consistantly tighter tolerances in the wall panels and panel openings are maintained throughout manufacturing and erection, that a tighter, and more precise building envelope can be obtained.

\section{Comments}

The innovations being developed by Mr. Nelson appear to be directed towards reducing the cost of as well as the amount of time spent manufacturing of and in erection of the components in the field. The innovations are a direct spin-off of the metal stud framing system, but at least some could have direct application to wood framod construction. Interestingly enough, the innovations developed by Mr. Nelson, could benefit both industrialized as well as conventionally (site) built housing.

The following are some of the innovations that Titan Manufacturing is working on:

- A "truss shoe" which is attached in the plant to the top of a panelized wall assembly that eliminates several time consuming steps in the field; measuring and location of trusses and final attachment of the truss. The truss shoe is such that the truss is placed into the shoe and snapped into position, once snapped in, the shoe is capable of permanently bolding the truss without any further mechanical fastening.

- A "truss plumb block" which allows the installer to plumb the truss as well provide X-bracing to adjacent trusses at the same time. TLe plumb block eliminates the need for any additional tools or equipment to plumb or brace the truss as the plumb block will not snap into position until the truss is plumb. Further, once the plumb block is snapped into position, no further mechanical fastening is required to secure it to the trusses.

- A "panel clamp" which allows two wall panels to be mated and snap locked together without any further mechanical fastening required.

- New shapes for various structural members to either provide greater structural capabilities or ease of assembly in the field.

- Pre-formed facia and soffit assemblies that require only a snap on attachment in the field, and which also allows for painting before or after installation as well as allowing for the attachment of various other finishes over it such as wood if desired.

Titan Manufacturing presently gains economic advantage in construction through the savings in material costs as outlined earlier. However, Mr. Nelson foels that steel stud framing can very easily be cost competitive with wood framing using "full cost" steel with even a small quantity of homes being produced. Presently, be contents that his costs for manufacturing and erecting a home are significantly lower than a conventional rough framing crew on the same house, and with any sort of quantity at all, there would be no comparison in costs between the two systems.

To date, Titan has been able to compete in the rnarket place not because of volume of work produced, but rather by being cost competitive through the cost savings of the raw materials used. Mr. Nelson of Titan will typically travel to various steel operations in the state and purchase sheet metal of the gauges required for otuds. The sheet metal purchased is reject material obtained at very low prices due to it being visually blemished 
and therefore not acceptable for use by the supplier. The supplier is typically utilizing the sheet metal to roll form metal wall and roof panels. Titan manufacturing will typically have the seller roll the sheet metal into the stud shapes he requires for his work as part of the purchase, as Titan does not bave the capability to roll the shapes they require presently.

When posed the question of what is the perceived benefits of producing homes in this manner, Mr. Nelson noted, interestingly enough; 1-cost savings through quantity materials purchasing, 2-inexpensive labor force (the manufacturing operation can utilize completely untrained people, an employee can be trained in two days to perform the tasks required), 3-ability to produce components in a controlled environment (out of the weather, and with the ability to utilize quality assuring machines such as jigs).

The two perceived hurdles to acceptance of metal stud framing in a bome are home owner misconceptions of metal stud systems (sometimes perceived as being somehow inferior to wood framing) as well as some builders reluctance to utilize metal studs instead of wood. The advantage of reduced costs appeals to the builder. However, in most cases to date, these cost savings have not been passed on the homeowners. The homeowners who, after having lived in the homes, have been queried about their concerns over the metal stud systems, had no complaints about the system. 
Facility visited:

\author{
Ryland Homes \\ Northeast Division \\ 7120 Oakland Mills Rd. \\ Columbia, Maryland 21046 \\ Visit Date: Feb.2,1989
}

Host: John Slayter, V.P. research, engineering, tech support (301) 730-7222

P.R. (Dick) Drass, plant manager (301) $381-1300$

Project Staff: Phillip Fairey, Lawrence Maxwell, Bill Swart, John Rivera, Carla Kish, Marvin Gorelick

Report Prepared By: Lawrence Maxwell

\title{
Company Profile
}

Ryland Homes is a $20+$ year old corporation which produces both modular and panelized hornes for retail sale. The company also has mortgage subsidiary as part of its group of operations. The company has operations in the Mid-Atlantic region, Florida, Southwest, Central region, and California. Ryland sells primarily to the first time and move-up home buyer in the market range of $\$ 70,000$ to $\$ 325,000$ price range. The company builds mainly single family detached housing, but does build some multi-family attached housing.

The plant visited in Columbia, Maryland, is a open-panel wall assembly and roof truss fabrication plant.

\section{Business Volume and Stafing}

$\$ 800$ - million/yeur(company wide) over 9,000 homes/year (company)

Design Staff =

Production Staff $=75$

Administrative Staff =

Sales Staff $=$

\section{Desion Procedure}

Ryland Homes builds homes from a fle of standard plans which may be occasionally altered from a list of options available to the prospective buyers. Major revisions or custom designs are typically avoided. 
When the company makes a determination that a new product is desirable, the new design is initiated by the head office. Within the head office, a group consisting of sales, marketing, financial, and design personnel get together to determine what the new product should be. The design is created, drawings are produced, including specific manufacturing drawings, and then distributed to the manufacturing plants that may produce it.

\section{Energy Design Decisions}

Ryland Homes builds homes to meet code energy efficiency requirements. A "Super-E" upgraded energy efficiency package is available as an option to the buyer.

\section{Automation and Computerization}

The amount and type of computerization utilized at the corporate level is unknown. At the plant level (the plant visited), computers are used in two areas; administrative functions and production. The administrative functions are typically for payroll, accounting, etc.,for production the computer is utilized to provide a print out of panels required for production of a bome, along with a listing of the materials required.

Computers are not utilized for project scheduling, or work order scheduling, nor is any computerization or automation incorporated in the manufacturing operation.

\section{Products Manufactured}

At the plant visited, wood fracoed open wall panels and roof trusses are constructed. Botb exterior and interior walls are manufactured, with exterior panels having the exterior subsheathing attached at the plant and the interior walls having only the framing produced.

\section{Raw Material and Inventorr}

Lumber is purchased in large quantities, with inventory turn-ovor occurring about 12 times a year. All lumber materials are stored in an open yard, and unprotected from the weather. All the additional materials required for the home such as siding, sheathing, roofing, etc., are purchased in quantity by the plant and sent to the site as required.

\section{Manufacturing Methods}

Manufacturing is performed in a 60,000 s.f. plant. Computer generated printouts of required wall assemblies are utilized to produce all wall panels required for a home. Material is assembled from the yard and cut down utilizing hand operated power tools. Door and window opening subassemblies are constructed and moved to the main wall assembly line. Walls are constructed on setup tables, all material is manually placed in the jigs and all nailing is performed by hand held pneumatic nailers. The wall panels are then moved by hand to the sheathing application table. The sheathing is placed and positioned by hand, then a automatic stapling bridge attaches the sheathing to the wall framing. The wall assembly is then moved manually and placed on the trailer for transportation to the construction site. While the loading of wall assemblies is taking place, other construction materials are also loaded on to the trailer in such a fashion as to insure the transportability of the entire load. Adjacent to the wall assembly line, is the 
truss assembly line. Similar to the wall assembly operation, all materials are manually cut, positioned, and the truss press is manually positioned at each connection plate prior to pressing of the plates. The trusses are then manually carried to the trailer and loaded for transportation.

\section{Quality Control}

A quality control position has been created in the plant to determine where a field identified problem may have occurred, or if the problem occurred after an assembly left the plant. No other quality control measures were identified.

\section{Energy Performance}

No energy efficiency improvement measures appear to be implemented in the plant. Further, since all the remainder of the construction in the field is conventional construction practice, it is assumed that the energy performance of the finished product is comparable to a similar site constructed home.

\section{Comments}




\section{Energy Efficient Industrialized Housing Project}

\section{TRIP REPORT}

Facility visited:

American Standard Building Systems

700 Commerce Court

Martinsville, VA
Visit Date:

1 June 1989

(text revised $7 / 14 / 89$ )

\section{Fiost:}

Project Staff: Jim Roland, Bill Swart, Ahmad Elshennawy

Report Prepared By: Jim Roland

\section{Company Profile}

American Standard is a twenty-year old manufacturer of open panels. Their plant was the newest and most modern of those seen on the Virginia tour. They are producing 15 housing units per week and have a capacity of 30 .

\section{Business Volume and Staffing}

19 - million/year

800 homes/year

Design Staff =

Production Staff =

Administrative Staff $=$

Sales Staff $=17$

Total Staff is 180

\section{Design Procedure}

American Standard has a large number of standard plans, but as in the case of all manufacturers, each project is unique. American Standard uses a CAD program for design of walls and trusses. They are not as advanced as National in use of computers, but much more advanced in tools in the plant.

\section{Automation and Computerization}

This plant had the highest degree of automation. They have many operational siations that use automatic saws, routers, punches, etc.

Products Manufactured 
Open panels with or without exterior siding, with doors, windows, etc. American Standard also manufactures doors, stairs and other components.

Raw Material and Inventory

\section{Manufacturing Methods}

Probably as close to automation as any American housing company. They construct panels, trusses, doors, moldings, etc. using modern equipment and in many cases automatic tools.

\section{Quality Control}

Probably has tighter construction quality than some of the other plants. Quality Control is a concern and exercised in the plant with inspectors and a manual.

\section{Eneroy Performance}

No special concern for energy. Constructing open panels only and building what the market. Energy decisions are made at the local level between the purchaser and local builder.

\section{Comments}

Most modern looking impressive plant. Still beavy user of labor, but has many automatic tools.

American Standard delivers to builders, but does not provide crane service as National does. 


\section{Energy Efficient Industrialized Housing Project}

\section{TRIP REPORT}

Facility visited: Cardinal Homes

P.O. Box 10

Williesburg, VA 23976

(Not associated with Cardinal Industries)
Visit Date: $\quad 31$ May 1989

$1: 30 \cdot 3: 30 \mathrm{PM}$

(text revised $7 / 12 / 89$ )

Host: Don Cappaert

Project Staff: Jim Roland, Bill Swart, Ahmad Elshennawy

Report Prepared By:Jim Roland

\section{Company Profile}

Cardinal Homes, Inc. is a private company constructing modular homes. They sell in Virginia, West Virginia, North Carolina and Maryland. The facility includes a 42,500 square foot plant (Butler building type). They sell to builders, developers. Modules are either 12 feet or 14 feet wide.

Business Volume and Staffing

- million/year 250 homes/year (approx 1 house/day)

Design Staff $=$ Production Staff $=90$

Administrative Staff =

Sales Staff =

\section{Design Procedure}

Cardinal has a number of standard designs of 24 feet and 27 feet width. They also offer options and accept customer options.

\section{Automation and Computerization}

No automation was evident in the factory.

\section{Products Manufactured}

Modular houses using modules 12 feet or 1.4 feet wide lengths up to 56 feet, one story and two stories. Wood construction, $2 \times 4$ studs covered with plywood and various sidings. Interior smooth dry wall walls, stipled ceilings with molding at the floor and ceiling. 


\section{Raw Material and Inventory}

Material is stored under roof. Quality appeared good. All material trucked in. Inventory set, based on delivery expectations, e.g. if it takes 4 weeks to obtain a particular product they keep at least 4 weeks supply.

\section{Manufacturing Methods}

They use various self-built jigs and fixtures. No automation is used. Very little pre-cutting and pre-drilling is done. For example, the electrician does his job (from the outside) hauling a drill and 100 foot extension cord, drilling studs and plates as necessary.

\section{Quality Control}

A Quality Control inspector who reports to general management is used. A quality control manual is used. The quality inspector inspects at each station and reports any problem to the foreman of that shop. In case of conflict, the inspector can go directly to management.

\section{Energy Performance}

No special energy features are included. They can be ordered as options. See attached features and options sheets.

\section{Comments}

At this plant and at all the plants comments were made to the effect that "you can't sell energy these days, no one is interested."

Quality and features of the basic house at this plant is judged to be OK, but, not great. One of the other visitors said their units were somewhere between mobile homes and modular units. Their model home $1050 \mathrm{ft}^{2}$ sells to a builder dealer for $\$ 25,000$.

Labor rates at this plant average around $\$ 5.00$ per hour. Keeping qualified labor was reported as a maior problem.

Code approvals were reported as no problem except in North Carolina.

Sizes are from $900 \mathrm{ft}^{2}$ to about $1500 \mathrm{ft}^{2}$. My tour guide said most of theirs are between 900 and $1200 \mathrm{ft}^{2}$. 


\section{TRIP REPORT}

Facility visited: Fleetwood Enterprises, Inc. 1603 Grove Ave. P.O. 37

Visit Date:

Haines City, Fl. 33844

Mar. 25, 1989

(813) 422.7591

Host: Phill Tanner, Plant manager

Project Staff: Subrato Chandra, Jim Roland, Bill Swart, Lawrence Maxwell, Tim Branson

Report Prepared By: Lawrence Maxwell

\section{Company Profile}

Fleetwood Enterprises is the largest manufactured home builder in the U.S., with production facilities throughout the country. The company manufactures both HUD code (mobile homes) as well some recreational vehicles. Fleetwood has two manufacturing plants in Florida. The plant visited manufactures for the retiree market, while the other Florida plant manufactures bomes for the fanily market.

The corporate offices of Fleetwood Enterprises are located in California.

\section{Business Volume and Staffing}

\$26-million/year

1300 homes/year (this plant)

Design Staff $\approx$ unavailable

Production Staff $=145$ to 185

Administrative Staff $=$ ?

Sales Staff = (sales staff consists of mobile home dealers who purchase units from Fleetwood for retail sale)

\section{Desien Procedure}

The design of new homes by Fleetwood occurs at the corporate level and is undertaken in California, even though the new product may be for a specific market such as the Florida retiree market. The local manufacturing group will determine that a new product is desired either by the type of requests received from the dealers that market the homes, or based on observations of products manufactured and sold by competitors. This information is relayed to the corporate offices in California where the decision to develop a new product will be determined. If the decision is made to create a new product or change and existing one, the design and development will take place in the California offices. 
wiring. The roof assembly, which consists of trusses, ceiling, insulation, and HVAC ducts, is moved as a complete unit from its assembly area and attached to the top of the walls. Roof sheathing, felts, and shingles are attached to the roof assembly after the assembly has been attached to the main structure. Exterior wall finishes and the balance of interior wall finishes, are applied. By this time, the plumbing and electrical work is completed and testing of the wiring as well as pressure testing of the plumbing systems is carried out. Finish trim and molding os attached, and doors are adjusted for proper closure.. At this time the production is complete and the unit is ready to be moved out of the assembly building.

\section{Quality Control}

Third party code inspectors (DOT inspectors) are on hand at the plant to confirm code compliance.

In-house QC measures were not detailed during visit.

\section{Eneroy Performance}

The units manufactured by Fleetwood are designed to HUD code energy performance requirements.

\section{Comments}

Automation is not incorporated in to the manufacturing process. The use of pneumatic stapling guns represents the level of mechanized equipment utilized in the manufacturing process. All materials control, handling, cutting configuring, fastening, or assemblies movement is performed manually. Inventory control, production management and control, and scheduling are performed manually. This plant was stated to be fairly representative of Fleetwood's manufacturing operations around the country. 
Energy Efficient Industrialized Housing Project

Trip Report

Facility Visited: Acorn Structures 1 Rear Keef Road Acton, MA 01720

Visit Date: March 2, 1989

$3: 45 \cdot 5: 00$ p.m.

Host: Mark Kelley, Energy Engineer, (508) 369-4111

Prolect Staff: Subrato Chandra, Phillp Fairey, Bill Swart

Report Prepared by: Subrato Chandra

\section{Company Profile}

Acorn is a 41 year old panelized (open) builder catering to the custom home market ($\$ 100 /$ sq ft + range). Acorn sells primarily in the Northeast and the Washington, DC aren, although they have shipped homes all the way to California!

The Acorn facility is composed of office and manufacturing facilities as well as a sales and model center. Acorn works directly with affluent homebuyers who want custom homes. Acorn uses Acorn trained builders to build the bome.

Acorn has a distinguished history of building energy efficient housing. They have a direct gain solar house as a model house and offer active solar heating/water heating options on their homes. They have $600+$ active solar houses and many more passive solar houses operating in the field.

\section{Business Volume and Staffing}

\$13 - nillion/year $\quad 200$ to 400 homes/year

Design staff $=22 \quad$ Production staff $=8$ to 10

Administrative staff $=12$ (including finance, data processing, R\&D, Marketing)

Sales Staff $=39$

\section{Design Procedure}

There are three levels of design service:

- Standard plan, as in catalog $w /$ minor modifications

- Major additions or modifications to catalog designs

- Architecture from scratch.

Acorn works with the homeowner to design the house. The house plan and elevations are done manually. A graphics computer (or two?) is exclusively used to update construction detail books common to Acorn houses. 


\section{Energy Desion Decisions}

Fleetwood energy design decisions are market driven. If the market demands increased energy efficency, Fleetwood is willing to provide it. Otherwise, Fleetwood works to meet HUD code minimum standards.

\section{Automation and Computerization}

Computers are not utilized in the plant other than for some clerical and administrati functions. Inventory and production scheduling and control are performed manually.

\section{Products Manufactured}

Fleetwood manufactures HUD code bomes in the Haines City plant. The units manufactured are single and double wide mobile home units targeted for the retiree market. The assembly line will bave 10 units on the line at different stages of construction at a given time, and production is set up so thet in a run, they will produce a pre-determined number of identical models. This allows the production staff to produce a number of identical units simultaneously, instead of working on 4 or 5 different model types at the same time.

\section{Raw Material and Inventory}

Fleetwood purchases their materials in large quantities. The purchasing agents will typically purchase items such as lumber for 2 or 3 plants at one time ensuring the greatest possible pricing advantages. Bulk items such as lumber will be brought in by rail in quantities that will insure a 2 week supply of stock to avoid any shortages of materials which could potentially stop production. All materials are kept in enclosed buildings to maintain moisture content limits and prevent deterioration. Construction inventories are turned over approximately 24 times a year. Material waste is not monitored or tracked in the production process and figures for the quantities or material lost to waste were not available.

\section{Manufacturing Methods}

The manufacturing of a unit begins vith the construction of the steel chassis. The steel members for the chassis are configured on a jig and welded. When the chassis assembly is completed, it is taken outside for painting. Once painted, the chassis is brought back into the plant, placed on a dolly which facilitates its travel sideways through the production sequence, and begins its journey down the assembly line. The assembly thin begins with the construction of the floor platform on the chassis. The floor joists are attached to the chassis and the plywood subflooring is glued and stapled to the joists. Floor coverings are applied to the platform. During the assembly of the floor platform, inlerior walls, cabinetry, and roof assemblies are constructed in areas on either side of the main production line. As the main assembly moves down the production line, the subassemblies are moved over the main production line and attached to the platform. Nearly all subassemblies are hand carried to the production line, except for the roof system, which is too large to be manually lifted. Exterior wall framing is attached to the platform, electrical wiring is routed, and exterior insulation is installed and fished through the 


\section{Energy Design Decisions}

Acorn makes a conscientious effort to design and build very energy efficient bomes. This is by utilizing architects and engineers who are very well versed in both passive and active solar energy technologies as well as eaprgy efficient design and construction tochniques.

\section{Automation and Computerization}

They have a VAX cluster and three VAX minicomputers to perform management tasks (accounting, payroll). A networked PC running VersaCAD is used to draw panels. They strive to design to a $4 \mathrm{ft} \times 8 \mathrm{ft}$ panel. A complete set of blueprints of the house is used to prepare shop drawings for panels. Even with the VAX, there is a lot of manual counting and checking. About 3-man days are required to produce material take-offs. The computers are not run at night. They are in the process of examining ICG's computer software in hopes that it can better integrate their operation.

\section{Products Manufactured}

Acorn uses a traditional frame structure using rafter assemblies rather than trusses for roofs. They pre-cut the roof rafters and pre-assemble open wall panels in the factory. They assemble their own fixed windows and buy operable windows and doors. The manufactured products are trucked to the site.

\section{Raw Material and In'entory}

All lumber used kiln dried, the best quality available. All lumber is stored under a roof. Raw material inventory is typically 1 to $11 / 2$ months.

\section{Manufacturing Methods}

Manufacturing is done in a 60,000 sq ft factory. Radial arm saws cut the lumber for roofs and wall panels. The wall panels and windows are assembled on two separate lines on workstations having jigs. The material is moved everywhere manually by handtruck, forklift and cranes. The plant gets custom drawings for each panel manufactured from the design department. Theso drawings are stapled to the panels as they go down the production line and are removed by the stacker who checks the construction quality.

\section{Quality Coptrol}

In the plant, the supervisor checks to see that the panels are correctly made as per the drawing. The builders are trained and preapproved by Acorn. Acorn personnel, in field, perforin quality control checks and educate the builder about properly installing infiltration barriers, caulking, etc. Measured infiltration rates in Acorn homes are 0.1 to 0.4 airchanges per bour. These are very tight homes and thus Acorn installs air-to-air heat recovery ventilators in most homes.

\section{Enerey Performance}

Acorn houses are very energy efficient and have an overall heating requirement of about $3.5 \mathrm{Btu} / \mathrm{DD} / \mathrm{sq} \mathrm{ft}$. Typically their passive solar direct gain homes have a backup fossil 
energy consumption of $2.5 \mathrm{Btu} / \mathrm{sq} \mathrm{I} / \mathrm{DD}$ and their hybrid homes have backup requirements of about $1 \mathrm{Btu} / \mathrm{sq} \mathrm{It} / \mathrm{DD}$. This high level of energy efficiency is achieved with a high level of design expertise, use of R.19 walls, R-30 cellings, low.E glass, an infiltration control package, builders trained in low infiltration construction techniques, use of high quality materials and tight tolerances in manufacturing (1/16" in all wood cutting operations). However, this is achieved with skilled production crews and a very low level of factory automation.

\section{Comments}

Acorn is committed to building a very high quality and very energy efficient product. Tho desiga of Acom houses in aesthetics, amenities, and space layout is outstanding. Their buyers buy energy efficiency and solar not totally due to economic reasons. Environmental ethics is a strong motivation in many Acorn buyers.

Acorn used to manufacture closed panels (insulated, wired, plumbed, etc.) which would be erected in the field in a tilt-up mode. They have abandoned that because of difficulty in getting inspection approval.

Acorn is very supportive of the EEIH project. They are willing to work with the project team. They are especially interested in air distribution systems research and technology, and in design for microloads. 
June 21, 1989

INDUSTRIALIZED HOUSING PLANT VISIT

Title:

Acorn Structures Plant Visit

Date:

April 18, 1989

Location:

Concord, Massachusetts

Attending:

Barry McGinn, Center for Housing Innovation, University of Oregon

Purpose:

To view an industrialized housing plant.

Sponsor:

Energy Efficient Industrialized Housing Research Program

Supporting Documents: Annapolis House Plan

On April 18, 1989, a representative of the Center for Housing Innovation at the University of Oregon visited the plant and office of Acorn Structures in Concord Massachusetts. Acorn manufactures a $4 \times 8$ open panel housing system, which allows them a good deal of flexibility in developing varied house plans and massing.

\section{Marketing}

Acom has a standard catalogue of 45 plans which fall into five major families of house offerings. These are attractively set forth in their extensive color brochure "The Art of an Acom." The house families are categorized as per their salient architectural massing features, such as shed roof forms, wrap around hip roofs, and saltbox forms. They are further elaborated on in separate family brochures, which explain in detail each model in the family. Their model houses are located in Acton, MA and Morristown, NJ. In addition, display offices are located in Westport CT, Annapolis MD. and Fairfax VA.

Approximately $30 \%$ of Acorn panelized house buyers purchase straight catalogue houses, $20 \%$ purchase totally new designs, and 50\% purchase modified catalogue house designs. The professional architects and designers on staff at Acorn have a plan library of standard changes to catalogue houses that number in the several hundreds. Their market goals are to reach out to new builders and building dealers.

\section{Broduction}

The plant operates with three standand $4 \times 8$ panel lines and two $8 \times 8$ special sub-assembly panel lines. Special jigs for frame alignment and racking are employed, as well as hand held pneumatic nailing guns.

Acorn stock a large number of sealed glazed units of various configurations from which they build their own fixed windows. They use standard Pella operable windows. This affords them considerable flexibility in configuring window layouts and window walls and it is obvious they capitalize on this feature in their house designs. Their sealed units are purchased with a 13/16 in. airspace as opposed to the usual $3 / 16$ in air space for improved energy performance. Low emissive 
glass is used exclusively for the same reason. The in-hous millwork shop fabricates all the sash, window frame, and trim. The window units are assembled into a frame on the $8 \times 8$ sub-assembly panel line and shipped to the site as a panel.

The floor decks are stick built on site; apparently floor cassettes proved too costly for the complex house designs used. The panels are simply nailed together and to the deck with the aid of a lever gadget for alignment that was invented for the purpose. The wall panels are self supporting while the roof is supported by an intemal heavy timber frame of fir posts and glue-lam beams. A 4x10 solid fir header is utilized for extemal wall openings. A special vent spacer detail for the open ceilings has also been developed.

\section{CAD and Energy}

In 1974, Acorn developed and commenced manufacture of a large format/arge volume active solar system incorporating their own flat plate collector design. As well as the active system, many of their house designs incorporate passive solar heating elements such as solariums with mass heat storage in the floors.

They perform energy performance analysis on a separate computer from the $\mathrm{CAD}$ for the various active/passive solar systems used as well as site conditions. They are presently reassessing their CAD system requirements and are not using the CAD system for design. They simply track house construction (plant panel fabrication) on a wall, similar to what you might find in a construction site office. The production department does a take-off with a separate computer which generates a cutting list and a packing list.

Many of the Acom designs incorporate extensive vertical open planning but do not seem to be taking advantage of the stack ventilation potential inherent in this design approach. There is also the issue of winter-time heat stratification which must also accompany this spatal design strategy and which does not seew to have been addressed.

Most of the smaller homes in the various family house categories start at about $\$ 140,000$ with the exception of the luxury family group, and range up to about $\$ 360,000$. Acom builds a quality panelized home and definitely seems to have extender the aesthetic possibilities of this production mode. 


\section{TRIP REPORT}

Facility visited:

Ryan Homes

Visit Date: Mar.24,1989

4408 N. Airport Rd.

Plant City, Florida 33566

Host: Daniel J. Ball A.I.A (813) 754-0555

Project Staff: Subrato Chandra, Jim Roland, Lawrence Maxwell, Bill Swart, Tim Branson

Report Prepared Br: Lawrence Maxwell

\section{Company Profile}

Ryan Homes is a home builder utilizing a factory setting to produce open wall panel assemblies. The company produces both homes from a file of designs as well as custom homes and homes from plans broight to them by builders and home buyers. The homes built range in cosi from $\$ 60,000$ to $\$ 250,000$ each including land costs.

Ryan Homes facility consists of Administration building, 3 buildings for production, and a materials storage facility.

\section{Business Volume and Staffing}

$$
\text { - million/year homes/year }
$$

Market: Move up home buyers $\$ 70,000$ to $\$ 350,000$

Design Staff $=9$

Production Staff $=30$

Administrative Staff $=7$

Sales Staff $=$

\section{Desion Procedure}

Ryan Homes design department consists of architects, engineers and draftsmen. The group is continuously developing new home designs. Through an independent msirket research company, potential home buyers are quizzed as to what they are looking for in a home, they are also asked to comment on and criticize desigas that are being developed by Ryan, even though they are not informed as the actual company who is developing the designs. The comments received from the prospective buyers are incorporated in to the designs and the homes are built. Most of the actual design work is accomplished in the more traditional manner, i.e. sketching v.s. by computers. 


\section{Energy Design Decisions}

Energy decisions are derived by providing complaince with the local code requirements in the most cost effective manner. Decisions are developed by the designers along with the market managers. No energy upgrade option is offered, but can be provided if insisted upon by the buyer. Equipment such as hvac units are sized based on worse case scenerio, and with agreements with equipment manufacturers, the actual units installed will be sized by the mechanical contractor, and are usually downsized from the unit specified. Upgrades for items such as kitchen applainces will be based on added amenities in the unit v.s. incorporating a more energy efficient unit.

The company wants to be fully market driven in their decision process. The company does not provide a energy efficiency upgrade option at the present time. The option would be offered if the market expressed a desire for such.

\section{Automation and Computerization}

Ryan Homes utilizes computers for administrative functions and for advanced product design and engineering. At the administrative level, computers are utilized for accounting, payroll,and similar functions. At the design and engineering level, computer aided drafting is utilized to produce the final production drawings which include such things as panel configurations materials take-offs and cost estimating. The computers in house are networked together and have the capability to interact with the central computer system at Ryans some office. Computers are not utilized in the manufacturing process, or in scheduling of work but is utilized for inventory control.

There is limited use of automation in the assembly plant. An automated truss member cutting machine is utilized, however, the actual truss fabrication machine requires manual setup, material placement, and truss assembly removal. The balance of the manufacturing operation in the plant is nnnautomated.

\section{Products Manufactured}

Ryan Homes manufactures open wall panels and roof trusses for construction of their speculatively built homes. The company also produces pre-hung doors utilizing purchased door blanks, and produce stairs and railings in their millwork shop. On occasion, they nill produce wall panels for builders from the builders drawings on a bid per job basis.

\section{Raw Material and Inventory}

The plant inventory is changed over approximately 12 times a year. All wood products are stored under a shed roof to protect, from weather, but humidity control is not provided. Doors are stored as blaniks and pre-hung on a as needed basis. Windows are prepurchased and utilized as required. Kitchen and bath cabinetry are purchased knocked down and assembled in the plant for use in the new construction as they are required. Counter tops are produced in the plant.

\section{Manufacturing Methods}

Manufacturing is accomplished in 3 buildings, one of approx 20,000 s.f. for walls and 
millwork, one of approx. 15,000 s.f. for trusses and casework, and one of approx. 8,000 s.f. where rough cutting of material for the truss fabrication operation occurs.

Walls are produced on jig tables with manual cutting and placing of materials, and pneumatic nailing of materials. Exterior sheathing is attached in the plant as required, windows may be assembled into the wall panel at the plant. Trusses are produced on a truss plate press which requires manual set-up and materials placement, and manual truss removal. Several different sized truss presses are utilized in the plant. In the millwork shop section of the wall assembly plant, pre-hung doors are produced along with such items as stairs and stair railirgs. These are produced by hand and with some conventional finish carpentry equipment.

\section{Quality Control}

During the manufacturing process, the foreman checks panels to ensure that they are correctly constructed and are square. As this is an open panel operation utilized to speed up field construction and reduce site losses, the construction tolerances are not perceived to be necessarily critical. The tolerances are what is reasonably required to allow erection in the field with a acceptable level of quality.

\section{Eneroy Performance}

Ryan Homes will provide an upgraded energy efficiency package consisting of increased insulation thicknesses and higher quality windows if requested by a buyer. However, Energy efficiency through factory technologies is not the pirpose of the operation. Furthermore, the tolerances established in the manufacturing operation is to allow reasonable construction quality in the field rather than improvement of energy efficiency.

\section{Comments}

Ryan Homes started their manufacturing operation producing closed wall panel systems and 3 dimensional wet cores. However they have abandoned this approach because the system prevented the flexibility that was required by market conditions. At this time, they are producing open wall panels to reduce code inspection problems, and increase flexibility. They desire to be more market driven and less technology driven. 


\section{Energy Efficient Industrialized Housing Project}

\section{TRIP REPORT}

\begin{tabular}{|c|c|c|c|}
\hline Facility visited: & $\begin{array}{l}\text { MOD-U.KRRF Homes Inc. } \\
\text { P.O. Box } 573\end{array}$ & Visit Date: & $\begin{array}{l}2 \text { June } 1989 \\
\text { (text revised 7/14/89) }\end{array}$ \\
\hline
\end{tabular}

Host: Robert Fitts, President

Dale Powell, VP Operations

Project Staff: Jim Roland, Bill Swart, Ahmad Elshennawy

Report Prepared By: Jim Roland

\section{Company Profile}

Mod-U-Kraf is a publicly beld moàular builder formed in 1971. The facility includes an office (contained in the plant) and a very, very tight $20,000 \mathrm{ft}^{2}$ plant. The market area is Virginis and the surrounding states. House size varies from about $900 \mathrm{ft}^{2}$ up to $3000 \mathrm{ft}^{2}$. Sales are to local builders with house prices in the mid-range. The model home we visited in Roanoke was reported to sell at $\$ 129,000$ complete on a lot there with septic tank or hook-ups. That house consisted of five modules and totalled $2230 \mathrm{ft}$. (See attached photo).

\section{Business Volume and Stafing}

7.2 - million/year

Design Staff $=5$

Administrative Staff $=$

Sales Staff =

\section{Design Procedure}

The company has 76 standard models. Almost every house is, however, customized. Re-design and drafting is done manually now. The company just installed an AutoCad system and is training personnel on its use.

The modules are constructed in the plant using standard drawings such as a stick builder would use.

\section{Automation and Computerization}

No Automation. Plant size is very small and would limit use of large tools or fixtures. They are now converting to AutoCad in the Engineering Department. 


\section{Products Manufactured}

Modular houses with modules 12 feet or 14 feet wide and up to 54 feet long. These can be grouped in various configurations for one story or two story houses. Type of siding is an option. Vinyl is common.

\section{Raw Material and Inventory}

Materials are stored under roof in a separate building. Plant space is so limited only absolutely necessary materials are kept in the plant. No special inventory control is used.

\section{Manufacturing Methods}

Housing modules are basically stick built under roof. A module progresses down one line to the end, is transferred over and progresses down the other line and out the door to a transporter.

I saw lots of hand measurements using tapes (laying out the floor, for example). Trusses are purchased, cabinets are purchased. The electricians job was made easier by pre-grooving the base plate.

\section{Quality Control}

Quality Control inspector reports to the president. They have a QC manual. They take responsibility for the house module, but, not the foundations and site work. Modules appeared well caulked and tight.

\section{Energy Performance}

Energy features are standard R11 insulated walls and floors, R19 ceiling, baseboard heat vapor barrier and double pane windows. Options are available including R-19 fiberglass insulation in the floor and $\$ 38$ in the ceiling. They offer R-13 (Owens-Corning 3-5/8n thick fiberglass) in the wall with an extra insulating board R-4 over that. The insulating values are selected based on material availability and thickness of cavity into which it is placed. The Mod-U-Kraft representative stated that his company is concerned about energy and promotes energy efficiency. The are, however, customer driven.

Standard heating is baseboard electric. Ducts are not installed because of transportation problems. If a heat pump is desired by the customer the factory provides registers only. The heat pump is selected by the customer or local builder and installed by the local builder. This manufacturer tries to Tocalize" those components which may require follow-on service. The house manufacturer removes himself from that loop completely.

The house manufacturer also removes himself from the appliance loop. He provides Sears kitchen appliances with che thought that the customer can get service practically anywhere in the country.

Mod-U-Kraft reports they are changing hot water tank vendors from AO Smith to Mor-Flo. The hot water tank they provide is an energy efficient model. 
TRIP REPORT

TITLE: Meadowood Industries Tour

DATE: July 26,1989

LOCATION: Lebanon, Oregon

ATTENDING: $\quad$ G.Z. Brown, Rudy Berg, Center for Housing Innovation

PURPOSE: Facilities Tour

SUPPORTING

DOCUMENTS: Test Data

REPORT

PREPARED BY: Rudy Berg

We visited the "plant" (actually a farm building) of Leonard Opal, a Willamette Valley grass seed farmer who has developed a resin-bonded ryegrass-straw building panel called Meadowood. Mr. Opal has been at work on this product since about 1977.

Presently his entire production apparatus consists of a hay chopper, a modified dryer-tumbler used to mix chopped straw and resin, and a pair of heated presses, the largest of which $\left(4^{\prime} \times 8^{\prime}\right)$ is the sort of low-pressure (240 psi) press used to make plywood. A smaller, higher-pressure press is used for smaller test panels.

Basically production consists of chopping the straw into 2 " lengths, mixing it with liquid resin, spreading the mix by hand between metal "caul plates" inserted into the press, then using proper combinations of heat and pressure to solidify the mass into a solid sheet. The resin Opal uses is proprietary; he did mention that it cost $\$ 1.50 / \mathrm{b}$ vs. 15 cents $/ \mathrm{b}$., for the formaldehyde-based resins commonly used for wood products, and constitutes $2-3 \%$ by weight of the finished product. A press cycle (which might produce 6 or 8 sheets in one pressing) requires about 10 minutes.

Virtually all stock made in this way so far has been $1 / 4^{\prime \prime}$ thick.

In short, Opal's products at this point are hand made, inconsistent and expensive -- presently about $\$ 15.00$ per $1 / 4 "$ sheet. Still, the results are interesting. Meadowood, like the various bonded-wood products it resembles, can be made with various densities, overlays, and raw materials. It can also be made into 3-D shapes; we saw experimental one-way pallets with molded-in ribs, and comugated sheets of several patterns.

One interesting property of Meadowood seems to be its ability to form small-radius bends and variable thicknesses with little structural effect. Another, when the raw material is rice straw or especially rice hulls, is to use the high silicate content present in these materials to achieve considerable fire resistance.

In this regard, Opal has had Meadowood tested (see notes attached) with promising results. It achieved a Class $C$ fire rating; in practical terms Opal demonstrated how the product would not continue to burn in the absence of flame. It also appears to provide $R=.68 \mathrm{per} 1 / 4^{\prime \prime}$ sheet, or $\mathrm{R}=2.7 /$ inch. Mechanical properties are equal to or superior to particle and wafer boards. Like OSB, Meadowood absorbs water and swells considerably at its edges, but much less through its faces. 
Opal has provided samples of Meadowood to Western Insulfoam (see trip report 7/26/89) who have fabricated stressed-skin panels using his $1 / 4$ " product, and are testing the resulting units. He is also working with an engineer to develop a production system, at least partially toward the goal of turn-key manufacturing plants for Asian countries or other states such as Califomia, whose rice growers have shown some interest in Meadowood. 
July 14,1989

TRIP REPORT

Title: Site Visit to Westem Insulfoam/R-Control Panels

Date: June 23, 1989

Locationi $\quad 1904180$ th Ave. S., Kent, WA.

Attending: G.Z. Brown, Rudy Berg, Margot McDonald

Purpose: To study design and manufacturing of energy efficient panels in order to identify appropriate software tool development.

Sponsor: . Center for Housing Innovation; Energy Efficient Industrialized Housing Research Program

SupportingDocumentsi R-Control Panel Building System booklet, Better Homes and Gardens article, AFM R-Control Panel Load Design Charts, R-Control Stress - Skin Loading Bearing Panels sheet and brochure.

Report prepared by: Margot McDonald, Rudy Berg

Premier Building Systems is the leading manufacturer of insulated foam panels for building construction. They are also the largest constituents of the A.F.M. (Association of Foam Manufacturers) board. During this visit we met with Loren Haug and General Manager Mike McKinney who discussed design, marketing, and manufacturing strategies. This included a plant tour at the same location.

\section{Company Overview}

An important feature of Western Insulfoam products is their use of EPS (expanded polystyrene) rather than urethane, another plastic foam in use by manufacturers such as Winter Panel. EPS products are expanded with steam (details below) while urethane foams employ Freson or other CFC gases, which damage the earth's ozone layer.

Western Insulfoam manufactures a wide range of foam products from hot tub covers to Geotech (foam beads bonded with asphalt to create a drain "gravel" panel) to movie set props. Although we visited the entire manufacturing plant, we focused our discussions on the building panel. We began with a general discussion of the R-Control panel which is a product of Premier Building Systems.

\section{Manufacturing Process}

The manufacturing of insulated foam panels is an efficient process performed in a relatively clean factory environment. The original foam beads are 1/40 their final size which makes for efficient shipping, storage, and handling. Because the beads (moldable polyethylene copolymer) are a petroleum based product, they are subject to large price fluctuations. Two suppliers used by Western Insulfoam are BASF (Parsnippany, N.J.) and ARCO (Newtown Square, PA.).

The preparation of foam stock from these beads is a two-stage process: first the beads are subject to steam heating in a hopper, rather like a commercial popcorn machine, which puffs them to some partial degree. These are sorted for size and stored in large overhead sacks to dry. All transport at this stage is pneumatic. Then the dried, sorted "pre-puff" beads are fed in measured batches into a large mold equipped with a steam/vacuum manifold. Here they are steamed again, but subject to 
compression as they expand, so that they cohere into a large block. Once expanded, the foam is subjected to a vacuum to draw off excess molsture, and ejected from the mold. This second expansion/mold process requires only two or three minutes. Again, this block is stored in a hot room for several days to permit moisture to escape.

The machinery involved in the bead-molding process, at least as performed at Western Insulfoam, is larger and more expensive than anything else we have observed in the housing industry, short of basic lumber mill machines. It appears, too, that the amount of energy consumed in this process is rather large.

There is virtually no waste. Standard foam blocks are a nominal $3^{\prime} h \times 4^{\prime} w \times 24^{\prime}$ long. Sections are wire cut to shape. Remnants are ground up and vacuumed to another part of the factory where they are used for other foam product such as bean bag chairs. Some products, such as R-Control panels and "dryvit" coated foam, require $100 \%$ virgin foam. This is to maintain quality and conformity in bead size and texture. Also, some recycled foam may have been used with food products and may contain residue.

\section{The R-Control Product}

The R-Control panel is constructed of an exterior layer of O.S.B. (oriented strand board), one of several thicknesses of E.P.S. (expanded polystyrene foam) and an interior layer of either O.S.B. or gypsum wallboard. It is used for roof, wall, and floor systems.

It is made as follows. The two outer layers are run (separately) through a glue machine which contains a two part solution of ISOSET (isocyanate, water based) glue. The outer layer is set down (glue side up) on a stack where the foam is applied. The stack works like a jig such that the foam can be properly located on the outer layer. Next the other outer layer is covered with glue and set on top of the foam to form a sandwich. Panels are stacked in this fashion and, when the correct number is prepared, the panels are pressed. The press makes the structural bond occur between the glue, outer layers, and foam. Premier Building System employs two presses - a $4 \times 8$ unit whose products can be handled to two people, and an $8^{\prime} \times 28^{\prime}$ press for oversize panels requiring lifting machinery.

Assembly of the panels requires use of O.S.B. splines which are driven between two panels along the shorter dimension. In the longer direction, $2 x$ plates are run the length of the pariel and nailed to it.

\section{Product Quality Control}

A Q.C. or quality control inspector is an in-house staff member. This individual collects samples of every run of panels. Three 12" x 12" samples are taken. From this a 6" square piece is extracted and subjected to tensile (suction) and pressure testing. These samples are retained to demonstrate adequate strength of the panels to U.L. inspectors who visit the plant several times a month. The sample must meet a 17 psi minimum to pass the stress test.

\section{How R-Control Panels are Introduced to the Market}

Premier Building System's designer, Gary __ works with the public to develop ho ase drawings that utilize R-Control paneis. In this case, the "public" is either consumers or builders using stock plans or the consumer who is purchasing drawings from R-Control. Premier Building Systems offers numerous stock plan options which have detail references and drawings using the panels for a nominal cost. Interestingly, these company drawings do not attempt to optimize the modular panel system. Instead typical house designs, as one would find in any house plans book are sold.

The major obstacle facing this industry is the lack of familiarity contractors and architect have with the panel system. There is a resistance to accept new and different techniques. In addition, contractors find it difficult to estimate the savings brought about by substituting the paneis for 
conventional systems. Although materials cost is more for the panels over a typical roof, wall, or floor assembly, labor is potentlally less. Untll contractors begin acquiring expertence with the product, it will be difficult to attain widespread acceptance.

\section{Building Code Compliance}

Similar to the problems encountered with builders and designers who are not familiar with (and therefore hesitant to use) the product, most building departments are not familiar with it elther. Premier Bullding Systems has had some success with repeat projects in Clark County, Washington, because the building official there (Duane Keran) was on a national building code committee and reviewed the panels previously. Premier Bullding Systems has taken it upon themselves to educate builders and inspectors alike in order to gain more acceptance of their product.

\section{Energy Conservation}

Portland General Electric (P.G.E./ Jack Waldron) has familiarized themselves with the R-Control panels and have begun their own campaign to promote their use in construction based on energy efficiency.

Freedom Homes (Washougal, WA.) has been marketing homes which use the panels based on improved energy performance.

\section{Computer Use}

Premier Building Systems used Autocad and abandoned it. They found that it was an excessive amount of time to input the customer's design in order to develop panel details. The panels themselves are standard and not subject to much change. Therefore, panel drawings need only be xeroxed and notated for the occasional irregularity. If scanning capabilities had existed and been affordable at the time this company was using computers, the tool may have proven effective. Instead, the company spend many man hours learning a system which could be more effectively dupilicated by hand.

Western Insulfoam uses computers for wire cutting. In this case, an optical scanner traces out the pattern to cut by following a full scale drawing of the design. The drawing may be computer generated or hand drafted. In the case of the former, it would be a natural progression to generate numerical control codes to run the machine direct from the computer rather than pasting up the image.

The manufacturer of "Big Wally," the wire cutting machine with an optical scanner is Gateway Precision Systems.

\section{Future Marketing Strategies}

In order to remedy several sales obstacles facing their furm, Premier Building Systems is focusing on a three year marketing plan which includes the following:

* complete residential package (house drawings)

* dealer networks

* finished product (model after manufactured housing)

* speculative housing (includes land)

Century 21 (real estate) made a marketing proposal which included land sale data banks where an interested buyer could locate all available properties listed by this realtor. The data bank would be located in a housing park which manufacturers buy into for approximately $\$ 100,000$. This way potential homeowners can select both a house and a home site at one location.

\section{Ideas for Product Improvements}


The company has been approached by an Oregon grass seed farmer (Meadowood Industries, 33242 Red Bridge Road, Albany, Oregon, 97321, (503) 259-1303) to consider a composition Ryegrass board as a substitute for the O.S.B. The ryegrass board has a better R.value and is more fire resistive. One negative aspect of the ryegrass board is the large amount of grass it requires per board. The industry is not yet in mass production.

\section{Conclusions}

The major obstacle facing this insulated foam panel manufacturer is the lack of famillarity to the public and building industry, Efforts are underway to educate architects, builder, and students of building trades, as to the merits and uses of this product.

In addition, no signiticant effort has been made to make modular designs out of a modular product thus optmizing its inherent cost efficiency. Perhaps this is an area where our computer tool can marry technology and design interactively and in the hands of the consumer. 


\section{A/E/C Systems Conference Trip Report}

June 19,1989

TTTLE: The DesCon' 89 A/E/C Systems ' 89 conference

DATE: June 5.8, 1989

LOCATION: Anaheim Convention Center in Anaheim, California

ATTENDING: G.Z.(Charlie) Brown, Margot McDonald, and Tomoko Sekiguchi

PURPOSE: Gather information on software in the architecture, construction, and building industries and to gain information on trends of the industry by attending seminars

SPONSOR: Center for Housing Innovation

SUPPORTING DOCUMENTS: Description by Margot MCDonald of the seminars that she attended. Copy of the program and exhibit guide which contains a list of exhibitors, all event which took place at the conference, and speakers at each event. An index of all documentation gathered from the exhibits.

TRIP REPORT PREPARATION: Tomoko Sekiguchi

Schedule for Tomoko:

Monday

8:30-5:00 Plant visit to Fleetwood Enterprises, Inc., Riverside California

Tuesday

8:30-10:00 Seminar - Spectal Punel - System Compatibility: Translators, Interfaces and other

Exchanges

10:00-2:00 Touring of exhibition hall

2:00-5:00 Concurrent Conference - MacForum

Wednesday

8:30-10:00 Seminar - Special Panel - Future Directions in MicroCADD

10:00-11:00 Macintosh Special Session - The Engineers' and Contractors' Forum

11:00-12:00 Seminar - New Tools for Specifiers

1:00-3:00 Touring of exhibition hall

3:00-3:20 Seminar - The Use of Computers in Japan

Description of schedule items:

The Fleetwood Trip report will be made by Margot.

Seminar - Special Panel - System Compatibility: Translators, Interfaces and other Exchanges - Five panelist discussed systems compatibility for CAD system on PC computers. The discussion was elementary. The most important information obtained from this seminar is the fact that the data format of each CAD system can be different and there are no real solutions to this problem due to the competion among $C A D$ vendors for the $P C$.

Touring of exhibition hall - This was the most worthwhile portion of the conference. Often the names of exhibitors were mentioned in seminar session and it was extremely useful to be able to immediately talk to the exhibitors about their product. There were over 400 exhibitors. We picked up literature or demonstration software from over 40 of the vendors. This information will be included in our library and used in enhancing our software survey. 
Concurrent Conference - MacForum - This was a simple overview of the history, current state, and future of Macintosh hardware and software. "The speaker mentioned names of software and hardware vendors from which we were able to get literature in the exhibition hall.

Seminar - Special Panel - Future Directons in MicroCADD - There were three speakers. One speaker from the Whitrey Group from Texas is a principal in an all computerized firm of 23 employee. The software they use is Intergraph on the Macintosh. The other speakers were CRSS from Irvine, Califormia and LPA from Callfornia both of these firms are much larger with over 150 employees each. They also used Intergraph software on PC and VAX computers. The emphasis of the speakers was on the use of CAD as a designt tool rather than a production tool because CAD systems are able to produce a database of information while drawing. So while drawing a design you are able to create materials lists, etc.

Macintosh Special Session - The Engineers' and Contractors' Forum - This session was also elementary. The interesting part of this session was the creative use of Microsoft Excel to do job estimating and tracking and the extensive use of macros to reach this end.

Seminar - New Tools for Specifiers - Extremely elementary session which brought to light the unsophisticated state of the specification tools for the industry.

Seminar - The Use of Computers in Japan - I was only able to attend the first one thind of this seminar due my departure schedule. But I was able to obtain the script of the speaker. The speaker flashed quickly through slides of work produced by his company, BUS Inc.

In summary this was a very productive trip for gathering information and measuring the temperature of the architectural, engineering, and construction industries' advances in computerization. Information of the future direction of the computerization of the industry was not etmphasized but the current state of the industry was. 
Seminar - Special Panel - New Tools for Speciflers - One speaker, an architect who is also a committee member on AlA Master Speo, spoke on electronic specifying. Products include Sweets Spec (an automated system for producing speclfications based on a query approach); Superspeo (a checkllst completed by the designer, malled in, and specifications returned); CSI- Speo text (word processor for specification editina only); SpecEditor, R-Com, Eclat (all word processors for spec.s). There is also an on-line database called Sweets Search which uses CD-Rom technology.

More manufacturers are making product literature, formerly in hard copy only, available on disk. This may be specification information, CAD drawings for a symbol library, engineering calculations, estimating/budget information, and design detalls.

There is currently a committee underway to evalute and set standards for specification writing and processing. AlA MasterSpec is one committee.

The speaker encouraged the exchange between manufacturers and designers for experience sharing of these new specifying tools.

'Seminar - Special Panel - Artificial Intelligence and Expert Systems This panel of three speakers discussed current developments in the fields of Al/ES as it pertained to their work. The speakers represented:

CERL - Construction Engineering Research Laboratory, US Army Corps of Engineers - This speaker presented a number of Al/ES projects underway at CERL including a large government grant to study alternative energy (l.e., solar) including alternative methods of construction (i.e., modular).

SOM - Skidmore, Owings, \& Merrill - This speaker described the development and use of in-house knowledge based software. One tool already implemented is the RBC, or Rule Based Calculator. (Attached is a copy of an article by the program author.)

CPSLO - California Polytechnic University at San Luis Obispo - This speaker presented a knowledge based software tool which is based on a comprehensive modeling of the design decision making process. The sottware is being developed on a Hewlett-Packard computer using Mountaintop software. The software should be ready for beta-testing in December. 


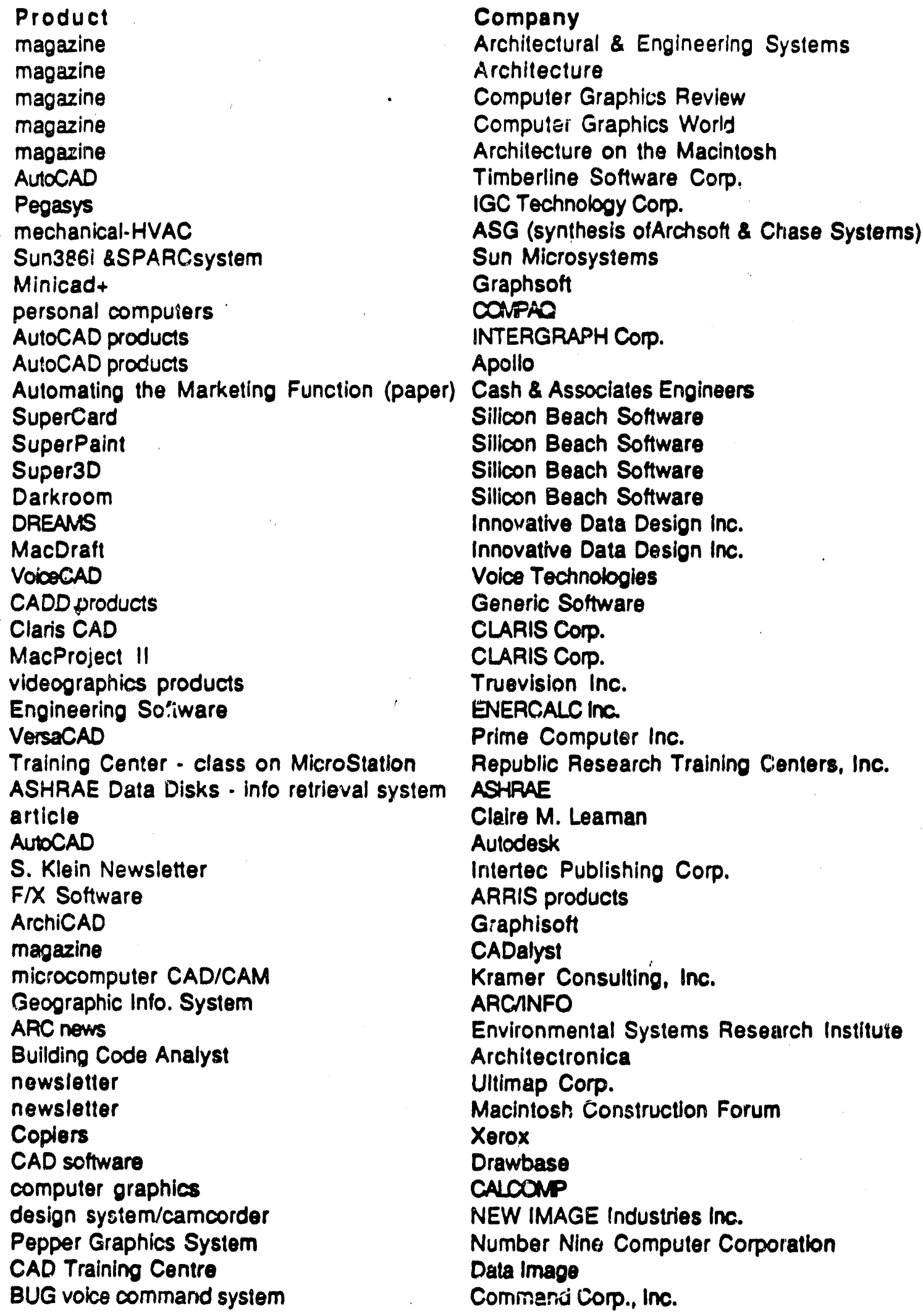

Company

Architectural \& Engineering Systems

Architecture

Computer Graphics Review

Computer Graphics World

Archilecture on the Macintosh

Timberline Software Corp.

IGC Technology Corp.

ASG (synthesis ofArchsoft \& Chase Systems)

Sun Microsysiems

Graphsoft

CONPAO

INTERGRAPH COIP.

Apollo

Cash \& Associates Engineers

Silicon Beach Software

Silicon Beach Software

Silicon Beach Software

Silicon Beach Software

Innovative Data Design inc.

Innovative Data Desion inc.

Voice Technologies

Generic Software

CLARIS Corp.

CLARIS COIP.

Truevision Inc.

ENERCALC Ina.

Prime Computer Inc.

Republic Research Training Cienters, Inc.

ASHRAE

Claire M. Leaman

Aulodesk

Intertec Publishing Corp.

ARRIS products

Graphisott

CADalyst

Kramer Consulting, Inc.

ARCINFO

Environmental Systems Research Instifute

Architectronica

Ultimap Corp.

Macintosh. Construction Forum

Xerox

Drawbase

CALOONP

NEW IMAGE Industries inc.

Number Nine Computer Corporation

Data Image

Commenú Corp., Inc. 
QuikCAD

Dimensions Presenter

CAD products

MicroArchltect

FastTrax

computer sottware

CAD/ Laser Cutting

CAD products

ProfitCAD/ProfitBID

design solutions

Archi-TREND

ALSFONT

CAD products

MAC ARCHITRON/I \& II

HVAC soltware

software programs

marketing specialists

ARTIST (newsletter)

Dimensions

accounting sottware

Swivel 3D

ModelShop

Windows

newsletter

special report

Mac products

software info.

MacPerspective

Assuring Our Energy Future (brochure)
Weather Shield Mfg., Inc.

Visual Information Development, Inc.

Houston Instrument

IDEA GRAPHIX

Dupont

HOKCSC Computer Sottware

Scale Models Unlimited

Numonics

Construction Data Control, Inc.

CADAM INC.

FUKUI Computer

Graphic Computer Services

GTCO Corporation

Gimeor, Inc.

TopDUCT

I.m.a.g.e. Software

Catalyst Marketing Group

Control Systems

Visual Information, Inc.

SAWSARA

PARACONP

PARACONP

Pella

MacWEEK

Apple Business

Turtle Creok Software

Apple Computer, Inc.

Knick Drafting, Inc.

California Energy Commission 
June 22, 1989

TRIP REPORT

Title: Fleetwood Enterprises, Housing Group

Date: Monday, 5 June 1989

Time: : 8:30am-5:00pm

Location: $\quad 3200$ Myers St, Riverside, CA. 92523

Purpose: To determine operating and decision making structure in design and production with an emphasis on computer use and potential.

Attending: G.Z. Brown, Tomoko Sekiguchi, Margot McDonald

Sponsor: Center for Housing Innovation; Energy Efficient Industrialized Housing Research Program

Supporting Documents: Photocopies from Fleetwood; Illustrations of production process.

Report prepared by: Margot McDonald

Why Fleetwood

Our visit to Fleetwood Enterprises, the nation's largest manufacturer of mobile homes, was arranged for several reasons. First, because of their production volume and sales, Fleetwood offered a model environment for studying marketing, design, manufacturing, and other processes related to the production and sales of mobile homes. In particular, the Riverside location is the design headquarters for all regions.

Second. Fleetwood is already a paricipant in our research grant. Jon Nord, Fleetwood's Senior Vice-President, is a steering committe member. We have therefore established the common objective of research as:isting industry and vice versa.

Lasty, we were attending the A/E/C (Architecture/Engineering/Construction) Systems Conference in Anaheim, CA., which is approximately thirty miles from Fleetwood and decided to combine visits.

\section{Company Profile}

Fleetwood consists of two manufacturing divisions: mobile homes ( 5.0 billion sales) and recreational vehicles (R.V.) (1.0 billion sales). Although some of the processes in R.V. design and production may apply to our interests, we focused on the mobile home product line. Fleetwood produces 35,000 motile homes a year and distributes nationwide. There are 26 manufacturing plants in 5 divisions. The divisions are sectioned by geographic region: Western Div., Central Div., Mid Atlantic Div., Southeast Div., and Florida Div. (See p. Al.) Most sales fall within a 300-400 mile radius. Fleetwood mobile homes are sold exclusively through dealers. 


\section{The Housing Group}

Our visit to Fleetwood's mobile home division (called "The Housing Group") was well organized by their staff, allowing us to meet with many members of top management. In the morning, we began the visit by attending a presentation of Fleetwood's organizational infrastructure and marketshare. This was delivered by Jon Nord, Senior Vice-President, Ed Salsbury, Engineering Manager, Jeff Wooldridge, Design Manager, and Dick aftemoon, we toured the Rubicell manufacturing plant with Doug Mechanical Engineer. In the plant tour was followed by a retum to Fleetwood headquarters where we visited the drafting department and met with - Drafting Supervisor. To conclude our visic, we shared in a round table discussion on automation and computer use with Wayne Smart, MIS Director, Ed Salsbury, and Jon Nord.

The charts on pp.A2 and A3 outline the organization of management and staff in the Housing Group and Production and Product Engineering.

\section{Product Development}

The Housing Group consists of three main branches in the area of product development: design, engineering, and manufacturing. Because Fleetwood's product is market driven, design and marketing functions are merged. It is the designer's role to anticipate future trends and respond to specific customer preferences. In order to accomplish this, the Design Manager spends a significant amount of time out in the field meeting with dealers. The manager also attends national conferences (e.g., NAHB), seminars (e.g., Color Marketing Group), conducts or uses existing statistical surveys, and stays current with trade publications. The engineer's role is to make the in-house designer's concept buildable and to check for code compliance with these and other customer modified orders.

Engineering together with the $Q C$ (quality control supervisor) have the capability to review for DAPIA and IPIA compliance. Areas outside their jurisdiction are sent to RADCO, an independent testing agency. Tum around time from both engineering and RADCO varies but, in both cases, slows down the manufacturing process especially if a non-standard item is not discovered until the order reaches the plant floor.

\section{Construction Documents}

Standard Fleetwood models are built from pre-approved floorplans, details and schedules. These engineering documents are kept in large volumes and serve as reference material for coordinators who oversee working drawings. Similarly, a QC inspector has access to approved specifications (Federal Standaris for HUD-Code Homes) for dealing with non-standard items in the plant.

The purpose of these engineering documents is to establish S.A.M.s or Standard Assembly Methods for standard models with some variations. These documents are vital to the plant operation because they contain information for manufacturing.

Product data sheets list all possible options within a product line. (See p. A6.) This sheet is completed by the designer to describe a model for manufacturing. For example, roof, wall, and floor construction, and interior finishes are specified on this form.

Manufacturing works from these product specifications or a similar form completed by a salesperson in the dealer's showroom. This verbal description together with a flocrplan (p. A11) are the construction documents used to build a mobile home. Customer changes to a floorplan are simply notated on the plan and not redrawn. 


\section{Manufacturing Efriciency}

Fleetwood's manufacturing principle is to hire unskilled labor to do a discrete task in the factory. Changes in configuration are costly in terms of retraining laborers and interrupting the assembly line. Although labor is $15 \%$ of the cost in manufacturing a mobile home it is a critical factor.

\section{Energy Issues in Design and Marketing}

As with the product, Fleetwood's response to improved energy efficiency is also market driven. For example in Oregon where the Bonneville Power Administration (B.P.A.) offers an incentive to increase residential energy conservation, Fleetwood offered mobile homes that met the program's standards. The "Super Good Cents Program," as it is called, uses a computer program called Wattsun. The Washington State Energy Department made this computer program available to Fleetwood's mechanical engineer and worked with him to reach compliance. In some cases, special construction details need to be developed to accommodate increased insulation (especially in floor and roof construction).

Otherwise, designers, engineers, and $Q C$ inspectors work to meet HUD's minimum standards for energy conservation. For example, tables in engineering reference volumes outline altematives to achieve glazing per sq. $\mathrm{ft}$. as window areas are modified in a design.

\section{Computer Tools}

The MIS Director on the Housing side gave us a full description of the computer equipment currently in use at Fleetwood. Corporate computing needs are met on a DEC VAX. Fleetwood has been using DEC equipment for at least 13 years starting with PDP 8's, upgrading to DECMates, and then to the VAX. Corporate applications include payroll, accounting, sales analysis, spreadsheets, warranty claims history and analysis.

On the R.V. side, VAXes are also being used. Applications include MRP (materials resource planning) for invoicing, and dealer activity.

Fleetwood has centralized computing at its headquarters and networks with five satellite plants in California, Indiana, Virginia, and Oregon. The network used is Paradigm. The goal is to network to all plants (50 plus faciories) with the VAX having 4-6 terminals and 2-3 printers per stacion.

Besides the VAX, employees initiated a Macintosh trend by bringing computers in from home. The company made the Macintosh the corporate standard because of the wide acceptance of this personal computer and because of the natural connectivity with the DEC. Applications run on this machine include Excel.

\section{Observations}

Many of the tasks, especially in design and engineering of the mobile home, were prime candidates for automation. Standard drawings, specifications, schedules, codes, could be electronically stored and manipulated. To go one step further, this information could also be viewed electronically on the factory floor. Increased direct communication in the form of data sharing may limit the non-approved custom model bottleneck currently experienced in the factory.

The same constriction communication gap that exists between coiventional site builders and designers, is found between mobile home manufacturess and their designers. The manufacturer, whose primary concem is production efficiency, is faced with incorporating custom designs into the assembly line framework. The designer, on the other hand, is responding to customer demands which often stem from transporting conventional housing ideals to a manufactured home irrespective of the manufacturing process. One area of improved efficiency is the cross education of design about manufacturing. In this way, manufacturing efficiencies can be designed into a product from its inception. 
Fleetwood is primed for automation. Currently, four controllers in the corporate office use Macintosh SEs. The Drafting Supervisor is experimenting with Claris CAD and VersaCAD on the Mac II. The main accounting operations are carried out on a DECNAX mini computer. The hardware configuration is excellent for networking (Macs to DEC). Moreover, because they are using Macintosh, they are compatble with "Energy Scheming," the energy software tool developed at the $U$ of $O$.

\section{Conclusion}

The visit to Fleetwood was very informative about the design and manufacture of mobile homes. Direct meetings with engineers and managers gave a more realistic view of how we might contribute to the process. The visit also served to bring the public sector up to date on our more recent research goals. The interchange was invaluable. 


\section{TRIP REPORT}
TITLE:
Automated Builder Magazine
DATE:
June 2, 1989
LOCATION:
Cappinteria, CA.
ATTENDING:
Margot McDonald
PURPOSE:
To discuss existing computer use in the industry and computer survey
SPONSOR:
Center for Housing Innovation; Energy Efficient Industrialized Housing Research Program

SUPPORTING DOCUMENTS: Advertisement, article.

One aspect of establishing baseline data for the computer software tools task involves surveying a representative number of manufactured housing firms to determine type and degree of automation. As the industry's leading trade publication, Automased Builder Magazine was contacted for background information on the state of automation in the industry, for initial leads in narrowing the field of firms to survey, and to assist with the review of survey content. To collect this information, I arranged a visit with Don Carlson, president of Automated Builder Magazine (Carpinteria, CA.) and member of the EEIH Stcering Committee.

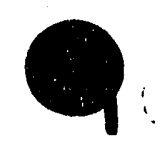

'First, Don provided valuable information reganding the state of automation within the manufactured housing industry. Automation started with the engineering of truss plates where computers were used to do complex engineering calculations. For this reason trusses were always engineered by a truss plate company who owned its own software which was usually developed in-house. The software was eventually made available to truss companies directly at little or no charge so that they could engineer and manufacture their own trusses. For many years, this was the only noteworthy type of computerization known to the manufactured housing industry. Since then, other aspects of the building component industry has become automated with the arrival of computer control setup for truss assembly (variations on multihead presses, rollers, and plattens connecting plates to truss members). Some truss manufacturers are using lasers to locate attachment points for truss plates on members laid out with a framing jig.

Another recent computerized development in the industry is the computer controlled saw. For manufacturers who have a repetitive cut procedure the investment has proven cost effective although the initial cost of the equipment remains high. One such company is Speedcut (Corvallis, OR.). Another, Auto-Omni, has a model costing approximately $\$ 125,000$. A manufactured housing company using this technology is Shelter Systems Group (Hainesport. NJ.). As with any machining task, setup time usually far exceeds time spent in producing the desired result. Often house designs are arrived at by designers with no knowledge of this manufacturing principle, and therefore the process is too non-repetitive to effect any savings.

In the second area of narrowing the field to be surveyed, Don Carlson identified software packages used in manufactured housing industry and firms that he knew used cornputers either in the past or present. These include:

1) On-line Data (Richardson, TX.)

2) The Plan (Ted Dasher \& Assoc., Birmingham, AL.); wall/roof/floor component producer

3) ARCE (Florida)

4) Mimsco (Saco, Maine); computer operated wall system

5) Auto-Omni; computer operated saw

Automated Builder Magazine 
6) ICG (Integrated Computer Graphics, Atlanta, GA.); complete CAD

design/drawirig/estimating/... system

7) N.V. Ryan; manufacturer using ICG on multiple terminals with in house program add-ons

8) Alpine Engineering Products

9) GangNail

10) Hydro-air

11) Clarity Corp.

12) Teelok

13) B-Max

Don recommended that we contact these companies for more information on product and application. In the area of marketing, Don knew of one firm that used the computer as a demonstration tool; that is, Nanticoke (Delaware/contacts: John Mervine, pres., or Gregg Mervine). He was unsure as to their success and thought that they had dropped the tool altogether.

In the area of foreign technology, Don knew of a number of successful Japanese firms which he has visited five to ten years ago. These include: Sekisui-Time (steel panel construction using robotics for welding); Masawa Masanoto. Don described the wood technology used in Japan which is a wood panel, tongue and groove lattice.

Most of the firms named above are known to do some work with computers. His recommendation for a survey across the entire manufactured housing field was to look at the top 100 firms and survey a portion of that list knowing that the $20-80$ rule applies (by surveying $20 \%$ of the industry we can discover what $80 \%$ of the industry is doing). The August issue of Automated Builder had a top 100 home producers list. Also, the magazine publishes a directory of manufacturers (with full statistics) which is updated yearly.

Finally, in the area of survey content, it became clear that due to the apparent low. level of automation in the industry we should focus on automation potential and understanding in-place manufacturing processes. We will also be able to determine computer hardware trends; that is, what equipment is currently being used for other in-house manufacturing functions such as accounting, marketing, inventory control, etc. 
July 12,1989

TRIP REPORT

TITLE: $\quad$ Blazer Industries Plant Tour

DATE: $\quad$ June 1,1989

LOCATION: $\quad$ Silverton, Oregon

ATTENDING: Barry McGinn and Rudy Berg, Research Assistants

Center for Housing Innovation

PURPOSE: $\quad$ Plant Tour

SUPPORTING

DOCUMENTS: None

On June 1, 1989, Barry McGinn and Rudy Berg of the Center for Housing Innovation toured the manufacturing plant of Blazer Industries near Silverton, Oregon. They were guided by Chuck Hill.

Blazer produces custom, chiefly modular buildings, though at times they have shipped panelized buildings. Many of their products such as construction offices and temporary school buildings are mounted on wheeled chassis, yet all are built to UBC rather than HUD standards. Blazer builds entirely to order. They have no inventory of standard models. Buildings of several thousand square feet, two-story buildings, and shipments as far as Alabama and Alaska are some of Blazer's accomplishments. The firm offers engineering, design and drafting, lumber grading, certified welding, and truss design and construction services as well.

On a 12 -acre site, Blazer has about 42,000 square feet of production, storage and office space. The plant is rather modesh with some of the funkiness and disorder that accompanies unplanned growth. The newest and largest building houses the framing operations. The "production line" is rather non-linear. Virtually the only industrialized tooling here consists of a pneumatic wall framing table, overhead cranes, and pneumatic staplers.

Wall sub-assemblies such as door and window frames are produced in an adjacent building, as are roof trusses. Those in evidence during our visit were about 14 foot span, in bowstring and flat varieties. Other roof structures are discussed below.

Floor decks are framed stick-fashion on the building floor, except that one rim joist is temporarily screwed to a steel angle mounted in the concrete. This holds one rim joist fixed and straight while framing is completed and squared. Blazer uses laminated veneer lumber as rim joists because of its strength, and because it is available in lengths to 66 feet. The floor is usually insulated with Fiberglas batts and covered beneath with reinforced plastic film. If the deck is to be chassis-mounted, it is hoisted aboard and fastened to the chassis rails with lag screws and clips.

Walls are framed, squared and sheathed or paneled (interior) on the framing table. LVL is used here for single, full-length top and bottom plates. A hoist lifts walls to the deck, where they are installed. Many of these units are double wide, and some such as school buildings comprise single clear-span rooms as large as $28^{\prime}$ x $32^{\prime}$. To accomplish this span, laminated veneer beams are again used. These in the interim stages act as headers along nearly nonexistent marriage walls. When the building halves are mated, a doubled ridge beam results -- for 32 foot spans at 40 psf snow load these are 24 " deep. Special braces are installed to prevent rotation of the ridge beams. T-ber ceilings were used in every building we saw. 
There was one notable exception, however. Blazer has developed a modular public bathroom for California rest stops. This unit employs a hip roof, and an exposed-beam ceiling with roof decking. The roof frame splits at the ridge, and when fully assembled looks quite unlike any "industrialized" roof we have seen. Since these units are installed on slabs, they are built without floors, and hoisted and anchored using a clever, proprietary system of wall-base anchor plates and long lift rods. The rods are threaded into the anchor plates (which are in turn screwed to the bottom plates of the walls) and extend up through the wall and roof, ending in lifting eyes. After a modular is set, its rods are unscrewed and pulled up through the roof. The roof is patched, and the anchor plates are field-welded to matching plates cast into the slab.

Hill declared that Blazer's operation was too small and varied to make effective use of the computer. He was also skeptical of the likelihood (or value!) of uniform building codes, and third party inspection. Altogether he and Blazer seemed like good examples of the small, innovative, independent-minded firms comprising the majority of U.S. builders. 
June 23,1989

\section{TRIP REPORT}

TITLE: Ryland Modular Homes

DATE: Apri1 27,1989

LOCATION: $\quad$ New Windsor, Maryland

ATTENDING: Rudy Berg, Research Assistant, Center for Housing Innovation

PURPOSE: $\quad$ Manufacturing Plant Tour

SUPPORTING

DOCUMENTS: Roof detail photos, inspection sheets

Ryland Modular Homes consists of three plants in Maryland and Virginia. The new Windsor facility, covering 100,000 sq. ft., produces several models of SFD homes and townhouses. These are produced on two parallel production lines (models are mixed) which split into four lines at the finish stages. Mating halves are kept abreast of each other and check-fitted before they are shipped. A tyoical home is built in about 7 work days, then loaded onto trailers and shipped to a site prepared by the dealer's crew. About $90 \%$ of the units travel less than 100 miles.

Production tools and techniques at this plant seem fairly typical of industrialized housing: pneumatic framing tables and nail/staple guns and overhead cranes, for example, with tasks such as door hanging and truss building performed adijacent to the mair: production line.

Several production ideas were new to this observer, however. These are pictured in photos A, B, and $C$ attached. Photo $A$ shows the gable end of a $1 / 2$ house unit sheathed in "Thermo-Ply" sheathing. This material, due to its foil faces, provides some ( $R=2$, as I recall) small insulating value, but its chief virtue in production is its small thickness--about $1 / 8$ "--permitting lapped instead of butted joints, and faster sheathing installation as a result. This photo also shows the roofing "mezzanine" from which shingles are installed. In some models with steep roof pitches, travel height limits require folding roofs. Photo B shows the hinge line of such a roof, and Photo $\mathbf{C}$ shows the folding knee wall (here temporarily erect) which holds the trusses in their final position. Photos $B$ and $C$ also show a ceiling, which forms the base of the roof assembly. Drywall sheets are laid face down on a smooth table, then trusses are assembled on them and "glued" in place with foam sealant Photo $B$. The result is a reliably flat ceiling, and no overhead railing.

Quality is carefully monitored in the plant, as the attached inspection forms suggest. The "subcontractor" is simply the production worker responsible for a given operation; the term is carried over from an earlier system of organization.

Third-party inspectors also exarnine virtually every Ryland Modular Home at some stage before it leaves the plant. My impression was one of consistent quality in these products, even though they were fairly modest homes.

Ryland's standard energy performance is established by R-13 wall insulation, R-30 ceiling insulation, and $R-19$ insulation at the floor perimeter. They offer a "Super-E" package which adds $5 / 8$ " Atlas Energy Shield Insulation over the studs, boosts ceiling insulation to $R-38$, and insulates the entire floor to $R-19$. 


\section{TRIP REPORT}

TITLE: Ryland Construction Systerns (Panelized) Manufacturing Plant

DATE: April 27, 1989

LOCATION: Columbia, Maryland

ATTENDING: Rudy Berg, Research Assistant, Center for Housing Innovation

PURPOSE: $\quad$ Manufacturing Plant Tour

SUPPORTING

DOCUMENTS: Wall/Deck Fabricator Lists

Many aspects of this plant's work have already been described in the March 1989 Industrialized Housing Research Project trip report memo from Larry Maxwell of FSEC. I will add some further details and observations.

The Columbia plant, about 50,000 square feet, is presently operating at $150 \%$ design capacity, producing roughly 3,000 units per year. As the earlier report noted, computer use is limited. An HP 3000 is used for administrative and secretarial functions and to generate fabricator lists like those attached.

The tour guide, Ken Plerce, stated that the plant was just beginning to involve Autocad in its operations.

Work at this plant is high-volume, as the 3000 unit tigure would indicate. Lumber is purchased direct from mills and consumed at the rate of three or four carloads per week. Pierce announced that the crew on one framing table had produced "a mile of walls" in one shift recently.

The work tended to appear frenzied and low-tech, but it certainly provided employment for many who would probably not otherwise find jobs in the building trades. Another social sidelight is that Ryland has programs to help its employees buy Ryland homes, again with the likely consequence of providing entry (in this case, to home ownership) to the otherwise unqualified.

One kind of potential in the industrialization of housing, then, might be self-housing for the poor. Ryland seems to be recognizing this, or to have discovered it inadvertently.

As our work focuses on industrialization (i.e., automation) we might recall the social differences between the U.S. and its Japanese and Scandinavian mentors. What level of industrialization is appropriate here? How can we help solve one set of problems, and not aggravate another? 


\section{CONFERENCE REPORT}

TITLE: "Modular Housing: The Trend for the 90 's"

DATE: $\quad$ April 25-26, 1989

LOCATION: Penn State University

ATTENDING: Rudy Berg, Research Assistant, Center for Housing Innovation

SPONSORS: $\quad$ Industrialized Housing Manufacturer's Association (IHMA); Penn State Housing Research Center

SUPPOR'TING

DOCUMENTS: Program

This was a first-time event put together by Jack Willenurock, Professor of Civil Engineering at Penn State, and James Shields, IHMA Executive Director. About 150 attended, maybe $40 \%$ manufacturers, $40 \%$ builders, and the remainder people from finance, government, architecture, and academics.

Willenbrock exhorted the manufacturers to trade information (the "science" model) rather than sell. To varying degrees they complied.

The mid-Atlantic states are about seven years into a building boom. Pennsylvania is the chief modular producer (40 manufacturers) and exporter: two-thirds of its output goes to other states. It looks quite prosperous.

"State of the Art Modular Housing," Steven Winter: Opened with statistics -- claims modular was $6 \%$ (vs. 3\% Red Book) of U.S. starts -- the only industry segment that grow in 1988. In NE represented $12-15 \%$, almost nonexistent on West Coast. Modulars have doubled capacity in seven years, expanded upscale. 87 modular plants between Maine and Virginia. SFD bigger, more custom, more amenities. Thus more complex design/fabrication, more computerization -- maybe special "boutique" operations/crews. "Prefab" not a dirty word to consumers anymore. Prefabs will peak at $55 \%$ of starts. Affordability = zoning; lots of resistance to higher densities. In constant dollars, housing construction costs have fallen 25 years straight. Muld-family holds promise for growth and innovation; recent progress with steep and folding roofs. Winter showed a slide of an ultra-low-cost condo (built) designed to sell for $\$ 30 \mathrm{~K}$. Sees need for 900-1100 S.F. modular infill for \$50K. Manufacturers need flexibility - medical, schools, jails are new markets. Deluxe Homes (PA) makes nailable steel-frame modulars, sells to NYC (code there likes "noncombustible" idea!)

\section{Questions/Answers:}

Energy Savings? Manufacturers only make what sells; modulars are tighter coincidentally, thus energy efficient.

Steel? Material costs much more variable than wood. 
Forelgn competition? No imports of forelgn prefabricated housing, but lots of components/100/s. Thus, a threat to the U.S. economy, not housing industry, Mitsubishi and others eyeing industrialized housing industry, could dominate and likely will. Japanese already own U.S. companies and real estate; "they're crazy not to buy us."

"The Assembly Process," John Mervine, Nanticoke Homes. Very impressive. Started raising chickens, converted chicken house to modular factory. Now, \#6 in Automaied Builder's top 100 Manufactured Home Dealers, \$65 million in sales in 1988; top modular manufacturer. While retardataire in some ways (still builds walls on the floor decks!), his was the only house shown with energy performatice beyond code as standard construction. Adds 1" foam over $2 \times 4$ studs (Delaware). Air tests houses, guarantees energy performance. Yet when asked about vapor barrier -. (facetiously) "What's that?" Idiosyncratic and shrewd. Day care for employees, highly regarded. Has 12 draftspursons, 1 architect on payrull. Builds five houses a day. Showed 7,000 S.F., three car garage, $71 / 2$ bath single family dwelling. On inner city Baltimore: "You drop a sheet of plywood, it never hits the ground."

Elliott Fabri, Chelsea Homes: Also felt "no problem" omitting vapor barrier. Ducting a problem: builds 6-module home costing $\$ 500 \mathrm{k}$.

"Dellvery and installation," Bob Killkelley, New England Homes: Many problems of season, weather, laws -- need more uniform laws. Foundations a recurrent problem -- shell needs tolerance $\pm 1 / 4^{4}$. Introduced topic of when to get paid: common practice is before setting modules, at which point they turn into real estate and can't be repossessed. Builders upset with this C.O.D. idea, unlike other major material deliver/pay arrangements. Site arrangements responsibility of builder-dealer. Tricky points of "builder" as "broker" or "delivery system."

Steve Stahly, Kyland Homes: Unlike many builders, Ryland uses bottomless 2nd floor modular -. removable braces instead. Many arrangements in use re: setting, inspection, delivery, FOB. Some use roll-on (rail) installation; saves crane costs, takes longer, one story only. Ryland has 10 year warranty to builder.

"Finishing," Sharon Jensen, Harbor Light Homes: Detailed post-set work -. seaming carpet, drywall/trim on marriage line, utilities. Turnkey builder can "educate" a buyer.

"Advantages of Industrialized/Modular Housing," Steven Kerr, Westchester Modular Homes: Advice to builders: "Don't become a dealer." (Suggests industry needs builder -- at least as image or "front man" -. as "factory authorized builder.") Sells 6-module, 2-story unit $7 / 12$ roof for $\$ 89 k$ on builder's foundation, requires 2-3 weeks to finish. Saves about $8 \%$ over stick-built. Most houses produced in plant in 6-7 days. Trash on site, isposal a bis deal, especially on Long Island. Another virtue of modular.

"The National Regulatory Atmosphere," Bob Wible, Executive Director, National Conference of States on Building Codes. Another impressive speaker. Mentioned "Street of Dreams" in Oregon last year, where Japanese showed a prefabricated house (?).

Ten percent of housing cost (and rising) is due to regulation. Four major forces at work regarding housing:

1. Economic development -. cost tied to housing, development sometimes restricted by housing lack (GM moved Saturn plant to Tennessee from Indiana, for example).

2. Homelessness $-11 / 2$ to $31 / 2$ million, $50 \%$ are familles, 32\% have working parents, DC has welfare hotels where homeless have lived six years.

3. Shift of responsibility from Washington to states -- state governments now deal with major issues, HUD has recommendations but no money.

4. U.S. economic competitiveness - in 1992 when Europe consolidates, can have fast technology transfer, we need to screen for costs of changing U.S. codes. 


\section{"Future Trends: Innovative Applications and Automation in Modular Housing,"}

Dan Desmond, Deputy Director, PA Eirergy Office: Newly industrialized countries add to energy/resource problems, waste disposal costs now at $\$ 100-150 /$ ton in East, sees molded paper replacing many plastic pars (roof vents, etc.), some stick builders (including in Eugene) building hypo-allergenic houses, heat recovery and waste processing at home, hydrogen fuel likely, sees 20 year development time for modular industry. Heat distribution systems lose at $40 \%$ of heat, mostly through infiltration in returns. 
June 21, 1988

INDUSTRIALIZED HOUSING PLANT VISTT

Title: $\quad$ Advanced Building Systems (ABS) plant visit repor

Date: $\quad$ April 19, 1989

Location: Bennington, Vermont

Attending: Barry McGinn

Purpose: To view an industrialized housing plant.

Sponsor: $\quad$ Energy Efficient Industrialized Housing Research Program

Supporting Documents: Computerized Fabrication Plans; House Plans

On April 19,1989, a representative of the Center for Housing Innovation at the University of Oregon visited the offices and plant of Advanced Building Systems in Bennington, Vermont. Under its new manager, Kurt O. Dahlin, the $40,000 \mathrm{sq}$. ft plant manufactures large panel condominium residences. A.B.S. has recently developed a new line of detached single family homes and a marketing strategy (attractive brochure and dealer network) to sell the product. Both of the house designs in the American series are steep roofed bungalows; one is two stories and the other is one story. The two Scandinavian series houses are your basic Swedish cottage. Both of these series were designed in-house or by ABS's parent company, Faluhus AB,Sweden. The third series are upper end two story designs put out by Schoz Master Builders Inc.--a 'Victorian' and a 'Colonial'. Through its well developed CAD system, perspective customers are encouraged to customize their house package within set parameters. Examples of this include adding on rooms and porches and changing window sizes and wall insulation.

ABS's CAD system consists of a Sun 360 workstation running a ICG Integrated Computer Graphics) Aries CAD system using a HPGL Unix CAD operating system. The computer has a 16 $M B$ memory and uses a 724 hard disk drive. They have plans of expanding to four workstations in the near future. The CAD system interfaces with a Hewlett Packard $9000 / 300$ which is programmed to run their menu driven construction library.

The procedure is to first run the various construction menus to select stud size and spacing, window type, insulation, etc., on the H.P. Then modify the catalogue house design as required on the Sun which will feed the design information to the H.P. via a DFX Translator (mathematical co-proceseor). The H.P. will generate four lists to instruct the shop personnel in manufacture. The first is the piece 
list (plate curting list) for use at the automatic cross-cut saw in cutting the various plate lengths (Appendix-1). The second is the plate list used at the framing jig for assembling the wall frames (Appendix-2). The third is the buck list which is a subcomponent framing schedule e.g., door frames, partitions (Appendix-3). The fourth is a pool list which lists all the items which are shipped out as par of the package and serves as a final check of all the pieces.

The plant is based on Swedish Factory Crafted House factory layouts as designed by such furms as Nordisk Kartro. The plates and subcomponent framing assemblies are precut on the automatic cross-cut saw. This Swedish saw has five different cutting length settings which operate stops on the outfeed table. The stock is driven forward by roller action and when it contacts the selected stop a circular saw blade swings up from below the cutting table to make the cut. The lumber is then set on to the framing jig; the studs between teeth that swing up from below the jig bed while the plates are pressed between end stops. An integral nailing gun slides along the entire length of the jig and automatically stops at each $2 \times 6$ stud to insert three nails.

The wall frame is then slid on to the next station where an $8 \mathrm{~mm}$ Swedish vapor barrier is rolled off a suspended roller and is manually stapled in place. The next station is the squaring jig where the frame is aligned with hydraulic jacks and interior furring strips applied over the vapor barrier to accommodate the $11 / 2$ " of interior fiber glass insulation. Temporary sheathing is applied at the next station to prevent the furring strips from getting caught at the next station - the panel turning jig. This jig effects a 90 degree change in production process direction. The insulation is then manually set in place. The insulation is stored adjacent to this space in a storage area above the office area.

Following this, the wall panels are turned an additional 90 degrees on a system of ball bearing type conveyor tables and sent back the direction they came to complete a U-shaped plant layout. At the four remaining stations the exterior sheathing, subcomponent elements, siding, and exterior trim are applied.

The completed panels are then set up against the storage area wall in their respective housing packages to await transport to the site. A house package usually comprises two separate truck loads; wall panels loaded vertically for easy unloading at the site by a crane and another truckload with everything else. Temporary furring strips at the edges of the panels prevent damage during transport.

The panels are shipped open faced but have flexible plastic electrical conduit in place as well as predrilled plates and studs for plumbing. The panels leave complete with lag bolts at the comers for quick assembly on site. The walls are R.25 and the roof is R-38. A Swedish double bulb rubber gasket seals the bottom plate to the floor deck and the windows are lined with rubber gaskets to climinate any infiltration. The second story floors are manufactured as $8^{\prime}$ by up to $32^{\prime}$ trussed floor cassettes. The plant purchases the pre-manufactured roof trusses from ar outside source and does its own erection with a fairly heavy rented crane. The plant is currently operating at reduced capacity, alternately manufacturing and erecting two-story condomirium units in sets of four in near-by North Adans, Massachusetts. The crane is rented in one day blocks for the erection of two units at a time.

This Swedish subsidiary plant has targeted middle income house production, while many other east coast industrialized housing plants have or are in the process of dropping their middle income house packages and gearing up for higher end production. Kurt Dahlin is confident he can competitively supply energy efficient factory crafted homes to an eager marliet and it will be interesting to follow his progress in this venture. 


\section{CONTACTS}

Advanced Building Systems

Kurt O. Dahlin

Manager

Advanced Building Systems

Christopher T. Stitcher

Engineering Manager

(CAD Specialist)

Morse Industrial Park

Route 67A

P.O. Box 140

Bennington, Vermont 05201

Tel: 802-447-3511

Fax: 802-447-3510

Swedish Executive Homes

Lenart F. Lekborg

President (ABS sales agent)

20 Fopes Lane, Danvers, MA 01923

Tel: $617-598-1818$ Fax: 508-777-7410 
June 21, 1989

\title{
INDUSTRIALIZED HOUSIYG PLANT VISIT
}

\author{
Title: Key-Loc Homes (Division of Hodgson Houses Inc.) Plant Visit \\ Date: $\quad$ April 17, 1989 \\ Location: Suncook, New Hampshire \\ Attending: Barry McGinn \\ Purpose: To visit an industrialized housing plant. \\ Sponsor: $\quad$ Energy Efficient Industrialized Housing Research Program
}

On April 17, 1989, a representative of the Center for Housing Innovation at the University of Oregon visited the offices and plant of Key-Loc Homes in Suncook, New Hampshire. The plant manufactures modular housing from a catalogue of forty basic plans, ranging from two-story colonials, gambrels, and capes to ranch-style bungalows.

In response to a $\$ 300,000$ marketing study, the firm is redirecting their housing production toward the upper-middle income group. They are just completing a prototype model on the premises which will become the basis for a new line of fully customized luxury homes and they will presumably phase out their economy models. The prototype is a large two-storied gabled home with a two story bay element rising up centrally in the rear, a balcony/front porch element and three front attic roof dormers. The interiors are characterized by a central stair, nine foot ceilings, a master bathroom with a jacuzzi under a large window, and tub on the inside wall with an adjoining toile//vanity anteroom and a master bedroom with a dry sauna.

The firm is in the process of developing a two fold marketing approach: 1) marketing to the top end builder, 2) marketing on a retail basis by scattered sales lots and suppling buyers' names to builders. The modules they build are a totally closed-in unit with fully finished interiors complete with electrical and plumbing stubbed off into the crawlspace or basement. The exterior siding is applied on site after the units have been set on the foundation and connected together.

The floor decks, which are the first stage of construction, are built especially strong to reduce the risk of damaging interior drywall finishes due to settlement. The $2 \times 10$ floor joists are supported on a ledger boand attached to the inside of the double $2 \times 12$ joist header and are end-nailed through the header. The 5/8" floor sheathing is then glued, resin stapled, and caulked for a level surface. The deck is then lifted off the jig by the overhead crane, set on to low rolling dollies, and pushed over to the next station to receive the wall and partition frames. 
The frames, complete with sub-assembly frames made in a neighboring building, are assembled and nailed on A-frame jigs and lifted on to the waiting floor deck by the overhead crane. The interior wall boarding is then applied and the electrical and plumbing roughed in. The electrical boxes and other wall penetrations are caulked from the inside to eliminate any infiltration.

The unit is then $y$ tuthed over to the next station to receive the trussed wall assemblies which are built directly adjas int the ceiling wallboard is layed out on a perfectly flat bed and the half trusses are then positioned atid attached with a foam adhesive. This allows for flat finish ceilings - no spraytex stipling needed! An electrical tray (built in-house) is installed in the ceilling and the copper wiring installed. Also at this station the insulation is installed and the exterior plywood sheathing is installed. The joints in the sheathing are caulked and sanded smooth.

Each modular unit is lifted down on to the highway transport dollies which are of particularly heavy six axle construction so as to not damage the finished drywall. Two long columns of units are formed down a longer building at right angles to the sheathing station. The three coats of drywall mud are applied and sanded at all joints with the drying helped along by portable gas heater/blower units placed in various rooms. Lesser establishments, as you know, simply run plastic moldings around the inside edges to hide the ugly joints. The column runs alongside a second story shingle storage area which is convenient for the roofing operation. The $2 \times 6$ walls provide an insulation value of R-19 and the roof is R-38. All materials are stored in covered open sheds or in enclosed warehouse areas.

The firm does have a CAD system used primarily for generating production drawings and cutting lists, but expects to use it more as a sales/design tool as they get into the fully customized upper end modular house.

The plant appears to be utilizing the plant facility to produce a higher quality product than is possible with a conventional stick built home and they feel confident they can compete in the upper end market. 


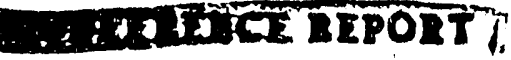

Annual Meeting National Association of Home Builders

January $19-22,1989$

Atlanta, Georgia

This meeting was structured around a lacee exposition with seminars and educational sessions running simultanaeously. Approximately 65,000 people registered as attendees, there were another 900 or so corporale exhibitors ranging in size from a one or two person booths to several thousand square feet.

There were 197 scheduled 90 minule seminars or presenations. Each had a theme that was formally discussed by a panel and moderator concluding with question and answer format. These varied in size from about 50 to 350 . I attended six of these sessions: An Cverview of Consumer Preferences and Emerging Design Ideas in New Homes; Affordable Housing: $\mathbf{Z} e y$ Factors in Housing's Future; Making Staall Lots Work / Smaller Smarter, More Affordable Housing: Architecture Into the 21st Century and Foreign Competitors in the Single Famity Market. Or these the Key Factors in Housing's Future (William Apgar on demographics, Jim Schuyler on politics, David Seiders on economics and Lew Wise on technology) and Foreicn Competitors in the Single Family Market (David Engel from HUD, Michael Joroff from MIT. Bob Irwin with the UR trade council and Terry Mc Hammer a developer from Washington working under foreien ownership -moderator Deane Evans from Steven Winter Assoc.) Were the most substantive and provocative. Most of these sessions were taped and are available from a firm in Maryland I have an order form and cataloe.

During the Key Factors in Housing's Future session NAHB released their official long range planning report 'framework tor the Future: $1999-1991$ ' (one supposes that two years constitutes long rang planning in the housine industry). This report examines Demographics, Economics. Technology. Politics and Social Trends for their infiuence on housing. I managed to get one of the few copies available. More car be oblained from NAHB. One of the panelists was Joan McCloskey. Executive Building Editor of Beter Homes and Gardens distributed copies of her presentation 'How Changing Family Lifestyles Affect Housing Now, and in the Future'. The former document in particular can contribute sienificantly to our report and I urge everyone to read it.

There wer. number of component builders in attendance. I introduced myself to Lew Wise who is president of the NVRyans new building syotom company. They seem to be going aner components and systems building in a bis way. He was asreeable to sending us a video and follow up cốrítíponớence. 
I also met the marketing director of Shelter Systems, Janel Hofrman who will send us a copy of a video 'The Great American Build-Orf that visually compares the construction of a sile built with a component built one. They have just purchased a plant in Sacramento.

Another firm Pre-Fab Systems uses a truss based production framing system they are marketing on a kind of franchise basis. I met David Saunders ('Mr. Pre-Fab') who 'claims' they can do the whole process from design to production on computers over the phone.

I also met Ted Cheney of Cheney Building Systems, a stressed skin panel producer who has built public housing in the Chicago area. He promises documentation of a multi-family project using his systhm.

FSEC seams to have signed up Don Carlson editor of Automated Builder for the Steering Committee.

Cardinal is on the verge of Chapter 11 bankruptey.

Several of the Universities in the NAHB/NRC housing research networt presented work in progress (IIniversity of Minnesota; Colorado State; Texas A \& $M$ and Penn State specifically). Texas has a report just published on "Factors Contributing to Sucess in the Factory Built Housing Industry'. Penn State will sponsor a symposium on 'Modular Housing: The Trend for the 90's' on April 25 and 26. Minnesota was curious if we were interested in siening up.

The loneest line in the exposition was to get into Nest 89 a modular house by Berkus

The GE plastic house and NAHB's Smart House came across as overmarkeled air. The electronics industry has a CBUS system that will compete directly with Smart House and use a simpler appliance based (as opposed to house based) technolosy.

The presence of archilects and the AIA was unique and interesting. Several of the desien oriented seminars were organized, chaired, and presented by national housing desien firms. Over 40 architectural and desien firms had booths -- all were very conspicuous. Most sold plan books, had protfolios available and agressively marketed their services. The AIA sponsored a best of housing design session that was yery well attended and slickly produced. They also sponsored separate site plan and building design review workshops that were very popular. It looked like many new consulting and design commisions were forged in the process.

Small houses on small lots was a very visible issue and lopic of discussion. The emphasis being placed on smarter over smaller for a value conscious buyer. Mang of the desien strategies promoted - simpler forms; added volume throuph higher plates and steeper roofs; better site-building fit; inclusion and careful desien of adjacent outdoor spaces; better light: planning for expansion. multiple use of space and so on all seem to be improving the design of developer housing in those areas dominated by this house form.

Wide / shallow (zipper) and 2-lots are in for their curb appeal and bettor light opportunities. Kuch debate centered on the appropriate dimensional

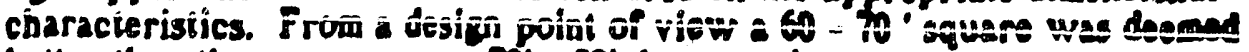
befter than the more common $70^{\prime}$ × $50^{\prime}$ deep version. 
Housing has become more of a commodity in the hearts and minds of more people than I had ever imagined. Houses were consistently called 'product'; interior designers have become 'interior merchandisers' and landscape architects 'exterior merchandisers'.

Wel paving. like slightly moist or oiled skin in cosmetic and perfume ads is very much 'de rigeuer' in residential architectural pholographs these days.

Entry portals and gates have gained new import to 'begin the owners experience' as soon as possible on the site.

Bathrooms and kitchens will continue to get bigger with double sinks etc. while overall house size decreases as iwo income families need to cook and get ready for work at the same time. Banquetles are becoming popular next to rood prep areas.

The affordable housing drive of NAHB is first and foremost an attack on codes and regulations. They have a checklist with which to prill your local building officials and promise to fly out experts to testify on behalf of builders seeking relasation or substitutions.

Next to the maturine baby boomers the next largest group is over 75 who will seek good quality expensive housing with opportunity for adaptive remodel as they become less mobile.

House buyers have acquired more family and home oriented lifestyles.

Duplexes are back in vitalized form.

Next year is predicted to see 1.38 million starts (-7\%). About 1 million of those will be SF. In the future 1.5 million will be seen to be a very good year.

Weyerhaeuser predicts 1.3 falling to 1.03 the year aner.

Median house size has diminished from 1911 sf in 1987101808 of in 1988. Read my lips "no new square feet"

111/2 hour commutes are an seen to be acceptable as afoordable land needs push housing development even farther out into rural and small town areas surrounding larger cities.

Japan will have more housing starts in the next few years (about 1.7 million) than the US.

In 1983 the US had a \$40U million surplus in buildine products trade. In 1998 that has become a $\$ 6$ bilion deficit exclusive of HVAC, paint and electrical producta.

The US spends less per capita on Rand D than any other industrialized nation and within the US the building industry spends less than per Ssaltes than any other.

Increased liability exposure is perceived to be a barrier to innovation.

National politics is expected to see an sienificant interest in firat tins homebuyers. Possibly though a remodel of FHA policies. 
The real Japanese threat to the building industry is seen to be at least 10 years away. Japanese companies are now buying real estite in secondary markets -50,000 acres in Riverside CA, Montanta, and so on. Even though Japan buys less than other countries it is their tendancy to use these investments to leverage their way into this and other markets from those positions that causes concern. Once in place the products and services to sell will follow automated office systems to their tenants; building products to their developers and $50 \mathrm{~cm}$.

In the UX land costs are $50 \%$ of the cost of housing while they are about $25 \%$ here.

Foreign companies will not come here seeking to sell whole building sytems but will instead find market niches where no US products are available and there are few competition.

The perception that the US market is and industry is too diverse, disacgregated and dominaled by flexible, low capital businesses is changing rapidly. As a consequence it will become less insulated against unilateral interventions.

There were a number of products with some local inierest. Gyp-crete -- a lightweight gypsum levelling mirture that sets up in 90 minutes can give wood Moors a fire rating and acoustic attenuation. A number of prefabricated stair suppliers. Matsushita is marketing a sound insulating and fire retardant plants Mooring. Laco lumber has turned T-111 into lap plywood siding. STO is marketing a range of exterior insulation and finish systems for highrise and renovation applications. Werzalit is marketing high-density moulded wood trims and finishes with acrylic and melamine surfaces (milled 'unwood').

Notes by

Rellett. 


\section{EEIH}

Center for Housing Innovation

University of Oregon

\section{TRIP REPORT FORM [jSS89.14a ]}

Date of Report:

Place Visited:

Dates of Visit:

Attending:

Purpose of Visit:

Visit Report:
$12 / 01 / 89$

mult family housing subdivision in Ingebo, Sweden (about 20 kilometers south of Linkoping)

\section{$09 / 07 / 89$}

\section{J. Finrow}

View subdivision using SFC housing units

While subdivisions are somewhat unusual in Sweden, they are not unprecedented. This project is located in a small town in a rural setting and included close to 100 housing units mainly in the form of duplex, triplex and quadplex arrangements of townhouse types. The manufacturer of these housing units was not determined, but it was possible to view housing units at various stages of assembly. The most interesting aspect of this visit was seeing the foundation systems which were made of prefabricated concrete elements. There was no site casting of concrete for any of the foundations for these housing units. Trenches were cut into the ground and leveled, with precast foundation elements set into them. The system represented essentially a precast grade beam system with intermediate beams as needed to support panel points in the center of the house. Houses were very simple, probably in the area of 70 to 80 square meters. Parts of the project were completed and occupied, and parts were still just beginning. Occuspants in part of the project were beginning to put up fencing and other elements of personalization.

Supporting Documentation: Slide documentation. 


\section{EEIH}

Center for Housing Innovation

University of Oregon

\section{TRIP REPORT FORM [jS89.15a ]}

Date of Report:

Place Visited:

Dates of Visit:

Artending:

Purpose of Visit:

Visit Report:
10/01/89

Bromma District of Srockholm

$09 / 10 / 89$

\section{J. Finrow}

To photograph a post WW II prefabricated housing development

Swedish prefabricated housing bullding technology has been used since the 1900's. There are many sub areas of Siockholm where small communities have been built in the 1930's and after WW II using prefabricated wood housing building systems. Most of the major SFC housing companies got their start during these times. The Bromma district is such an area. It comprises several acres of land with gently curved roads lined by small wooden two story houses that are brightly painted. Since the original development of the site, occupant have planted trees and othe landscape elements and have changed the colors of their houses as well as have added to and changed the character of their houses. The neighborhood now is highly sought after as a place to live because of the very nice quality that is present there as a result of the scale and nature of these small houses. In a certain sense, these con wunities illustrate the potential of developing energy efficient industrialized housing and what a I community of houses could be like in 40 years.

Supporting Documentation: Extensive slide documentation of this community. 
EEIH

Center for Housing Innovation

University of Oregon

TRIP REPORT FORM [JS89.14b]

Date of Repor: $\quad$ 10/01/89

Place Visited: Hostevetet 1, Stockholm, Sweden

Dates of Visit: $\quad 09 / 09 / 89$

Attending: J. Finrow

Purpose of Visit: $\quad$ To photograph an energy efficient atrium housing project

Visit Reporn: $\quad$ Building in 1986, this 4 story apartment block utilizes a glassed over atrium space in the center of the project and innovative heat pump technology to develop new ideas in urban energy efficient housing. The interior atrium space is fully glazed (as different form the Bodbetjanten project which has a roofed atrium), with a small winter playground in the center space. Having the atrium provides some energy efficiency by providing passive "greenhouse" type heating that at certain times of the year, reduces the temperature differential between unit and "outside" (courtyard) space. The atrium is also used as an element in the heat pump system which utilizes quite deep earth boreholes for a heating source. Apparently problems have been encountered in the controls for the heating system, and the project is inovolved in long term monitoring by the Swedish Council for Building Research.

Supporting Documentation: Slides and book documentation 


\section{EEIH}

Center for Housing Innovation

University of Oregon

TRIP REPORT FORM [JS89.14c]

Date of Report:

Place Visited:

Dates of Visit:

Attending:

Purpose of Visit:

Visit Report:
$10 / 01 / 89$

Kejsaren 20, Stockholm, Sweden

09/09/89

\section{J. Finrow}

To photograph an urban energy efficient housing project

The Kejsaren project is an urban infill project located in the Southern part of Stockholm in an urban redevelopment area. The site for the project is very constrained and the building is just a piece of a larger street of similar buildings. The building is 6 stories high and is capped with a large active solar collection array that provides hot water that is utilized through a heat pump system to heat the apartment units in the building. Heat from the solar collections is stored in a thermal storage area in the basement of the building and then hot water is piped to the apartments and is circulated through the holes in the core floor slabs providing both a heated floor and cieling in each unit. Each building has a balcony and because of the tightness of the site, an interior artium is not possible to provide for this project. The building fits into the urban context quite well.

Supporting Documentation: slides and some book documentation 


\section{EEIH}

Center for Housing Innovation

University of Oregon

\section{TRIP REPORT FORM [iS89.14d]}

Date of Report:

Place Visited:

Dates of Visit:

Attending:

Purpose of Visit:

Visit Repor:
$10 / 01 / 89$

Sjukskoterskan 5 housing project

$09 / 09 / 89$

J. Finrow

To photograph a Swedish energy efficient apartment complex

This project was designed to take advantage of a small scale project based district heating plant. Built in 1985 as a three story project with a single loaded corridor, the project is pleasent, but not particularly architecturally innovative. The heating plant, while apparently quite efficient, shows little on viewing.

Supporing Documentation: none 


\section{EEIH}

Center for Housing Innovation

University of Oregon

TRIP REPORT FORM [jSS89-14e]

Date of Report:

$10 / 01 / 89$

Place Visited:

Konsolen 1, energy efficient housing project

Dates of Visit:

09/09/89

Attending:

J. Finrow

Purpose of Visit:

To photograph an energy efficient mult-family housing project

Visit Repor:

While not being particularly visually interesting, the Konsolen project pioneers some very interesting energy efficient ideas. The main innovation is a precast concrete exterior wall that provides thermal mass storage and the opportunity for preheating ventilation air into the housing unit. The exterior wall panels facing south have cavities (ducts) in the wall which provide circulation for ventilation air over along distances in the wall (to gain heat) before accessing the housing unit. In addition, the project makes use of innovative heat pump technology and a central heating plant to improve energy efficiency in heating interior air to the housing units. The project is very conservative in it's appearance and offers little of interest except for the innovative use of the exterior mass wall panel.

Supporting Documentation: a few slides some book documentation. 
EEIH

Center for Housing Innovation

University of Oregon

TRIP REPORT FORM [jSS89.14f ]

Date of Repor: $\quad$ 10/01/89

Place Visited: Skogsalmen 2 housing development, Stockholm

Dates of Visit: $\quad 09 / 09 / 89$

Atrending: J. Finrow

Purpose of Visit: $\quad$ To photograph an innovative energy efficient industrialized multi-family housing project

Visit Report: $\quad$ This project is one of the more interesting of the new energy efficient experirnental houses supported by the Swedish Council for Building Research. The project is formed of two and 4 story housing blocks organized around interior courtyards of comment activities such as day care, communal gardens, etc. The most striking feature of this project are the large glazed sun spaces that are used on the south side of the building to buffer the exterior wall of the building from the direct outside air and thus providing some reduction in heating needs. The sun spaces are very effective and also provide an added room for the aparments and are extensively utilized by residents for a variety of activities. In addition, there is also a central heating plant that provides hot water to the apartments and a heat exchange system for preheating outside ventilation air. Heat from the sun spaces are blown through the core slabs to heat up the floor and cielings of the apartment units. The project is quitel interesting and seems to be successful.

Supporting Documentation: Extensive slides and some book documentation. 


\section{EEIH}

Center for Housing Innovation

University of Oregon

TRIP REPORT FORM [jFS89-14a ]

Date of Repor:

$10 / 01 / 89$

Place Visited:

Housing project at Bodbetjanten 1, Stockholm, Sweden

Dates of Visit: $09 / 09 / 89$

Attending:

J. Finrow

Purpose of Visit:

To photograph an innovative urban energy efficient housing project in Sweden

Visit Repor:

The Bodbetjanten project is one of the experimental housing projects supported by the Swedish Council for Building Research located in a southern suburb of Stockholm. the project is an apartment block occupied in 1985 which makes use of several innovative energy ideas. The most significant idea in this project is the use of an atrium space for solar gain and for advanced heat pump technology used to provide space heating for the apartments in the building complex. In addition, the problem utilizes mixed use activities that are meant balance the heating needs of the building. To the north are placed offices which generate heat form the workers and their machintes which is passed to the apartments which need heat to keep them at comfortable heating ievels. The exchange of heat is accomplished throught the atrium space and from heat exchange technology used in extracting heat from the offices and purting into the apartments. This project is part of a long term monitoring research project which is examining the success of the project in terms of its innovative components.

Supporting Documentation: Slides and book documentation. 
EEIH

Center for Housing Innovation

University of Oregon

\section{TRIP REPORT FORM [jS89.13b ]}

Date of Report:

10/01/89

Place Visited:

Housing project (unknown) in south Linkoping, Sweden

Dates of Visit:

09/07/89

Attending:

J. Finrow

Purpose of Visit:

To photograph a new housing project under construction that combined a significant area of SFC housing with more conventional multi-family site built housing.

Visit Report:

This project was underconstruction when visited with completion scheduled for October. The project consisted of one area of multi-family housing and one area of single family detached housing. The second area was composed of small panelized SFC houses. These houses were located across a major road from the multi-family part of the project. Most of the houses were occupied. While a very nice project, there was nothing particularly remarkable about it . The mult family housing area $\backslash$ utilized an interesting combination of 6 story and 2 and three story $\backslash$ housing types together than created a reasonable scale. Nicely defined and developed commons spaces were made and there was some use of "sunspaces".

Supporting Documentation: Slides 
EEIH

Center for Housing Innovation

University of Oregon

\section{TRIP REPORT FORM [jS89.13c ]}

Date of R.epor:

Place Visited:

Dates of Visit:

Attending:

Purpose of Visit:

Visit Report:
$10 / 01 / 89$

Lambohov housing area, west of Linkoping, Sweden

$09 / 07 / 89$

J. Finrow

To photograph an experimental housing project supported by the Swedish Council for Bulding Research

The Lambohov project is located in a new development area which is southwest of the Technical School in Linkoping. There are several different kinds of housing projects in the general development area The energy project that was visited includes several row housel buildings all oriented south with active solar collectors for roofs. There are about 70 dwelling units in the experimental area. In addition to active solar hot water collection systems, this group of housing also utilizes heat pump technology and thermal mass energy storage systems. Ho'dsing units typically have north side entry access with fenced garden areas to the south. The long rows of housing seern a bit monotonous and rigid with the black solar panels to the south creating a heavy and dark appearance, especially in contrast to a project close by that is much lighter and more cheerful character. Converstations with a few residents pointed out that the people who lived here seemed to like the place and felt that they were important as part of a national building experiment. The active solar panels were positively regarded and people felt that, while their roofs did not look like other houses, they did not feel that the panels detracted from their houses. There was a certain spirit of adventure that people expressed living in this project. Residents mentioned that there were not problems with the solar panels, but one resident mentioned that their panel had leaked into the house and did destroy some fumiture, but that it was quickly repaired and did not leak again.

Supporting Documentation: Slides 
EEIH

Center for Housing Innovation

University of Oregon

TRIP REPORT FORM [jS89. 12a]

Date of Repor: $\quad$ 10/01/89

Place Visited: $\quad$ Myresjofonster AB (a window plant owned by Myresjohus)

Mr. Thomas Jamland, Box 153, S 57401 Vetlanda, Sweden

Dates of Visit:

09/06/89

Arending:

J. Finrow + Minnesota group lead by Paul Kando

Purpose of Visit:

To visit a state of the art automated window plant

Visit Report:

This plant is extremely highly automated and vertically integrated company that supplies window units to the Myresjohus company and aiso on the open market including export. This company is the third largest window producer in Sweden. They employ 325 people and produce about 300 million SKR in windows each year. Their production is allocated as follows: $30 \%$ to contractors for special windows, $25 \%$ to the home improvement market, $41 \%$ to the SFC industry (with Myresjohus being only 9\%) and about $4 \%$ for export. They currently cannot keep up with their orders and have a 16 week backlog of unfilled orders. First we toured the older part of the plant where windows are produced in a less automated fashion. This plant was still well organized, but after a visit to the main plant, it was clear that this facility was not paricularly automated. The main plant was well organized with extensive use of automated milling machinery that was computer controlled. All casing materials and millwork was formed by automated machines. They have developed a particularly innovative automatic painting facility that was able to seal, paint and dry a high volume of casing materials in a few hours. window frames and casings were put together in a hand operated jig and glass installed in a rather labor intensive setting. hardware was the last to be installed. On the plant site was also a plant that took glass and made insulated window units. These triple glazed windows were use in the frames that were manufactured in the other plant facility a few meters away. This facility was quite important as it provided the glass for the frames. In addition to the vacum bed for creating the chambers between layer of glass, there was a special section for making gas filled and coatod glass units for special onder needs.

Supporting Documentation: slides and a standard window catalog 


\section{EEIH}

Center for Housing Innovation

University of Oregon

TRIP REPORT FORM [jS89-12b]

Date of Report:

Place Visited:

Dates of Visit:

Attending:

Purpose of Visit:

Visit Report:
$10 / 01 / 89$

Myresjohus AB, Ms. Catharina Ekwall, S 57485 Vetlanda, Sweden

$09 / 06 / 89$

\author{
J. Finrow + Minnesota group lead by Paul Kando \\ to view the state of the art in SFC technology
}

The Myresjohus plant is the most automated factory in Sweden. In addition to the house plant, the factory also has a complete sawmill which produces wood for both the plant and for sale to other companies. This plant produces 1,800 houses per year with 150 export houses. The plant employes 210 people and has 40 sales offices in Sweden. The value of the production of the plant is 600 million SEK per year. $20 \%$ of the wood use in the house factory comes from the sawmill with $80 \%$ being purchased from marker sources. $40 \%$ of the factory production is in the form of mult-family housing units. This plant is the most highly automated of all of the plants visited. They were also in the process of making a significint addition to the basic plant in order to add an additional production line that would increase production from the plant. The sawmill was fully automated with computer control for most of the cutting and sorting activity of the plant. After cutting, the wood was dryed in large kiln dryers that were also located on the plant site. There was a considerable stockpile of basic wood on the plant site. The house factory was impressive because of the highly automated nature of the plant. The most innovative part of the plant was the fully automated floor production facility and the automated insulation insertion machine which is the only such machine in Sweden (or any other place). Working with Nordisk Karto (an equipment manufacturer and fastening system supplier) and an insulation company, Myresjohus has developed a way of automating insulation installation into wall and floor panels. The insulation arrives in fully cut batts that are dropped into the wall cavities as the wall passes the insulation station. Normally this process is done by hand and has been the one par of the production process that has been least industrialized. Bugs were being worked out of the system during our visit. The plant engineer discussed the issue of productivity. This was a very impressive plant operation.

Supporting Documentation: Myresjohus promotional brochures only, cameras were not allowed in the plant itself. 


\section{EEIH}

Center for Housing Innovation

University of Oregon

\section{TRIP REPORT FORM [jS89-12c]}

Date of Report:

Place Visited:

Dates of Visit:

Atrending:

Purpose of Visit:

Visit Repor:

\section{$10 / 01 / 89$}

4 plex apartment under assembly in Vetlanda

\section{$09 / 06 / 89$}

J. Finrow + Minnesota group lead to the site by Ms. Ekwall

to view a multifamily housing unit under assembly

This Myresjohus multi family unit was a 4 unit flat house with two units up and two units down. the house had the exterior walls in place and the roof was just finished. The building had just been enclosed and much work remained on the interior. The main floor was slab on grade. The second level floor was formed of precast concrete slabs. All interior partitions were to be site built and the exterior finishes were to be completed in brick. The panels come to the site for this project unfinished on both sides. The design of this project was uninspired and lacked interest. The size of the two bedroom units appeared to be quite small. The extent of industrialization in the project seemed very limited with only the wall panels and roof trusses factory produced.

Supporing Documentation: slides cí the project. 


\section{EEIH}

Center for Housing Innovation

University of Oregon

\section{TRIP REPORT FORM [ifS89-11b ]}

Date of Report:

Place Visited:

Dates of Visit:

Attending:

Purpose of Visit:

Visit Report:
$12 / 1 / 89$

Gullringshus AB, S 59081 Gullringen, Sweden contacts Mr. Heinz Will and Mr. Mats Borsjo

\section{$09 / 05 / 89$}

$$
\begin{aligned}
& \text { J. Finrow + Minnesota group lead by Paul Kando } \\
& \text { to visit and document SFC plant }
\end{aligned}
$$

Gullringshus is one of the largest manufacturers of SFC housing in Sweden. The plant we visited produces about 1,200 houses per year with $30 \%$ of their production in multi-family houses. 400 units are site assemble by their own crews rather than by local erectors. They currently have a 20 week waiting period before delivery. $15 \%$ of their production is exported, mainly to Germany. They have a total of 60 sales offices in Sweden. Their average house is about 720,000 SEK excluding the land. The plant manager mentioned the current boom in SFC housing production and discussed the tax issues involve in the current production run. The plant is highly automated with very efficient panel lines, especially the floor panels which had little human operator needs. The plant was very large and allowed for each line to product panels that were stacked and coordinated for delivery. We also visited a supply warehouse where cabinets, appliances and other support items were being stockpiled for delivery with houses. Cabinet parts were completely prefabricated and sent with the house parts for final assembly. Suppliers were encouraged to provide "just in time" items for the houses and the warehouse was not very full. We were able to view a house being placed onto a truck which was an interesting experience. The stacking of house parts into the truck is very ordered, with the parts needed first stacked last so that taking parts of the truck was organized and coordinated to assembly nieds. It was also mentioned that there were problems associated with site i sembly that would probably mean that eventually all site assembly would be done by the company.

Supporting Documentation: slides of the production process including truck loading and company brochures. 


\section{EEIH}

Center for Housing Innovation

University of Oregon

\section{TRIP REPORT FORM [jSS89-11a ]}

Date of Report:

Place Visited:

Dates of Visit:

Atrending:

Purpose of Visit:

Visit Report:

\section{$10 / 1 / 89$}

Hultsfreds-Hus Ab, Box 501 S 57700 Hultsfred, Sweden Mr. Tore Falkenhaug and Ms. Ragnhild Ekselius

\section{9/06/89}

J. Finrow + Minnesota Group lead by Paul Kando

\section{To view an SFC plant}

Hultsfreds plant was interesting because it had a sawmill attached to the plant and also they utilized a small panel concept in addition to a new large panel facility. The total production of this company is about 2,500 houses per year with the factory we visited producing about 1,000 houses. About 10\% of their production is for export and the rest for the domestic market. The production line in this factory was more industrialized than that of Boro Hus. The use a CAD system in the plant to support the internal needs of the factory (they do not use it in a sales environmen... They produce 1.2 million small panels per 'year. The cost of a typical house from their plant is about 6,000 to 7,000 SEK (Swedish Kronor \$1 = 6.4 SEK) per sq. meter and about 5,000 to 6,000 SEK for multi family housing units. The average range of house sizes are between 110 to 120 square meters, they anticipate in the future to be building larger home, in the range of 130 to 140 square meters. Most buyers are people who already have a home and want to "buy up" to a larger and better qualtiy house. They have some problems in attracting workers to their factories. They use a lot of foreign workers, at the moment they have mainly Icelandic workers. It was also mentioned that new regulations will present certain problems for them in the need improve the quality of their product because of more stringent warrentee issues. They will likely become involved more directly in the assembly of the houses in the furure.

Sujporting Documentation: slides of the plant operation and company sales brochures. 
EEIH

Center for Housing Innovation

University of Oregon

TRIP REPORT FORM [jS89.11c]

Date of Report:

$10 / 01 / 89$

Place Visited:

The home of Mr. Heinz Will, plant engineer for Gullringshus in Gullingen

Dates of Visit:

09/05/89

Attending:

J. Finrow + Minnesota group lead by Paul Kando

Purpose of Visit:

to view a Gullringshus

Visit Report:

Mr. Will invited us to visit his house to see what a Gullringshus looks like. His house was built about 5 years ago and was a one story house built over a full basement. The main living floor had two bedrooms and all of the public spaces of the house. The basement had two bedrooms, a kind of family room, a sauna and workshop room The house had brick exterior cladding and tile roof. The interior finish is mainly wallpaper over gypsum board with a very fine wood ceiling. The overall feeling of the house is quite pleasent with reasonable light and high quality finish. We were also able to visit another house next door to Mr. Will which was just recently completed. While this house was also nice, it did not feel quite the same as Mr. Will's house. There was a stronger sense that this house was a manufactured house. The wall board materials had a joint that while different than a U. S. mobile home wall panel batten, gave much the same feeling.

Supporting Documentation: none except direct experience. 


\section{EEIH}

Center for Housing Innovation

University of Oregon

\section{TRIP REPORT FORM [jS89-10a]}

Date of Report:

Place Visized:

Dates of Visit:

Atrending:

Purpose of Visit:

Visit Repor:
10/01/89

Burmek, AB / Verkstadsgatan 7 / S 57100 Nassjo, Sweden

\section{$09 / 04 / 89$}

J. Finrow + Minnesota group guided by Paul Kando

To document an equipment manufacturing plant for SFC technology

This plant pruduces much machinery for SFC plants in Sweden. They currently are working to develop new machines that will improve the productivity of SFC plants, especially related to the railing of sheathing to floor and wall panels. The plant is highly sophisticated producing from stock just about all of the parts to complete a SFC factory including valves. The plant currently has a backlog of orders for production of various machines for plant located in Smaland. We saw several of this plants new machines being installed in factories on out visits to SFC plants in the areas. The factory also offers complete planning and design services for new factories including fully computerized plant design capability. The factory was recently purchased by a group of investors but the plant manager, Mr. Rolf Burman, remains the main person in the firm. In addition to the production of plant equipment, this plant has a very sophisticated electronics sub assembly area where all of the wiring for the production machinery is completed.

Supporting Documentation: slide documentation of the plant and some brochure materials provided by Burmek. 


\section{EEIH}

Center for Housing Innovation

University of Oregon

\section{TRIP REPORT FORM [jS89.10b]}

Date of Repor:

Place Visited:

Dates of Visit:

Attending:

Purpose of Visit:

Visit Report:

Supporting Dosumentation: slide documentation of the factory plus marketing literature form Boro Hus showing house types sold by the company.

$10 / 01 / 89$

Boro AB (plant for Boro Hus) in Landsbro, Sweden the contact person was Mr. Elon Gustavssun S 57012 Landsbro

$09 / 17 / 89$

\section{J. Finrow + Minnesota group lead by Paul Kando}

to visit an SFC plant of Borohus the largest of the various SFC companies in Sweden

The Boro Hus plant was at full production when visited. The manager arranged a general meeting to discuss the plant and the Boro Hus perational concept then lead a tour of the plant. The manager said that materials for the SFC plant were also purchased on the open market in order to get the best price for the product. The plant was quite automated. but was not the most automated plant visited. They were also in the process of installing a new panel line using equipment supplied by Burmek. One of the more interesting parts of the plant was the small component production line where bay windows and gable end walls were manufactured. These items were essentially hand made, but in a factory setting. This factory utilized the "trus stud" elements that appears to be quite important to the thermal performance of the SFC house. The sub area where these studs are manufactured was quite interesting, but was not particularly automated. Two operators set the cords and lay in the stud plates while a rolling press formed the three elements together. The factory was well organized and quite clean. Workers were working hard, but not particularly stressed. The general sense of the factory was positive, good lighting and not overly loud 


\section{EEIH}

Center for Housing Innovation

University of Oregon

\section{TRIP REPORT FORM [jS89-10c ]}

Date of Report:

Place Visited:

Dates of Visit:

Attending:

Purpose of Visit:

Visit Repor:
$10 / 01 / 89$

Myresjohus under assembly near Vetlanda

\section{9/04/89}

J. Finrow and Mary Vogel of the Minnesota group

to view an SFC house under construction

Apparently it was not possible to actually visit a house that was being assembled, but we did manage to find a house that was almost completed and to view it. The house had all of the panels in place and the roof on but the panels were not completely sealed and it was possible to see the panels and how they were attached. Roofs seem to be site built based on wood trusses that are set and stripped on the site with tiles set on the roof. This particular house had a completely prefabricated dormer in the roof which was an interesting sub assembly item that can be added to any Myresjohus house. In this house the exterior was clad with board on board solid wood siding that was stained. The interior had yet to be finished in a coventional gypsum board fashion, probably with wall paper. There was also a completely site built fireplase unit the foundation also looked to be precast concrete elements rather than poured in place foundations. Our visit occured in the evening and no workers were on the site to discuss the project with.

Supporing Documentation: slides 
EEIH

Center for Housing Innovation

University of Oregon

TRIP REPORT FORM [jS89-11c ]

Date of Report:

$10 / 01 / 89$

Place Visited:

The home of Mr. Heinz Will, plant engineer for Gullringshus in Gullringen

Dates of Visit:

$09 / 05 / 89$

Attending:

J. Finrow + Minnesota group lead by Paul Kando

Purpose of Visit:

to view a Gullringshus

Visit Repor:

Mr. Will invited us to visit his house to see what a Gullringshus looks like. His house was built about 5 years ago and was a one story house built over a full basement. The mair. living floor had two bedrooms and all of the public spaces of the house. The basement had two bedrooms, a kind of family room, a sauna and workshop room. The house had brick exterior cladding and tile roof. The interior finish is mainly wallpaper over gypsum board with a very fine wood ceiling. The overall feeling of the house is quite pleasent with reasonable light and high quality finish. We were also able to visit another house next door to Mr. Will which was just recently completed. While this house was also nice, it did not feel quite the same as Mr. Will's house. There was a stronger sense that this house was a manufactured house. The wall board materials had a joint that while different than a U.S. mobile home wall panel batten, gave much the same feeling.

Supporting Documentation: none except direct experience. 
EEIH

Center for Housing Innovation

University of Oregon

TRIP REPORT FORM [jS89.10a]

Date of Repor: $\quad$ 10/01/89

Place Visited: $\quad$ Burmek, AB / Verkstadsgatan 7 / S 57100 Nassjo, Sweden

Dates of Visit: $\quad 09 / 04 / 89$

Attending: $\quad$ J. Finrow + Minnesota group guided by Paul Kando

Purpose of Visit: $\quad$ To document an equipment manufacturing plant for SFC technology

Visit Repor: $\quad$ This plant produces much machinery for SFC plants in Sweden.

They currenty are working to develop new machines that will improve the productivity of SFC plants, especially related to the nailing of sheathing to floor and wall panels. The plant is highly sophisticated producing from stock just about all of the parts to complete a SFC factory including valves. The plant currently has a backlog of orders for production of various machines for plant located in Smaland. We saw several of this plants new machines being installed in factories on out visits to SFC plants in the areas. The factory also offers complete planning and design services for new factories including fully computerized plant design capability. The factory was recently purchased by a group of investors but the plant manager, Mr. Rolf Burman, remains the main person in the firm. In addition to the production of plant equipment, this plant has a very sophisticated electronics sub assembly area where all of the wiring for the production machinery is completed.

Supporting Documentation: slide documentation of the plant and some brochure materials provided by Burmek. 
EEIH

Center for Housing Innovation

Lniversity of Oregon

\section{TRIP REPORT FORM}

Date of Repor:

$9 / 18 / 89$

Place Visited.

Architectural Museum and Bookstore, Copenhagen, Denmark

Date of Visit:

$8 / 26 / 89$ (jfS89-3a)

Atending:

J. Finrow

Purpose of Visit:

Locate literature related to energy efficient industrialized housing design

Visit Report:

I found and purchased several items that relate to the EEIH project which are listed below.

Supporting Documentation: Industrialized Housing in Denmark; Kjeldsen, Marius, Danish Building Center Bookshop, 12E Skolegade, DK-2500 Valby, Denmark, 1988, ISBN 87-503-71762

Danish Social Housing Coroprations, Vol In: Salicath, Neils; Danish Ministry of Housing and Building, Intemational Relutions Division, Slotsholmsgade 12,1216 Kobenhavn K, Denmark, ISBN 87-87744570.

Arkitekture i Danmark; Byg \& Bo 88 Qdense; no author given; Fremtidens Boligbyggeri pa Blandstedgard

Danish Architecture. 1879 - 1979; no author given; Arkitektens Foriag.

Tag Over Hoveder; Nygaard, Erik; Arkitektens Forlag, 1984; ISBN 87. 7407-064-9.

Laengeboligen: Orum-Nielsen, Jom; Kunstakademiets Forlag, Arkitektskolen og Arketektens Forlag, 1988, ISBN 87-87136-01-5.

(note: all books are personal copies of J. Finrow) 


\section{EEIH}

Center for Housing Innovation

University of Oregon

TRIP REPORT FORM [ jRS89.3b ]

Date of Report: $\quad 9 / 18 / 89$

Place Visited: Hosby Hus $\mathrm{a} / \mathrm{s}$

DK-7130 Juelsminde, Denmark

Dates of Visit: $\quad 8 / 26 / 89$

Attending: J. Finrow

Purpose of Visit: $\quad$ To view the manufacturing process of a Danish wooden factory crafted home manufacturer.

Visit Report: Visit was not completed do to the schedule of the company, I I was unable to visit. They would agree to have me visit at another time that would be more convienent to them.

Supporting Documentation: none 
EEIH

Center for Housing Innovation

University of Oregon

\section{TRIP REPORT FORM [ jfS89 - 4a ]}

Date of Report:

$9 / 18 / 89$

Place Visited:

Roslev Hus

2 Frisenborgvej

DK-7800 Skive, Denmark

Dates of Visit:

$8 / 27 / 89$

Attending:

J. Finrow

Purpose of Visit:

to observe the manufacturing process of a Danish wooden factory crafted housing manufacturer.

Visit Report:

Could not contact the plan, my phone calls were never answered. I later found out that this company has gone out of busniess because of a recent contact that will be mentioned later.

Supporting Documentation: none 


\section{EEIH}

Center for Housing Innovation

University of Oregon

TRIP AEPORT FORM [ jYS89 - 5a ]

Date of Report: $\quad 9 / 18 / 89$

Place Visited: $\quad$ Ebbeltoft recreational housing community north and east of Aarhus, Denmark

Dates of Visit: $\quad 8 / 28 / 89$

Attending: J. Finrow

Purpose of Visit: $\quad$ to view and photograph an industrially manufactured recreational community project.

Visit Repor:

I visited the project and took many photographs. I talked with a sales person about the project. It is a unqiue and interesting housing scheme because they intent to sell most of the housing to buisnesses who would use the project as a recreational facility for their employees.

A very interesting project with a nice sense of place. Location is a bit isolated and it did not seem very occupied.

Supporting Documentation: Sales brochures and descriptive information that will be placed in our library of literature. I have many personal slides of the project. 


\section{EEIH}

Center for Housing Innovation

University of Oregon

TRIP REPORT FORM [ jSS89 - 5b ]

Date of Report:

$9 / 18 / 89$

Place Visited:

xxxxxxxxx, Aarhus, Denmark

Dates of Visit:

$8 / 28 / 89$

Atrending:

J. Finrow

Purpose of Visit:

to view and photograph examples of contemporary Danish industrialized housing.

Visit Report:

This project was a low rise concrete housing system which was developed as moderate income attached housing. The project was nicely designed and adapted to the land of the site. The project shared a district heating system and the siting was done to minimize wind access to inner courtyard spaces - a good energy siting strategy.

Supporting Documentation: personal slides of the project 


\section{EEDH}

Center for Housing Innovation

University of Oregon

TRIP REPORT FORM [ jSS89 - 5c ]

Date of Repurt:

Place Visited:

Dates of Visit:

$\therefore$ itisnding:

Purpose of Visit:

Report of Visit:
9/18/89

?. Aarhus, Denmark

Aarhus Arkitektgruppe, architect

$8 / 28 / 89$

J. Finrow

to photograph and document energy efficient industrialized housing

A very nice project built in concrete small panel system with wood and brick facing. One of the buildings uses an interior greenhouse corridor which provides an energy efficient space between buildings that is highly used by residents. This space is probably about 20 feet wide with connections to community spaces including a day care center. The space was full of children some on small wheel carts using the space. See sketch below:

Supporting Documentation: personal slides of this project Including the greenhouse space. 


\section{EEIH}

Center for Housing Innovation

University of Oregon

\section{TRIP REPORT FORM [ jSS89 - 5d ]}

Date of Report:

Place Visited:

Dates of Visit:

Attending:

Purpose of Visit:

Visit Report:

Supporting Documentation: Mar
$9 / 17 / 89$

Energy efficient Co-Housing project, Fredrica, Denmark architect and specific name of project unknown

$8 / 28 / 89$

\section{J. Finrow}

to photograph and document a project using a large interior greenhouse to reduce energy usage.

This housing project was very interesting because it was a good example of the value of a "greenhouse" design concept that seeks to create a "thermal airlock" between the conventional outside of a building wall and the inside. There were two buildings in this project each of which was composed of several groups of apartments that shared a common interior greenhouse space (see sketch). The interior greenhouses were full of activity and life and also appeared to have an air distribution system for recycling greenhouse air.

Many sllies were taken which document this project. Later questloning of architects in Copenhagen did not furn up any additional information about this project. 


\section{EEIH}

Center for Housing Innovation

University of Oregon

\section{TRIP REPORT FORM [ jSS89 - 6a ]}

Date of Report:

Place Visited:

Dates of Visit:

Attending:

Purpose of Visit:

V:sit Report:
$9 / 18 / 89$

Byg and Bo housing exhibition site, Odense, Denmark large housing project involving inany different architects and developers

$8 / 29 / 89$

\section{J. Finrow}

To document and study the "state of the ar" in contemporary Danish multi-family housing, several projects of which employ inrovative energy and industrialized building strategies

This exhibit was opened in 1988 and is currently occupied. The exhibit was developed by the city of Odense (the third largest in Denmark) to celebrate the 1,000 th anniversary of Odense. The project includes about 600 housing units in 19 major buildings with over 1,500 occupants. Built on the site of an old manor house, the project was designed to create experiential diversity by using a number of important Danish architects. Two projects of this group utilized the "greenhouse" street idea in a bit different form than seen elsewhere in Denmark. In one case, there was a major cubic interior courtyand and in another case the greenhouse was a kind of enclosed street that formed the winter circulation pattern within the complex. Several projects macle use of attached "sunrooms" on balconies which provide and unheated extension of the living space in the better parts of the year. See diagrams below:

Supporting Documentation: Many slides were taken and a book of only limited technical merit were acquired to document the project. 


\section{EEIH}

Center for Housing Innovation

University of Oregon

TRIP REPORT FORM [ jSS89 - 6b ]

Date of Report:

Place Visited:

Dates of Visit:

Attending:

Purpose of Visit:

Visit Report:

\section{$9 / 18 / 89$}

Tinggarden housing project, Koge, Denmark architect: Vandkunsten architects

$8 / 29 / 89$

\section{J. Finrow}

Study and Document Contemporary Danish energy efficient housing

This project is comprised of two different parts, Tinggarden 1 and Tinggarden 2 , both designed by the same architectural office. The first project is designed as cluster housing with open garden areas between bulding wings. There are also extensive common facilities which are shared. Energy inr ovations include district heating. The second project was buil later and is more "urban" in the sense that public spaces are some what tighter and more finished with a greater sense of enclosure. The materials are also quite different and the character of the project is a bit "harder". This project also utilized district heating. Both projects are built with industrialized concrete panel construction systems.

Supporting Documentation:
Extensive slides were taken and both phases of this project are represented in the books purchased at the architectural museum. A 
EEIH

Center for Housing Innovation

University of Oregon

TRIP REPORT FORM [jPS89 - 6c ]

Date of Report:

$9 / 18 / 89$

Place Visited:

Holmebaek Housing project, Herfloge, Denmark Aarhus Arkitekt Gruppe

Dates of Visit:

$8 / 29 / 89$

Attending:

\section{J. Finrow}

Purpose of Visit:

To photograph and document the first major industrialized wood panel housing project in Denmark.

Visit Report:

This project pioneered the use of prefabricated wooden infill panels in concrete shell construction. Floors and party walls were made in poured in place concrete. Interior walls and exterior walls were factory produced wood panels that were clad on:site with finished material on both sides of the wall. In addition, prefabricated elements such as balconies, sun rooms, living room extensions, etc welre either factory made and added or site built to give variety the these buildings. This composite construction strategy has been extensively utilized in Denmark since this project and has significantly changed the way such housing is designed. See diagram below:

The project also utilizes a district heating plant and extensive garden plots.

Supporting Documentation: extensive slide documentation was done and this project is represented in the literature purchased from at the architectural museum. 


\section{EEIH}

Center for Housing Innovation

University of Oregon

\section{TRIP REPORT FORM [ jiS89 - 6d ]}

Date of Report:

Place Visited:

Dates of Visit:

Attending:

Puppose of Visi:

Visit Report:

\section{$9 / 18 / 89$}

Sun, Wind and Light Co-Housing project, Knge, Denmark

$$
8 / 29 / 89
$$

\section{J. Finrow}

Documentation and study of a significant energy efficient housing project

This project has pioneered a considerable number of energy efficient design issues while at the same time based on a communal housing design strategy. The project makes extensive use of active solar panels for hot water heating. Many of the housing units also have south side greenhouse spaces which are used as non-heated extensions of interior space as well as for domestic agriculture. The project also gains some power from a commercial power generation windmill that is located $1 \mathrm{~km}$ from the housing project site. The project is designed around a series of garden courtyands in parts of two to four units. The project is painted bright and light colors and generally projects a cheerful feeling. As in most of the Danish housing projects, there is a district heating plant in the project. This is a very interesting and inspiring project that demonstrates that it is possible to combine many different energy efficient strategies into one project in a good way.

Supporting Documentation: extensive photo documentation was carried out and the project is represented in the Co-Housing book. 
EEIH

Center for Housing Innovation

University of Oregon

TRIP REPORT FORM [ jIS89 • 6e ]

Date of Report: $\quad 9 / 18 / 89$

Place Visited: $\quad$ Tastrup Hoj development area west of Copehnagen

a large "new town" with many different project areas

Dates of Visit: $\quad 8 / 29 / 89$

Attending: J. Finrow

Purpose of Visit: $\quad$ Examine and document the development of the newest of the Danish housing developments.

Visit Report: $\quad$ Tastrup is located just west of Albertslund the land mark housing project in the Copenhagen region of the 1960's. Tastrup is intended to be a major "center" with a large population. The area aiready has many large but not very interesting housing projects and the new project is an attempt to create the physcial definition of a town. The project uses the latest thinking in urban design derivative of the theoretical ideas of the Krier brothers. Energy issues are not very important in the project center which combines commercial, office and housing space together along narrow and well defined streets which feel like a city. The surrounding housing projects that are par of the broader Tastrup community are somewhat less rigid, and take ad:antage of such energy efficient features as sun spaces, central heating plants and super insulation. One of the projects in this development was built by the Jesperson \& Son company that I visited on Thursday. This project was very nicely designed being organized around a well defined interior courtyard spaces. This project area is still underconstruction and will be interesting to visit in about two years as more of the town will be visable. It is unfortunate that energy considerations are not a signficant issue in the Tastrup area as it is the "leading edge" of current housing design thinking in Denmark.

Supporting Documentation: Slides articles from the Danish architectural magazine are available. 
EEIH

Center for Housing Innovation

University of Oregon

TRIP REPORT FORM [jSS89-9a]

Date of Report:

$10 / 01 / 89$

Place Visired:

North of Copenhagen

Dates of Visit:

$09 / 2 / 89$

Attending:

J. Finrow

Purpose of Visit:

Photograph a retro fit housing project

Visit Report:

This project is the best designed of all of the current group of 1950's \& 60 'S concrete housing projects that have been retrofitted in the last three years. The original project was a large project of 3 to 5 story concrete slab buildings organized around interior courtyards. The project had apparently deterioratai very badly and was in need of substantial rehabilitation. In addition to this work needed, the project was to be retrofitted in order to improve energy performance. In addition to improving the energy performance, the designers of the project sought to improve the general quality and character of the place at the same time therefore, making a more supportive and better environment. Roof trusses were installed with metal roofing to provide better weathering and to be able to install rouf insulation. Many existing balconies were rebuilt to fully enclnse them with glass creating "sun spaces" that would improve energy performance and provide an arditional living space for the housing units. Existing concrete pancls we.e insulated and resided with concrete board which provided better scale at the same time as improving energy performance in the wall. Windows were replace with triple glazed units. The landscape was also redesigned as were the open spaces to provide better quality general environment. The project is very successful in architectural terms and also gives improved energy performance as well.

Supporting Documentation: Main documentation through slides, this project has been published in the Danish architectural journal. 


\section{EEIH}

Center for Housing Innovation

University of Oregon

\section{TRIP REPORT FORM [jS89-9b]}

Date of Report:

Place Visited:

Dates of Visit:

Attending:

Purpose of Visit:

Visit Report:

Supporting Documentation:
$10 / 01 / 89$

Damgardsarealet project area in Albertslund

$09 / 02 / 89$

\section{J. Finrow}

study and photograph a project under construction using Danish composite construction technology

The Damgardsarealet project area comprises three project - phases 1 , 2 and 3 each of which was designed by a different architect. Phase three designed by Vandkunsten, was under construction and it was possible to see the technology that was being used. Phase 1 was designed by Martin Rubow and was occupied. Phase 2 was just finished and probably was 1/2 occupied. Both of these projects were built using the composite system and were finished in wood or concrete board siding. Phase three was about $2 / 3$ rds finished and it was possible to see buildings that were just being framed and some that were almost finished. Concrete slabs were poured for the ground floor, then precast intermediate walls (party and bearing walls) were set in place and then precast floor slabs set in place. This process was repeated for floors two and three. Then infill wood frame panels were installed. These wall panels were only partially finished and windows are added and finished interior and exterior surfaces. Wall panels were full insulated and had sheathing attached. Roofs were framed on the ground using preformed wood trusses and the whole roof assembly was then lifted by crane to its finished position and then roofing tile was installed. Exposed concrete around the paneis were insulated with loose insulation before exterior siding was installed. In addition to the prefabricated concrete and wood frame elements, kitchen cabinets and exterior and interior stairs are prefabricated for the project and installed on site. The site was highly organized with the large moving crane at its center. Materials were efficiently stacked and organized. The wood panels for this project were simply bid, with the supplier a Finnish firm called Makrotalo at RatamestarkinK. 11,00520 Helsinki, Finland. Panels were manufactured in Finland and then shipped to the site for instaliation.

Extensive slides taken of all three projects, some additional documentation supplied by Vandkunsten. 


\section{EEIH}

Center for Housing Innovation

University of Oregon

\section{TRIP REPORT FORM [jSS89.9c]}

Date of Report:

Place Visited:

Dates of Visit:

Attending:

Purpose of Visit:

Visit Report:

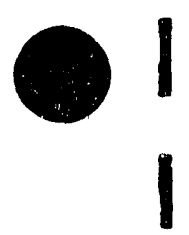

\section{$10 / 01 / 89$}

Sibelius-Parken housing project in West Copenhagen

$09 / 02 / 89$

\section{J. Finrow}

Visit housing project that makes extensive use of "sun spaces"

Sibelius-Parken is a well known project in Denmark because it was designed following the principles of "Defensible Space", the seminar theory work by Oscar Newman conceming housing public safety concerns. In addition to this design idea, Sibelius-Parken is also known because it has pioneered the use of balcony "sun terraces" as an energy efficiency strategy. The sun spaces are all oriented south and provide a rather large semi-enclosed space for each housing unit. Sun terraces are fully glazed and extend over most of the exterior wall of the housing unit. These spaces allow residents an additional space to use much of the year and also provides som: space "buffering" to reduce heat lost in winter. The project is comprised of a large open central courtyard with housing units surrounding. Circulation is around the perimeter of the project. The sun terraces provide a quite nice space that has been cirtensively personalized by housing occupants who use these spaces for gardening, cloths drying, sitting and other household activities. The energy benefit of the sun terrace space is in some dispute, but these spaces certainly do provide an added spatial dimension to the occupants of the housing units.

Supporting Documentation: Extensive slide documentation. 


\section{EEIH}

Center for Housing Innovation

University of Oregon

TRIP REPORT FORM [jSS89.9d]

Date of Report: $\quad$ 10/01/89

Place Visited: urban mixed use building (including housing) Etagehus, Alekstevej 168-9, Copenhagen, Denmark

Dates of Visit: $\quad 09 / 02 / 89$

Attending $\quad J$ Finrow

Purpose of Visit: $\quad$ Photograph an urban industrialized housing project

Visit Report: This project is very interesting as an example of a new kind of Danish industrialized construction technology that does not make use of any poured concrete. The whole system is prefabricated with the use of bolted connections between component parts all of which are prefabricared. The whole building is a kind of "kit of parts" system that forms a simple building system. The lower floor is a food store (supermarket) and the upper three floors are housing. A system of prefabricated concrete and steel elements form the floor framing system with metal and gypsum infill panels with metal siding. all building systems come from the exterior of the wall which allows tenants to move the interior partitions of the project. Greenhouse type sun spaces are utilized along the circulation floors at the 2 nd floor level and at the top floor level. units are two stories high using a variation of the "skip stop" - elevator arrangement. A large interior courtyard is formed which is for children to play and some limited parking with service access for supplying the food store. This is a very nice project with high quality and long lasting exterior materials. Has been published in the Danish architectural joumal.

Supporting Documentation: Exterior slide documentation. 


\section{EEIH}

Center for Housing Innovation

University of Oregon

\section{TRIP REPORT FORM [jSS89.8a ]}

Date of Report:

$11 / 15 / 89$

Place Visited:

Architectural office of Martin Rubow/ Hulse, Thure Neilsen and Rubow / Hermodsgade 24, 2200 Copenhagen, Denmark

Dates of Visit:

\section{$9 / 1 / 89$}

Attending:

\section{J. Finrow}

Purpose of Visit:

Discuss energy efficient industrialized housing production in Denmark and the work of Martin Rubow.

Visit Report:

Mr. Rubow is a well known and extremely active architect in Denmark who does work that is both energy efficient and very well designed. We discussed current developments in housing construction technology and he showed many building details from projects currently underway in his office. He discussed the development of composite construction systems using both concrete and wood panels systems. Most of his most recent projects were done in this way. We talked about the status of Ilanish wooden factory crafted housing systems and he mentioned that one large company recently went bankrupt (Roslev Hus) after having completed a part of one planning area in a project where he had one a project in Albertslund (Damgardsarealet phase two). We also discussed developments in retrofitting 1960's concrete elements housing projects in the suburbs around Copenhagen and the problems amd costs associated with this. He suggested that two areas be visited which would give a good idea of how this kind of work was progressing. He pointed out the importance of thinking about the architectural developments of these projects as well as the technical issues in solving the energy problems. He also mentioned that there was another Wooden house system manufacturer in Denmark called Trelleborg, which is located in the Copenhagen area.

Supporting Documentation: Project brochures from Martin Rubow's office. 


\section{EEIH}

Center for Housing Innovation

University of Oregon

\section{TRIP REPORT FORM [jS89-8b ]}

Date of Report:

Place Visited:

Dates of Visit:

Attending:

Purpose of Visit:

Visit Report:
$10 / 01 / 89$

Architectural Office of Vandkunsten in Copenhagen, Tegnestuen Vandkunsten, Brosmandsstraede 6, 1407 Copehnagen $\mathrm{K}$, Denmark

$09 / 1 / 89$

\section{J. Finrow}

Discussion of industrialized construction technology in Denmark

Vandkunsten is one of the best architectural office in Denmark. They have been involved in the design of several Co-housing projects as well as many other "conventional" housing projects. Their work has been widely published both in Europe and in the USA. The discussion was mainly with Seffen Kragh, an associate in the firm. Mr. Kragh discussed and showed several housing projects. We talked mainly about a new project currently under construction in a development area in Albertslund called Damgandsarealet, phase 3. The project demonstrates the new Danish system of composite construction utlizing traditional precast concrete slabs and party walls with exterior walls of prefabricated wood panels. Mr. Kragh discussed the development of this construction system and the fact that it is both more energy efficient and lower in cost than the traditional concrete panel systems. Wood panels are also much lighter and easier to work with than concrete panels. He suggested that a visit be made to the site in order to really view how the construction system is put together. He showed me around the office and then introduced me to Jens Arnfred, the main partner in the firm. I briefly talked with Mr. Arnfred about his work with co-housing clients. We talked about the Jystrup Sawmill Co-housing project and he discussed working with that particular group. He also talked about the state of industrialized housing in Denmark arid the development of the wood panel and concrete composite construction systems which he has, to some extent pioneered. We also talked about the exterior cladding materials which make extensive use of "concrete board". We looked at a few drawings and details concerning how the board is attached to frame walls.

Supporting Documentation: Photographs of the Damgardsarealet site and a brochure that they give to prospective clients about the work of the firm. 


\section{EEIH}

Center for Housing Innovation

University of Oregon

\section{TRIP REPORT FORM [jS89-8c ]}

Date of Report:

Place Visited:

Dates of Visit:

Attending:

Purpose of Visit:

Visit Report:

\section{$10 / 01 / 89$}

Norgards plantage (Norgards orchard) in Hesselbo, Denmark (northwest of Copenhagen)

$09 / 1 / 89$

\section{J. Finrow}

\section{To visit energy efficient industrialized Danish housing}

Norgands orchard is a large proiect of over 200 housing units located in an orchard in which the houriing project has been built. The project was designed by Vandkusten architects. The project utilizes Danish composite industrialized construction (wood panels and concrete slabs). The project is simple and clearly organized in an L looking into a large open space that is the orchard. Connected row houses create an edge next to the orchand and look out into the open space of the orchard. small one story row housing units run perpendicular to the edge building" and crrate alternative small gardens and walkways between building. The energy efficent aspects of the project include active solar, passive solar and a district heating plant. Gardens and planting is quite extensive, with community and private gardens for most housing units. Sun spaces are also included in some housing units.

Supporting Documentation: Slides and printed materials from Vandkunsten brochure materials. 


\section{EEIH}

Center for Housing Innovation

University of Oregon

\section{TRIP REPORT FORM [ jIS89.8d]}

Date of Report:

Place Visited:

Dates of Visit:

Attending:

Purpose of Visit:

Visit Report:
$10 / 01 / 89$

Fuglsangparken, Farum (north west of Copenhagen)

\section{$09 / 1 / 89$}

J. Finrow

Photograph contemporary industrialized housing project that utlizes Danish composite construction technology.

Fuglsangparken is one of the major projects designed by Vandkunsten architects using the wood panel and concrete construction system and also using energy officient design practices. The project is located near Copenhagen in an area of many other new housing projects. A very important part of this project was the design of the site to take advantage the existing landscape (including a small creek that goes through the site). The project is composed of several large open courts that are oriented south facing a larger open space along the creek which is the major common area of the site. A public school is located at the center of the projects and each of the courtyards are connected by a path system to the school complex. The project utilizes a district heating plant to supply energy for the housing units. There are also some greenhouses and sun spaces that are utilized for energy efficiency. The use of wood infill panels provides added thermal performance. The design quality of the place is exceptionally lively considerable visual and spatal riches created in the complex.

Supporting Documentation: Extensive slides were taken and some documentation in the Vandkusten firm brochure. 


\section{EEIH}

Center for Housing Innovation

University of Oregon

TRIP REPORT FORM [jS89.7b ]

Date of Report:

Place Visited:

Dates of Visit:

Attending:

Purpose of Visit:

Visit Repor:
$10 / 15 / 89$

Graese Bakkeby, low rise family row housing project

$8 / 31 / 89$

\section{J. Finrow}

View recent housing produced by Modulbeton concrete housing system

Host for the tour was Soren Bech, project manager for A. Jespersen and Sons a development and construction company that is $\$ 1 \%$ owner of Modulbeton concrete factory. The project was located about 5 kilometers for the concrete factory. The project was a number of row house buildings, each of which had between 3 and 7 housing units. The buildings were two story units with garages and private fenced back yards. Exterior finish material was brick. Several of the buildings made use of a glassed in sun porch area all of which faced south. Cccupants had done quite a lot of personalization including extensive gardening and interior development of the units. The project is fully occupied. Bech discussed the process of housing development that his firm uses for these project, partially developed through a group of users and partially sold in the private housing market. The energy performance of these buildings is quite good according to Mr. Bech relintive to other projects as additional insulation was used and the houses were sited to take maximum advantage of passive solar gain. The use of concrete as a primary building system contributes to the utilization of solar heating. Mr. Bech was the project manager on this project.

Supporting Documentation: slides were taken as well as brochures produced by Jespersen in their marketing activity for the project. 


\section{EEIH}

Center for Housing Innovation

University of Oregon

\section{TRIP REPORT FORM [jS89.7a ]}

Date of Report:

Place Visited:

Dates of Visit:

Attending:

Purpose of Visit:

Visit Report:
$10 / 15 / 89$

Visited Modulbeton, Concrete element factory

Kornmarkesvej 20 / DK-2605 Brondby / Denmark

$8 / 31 / 89$

\section{J. Finrow}

View the plant manufacturing process in a modern concrete panel plant.

Plant visit was hosted by Jimmy Witved, a Director of the plant and Peter Toksvig, Chief production engineer. The tour began with a discussion of the production process and the elements and systems that the factory manufactures. Photographs of previous projects were shown and discussed. Construction drawings were also reviewed in order to get a sense of the system they utilized. Current plant production is directed toward producing commercial wall systems and floor and party wall elements for housing. They currently were working on elements for housing in Sweden. We discussed changing concrete plant technology in light of energy efficiency. They showed detailed of wall panels with integral insulation. After the discussion, we went on a plant tour. The first area visited was the finishing and shipping area for completed wall panels. Next we viewed a casting bed for wall panels and then the vertical casting shed. In this facility, wail panels are cast in the vertical position which produces more parels in less space than in the flat casting area. Also vertically cast panels are cured in steam heated pressure chambers which speeds up the curing process. We also visited a floor slab casting facility where slabs over 100 meters long were cast and then cut into sections for shipping. The last stop was the concrete mixing plant which was fully computerized and quite impressive in delivering the correct kind of concrete to any par of the plant via overhead pumping tubes.

Supporting Documentation: The interior of the plant was extensively photographed (slides). 
EEIH

Center for Housing Innovation

University of Oregon

TRIP REPORT FORM [ jSS89.7c]

Date of Report:

$10 / 15 / 89$

Place Visited:

Torstorp Norreby, east of Albertslund in the Copenhagen region

Dates of Visit:

$8 / 31 / 89$

Attending:

J. Finrow

Purpose of Visit:

View energy efficient concrete low rise housing construction project produced by $A$. Jespersen using Modulbeton concrete elements

Visit Report:

Soren Bech was the host for this tour to one of the newest housinga areas in the Copenhagen region. This project was in an area that was visited previously. This project was under construction and it was possible to see the concrete elements being assembled. The project is comprised of numberous row house type buildings of 1 and 2 floors. Exterior finished cladding was brick and stucco. Houses had private gardens and parking areas. The organization of this project was highly regilarized and the housing took more of the form of urban courtyand housing than row housing. Interior courtyards were highly detined and planting was planned but not yet executed for this place. A few duplex housing units were also included in the general area of this project. The construction process involved the pouring of slabs on grade with appropriste perimeter slab insulation and then the prefabricated wall and second floor slabs were set in place and grouted. Roofs were formed of prefabricated wood trusses with concrete tile roofing. Insulation and then a layer of brick was installed over the exterior walls, none of the concrete panels were exposed. Soren Bech is the project manager for this project which is being sold on the private housing market. A typical 2 bedroom housing units sells for near $\$ 125,000$.

Supporting Documentation: Extensive slides were taken of this project. 


\section{EEIH}

Center for Housing Innovation

University of Oregon

TRIP REPORT FORM [ jSS89.7d]

Date of Repor:

Place Visited:

Dates of

Attending:

Purpose of Visit:

Visit Report:
$10 / 15 / 89$

Erik Skoven, Assistant Director of Studies, the Dannish International Stidies Program of the University of Copenhagen, Copenhagen, Denmark.

$8 / 31 / 89$

\section{J. Finrow}

To discuss possible architects, projects and other possible contacts related to energy efficient industrialized housing in Denmark

Erik Skoven is very familiar with current housing developments in Denmark as well as the architects who are active in this field. He suggested and called several people who were subsequently visited. He also recommended a number of possible projects which were also visited. He discussed important issues in this area including the differences between Sweden and Denriark in regard to the development of energy efficiency in housing design. He pointed out the differences in climate and culnural atritude and building traditions (less use of wood and single family housing in Denmark). His view was that Danish energy efficient housing was generally more "ecologically" oriented than was that in Sweden. He suggested discussions with Martin Rubow and Jens Amfred (Tegnestuen Vandkunsten) as the best people to visit. We discussed research contacts and he suggested contacting Erwin Petersen and Ivar Moltke at the Teknologisk Institut in Copenhagen for current information.

Supporting Documentation: Written notes 


\section{TRIP REPORT}

TITLE:

DATE:

LOCATION:

ATTENDING:

PURPOSE:

SUPPORTING

DOCUMENTS:
Kyoto C'niversity

August 15, $1989 \quad 10$ a.m.

Kyoto, Japan

G. Z. Brown

Kazuo Tatsumi, Professor of Architecture, Kyoto University Tetsukazu Akiyan a, Instructor of Architecture, Kyoto Univ.

To review ongoing research

Reviewed the state of industrialized housing in Japan from Tatsumi's perspective. Explained the Energy Efficient Industrialized Housing program and our desire to leam from Japan's experience in industrialization. Reviewed Tatsumi's publication which covers housing issues in Japan, including industrial housing. Industrialized housing is defined in terms of the degree to which firms integrate the roles of designer, developer, contractor, craftsperson, and seller. Fully integrated firms are called industrialized and cormprise 15\% of Japan's housing market of 500,000 units annually. (Sekisui House, Lid., the largest producer, manufactures 30,000 units annually.) Defining the industry by level of firm integration may have some advantages of the common U.S. practice of dofining industrializing by the type of constriction system---modu!ar, panel, etc., if the imporant issues are business rather than technical.

Marketing is a major factor in home sales with some firms using techniques like questionnaires which pinpoint buyers preferences for other consumer goods (clothes, furniture) which are then used to determine what model house they will prefer.

Tatsumi speculated that Japan's lack of concern for energy conservation stems from their traditional very low energy use in their houses (no air conditioning and charcoal heaters). The traditional emphasis on designing the house for summer rather than winter has made insulacion an unimponant consideration. There are currenty government subsidies for using insulation although the levels are much lower than in the U.S.

We visited a manufacturer's housing park that had models from each of the major manufacturers. The set-up was not very different from builders in the U.S. building models all on the same street, although the promotional literature was more extensive.

Publications attached

550/TripReportC1 
TRIP REPORT

TITLE: $\quad$ Waseda University, Tokyo, Japan

n:-TE:

LOCATION:

ATTENDDNG:

PURPOSE:

SUPPORTING

DOCUMENTS:
August 16, 1989

Tokyo, Japan

G. Z. Brawn

Nobuo Hozumi, Professor of Architecture and Dean, International Studies, Waseda Univ.

Shun Watanabe, Asst., Department of Architecture Computer Aided Design, Waseda Univ. Ken-ichi Kimura, Professor of Architecture, Waseda Univ.

To review ongoing research

Reviewed the research work being conducted by Kinuura covered in the papers and ongoing research in the environmental comfort chamber and solar dehumidification. The environmental comfor chamber (being used to test automobile heating and cooling systems when I visited) research is directed at determining comfort under conditions typical of passive systems, i.e., asymetrical radiant fields and difference between air temperanure and MRT. The dehumidification project involved testing to determine values needed to develop computer simulations that could predict rates of dehumidification for various parts of Japan.

Professor Watanabe is developing an AI-CAD system and demonstrated a prototype. The system as it currently stands will design a room based on a simple rectangle drawn by the user. The system produces the walls, windows and structural system. The user can query the program about any element in the systern (wall, door, window, etc.) and receive a description. Walls cr other elements can be added or subtracted. The program nuns on the Apple Macintosh, is programmed in Small Talk and displays multiple windows. The system would work well for industrialized systems that have a limited universe of parts.

Japanese currently pay about $\$ .20 \mathrm{kwhr}$ for electricity. Many'new houses use heat pumps for heating and cooling. Current codes restrict energy use to about 3-5 kilo calories/sq. meter of floor area, hr, ${ }^{\infty}$. which amounts to $5 \mathrm{~cm}$ 's of insulation.

449/TripReport/R1 
TRIP REPORT

TITLE:

DATE:

LOCATION:

ATTENDING:

PURPOSE:

SUPPORTING

DOCUMENTS: Product literature

August 28, 1989

G. Z. Brown strategies.
Misawa Homes Co. Ltd.

Takaido-Higashi Suginami-Ku, Tokyo, Japan

Hideaki Sagawa, Director/General Manager, Tech Dev. Div. Yoshiya Kato, Managing Director

Tomohiko Nomizo, Technical Manager

Isamu Suga, Manager, General Adm., Design Associates

Hiroaki Ishizawa, Asst. Mgr., Architectural Engineering Div.

To review housing products and marketing and manufacturing

According to the 10 minute film (we have a video copy) Misawa's primary concerns are a suitable place to raise your children, fire protection and earthquake protection. They express their concem for the customer's interest by offering extensive aid in planning the home and its furnishings, utilizing expert staff, interior show rooms and numerous brochures of images. Misawa manufactures two building systems - a stress skin pane! built on a wood grid infilled with batt insulation and glued skins applied to both sides and an autoclaved lightweight concrete (ceramic) panel. The major market thrust was using "technology to develop the 21st century house." There are 17 manufacturing plants in Japan, two of which make ceramic panels (see ceramic plant visit report). The ceramic panels are made of silica and limestone with a steel reinforcing grid. The steel is put in a mold filled with ceramic and then autoclaved. The panels are assembled into modules and completely finished inside and out, shipped to the site and erected using a crane. One of the models mentioned was for three generations on an urban site. They mentiones home automation as important but a later visit to a model revealed it to be a central on-off switching unit for lights, locks, etc., with little capability for programming times, partial operation, or temperature ranges. Misawa is apparently supporting research in Canada on wood products. They have several project locations around the world including the U.S. Misawa builds 40,000 units annually of which 26,000 are single family. Of the 26,000 , about $10 \%$ are ceramic.

At the conclusion of the film we visited their environmental test chamber which is large enough to accommodate an entire house. The testing includes hot and cold temperatures, radiation gain, rain, and wind. They had just completed a test of the ceramic system under cold conditions when I visited.

We had a general discussion of their interest in energy in their products. Currently their average of $\left(160 \mathrm{~m}^{2}\right)$ home consumes $7,500,000 \mathrm{kcal} / \mathrm{yr} . ?$ ? for heating, $1,000,000 \mathrm{kcal} / \mathrm{yr}$. for cooling, and $4,500,000 \mathrm{kcal} / \mathrm{yr}$. for water heating (see attached graph). They intend to cut this figure by $1 / 3$ in the next 5-6 years. They see this reduction as technically possible but difficult to achieve at an acceptable cost. They do vary the construction of their home with climare zone. The heating fuels are gas, oil, or heat purap. Their strategy for reducing energy use is three fold: 1) Improved envelope performance through increased insulation and better windows. Air tightness is currently good due to the industrialized process. Windows are an issue for them because of the Japanese Misawa Homes Co. 444/R1 
preference for large openings. They are currently investigating a bead wall system which sounds similar to that developed by Steve Bear in the U.S. 2) More efficient heating and cooling systems which use the floor construction systems. They said they were going to use the mass of the floor system as an off peak cooling strategy. I doubt it but something may have been lost in the translation. They do recognize dehumidification as a significant comfort problem and seemed interested in F8EL DESRED system. 3) Utilizing solar and ground water heating systems.

Misawa has made three aitempts at computerizing their sales, design and manufacturing operations. In 1974 they developed a CAD system on an IBM and Hitachi based on their free design (not one of their preplanned models) panel system. The system worked well but was very difficult to updaie as codes and specifications changed and fell into disuse. Their next attempt was based on the Japan/ARC(?) CAD system and was for intemal use to turn out drawings and specifications for their preplanned houses. It was unclear whether this system is still in use. The third system which is currently in use and undergoing further development is based on a CAD system developed at Misawa. In its current form it operates on a PC with a hard drive (nobody knew how big it was). The sales person develops the plan on paper with the customer using sample plans and photographs. Once the design has been developed it is input, using a tablet and stylus, by the sales person (only one or two people are knowledgeable per office I suspect). The CAD system has a data base of Misawa products, therefore when a wall is created the computer knows the specs for the panels involved. The drawing sequence is 1) exterior walls, 2) interior walls, 3) openings, 4) built-in fumishings like kitchen cabinets and bathroom fixtures. The exterior walls are created just by clicking on the module ( $910 \mathrm{~mm} \mathrm{\&} 455 \mathrm{~mm}$ width) grid on the screen, using the stylus or the tablet (like a mouse) at each wall beginning and ending point. After that interior rooms are created by clicking on the diagonal comers of the room and then the room type is selected from the tablet menu. Given a plan, the software will calculate the panel size ( $3^{\prime} \times 6^{\prime}$ or $8^{\prime} \times 12^{\prime}$ sizes) after the roof pitches and gable locations have been selected in roof plan. Once the drawing is complete the user then selectss the finishes from three groups, using either the laser disk system or photographs or sample or a mix of these techniques. The system will check to see if flsor panels have been mistakenly used for wall panels, etc. Interior room sizes and corridor widths are checked visually by the operator. The computer will print material lists and develop the cost estimates for the customer. The dealer (privately owned) then mails invoices to Misawa. The system has been in use four years.

This system is being upgraded to the ZIP system which will transmit information directly from a 16 bit terminal at the dealer to a 32 bit terminal at the factory. The implication was that once the data was in the factory terminal it could be used directly in machine control. The system is being developed internally with consultants. The ZIP system is expected to be operational in one year.

Misawa used a laser disk system at its main dealerships to assist customers in selecting finishes and materials. They went to the laser disk after a hard connection to a main frame computer proved to be too slow. The main menu is 1) exterior, 2) interior, 3) products, 4) image video about Misawa life sytles. There are submenus under each main menu item. For example, interior is divided into living room, Japanese room, children's room, kitchen, etc. Within each of these room catagories there are images of interior spaces. The general system was developed by the Ministry of Construction with support from all manufacturers ( 8 disks). Misawa then went on and prepsred two proprietary disks for its own use. The customers preferences are remembered and can be played back for final selection. If the dealer wants complete specifications on any product, a compute. Fax combination queries the main frame at Misawa which returns the specs via fax to the dealer. The system has been in use for four years. Because it is expensive only the major dealers have the system. It wasn't clear how effective Misawa thought it was as a sales tool. Product literature for all homes is available. 


\section{SOFTWARE BIBLIOGRAPHY}


Document Preparation

Spec-Writer: Pinkerton-Galewsky, 550 Fannin, Suite 100, Beaumont, TX 77701

DataManipulation

AEC Information Manager: AEC Management Systems, Inc., 20524 Amethyst Lane, Germantown, MD 20874

Excel: Microsoft Corp., 16011 NE 36th Way, Box 97017, Redmond, CA 98073

MacProject II: Claris Corp., 5201 Patrick Henry Drive, P.O. Box 58168, Santa Clara, CA 95052

MicroPlanner: Micro Planning International, 235 Montgomery St., Ste. 840, San Fransisco, CA 94104

More II: Symantec Corp., 10201 Torre Ave., Cupertino, CA 95014

SuperCard: Silicon Beach Software, Inc., P.O. Box 261430, San Diego, CA 92126

\section{Reference Data}

Masterspec AIA - A/S/C Edition: EPPS/Architectonix, 1950 Stemmons Fwy, Ste. 5001, Infomar, Dallas, TX 75207

Masterformat Outline Specification: Yeoman Technical Software, RFD $\# 3,629$ Voluntown Rd., Jewett City, CT 06351

Residential Construction Symbols Library: Engineered Software, P.O. Box 18344, Greensboro, NC 27419

SPECTEXT: CSI Data Services, 400 Oser Ave., Hauppauge, NY 11788

\section{Graphics Tools}

Archibus/FM: Jung/Brannen Research and Development Corp., 177 Milk St., Boston, MA ArchiCAD: Graphisoft, 400 Oyster Point Blvd., Suite 520, So. San Fransisco, CA 94080

Archi-Trend: Fukui Computer, Inc., Yokohama Office, Hodogaya-ku Kamadai 48-1, 5-403, Yokohama 240 JAPAN

Arris: Sigma Design, Inc., 6251 S. Greenwood Plaza Blvd., Englewood, C0. 80111

AutoCAD: Autodesk, Inc., 2320 Marinship Way, Sausalito, CA 94965

BorgCAD: (address not available)

CADA VANCE: Cadgraph Systems, Inc., 2727 152nd Ave. NE, Building 6A, Redmond, WA 98052

ClarisCAD: Claris Corp., 5201 Patrick Henry Drive, P.O. Box 58168, Santa Clara, CA 95052

Draw: HOK/CSC, 1831 Chesinut St, Suite 601, St. Louis, MO 63103

Dreams: Innovative Data Designs, Inc., 2280 Bates Ave., Ste. A, Concord, CA 94520

FDM: Facilities Design and Management: CADD Share Corp., 180 Techwood Drive, Atlanta, GA 30313

Generic CAD: Generic Software, Inc., 11911 N. Creek Pkwy. S., Bothell, WA 98011

MacArchitrion: Gimeor, Inc., 1815 H, St., Washington, D.C. 20006

MacDraft: Innovative Data Designs, Inc., 2280 Bates Ave., Ste. A, Concord, CA 94520

MacPerspective: Knick Drafting, Inc., 1275 S. Patrick Dr., Ste. P; Satellite Beach, FL 32937

MegaCADD Design Board: MegaCADD, 65 Marion St., Suite 301, Seattle, WA 98104

MGMStation CAD: Micro CAD/CAM Systems, Inc., 5900 Sepulveda Blvd. \#340, Van Nuys, CA 91411

MicroArchitect: IDEA Graphix, 2452 Branch Ava., Altanta, GA 30305

Modelshop: Paracomp, Inc., 123 Townsend St., Ste. 310, San Fransisco, CA 94107

MountainTop: Accugraph Corp., 5822 Cromo Drive, El Paso, TX 79912

Pegasys: IGC Technology Corp., 305 Lennon Lane, Walnut Creek, CA 94598

Point Line: Robi Graphiks, Lid., 122 E. Olin Ave., Madison, WI 53713

QuickCAD: Weathershield Manufacturing, Inc., P.O. Box 309, Medfond, WI 54451

SuperPaint: Silicon Beach Software, Inc., P.O. Box 261430, San Diego, CA 92126 
Super3D: Silicon Beach Software, Inc., P.O. Box 261430, San Diego, CA 92126

Swivel 3D: Paracomp, Inc., 123 Townsend St., Ste. 310, San Fransisco, CA 94107

The Plan: Ted Dasher \& Assoc., 4117 Second Ave. S., Birmingham, AL 35222

Trahus CAD: Borgstrom Enterprises, Lid., P.O. Box 731, 810 W. Broadway, Vancouver, B.C. V52 4C9

VersaCAD: VersaCAD Corp., 2124 Main St., Huntington Beach, CA 92648

Visionael: Advanced Graphics Systems, 5150 E. Pacific Coast Highway, Suite 219, Long Beach, CA 90804

Analysis Tools

ANSYS: Swanson Analysis Systems, Inc., Johnson Rd., P.O. Box 65, Houston, PA $15342-0065$

A.Systems Contractor III, Bidworx, AIAdraw: B.A.T., 777 River Ave., Eugene, OR 97404

Beam Analysis: Heizer General Corp., 1941 Oak Park Blvd., Ste. 30, Pleasant Hill, CA 94523

Building Code Analyst: Architectronica, P.O. Box 787, 300 The Village \#109, Redondo Beach, CA 90277

CADLight 1: EnergyWorks, Inc., Wiley Professional Software, John Wiley \& Sons, 605 Third Avenue, N.Y., NY 10158

CALPAS 3 \& A: Berkeley Solar Group, P.O. Box 3289, Berkeley, CA 94703

Controlite 1.0: Lighting Systems Research, Building 90-3111, Lawrence Berkeley Laboratory, Berkeley, CA 94720

Dalite: National Institute of Standards and Technology, Building 226, Room A-313, Gaithersburg, MD 20899

Daylit: Graduate School of Architecture and Urban Planning, 405 Hilgard Ave., Los Angeles, CA 90024

Deneb Construction Accounting \& Estimating System: Deneb, 201 Riverside Drive, Suite 2C, Dayton, OH 45405

DOE 2.1D: Simulation Research Group, Building 90-3147, Lawrence Berkeley Laboratory, Berkeley, CA 94720

Ductlink: Software Systems Network, Carrier Corp., P.O. Box 4808, Syracuse, NY 13221

Engineering Software Company: Engineering Software Co., Search Plaza Suite 760, 10670 North Central Expressway, Dallas, TX 75231

Enercalc: Engineering Software, 3432 Via Opono, Suite 207, Newpor Beach, CA 92663

Heatloss: Yeoman Technical Software, 41 Wedgewood Drive, Jewett City, CT 06351

Homebuilder: Timberline Software Corp., 9405 SW Gemini, Beaverton, OR 97005

Idle: Facet, Lid., Marlborough House, Upper Marlborough Rd., SL Alban, Herts., AL1 3UT, UK

LARSA: Innovative Analysis Corp., 330 W. 42nd St., N.Y., NY 10036

Lumen II/III: Lighting Technologies, 3060 Walnut Street, Suite 209, Boulder, CO 80301

MacNail 2.2: Turte Creek Construction, 651 Halsey Valley Rd., Spencer, NY 14883

Microlite: Department of Architecture, Graduate School of Design, Harvard University, 48 Quincy Street, Cambridge, MA 02138

Plan-Trac, Open-trac, Plan-Trac-cm: Computerline, Inc., P.O. Box 308, 52 School Street, Pembrooke, MA 02359

Profit Builder, Proft Manager, Profit Bid Estimating, Basic Builder: Construction Data Control Inc., 3675 Crestwood Parkway, Ste. 400, Atlanta, GA 30136

Quicklite 1: Windows and Daylighting Group, Building 90-3111, Lawrence Berkeley Laboratory, Berkeley, CA 94720

Simplespan, Backspan: Arch Software, 1642 Pullan Ave., Cincinnati, OH 45223

SSD: Small Systems Design, 2540 Frontier Ave., Suite 104, Boulder, CO 80301

Sticks and Bricks: Industry Specific Software, Inc., P.O. Box 25249, Grenville, South Carolina 29616

Superlite: College of Architecture and Environmental Design, Arizona State University, Tempe, AZ 85287

UWLight: Department of Architecture, Gould Hall, JO-20, University of Washington, Seattle, WA 98105 
Wattsun: Washington State Energy Office, 809 Legion Way SE, FA-11, Olympla, WA $98504-1211$

Manufacturing

Anvil 5000pc: Manufacturing and Consulting Services, Inc., 6 Hughes, Irvine, CA $92718-1895$

Auto-Omni: Engineering Services Company, P.O. Box 696, Rochester, MN 55905

BorgCAD: (address not available)

CADAM: CADAM Inc., 1935 N. Buena Vista St., Burbank, CA 91504

Gang-Nail Systems: Gang-Nail, Inc., P.O. Box 59-2037 AMF, Miami, FL 33159-2037

ICT: Information Control Technologies, Inc., 1901 N. Beauregard St., Suite 104, Alexandria, VA 22311

MGM Station CAD/CAM: Micro CAD/CAM Systems, Inc., 5900 Sepulveda Blvd. \#340, Van Nuys, CA 91411

Shortcut: Heurtistics Intemational, 32 River Road, Cos Cob, CT 06807

Source, Layout: Clary Corp., 1801 S. Great Southwest Pkwy, Grand Prarie, TX 75051

The Plan: Ted Dasher \& Assoc., 4117 Second Ave. S., Birmingham, Al 35222

TrusStar, TrusStar2, Trakstar: On-Line Data, Inc., P.O. Box 2750, Richardson, TX 75080

Trus-Calc: Alpine Engineered Products, (address not avallable)

Integrnted Systems

CADAM: CADAM Inc., 1935 N. Buena Vista St., Burbank, CA 91504

ICG: Integrated Computer Graphics, Inc., One Buckhead Plaza, Suite 800, 3060 Peachtree Road, NW, Atlanta, GA 30305

Smart CAM 4.0/Anvil: Personal Workstations Inc., 1201 Western Ave., Suite 204, Seattle, WA 98101

Other Systems

BUG Voice Command System: Command Corp., Inc., 6045 Atlantic Blvd., Norcross, GA 30071 


\section{COST COMPARISON OF SWEDISH $\&$ U.S. HOUSING}


3. Cost analysis of afrordability of SFC house in Sweden compared to site built $U$, S, housing. J. Finrow

The comparison presented here is of comparative affordability of housing within the context of each country. This analysis does not speculate on what the cost might be of SFC housing if produced in the U.S. A detailed analysis of that subject has been carried out by Paul Kando in a publication entitled When the Best Cost Less, published by the Swedish Trado Council, Chicago.

Myresjo Hus is one of the largest SFC housing companies in Sweden. Houses are marketed by this company in the same way as other companies through sales offices in the major citles of Sweden. In addition, Myresjo Hus usually has one or two houses in each region that prospective customers can visit (demonstration houses). These houses will be used for a few months then sold. The following cost information comes from a visit to one of these houses in Vetlanda, Sweden. The sale price of SFC houses do not usually include the price of the lot. The house for which this financial information is presented is not necessarily the "average" SFC house, but a "typical" SFC house. Comparative date taken for the "average" U. S. house is taken from statistics presented in various issues of the publication titled Housing Economics, a publication of NAHB.

The SFC demonstration house price totaled excluding land costs was 884,000 SEK (Swedish Kronor). In addition to the cost of the house, a $12 \%$ value added tax is represented in this price. In the tax is removed, the cost for this house is 777,920 SEK. Given the exchange rate at the time of the visit (6.416 SEK per U.S. dollars) the cost is $\$ 121,247$ and the tax of about $\$ 16,000$. The size of the house was 117.4 square meters or a little over 1,250 square feet making the cost of the house about $\$ 97$ per square foot. The average U.S. site built house was valued at \$117,555 (without land prices or sales taxes included) forl,995 square feet of area or about $\$ 59$ per square foot. The difference in price per square foot is \$38 per square foot. Land prices in Sweden and the U.S. are comparable as a percentage of contruction costs, being between $10 \%$ to $15 \%$ of the cost of the house. Of course this varies with location, highly desireable housing sites in the major urban centers of both countries are extremely expensive and would clearly exceed these figures.

In addition to the cost of the housing unit and land costs, financing costs are a significant factor in overall housing affordability. Loans in Sweden tend to be at a higher interest rate and for longer ptriods of time than conventional U.S. housing practice. Conventional home morigages in Sweden at the time of the visit were $11.5 \%$ interest for 40 years while in the U. S. interest rates at that time were about $10.25 \%$ for 20 year 
fixed rate mortgages, In order to enhance affordability, the Swedish government "buys down" the interest rates on home loans in the first 5 years of the loan. In the case of the Myresjo Hus demonstration house the interest rate in the first year was $5 \%$ which then raises to the full market rate of $11.5 \%$ at the end of the 5 year buy down period. This represents a significant subsidization of housing costs.

The initial downpayment for the demonstration house was listed as 64,000 SEK or just a bit under $\$ 10,000$ which is about $7.2 \%$. In addition, the purchaser pays the lot cost which in this case was 72,169 SEK or $\$ 11,250$ (a very inexpensive site) which makes a total cash payment needed to quality for the loan of a little over $\$ 21,000$ which is $15.4 \%$ of the cost of the house and lot together. Deducting these costs from the total costs of the house and lot leaves a balance to be financed of 820,000 SEK or $\$ 127,825$. It is interesting to note that the VAT is also financed in the case of this house purchase case. In the first year, payments would be about 47,448 SEK which is $\$ 7,396$ per year or $\$ 616$ per month. In order to make a comparetive analysis with U. S. housing, the cost per 100 sq. fi. per month for the SFC house @ 5\% interest is $\$ 51.30$ per sq. ft. per month. If the SFC house was not subsidized by the government and the full $11.5 \%$ interest rate charged, the cost per 100 sq. fi. for the SFC house would be almost twice this rate or $\$ 97$ per 100 sq. ft. per month. The average site built house in the U.S. using the same percentage of downpayment and interest rates in effect at the time of the SFC comparator house (10.5\% @ 20yrs) would cost about $\$ 59$ or only about $60 \%$ of the cost of the SFC house at full interest rate maturity.

While stimulating home buying by offering the buy down, each SFC house sold represents a substantial public subsidy. The full cost of housing at the prevailing interest rate would be $\$ 1,245$ per month or a total yearly cost of $\$ 14,936$ or a cost to the government of $\$ 7,540$ per year for each house in the first year. It is interesting to note that the VAT pays almost 50\% of the first year subsidy, In addition, as in the U. S., interest paid on home mortgages is fully tax deductable, so that the remaining \$7.396 that the purchaser pays is completely written off their taxes, which at the current tax rates in Sweden, is a significant tax opportunity. Over the course of the 5 ycars of subsidy, the total interest subsidy paid for this particular SFC house is a little over $\$ 22,000$ in addition to the tax deduction.

An additional issue in housing economics are energy costs. Acconding to Kando energy costs for SFC housing can be as little as $\$ 200$ per year (Kando, 1989, p. 45). If we also take his data for the "worst case" comparative energy costs (Houston) for an average U. S. house of $\$ 792$ per year, we a substantial difference in energy costs of $\$ 592$ per year. SFC house energy costs per year in Sweden is only $25 \%$ of that for $\mathrm{U}$. S. house. This is impressive energy savings, but when factored into the overall cost of housing it 
represents a very small percentage of total monthly housing costs. Even for the "bought down" SFC house, the energy costs per month $(\$ 16)$ represent only $2.6 \%$ of the total monthly mortgage payment. For the U, S. house, energy costs are more expensive (\$66) but still represent only $5.6 \%$ of the total mortgage payment. The added savings, when viewed in relation to the total cost of housing, is not an especially significant factor in increasing the affordabillty of SFC housing.

In spite of this massive subsidization, the SFC house in Sweden is still almost twice as expensive as its U. S. counterpart. In addition to examining the costs of SFC housing we have to also study the relative purchasing power of potential housing consumers in Sweden and in the U.S. According to the November 4, 1989 issue of the British publication titled The Economicss (page 123) the purchasing power of the average Swede is only about $75 \%$ of that of the average American. While having among the highest standard of living in the world, Sweden is still not quite up to the purchasing power level of the U.S. according to statistics presented in The Economist. This means that the average Swede has 75\% less purchasing power with which to buy a house that is almost twices as expensive as the average house in the U. S.

Given this economic analysis, it is likely th $\mathrm{t}$ SFC housing in Sweden is being purchased by people with much higher incomes than the average Swede. Those who cannot afford to buy an SFC house, are most likely to puchase multi-family housing which costs much less than SFC housing. While the cost of SFC housing is quite expensive, there is currently a boom in SFC housing production. This boom can be partly explained in terms of the taxing system and the degree of government subsidization of the SFC industry. According to the Gullringshus plant manager, the VAT on housing is likely to be doubled in the next year or so, which means that consumers are placing orders now to be well ahead of the possible increase in tax on housing in the next year or so. Given this example, this would add an additional $\$ 16,000$ to the cost of the house. Housing subsidies may also be cut back in light of general changes in the attitude of the Swedish government to subsidization. If both of these factors happen, then the cost of this SFC house would increase to $\$ 150,370$ or a financed amount of $\$ 128,416$ for an increase of over 8\%. Without interest subsidization coupled with the increased tax would make the toul cost per 100 sq. ft. per month for an SFC house of almost $\$ 107$ or about twice as expensive as it currently is in the first year of the mortgage. Such a substantial increase in the cost of housing would probably have a very serious effoct on SFC housing production. The same plant manager cited above responded to a question about this issue by saying that while he has no houses "in the stocking warehouse" this year, next year he is likley to have a warehouse full of houses. 
BASIC SFC HOUSE COST INFORMATION

Total House cost

Value Added Tax (12\%)

House cost

Typical Lot Cost

House size

Required down payment

Total Client payments

Percentage client payment

Cost per unit measure

with land cost

without land cost
884,000 SEK

106,800 SEK

777,920 SEK

72,169 SEK

117.4 sq. meters

64,000 SEK

136,169 SEK

$15.4 \%$

7,241 SEK/sq. meter

6,626 SEK/sq. meter
$\$ 137,802$

$\$ 16,536$

$\$ 121,265$

$\$ 11,250$

1,263 sq. ft.

$\$ 9,977$

$\$ 21,227$

$15.4 \%$

$\$ 105$ per sq. ft.

$\$ 96$ per sq. ft.

\section{BASIC AVERAGE U.S. HOUSING COST INFORMATION}

Total House cost

Lot $\operatorname{cost}(15 \%)$

Average house size

House cost

Down payment

Cost per unit measure with land cost

without land cost
$\$ 138,300$

$\$ 20,745$

1,995 sq. ft.

$\$ 117,555$

$\$ 18,103$

$15.4 \%$

$\$ 69$ per sq. ft.

$\$ 59$ per sq. $f$ 


\section{CONTACTS}

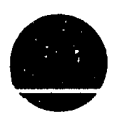


INDUSTRY CONTACTS

CONPANY
production
panelized
modular
HUD code
component

HUD code

Visit

\begin{tabular}{|c|c|c|c|}
\hline $\begin{array}{l}\text { NAHB Annual Meeting } \\
\text { Atlanta, GA }\end{array}$ & PK & v & $1 / 19 / 89$ \\
\hline $\begin{array}{l}\text { Ryland Homes Northeast Division } \\
\text { (pan) } \\
\text { Columbia, MD }\end{array}$ & $\begin{array}{l}\text { PF, LM, BS, } \\
\text { JR, CK, MG }\end{array}$ & v & 2/2/89 \\
\hline $\begin{array}{l}\text { Acorn Structures (pan) } \\
\text { Acton, MA }\end{array}$ & SC, PF, BS & $v$ & $3 / 2 / 89$ \\
\hline $\begin{array}{l}\text { MOD-U-KRAF Homes, Inc. (mod) } \\
\text { Rocky Mount, VA }\end{array}$ & $J R, B S, A E$ & v & $3 / 2 / 89$ \\
\hline $\begin{array}{l}\text { Titan Manufacturing Company } \\
\text { (pan) } \\
\text { Kissimniee, FL }\end{array}$ & $L M, J R$ & v & 3/2/89 \\
\hline $\begin{array}{l}\text { Ryan Homes (pan) } \\
\text { Plant City, FL }\end{array}$ & $\begin{array}{l}\text { SC, JR, LM, } \\
\text { BS, TB }\end{array}$ & v & $3 / 24 / 89$ \\
\hline $\begin{array}{l}\text { Fleetwood Enterprises, Inc. } \\
\text { (HUD) } \\
\text { Haines City, FL }\end{array}$ & $\begin{array}{l}S C, J R, B S \\
L M, T B\end{array}$ & v & $3 / 25 / 89$ \\
\hline $\begin{array}{l}\text { Lindal Cedar Homes (comp) } \\
\text { Dave Reed } \\
\text { Sacramento, CA }\end{array}$ & GZB, JR, RK & 1 & 6/_/89 \\
\hline $\begin{array}{l}\text { Key-Loc Homes (mod) } \\
\text { Suncook, NH }\end{array}$ & QM & v & $4 / 17 / 89$ \\
\hline $\begin{array}{l}\text { Acorn Structures (pan) } \\
\text { Concord, MA }\end{array}$ & BM & v & $4 / 18 / 89$ \\
\hline $\begin{array}{l}\text { Advanced Buiding Systems (pan) } \\
\text { Bennington, VT }\end{array}$ & BM & $\mathbf{v}$ & 4/19/89 \\
\hline $\begin{array}{l}\text { Gode Industries (pan) } \\
\text { Chuck Gode } \\
\text { Eugene, OR }\end{array}$ & $\begin{array}{l}\text { GZB, JF, RK } \\
B M, R B\end{array}$ & 1 & $4 / 20 / 89$ \\
\hline $\begin{array}{l}\text { Cardinal Homes (mod) } \\
\text { Williesburg, VA }\end{array}$ & JR, BS, AE & v & 4/31/89 \\
\hline $\begin{array}{l}\text { Nationwide Homes (mod) } \\
\text { Martinsville, VA }\end{array}$ & JR, BS, AE & v. & $5 / 1 / 89$ \\
\hline '89 Repor/Vol 2 Dist & & & \\
\hline
\end{tabular}


National Building Systems (pan) Collinsville, VA

American Standard Building

Systems (pan)

Martinsville, VA

Automated Builder magazine

Don Carison, Editor

Carpinteria, CA

DesCon '89 AVE/C Systems

Conference

Anaheim, CA

Fleetwood Enterprises Housing

Group (HUD)

Riverside, CA

Good Neighbor Care Centers

(mod)

Daniel Desler

Springfield, OR

Western Insulfoam (comp)

k'ent, WA

Modular Housing Symposium

Penn State

Ryland Modular Homes (mod)

Now Windsor, MD

Ryland Building Systems (pan)

Columbia, MD

Ryan Homes (pan)

Thurmont, MD

New Era Modular Home \& Design

Center (mod)

John Schuman

Westport, MA

Blazer Industrles (mod)

Silverton, OR

Bohemia Lumber (comp)

Goshen, OR

Blazer Industries (mod)

Chuck Hill

Silverton, OR
$J R, B S, A E \quad V$

$5 / 1 / 89$

$J R, B S, A E$

V

$5 / 1 / 89$

MM

V

$5 / 2 / 89$

GZB, MM, TS

V

$5 / 5 / 89$

GZB, MM, TS V

$5 / 5 / 89$

RB

V

$5 / 16 / 89$

GZB, MM, RB V

$5 / 23 / 89$

RB

V

$5 / 25 / 89$

$\mathbf{R B}$

V

$5 / 27 / 89$

FB

$5 / 27 / 89$

RB

$5 / 28 / 89$

RB

$5 / 30 / 89$

$R B, B M$

V

$6 / 1 / 89$
GZB, JF,DC V

$R K, B M, R B$

GZB, JF, RK I 
American Transpacific

Housing (pan)

Dr. Matthew Gruber

Salem, OR

Meadowood Industries (comp)

Leonard Opal

Albany, OR

Profile Building Systems (comp)

Chris Scott

La Jolla, CA

Street of Dreams Home Show

Portland, OR

AFM Corporation (pan)

Michael W. Tobin, Exec. Dir.

Excelsior, MN

Insul-Tray, Ine. (comp)

Edward W. Story, Pres.

Redmond, WA

Rick Henson, builder (pan)

Rick Henson,

Eugene, OR

Berichmark Homes, Inc. (mod)

George Kirby, Pres.

Brookville, OH

All American Homes, Inc. (mod)

Mike --

Decatur, IN

Unibilt Industries, Inc. (mod)

Vandalia, $\mathrm{OH}$

Pease Company, Inc. (comp)

Hamilton, $\mathrm{OH}$

Mansion Industries, Inc. (pan)

Robert B. Glassco, Pres.

Industry, CA

Barrier Systems (comp)

Bill Brod, Sales Manager

Canastota, NY

Electropane (comp)

Joseph Pastore, Pres.

Capitola, CA
GZB, RK, BM, I

$R B$

GZB, RB

V

$7 / 17 / 89$

$R B$

W, P

$7 / 25 / 89$

RB

V

$8 / 15 / 89$

$P B$

I, W

$8 / 17 / 89$

GTB

W, P

8/22/89

RB

1

8/23/89

$L M, S C$

V

$9 / 13 / 89$

LM

v

$9 / 13 / 89$

LM,SC

V

$9 / 14 / 89$

LM, SC

V

$9 / 15 / 89$

GZB, RB

$W, P$

$9 / 19 / 89$

FB

P

9/21/89

PB

$W, P$

$10 / 14 / 89$ 
Palm Harbor Homes (HUD)

SC

V

Plant City, FL

\section{DENMARK}

Architectural Museum and Bookstore

Copenhagen

Hosby Hus a/s

Juelsminde

Roslev Hus

Skive

Ebbeltoft Recreational Housing

Community

Aarhus

Energy Efflcient Co-Housing Project

Fredrica

Byg and Bo Housing Exhibltion Site Odense

Tinggarden Housing Project

Koge

Holmebaek Housing Project

Herfloge

Sun, Wind and Light Co-Housing

JF

$8 / 26 / 89$

JF

V

$8 / 26 / 89$

JF

$\mathbf{P}$

$8 / 27 / 89$

JF

V

$8 / 28 / 89$

Project

Koge

Tastrup Hol Development Area

West of Copenhagen

JF

V

$8 / 28 / 89$

JF

v

$8 / 29 / 89$

JF

v

$8 / 29 / 89$

JF

v

$8 / 29 / 89$

JF

$8 / 29 / 89$

JF

$8 / 29 / 89$

\section{JAPAN}

Kyoto University

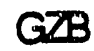

V

$8 / 15 / 89$

Kyoto

Waseda Universlty

GXB

V

8/16/89

Tokyo

Misawa Homes Co. Ltd

GAB

V

$8 / 28 / 89$

(pan)

Tokyo

Federation of Home Contractors

Tokyo

Issiki Architects

GAB

I

$8 / 7 / 89$

GZBB

I

8/17/89

Tokyo

Bullding Center of Japan

$G \mathbb{Z B}$

V

8/17/89

Tokyo 
Mitsui Home (com)

Tokyo

Sekisul Heim

(mod)

Tokyo

Meiji University

Tokyo

Sekisul House

Tokyo

Sekisui House

(pan)

Oskaba

Bullding Research Center Tsukuba City
GZB

$G \bar{B}$

$G \bar{B}$

GZB

GXB

G]B v

V

v

v

V

v
$8 / 18 / 89$

$8 / 29 / 89$

$8 / 31 / 89$

$9 / 1 / 89$

9/4/89

$9 / 7 / 89$

I

I

I

O

1

'89 ReportVol 2 Disk

$4-5$ 
5. LIBRARY 


\section{LIBRARY M. Fincher}

Library support for the Energy Efficient Industrialized Housing research program is provided by a half-time librarian from the University of Oregon Architecture and Allied Ars Library. She is responsible for collection evaluation, selection of materials, online database searching, reference assistance, processing of materials being accessed directly into the Energy Efficient Industrialized Housing collection, and management of all materials housed in the EEIH Project Room. The Acquisitions and Catalog Departments of the University of Oregon Library provide ordering, cataloging, and processing services for EEIH materials which are being cataloged for the Architecture and Allied Arts Library.

Items acquired for the EEIH collection include 13 serial titles, 150 journal articles, and 255 books, government documents, and technical reports in such areas as building components, energy codes, energy-efficient design and construction, housing, indoor air quality, mechanical systems, and U.S. and foreign construction technology. Out-of-print tilles have been borrowed through the inter-library loan system, as have artiries from journals not owned by the University of Oregon Library. Photographic slides documenting industrialized housing production and sites are being cataloged and stored under archivally approved conditions. There is also a collection of product literature and samples.

Information on all materials in the EEIH collection is entered into a Hypercard reference management system used with a Macintosh SE computer. Séparate stacks have been created for: 1) slides; 2) product samples; 3) relevant titles from the UO library collection acquired prior to the EEIH project, and 4) print materials acquired and purchased with EEIH funds. 


\section{INDUSTRIALIZED HOUSING MANUFACTURING SYSTEMS ANALYSIS -- Fleetwood}


University of Central Florida

Department of Industrial Engineering

and Management Systems

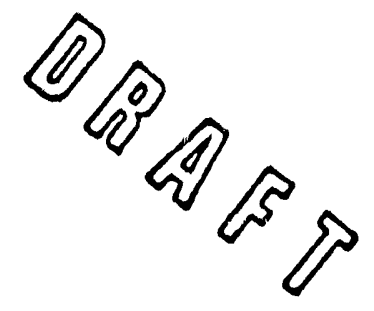

INDUSTRIAIIZED HOUSDNG MANUFACTURDNG SYSTEMS ANALYSTS

\author{
for \\ FLEETWOOD MOBILE HOME MANUFACTURERS \\ Haines City, Florida
}

Final Repor

Florida Solar Energy Center

$\log _{\diamond}$

Cape Canaveral, Florida

September 20, 1989 


\section{TABLES OF CONTENTS}

Page

EXECUTIVE SUMMARY

INTRODUCTION

\section{CHAPTER}

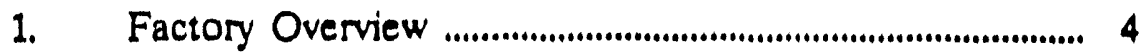

2. Warehouse Analysis .......................................................... 15

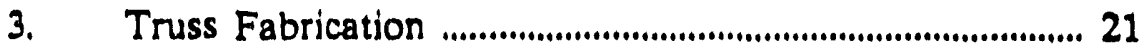

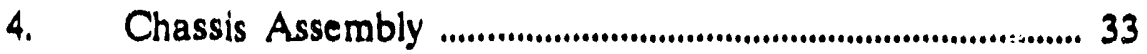

5. Flnor Assembly ........................................................................ 43

6. Exterior Wall Assembly ..................................................... 57

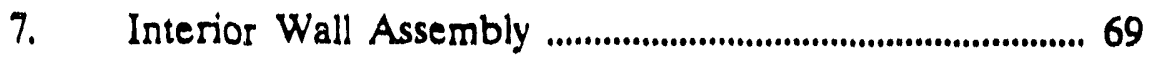

8. Interior/Exterior Wall Installation ...................................... 81

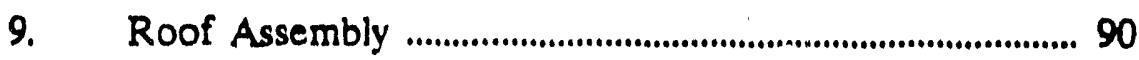

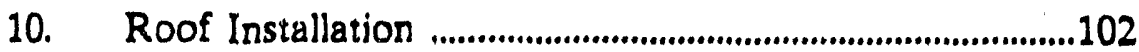

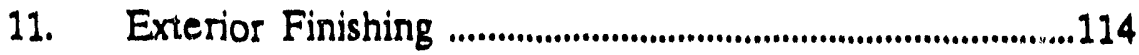

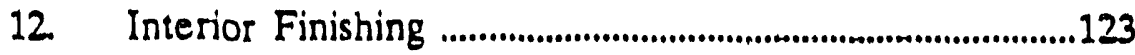

13. Inspection ................................................................................ 137

14. Other Potential Improvements ...........................................139

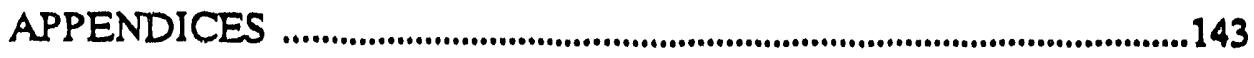
A Equipments List
B. Manufacturers List 


\section{EXECUTTVE SUMMMARY}

\section{INTRODUCIION}

This report is the first of a series which ultimately will provide a scenario depicting how energy efficient, affordable housing will be designed, fabricated, and erected in the 21 st century.

This study was conducted in order to gather baseline data for the development of a generic industry manufacturing model. This model will serve to develop a comprehensive industry manufacturing strategy that will anticipate future problems and bottlenecks, and define methods, procedures, and technologies most suitable for their resolution. Included in these strategies will be guidelines dictating if, when, and under what conditions various type of computerization, automation, and robotization will be candidates for implementation.

This report provides a description and documentation of current processes and facilities used by a "typical" industrialized housing manufacturers. Such manufacturers can be categorized as panelizers, modular, or mobile home builders. The latter category embodies processes common to all. Hence, the Haines City, Florida facility of Fleetwood Industries was selected as representative of industrialized housing manufacturers from a process and facilities point of view.

\section{FACTORY OVERVIEW}

Fleetwood produces single and double wide mobile homes at the Haines City facility. These homes are typically complete with wiring plumbing and all interior finishing iterns installed. Double wide homes are built as two separate modules, whereas singles are just one module. These modules typically range in size according to the 
following specifications:
1) Length: $32 \mathrm{ft} \cdot 60 \mathrm{ft}$
2) Width: $24 \mathrm{ft} .28 \mathrm{ft}$ (double wide)
$12 \mathrm{ft} \cdot 14 \mathrm{fth}$ (single)
3) Area: 752 sq. ft. 1500 sq. ft.

Each module is produced entirely within the factory environment through a number of cutting, fabrication, and assembly processes performed at various workstations.

Each workstation is described in detail in subsequent chapters. A general overview of the factory is presented at this point.

The factory is approximately 60,000 square feet not including office space with 65 percent of that being production space and the rest storage and transport space. To understand the plant's operations and how they are interrelated to one another, a brief overview is provided. The fabrication of the chassis is the first operation. The finished chassis is then moved to the first station of the main production line where the floor system is assembled. The floor assembly is moved to the next station where interior and exterior walls, bath and kitchen counters are installed. The wall systems have been brought from the assembly workstations located on either side of the installation workstation. The walls are manufactured at these stations. The house assembly is moved to the next workstation where the roof system is installed. The roof system has been produced at the roof assembly workstation adjacent to the installation station. The trusses have been fabricated at a workstation located outside of the main plant and then transported to the assembly station. Once the roof has been fastened to the home the decking and covering is attached and the assembly is moved to the next workstation where 
all exterior finishing such as the installing of siding, soffits, doors, windows, etc, are performed. These materials were supplied from a storage area located outside of the plant. The assembly is next moved to the interior finishing workstation where appliances, interior trim and finishing, lighting, etc. are installed. The appliances are transported,to the assembly from a storage area located adjacent to the finishing workstation. After " completion of the module assembly, a final test and inspection is performed. A detailed operations/activity chart, factory layout, and process flow chart are included with this as well as subsequent chapters.

\section{WAREHOUSE ANALYSIS}

Fleetwood Plant at Haines City currently has two warehouses located next to the main production building. The main warehouse contains most of the different panels, such as wall panels, floor and roof decks, and reiling boards. Other materials stored in this warehouse are the studs used for making trusses, floor and walls frames. Most of these materials, before taken to the production line, must first go to a cutting station. For this reason they are transported on pallets using a forklift.

The secondary warehouse contains all other materials that can be moved directly into the production line, such as finished trusses, doors, insulation material, screws, bolts, and carpets. Such materials are also transported to the production line using forklift trucks.

In addition, there are some outside storage areas for other materials such as uncut beams, wheels, bath tubs, windows, glass doors, and kitchen appliances.

There are four forklift trucks operating around the facility. Each truck has specific service areas, such as tloor/top assembly area, sheet metal, plumbing, and cabinets area. 
Purchase orders are placed on a weekly, biweekly or monthly basis, depending on the usage of the material. Most of their suppliers are located in the central Florida area. Orders can take from one to three days for delivery.

\section{TRUSS FABRICATION WORKSTATION}

The truss assembly area is located outside of the main plant. Truss production supplies the Haines City plant as well as other facilities in Lakeland and Plant City, both located also in Florida.

Raw materials ( $2 \mathrm{ft} \times 6 \mathrm{ft}$ studs) are stored in a warehouse on pallets. They are moved to the first cutting workstation using a forklift truck and placed in carts. At this cutting station studs are reduced to $2 \mathrm{ft} \times 2 \mathrm{ft}$ pieces. Pieces are then moved to both angular and small cut workstations.

Cut studs are then moved to the assembly station, where pieces of different sizes and shapes sre stored on top of the working area. Pieces are laid out and assembled using standard jigs, fixtures and a truss machine. Good pieces are selected for assembly and defective pieces are sent back to the small cut off station.

The following operations are performed at the assembly station:

- Place bottom plates.

- Layout truss configuration on top of the plates in fixtures.

- Place clips on top of truss members.

- Insert assembly into press.

- Activate press machine for final fabrication.

- Remove finished truss and place it in a cart. 
There are two truss assembly stations operating simultaneously. Finished trusses are stored in the secondary warehouse. Finished trusses can be shipped to other plants or move to the roof assembly workstation. Time to assemble one truss is 1 minute.

Seven workers man this station. Raw material is brought to the station on Forklifts. Between operations, material is stored and moved on roller carts. Finished products are placed on pallets and eventually moved to the secondary warehouse. Visual inspection detects defective studs which are sent to be cut into smaller pieces.

The report contains suggestions for improving layout, labor utilization, process, and materials handling.

\section{CHASSIS ASSEMBLY WORKSTATION}

Raw materials such as beams, wheel axles and wheels. are stocked outside the plant.

Beams are placed on a chain driven conveyor, and then on a roller convejor that transports them into the cutting station. Here beams are cut to length using an arm saw, and the residual part is welded to the next beam on the conveyor.

Cut beams are moved to the Chassis Frame Assembly workstation using a hoist. There the chassis frame is assembled by arc-welding. Welding machines are set up on an overhead rail for moving purposes in the assembly area.

The chassis frame is then moved to the final assembly area where the wheel axles and the hitch assembly are welded to the chassis support frame. Wheels are then attached to the axles.

The finished chassis is then taken out of the plant to the paint workstation using

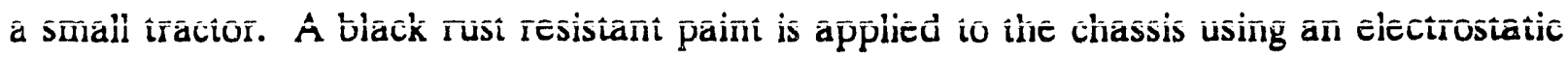


paint system. The chassis is then moved to a drying area. After drying, it is brought to the front of the production line. Time to produce one chassis is 45 minutes.

Six workers man this station. Raw material is brought to the station on Forklifts, a conveyor brings the beams to the cutting and welding area from where subassemblies are moved by crane. A tractor transports the finished chassis to the next workstation. No apparent formal inspection procedures take place at this station.

The report contains suggestion for improving the layout, labor usage, process, and material handling.

\section{FLOOR ASSEMBLY WORKSTATION}

The chassis is brought from drying area to the beginning of the production line. The chassis is placed on a rail system, which is driven by a chain-pulled conveyor. The cutting station is located behind the assembly area and plumbing materials are brought from an adjacent workstation.

The following operations are performed at this workstation:

- Cover chassis with plastic tarp. This serves as the bottom of the house. This is done to prevent dust from getting into the house at construction site.

- Apply insulation (R-7 fiberglass).

o Start electrical and plumbing conduits work.

- Assemble floor frame using pneumatic nailers. Plywood decking is brought to the floor assembly workstation from a cutting station, which is located behind the workstation.

- Electrical conduits are attached to the frame with tie wraps. 
- Screw frame to Chassis.

The chassis is then pushed to the deck assembly area where the following operations are performed:

o Finish electrical wiring and plumbing conduits.

- Apply glue to frame. A glue hose is attached to the top of this workstation where it can be moved through the work area.

- Lay sections of decking onto glue-coated frame and assemble using pneumatic nailers. Normal deck panel size is 4'x $8^{\prime}$.

Floor opening operations then take place at the next workstation where the following tasks are performed:

- Cut holes for toilets, electrical, and plumbing conduits. PVC connections are assembled in a workstation located to the right of the floor openings workstation.

- Reinspection, additional nails are used where needed and screws for floor support.

The following operations are performed at the next work area:

- Seal seams between boards (mud filler).

- Sand floor deck.

- Remove dust

- Place a foam padding onto deck for carpeting.

- Install carpet or vinyl.

- Cut off any excess carpet or vinyl.

- Cover carpet with plastic.

It takes 45 minutes to prepare one floor. 
A total of nine workers are active in this workstation. Material handling includes a tractor for the chassis, a chain driven floor conveyor system for the floor assembly, and a small conveyor system to transport studs. Inspection for leaks in plumbing conducts and missing nails in the floor deck is performed.

The report contains suggestions for improving the layout, process, labor utilization and material handling procedures.

\section{EXTERIOR WALL ASSEMBLY WORKSTATION}

Wall paneling and framing studs are cut to size in an area located behind the framing tables.

The following operations are performed at this workstation:

- Assemble wall frame, no jigs/fixtures are used.

- Install insulation ( $\mathrm{R}-11$ fiberglass).

- Apply glue to frame.

- Attach inside wall panel to frame using pneumatic nailers.

- Cut holes for windows and doors, electrical outlets and light switches.

- Move finished exterior wall to temporary staging rack.

$0 \quad$ Move exterior wall to production line with an overhead hoist.

Time to complete an exterior wall assembly is 50 minutes.

Five workers are employed at this workstation. Raw materials are brought to the station via Forklifts. Completed walls are taken to the installation area using overhead cranes. No formal inspection procedures appear to exist at this station.

The report contains suggestions for improving the process, labor usage, and 
materials handling. It also contains a more detailed description of the workstation for plumbing assembly.

\section{INTERIOR WALL ASSEMBLY WORKSTATION}

Two additional cutting stations, one for frame studs and one for paneling, are located behind and adjacent respectively, to the assembly tables.

The frame assembly consists of the following operations:

- Assemble wall frame with pneumatic nailers.

- Holes are drilled for electrical wiring.

- Install electrical wiring.

Finished frames are then placed in staging racks where they wait to be moved to the wall panel installation table adjacent to the framing table. The following operations are performed:

- Apply glue to frame.

- Install gypsum paneling. Adjustments are manually performed with tapes.

- Cut holes for elecirical boxes, and openings for doors.

Finished interior walls are then manually transported to another staging rack before it is taken to the production line with the hoist.

It takes 8 minutes to produce an interior wall.

Five workers are employed at this workstation. All material handling within the station is manual. Raw materials are brought by Forklift and the finished wall is transported to the assembly area by overhead crane. 
The report contains recommendations to improve layout, labor utilization, process, and materials handling.

\section{INTERIOR/EXTERIOR WALL INSTALLATION AREA}

Interior/Exterior walls are moved from both wall assembly workstations using an overhead hoist. A weather strip is first installed between the wall and the floor deck.

The wall is held up until it is screwed and nailed to the floor deck. When connecting walls forming a corner, a support clamp is used to hold the walls together while they are being nailed/screwed together, after which the clamp is removed.

The electrical wires are installed into exterior walls, a metal plate is used to support cables to exterior wall studs. Kitchen cabinets are also installed at this workstation.

It takes 45 minutes to install the walls.

There are a total of eight workers at this station. Interior and exterior walls are brought by an overhead hoist system. All other materials are moved manually. Inspection is performed to assure that walls are securely fastened.

The report contains recommendations to improve labor utilization, process, and materials handling.

\section{ROOF ASSEMBLY WORKSTATION}

Panels are brought to this workstation from the warehouse using forklift trucks. They are stored in the workstation and manually placed on a mobile pallet.

Panels are stacked on this mobile pallet which traverses the length of the table. The ceiling of the roof system consists of 4'x12' sheetrock panels (gypsum boards) which are laid out face down on the worktable adjacent to one another. Seams between panels 
are taped and trusses are set onto ceiling panels.

A front perimeter frame is laid along the edge of the ceiling and nailed to the end of the truss. The frame is made of 1'x $2^{\prime}$ boards and is attached to the truss with pneumatics. A similar operation is used for the rear perimeter frame which is laid along back edge of the ceiling and nailed to the large end of the trusses. These frames are made on a worktable adjacent to the assembly deck.

Polystyrene foam is sprayed in to connect trusses to paneling. The foam is very strong and provides a level ceiling surface. 2'x 4' studs are installed for support to the roof truss. Ventilation ducts are also installed at this workstation. From this workstation, the roof is lifted with a 4-ton hoist system and transported to the adjacent finishing workstation.

The following operations are performed at this station:

o Seams between wallboards are taped.

- Wallboards are finished with a drywall mud which is applied twice.

- Holes are cut for vents, lighting, etc. A pneumatic jig saw is used for this purpose.

The roof is then transported to the popcorn spray workstation where the popcorn finish is sprayed onto the ceiling. A popcorn mixer is located outside the plant. Vents are installed at this workstation. After the roof is finished it is moved to the production line using a hoist.

There are a total of eight workers in this station. Trusses and ceiling panels are brought to the station with Forklifts. Assembled roof panels are transported by overhead hoist through the rest of the operations. 
The report contains recommendations to improve the labor utilization and the process.

\section{ROOF INSTALLATION AREA}

The assembled roof truss is transported by a chain hoist to the production line and lowered onto the shell. Before it is secured, a weather strip is laid around the perimeter for insulation purposes. The roof is then fastened to the upper wall studs. Additional studs are screwed to the roof borders where fascia is later installed. A metal plate is then used to reinforce the roof system to the exterior walls.

A dry rock wool insulation material is applied by using a high pressure blower. The roof deck is laid and fastened to truss assembly. The paneling used for the roof deck is composed of randomly oriented compressed wood particle board. These panels are stored in containers located overhead mounted on a track which extends throughout the work area. Decking is attached using pneumatic nailers. Metal clips are used to hold them together. Measurements are made using a ruler to mark where cuts are to be made on the roof. These cuts are made by a powered hand saw. Then fascia is installed.

After installing the roof deck, a layer of black sealant is applied over the edges of the roof. A waterproof cover made of tar paper is rolled over the roof. Adjustments and alignments are performed manually. Excess material around the edges is cut with a knife. The waterproof cover is then stapled to the roof top. Shingles are then placed on top of this cover and stapled.

Time to install one roof is 45 minutes.

Eleven workers are employed at this station. The roof truss is brought to the line using the hoist system and lowered onto the walls. Roof decking is stored in 
compartments above the station and is manually brought down and placed onto the roof. Shingles, tar paper, fascia are also stored above and are manually retrieved for use. Inspection is performed to ensure that the roof is properly assembled.

The report contains recommendations to improve the process and materials handling.

\section{EXTERIOR FINISHING AREA}

Outside insulation is installed on exterior walls and sidings. This includes the installation of Extruded Polystyrene Insulation boards which are stapled to the exterior wall frame. The exterior siding is attached and stapled to the exterior wall insulation board. Sidings are hand cut to fit smaller spaces, such as between windows and doors.

Window and door frames are installed in exterior walls. A weather strip is also used to provide additional insulation. Windows and doors are then installed in a clam shell fashion.

Once siding, windows, and doors are installed, the exterior electrical wiring is connected, such as lights, switches, and electrical boxes. A plastic cover is used to protect the open side of the trailer.

It takes 45 minutes to do the exterior finishing on one assembly. Twelve workers are employed at this station. All materials are moved manually. One inspector is used to assure quality.

The report contains recommendations to improve the material handling system.

\section{INTERIOR INSTALLATION/FINISHING AREA}

Interior installations consist of the following operations:

- Bathroom and kitchen counters installation. 
- Living room cabinets.

- Bedroom closets.

Gypsum boards (also called dry wall panels) are cut to size for interior wall panels, then moved to the production line where they are stapled to the wall frame. Electrical wiring is installed inside the house which includes electrical switches. Sealing of walls and cabinets is performed before the house is cleaned and moved to the inspection area. A crown mold is installed to cover edges or seams between walls and roof. Also curtains/mini-blinds may be installed in this workstation. Kitchen appliances and interior lightings are also installed.

There is a final inspection, usually visual, performed by a supervisor of the finished operations. Inspection may include electrical testing for switches, connections, lighting, etc. It takes 45 minutes to do the interior installation and finishing.

Nineteen employees are employed at this workstation. Material handling takes places manually with the assistance of hand carts. At this station, a final inspection is performed to ensure that components are securely assembled and installed, and house is checked for any missing or out of specification elements. Electrical testing is performed to ensure that all lighting, plumbing, and appliances are working properly.

\section{OTHER POTENTIAL MMPROVEMENT OPPORTUNITIES}

This section elaborates on suggestions to centralize cutting, reduce inventory, improve the material handling systems, and to provide more inspection. 


\section{RNTRODUCTION}

This report provides a comprehensive review of the processes that take place with a "typical" Industrialized housing manufacturer. It is the first of a series which ultimately will provide a scenario depicting how energy efficient, affordable housing will be designed, fabricated, and erected in the 21 st century.

The scenario will assume that affordability and housing manufacturer costeffectiveness are directly related. It also assumes that, as competitive pressures increase, there will be an industry "shake out". This "shake out" will restructure the housing industry from one where a high percentage of the market share is held by a large number of relatively small competitors to one where that same share of the market will be held by a small number of competitors. This fhenomenon, already experienced by other industries such as food, will see the efficient, well capitalized, and marketing oriented firms acquire or simply drive the others out of the business. Of course, there will always be room for the regional, specially oriented manufacturer.

As successful companies grow, they will experience increasing pressure on their manufacturing facilities. These pressures will arise out of the need to increase production rates as well as out of the increasing need to enhance quality while being able to satisfy a great range of customer demands. To successfully overcome the challenges posed by these pressures, companies will have to develop comprehensive manufacturing strategies which will anticipate future problems and bottlenecks, and define the methods, procedures, and technologies most suitable to their resolution. Included in these strategies will be guidelines dictating if, when, and under what conditions various types of computerization, automation, and robotization will be candidates for implementation. 
This report documents a "typical" industrialized housing manufacturer for the purpose of providing base line data that can be used to develop a generic simulation model. Such a model will be the basis for detecting and classifying manufacturing bottlenecks and evaluating potential resolutions. The combined results of these studies will constitute the foundation for determining a manufacturing strategy for the industrialized housing industry.

\section{Selecting a Manufacturer}

Fleetwood Homes Industries, the nation's largest manufacturer of mobile homes, has a plant in Haines City, Florida, which is within reasonable access from the University of Central Florida. This company is represented on the advisory board of this research project and has been supportive in this research. Their headquarters office in Riverdale, California collaborated closely with another phase of this project conducted by the University of Oregon. These factors contributed to the selection of the Fleetwood Haines City, Florida plant as the "typical" manufacturer. However, the primary reason for the selection was that the processes that take place in the manufacture of mobile homes have a great deal in common with processes that take place' in both modular and panelized manufacturers. For example, the processes involved in the manufacture of wall systems at Fleetwood include the cutting of all raw materials to be used in the system, building of wall framing, and attaching the wall board to the framing. A similar process would be observed if a panelized or modular plant were being investigated. Fleetwood's roof system consists of the cutting of all roofing materials, building roof trusses and attaching them to ceiling material, spraying a finish on the csiling, and irstalling roof decking. Modular manufacturers build each component of the roof system precisely in the same 
manner. Fleetwood produces complete floor systems as well. This process includes the cutting of all raw materials to be used, assembling the steel chassis and floor framing, and installing the floor decking. Again the processes involved in the manufacture of this system are similar to those employed by other manufacturers.

The mobile home that Fleetwood manufactures can be viewed as a combination of modular and panelized housing types. All of the structural components are assembled within the factory environment. The process of prefabrication of the components is almost identical to the way in which panelized builders produce them. In addition, Fleetwood connects the three systems as well as all finishing components in the factory just as modular manufacturers do.

In spite of the above, certain differences must be acknowledged. Fleetwood does not generally mud and cure the interior walls of their units, a process which appears to create bottlenecks in certain modular home builders processes. The low roof pitches used in Fleetwood's units manufactured in Haines City, Florida ideal for hot and humid climates of the deep south. Manufacturers producing higher pitched roofs must include in their designs and processes manners in which to hinge and fold the roof during transportation. The impact of these, as well as some other differences between the various segments of the industrialized housing industry will be more fully evaluated during the generalization phase of the study where the findings at Fleetwood are welded into an industry process model. 


\section{FACTORY OVERVIEW}

Fleetwood produces single and double wide mobile homes at the Haines City facilit, These homes are typically complete with wiring, plumbing and all interior finishing items installed. Double wide homes are built as two separate modules (units), whereas single wide are just one module. These modules typically range in size according to the following specifications:

1) Length: $32 \mathrm{ft} .60 \mathrm{ft}$.

2) Width: $24 \mathrm{ft}-28 \mathrm{ft}$. (double wide)

$12 \mathrm{ft} \cdot 14 \mathrm{ft}$. (single)

3) Area: 752 sq. ft. 1500 sq. ft.

Each module is produced entirely within the factory environment through a number of cutting, fabrication, and assembly processes performed at various workstations. Each workstation is described in detail in subsequent chapters. Production runs are typically made in batches. That is, one day they will produce only double wide homes; another day only single wide somes will be produced. The batch types are determined by the specific production orders for that day. The production line typically contains an average of twelve modules 8 any one time. The daily production t: oughput averages about ten. It should be noted that this number can vary depending on the module size. Modules are transported from station to station lengthwise rather than the conventional widthwise orientation. The line is powered by a chain driven floor conveyor. A general

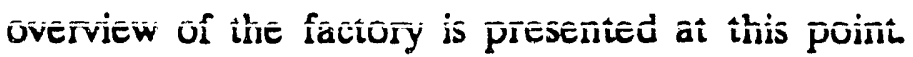


The factory is approximately 60,000 square feet not including office space with 65 percent of that being production space and the rest storage and transport space. To understand the plant's operations and how they are interrelated to one another, a brief overview is provided. The fabrication of the chassis is the first operation. The finished chassis is then moved to the first station of the main production line where the floor system is assembled. The floor assembly is moved to the next station where interior and exterior walls, bath and kitchen cabinets are installed. The wall systems have been brought from the assembiy workstations located on either side of the installation workstation. The walls are manufactured at these stations. The house assembly is moved to the next workstation where the roof system is installed. The roof system has been produced at the roof assembly workstation adjacent to the installation station. The tri:ses have been fabricated at a workstation located outside of the main plant and then transported to the assembly station. Once the roof has been fastened to the home the decking and covering is attached and the assembly is moved to the next workstation where all exterior finishing such as the installing of siding, soffits, doors, windows, etc. are performed. These materials were supplied from a storage area located outside of the plant. The assembly is next moved to the interior finishing workstation where appliances, interior trim and finishing, lighting, exc. are installed. The appliances are transported to the assembly from a storage area located adjacent to the finishing workstation. After completion of the module assembly, a final test and inspection is performed. The operation flow is summarized in the operations/activities chart at the end of this chapter. Specifically, this chart shows the sequence of processes, the relationship between them as one flows into the next, and ultimately how the flow through the plant is structured. A factory layout is also provided in this chapter to give an overall picture of the factory as 
it is laid out. This layout also provides information about the location of the various workstations within the plant. For example, in the center of the plant and running from top to bottom is the main production line. All of the blocks on either side of the main line are subassembly workstations. The addition, the blocks outside of the plant represent storage locations for inventory stock. These warehouses contain all of the materials to be the used in the manufacture of the homes. As they are needed, these materials are brought to the appropriate workstations for use. The production process previously described is summarized in the p, ocess flow chart at the end of the chapter. This chart is briefly discussed in the next several paragraphs.

A process flow chart is a device used to examine the flow of operations within a workstation or factory as well as the flow of items into and out of the stations. This flow chart is a useful tool for identifying problems with a layout resulting from inefficient material flow. A process flow chart can also provide an overall picture of what is actually taking place within the particular facility. The process flow chart can also serve as starting ground for restructuring a layout so as to optimize the sequence of operations as well as the flow of incoming and outgcing materials or assemblies. The flow chart should be superimposed onto the layout so that the exact location of each operation and storage area is correct for the analysis.

Each symbol has a specific meaning. Triangles represent storage locations. Circles represent operations, arrows represent transportation processes, a square signifies an inspection operation, and a $D$ represents a delay in a process. The flow of materials follows the direction of the arrows. For example, S3 signifies the storage area for chassis raw materials, T7 is the transporting of these materials to a staging area S10. O8 is the first operation to be performed at the chassis workstation, $O 9$ the second and so forth. 
T8 signifies the transporting of the finished assembly out of the workstation. This logic follows for all of the processes in this flow chart. Another example is TO which is the first transport in the layout. The chassis is being brought to the main production line to begin the first assembly operation $\mathrm{O} 1 . \mathrm{T} 1$ is the transport to the assembly to the second operation $\mathrm{O} 2$ and sc on. A complete listing defining all of the symbols is contained is this chapter.

It is hoped that this factory overview will provide enough background to allow the reader to work through this document with a good understanding of the material contained within the subsequent chapters which describe Fleetwood's manufacturing operations in detail.

\section{Production Rate Analysis}

This analysis is intended to verify the results obtained in the time studies. The criteria for verification is that the required daily production rates are satisfied. Three important factors must be considered in this analysis: 1) the production rates are based on total production capacity discarding problems that nay arise such as equipment downtime, low production orders, employee abscenteism, etc. 2) that operation times include transport times between stations. 3) operation times are based on one half of the home (module) because they are made as two separate halves and connected on-site.

The analysis is based on the following specifications:

1. Home size: 60' X 12' (double wide)

2. Production rate: 10 modules/day

3. Shift: $8 \mathrm{hrs} .-2(10 \mathrm{~min}$.$) breaks =460 \mathrm{~min}$.

4 Cycle time: based on the longest operation time in the workstation The production rate analysis for each workstation is demonstrated with the time charts. 


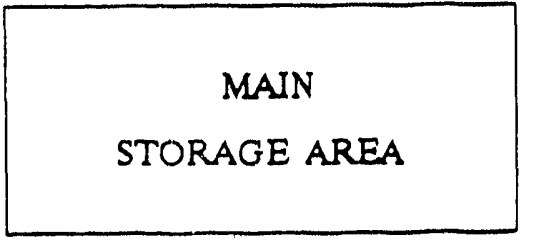

\begin{tabular}{|c|}
\hline SECONDARY \\
STORAGE AREA \\
\hline CHASSIS \\
PAINT AREA \\
\hline
\end{tabular}

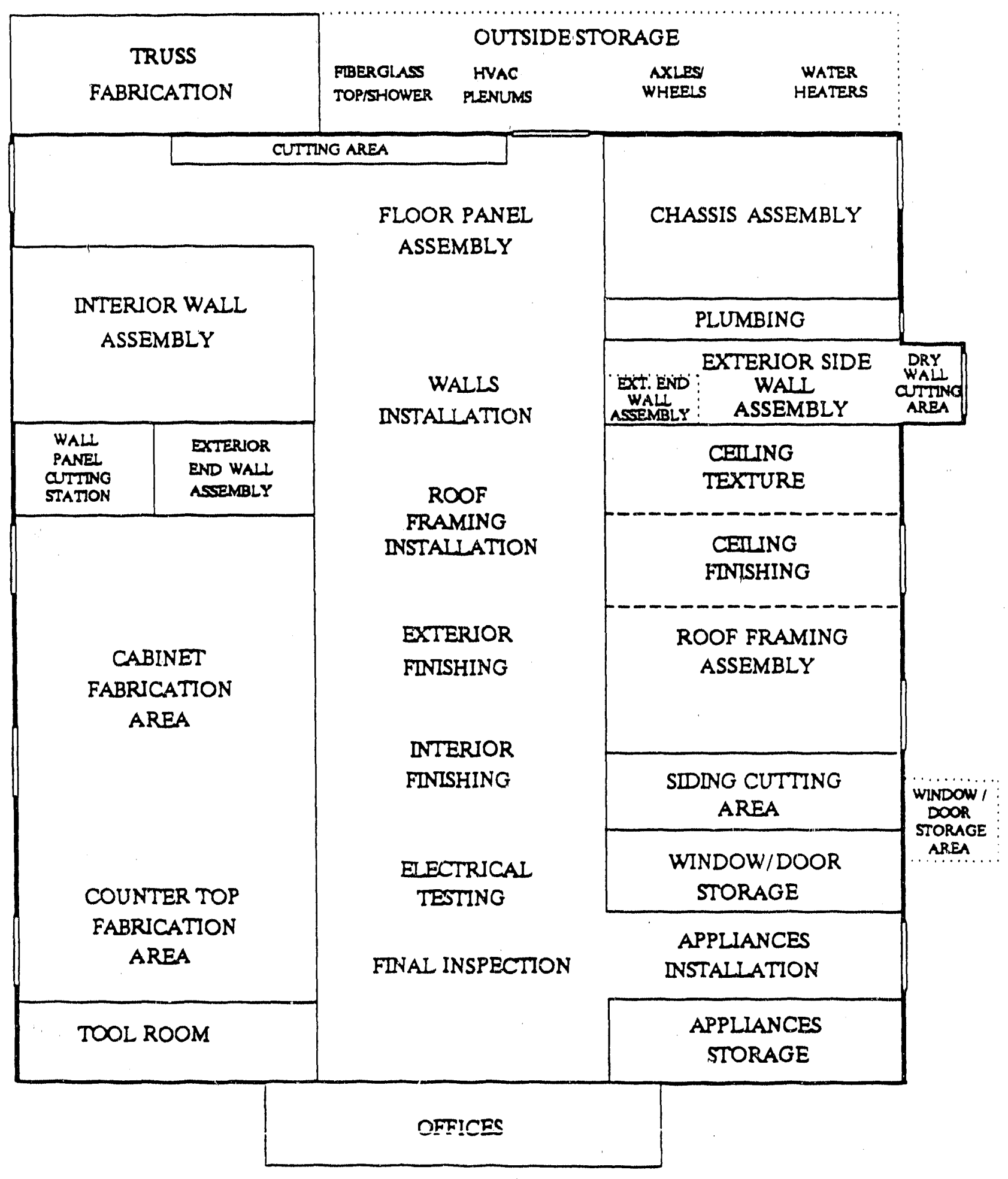




\section{MAJOR OPERATIONS / ACTIVITIES}

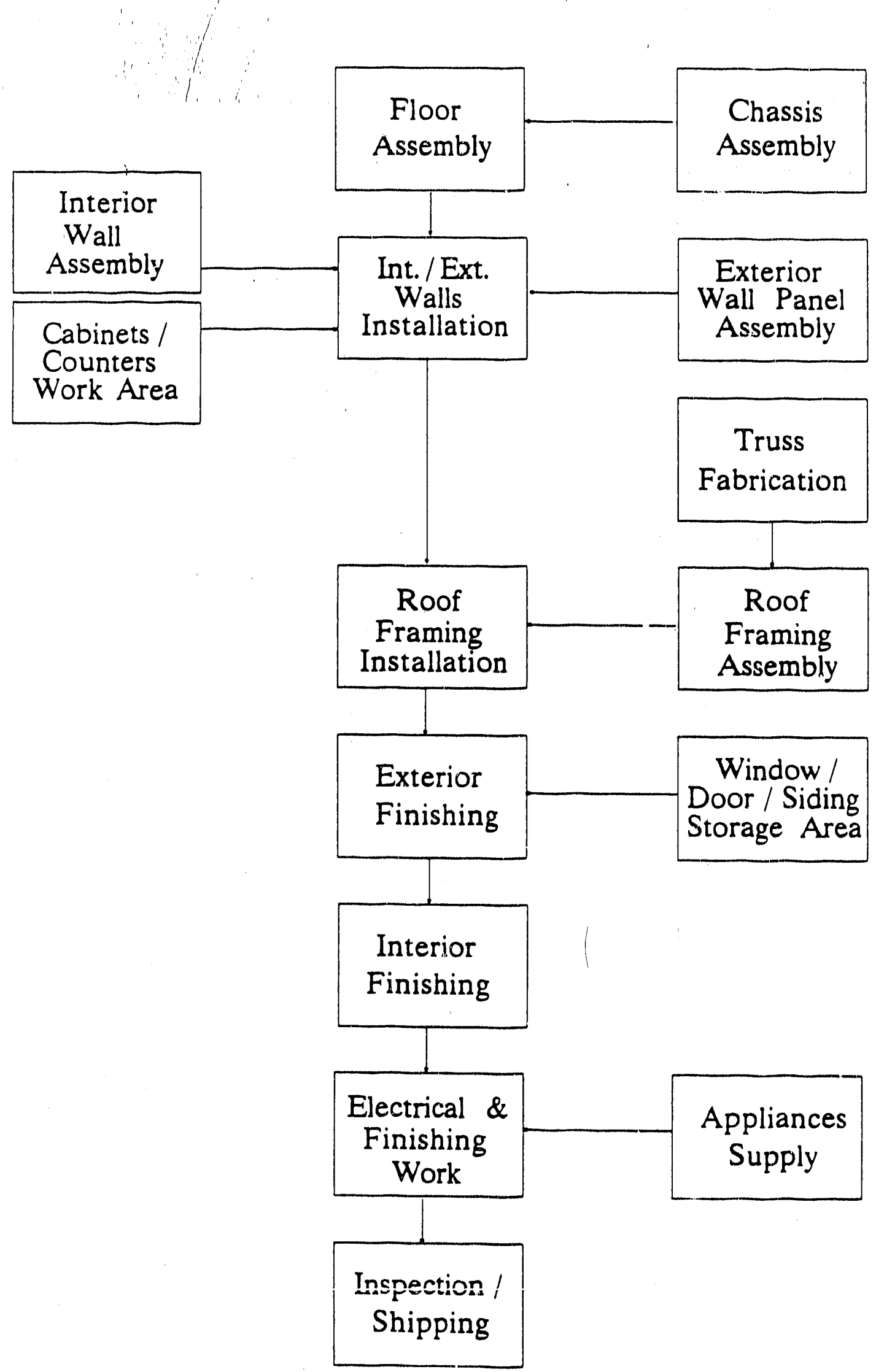




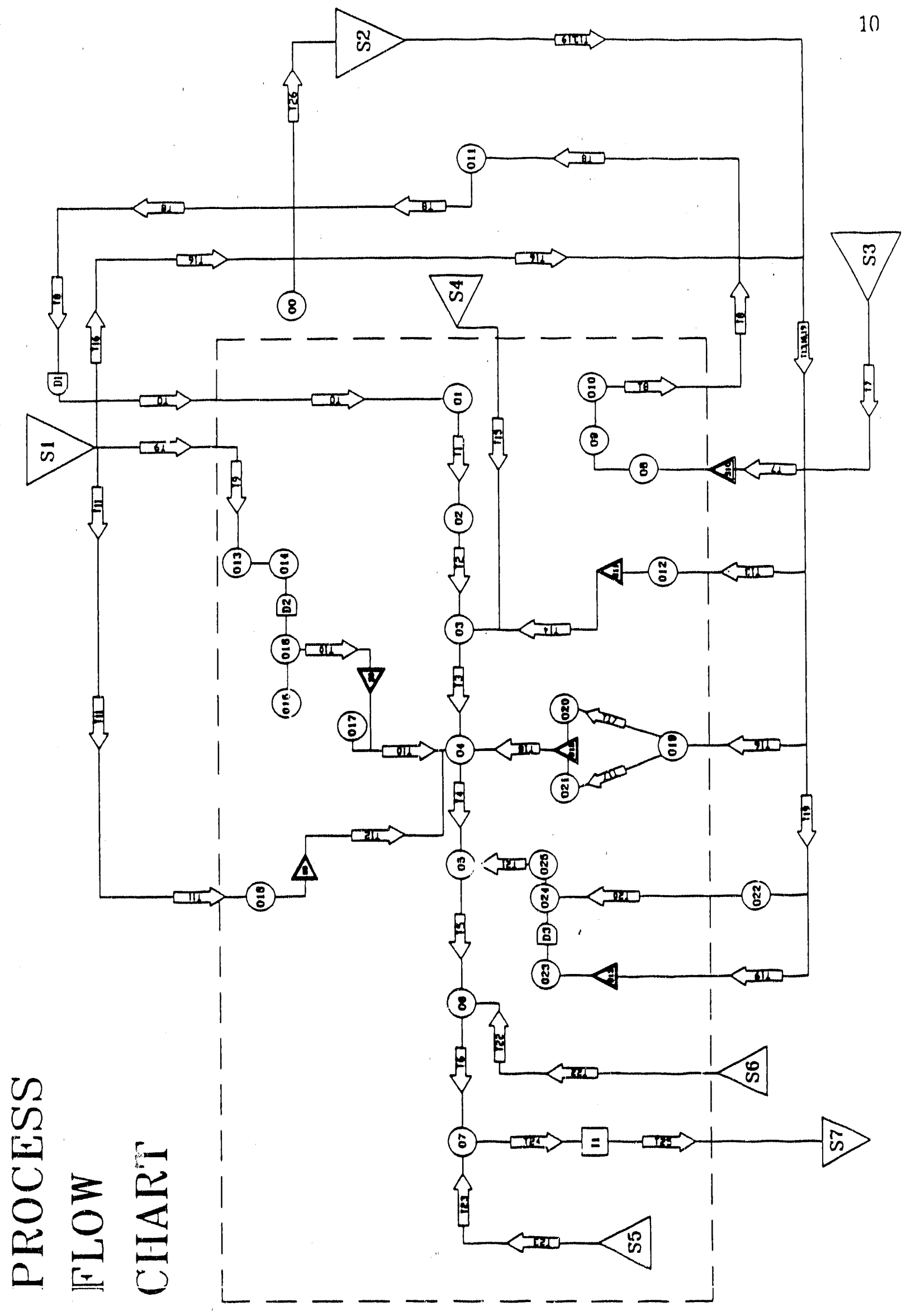

$\bullet$ 


\section{PLANT PROCESS FLOW DESCRIPTION}

\section{Stock}

S1: Storage for all raw building materials.

S2: $\quad$ Storage for trusses, toilets, sinks, mirrors, carpeting,etc.

S3: Steel beam stock for chassis assembly.

S4: Stock for showers, HVAC materials, chassis components.

S5: Kitchen appliance stock.

S6: Window and door stock.

S7: $\quad$ Finished product storage.

S8: Staging of assembled interior walls.

S9: Staging of cabinets and counters.

S10: Staging of chassis beam stock.

S11: Staging of bath items such as toilets, sinks, etc.

S12: Staging of finished exterior walls.

S13: Staging of roof components.

\section{Operations}

O0: Truss fabrication workstation.

O1: Floor frame assembly.

O2: Floor deck assembly.

O3: Installation of carpet, vinyl, showers and toilets. 
04: Installation of interior/exterior walls, kitchen/bath counters and cabinets and electrical wiring.

O5: Roof installation, roof deck installation, shingles, fascia.

O6: Exterior finishing, siding, windows, doors, etc.

07: Interior finishing, lighting, trim, mirrors, etc.

O8: Chassis beams are cut to size.

09: Chassis frame is welded and assembled.

O10: Final assemblies of hitch and axles.

O11: Paint station for chassis.

012: Plumbing cutting and assembly.

O13: Cutting for interior wall studs.

O14: Interior wall frame assembly.

015: Cutting for interior wallboard.

O16: Final interior wall assembly.

017: Exterior wall end panel assembly.

O18: Kitchen and bathroom cabinet/counter fabrication.

O19: Cutting for exterior wall paneling and studs.

O20: Exterior wall assembly.

O21: Exterior wall ass:mbly.

O22: Mixing station for ceiling drywall mud and finish texture.

O23: Roof truss assembly station.

O24: Ceiling finishing station.

O25: Ceiling spray station. 


\section{Transportation}

TO: Chassis is transported to production line.

T1: Unit is transported to floor deck assembly.

T2: Unit is transported to carpet and vinyl station.

T3: Unit is transported to wall installation.

T4: Unit is transported to roof installation.

T5: Unit is transported to exterior finishing.

T6: Unit is transported to interior finishing.

T7: Raw beam stock is transported to chain conveyor.

T8: Finished chassis is transported to paint statioi.

T9: Interior wall materials are transported to interior wall cutting stations.

T10: Finishid interior walls are transported to staging and then to installation.

T11: Cabinet and counter stock is transported to assembly station.

T12: Finished cabinets and counters are transported to installation.

T13: Sinks, toilets, and other plumbing items are transported to assembly station.

T14: Bath and plumbing items are transported to installation.

T15: Showers are transported to installation.

T16: Exterior wall materials are transported to exterior wall cutting station.

T17: Cut studs and paneling are transported to assembly tables.

T18: Finished exterior walls are transported to installation.

T19: Finished trusses are transported to the oof assembly workstation.

T20: Drywall finishing materials are transported to the ceiling finishing station.

T21: Finished roof truss is transported to roof installation.

122: Windows and doors are transported to exterior finishing. 
T23: Appliances are transported to interior finishing.

T24: Finished home is transported to final inspection.

T25: Finished home is transported to storage area.

T26: Finished trusses are transported to temporary storage.

\section{Delays}

D1: Finished chassis must wait until drying is complete.

D2: Interior wall frames wait until previous wall assembly is completed before panel assembly.

D3: Roof assembly waits for finishing station to be vacated.

\section{Inspection}

I1: Final inspection is performed on entire unit. 


\section{WAREHOUSE ANALYSIS}

Fleetwood's facility in Haines City currently has two warehouses located next to the main production building. The main warehouse contains most of the lumber, such as drywall materials, floor and roof decking. Other materials stored in this warehouse are $2 \times 2$ 's for truss fabrication, floor joists and walls studs for framing. Most of these materials, before being taken to the production line, must first go to a cutting station. For this reason they are palletized and transported by forklift (Figures 1 and 2).

The sscondary warehouse contains all other materials that can be moved directly into the production line, such as finished trusses, insulation material, screws, bolts, mirrors, and carpeting. Such materials are also transported to the production line using forklift trucks.

In addition, there are some outside storage areas for other materials such as uncut beams, axles, bath tubs, windows, glass doors, and kitchen appliances. Figures 3 through 7 show some of the outside storage areas for these materials which are transported to the production line using forklift trucks.

There are four forklift trucks operating at the facility. Each truck has designated service areas, such as floor deck assembly, sheet metal, plumbing, and cabinets storage.

Purchase orders are placed on a weekly, biweekly or monthly basis, depending on the usage of the material. For example, plumbing and drywall orders are placed every week, while low usage materials such as medicine cabinets and kitchen appliances are ordered on a monthly basis. Most of their suppliers are located in the central Florida area. Orders can take from one to three days for delivery. 


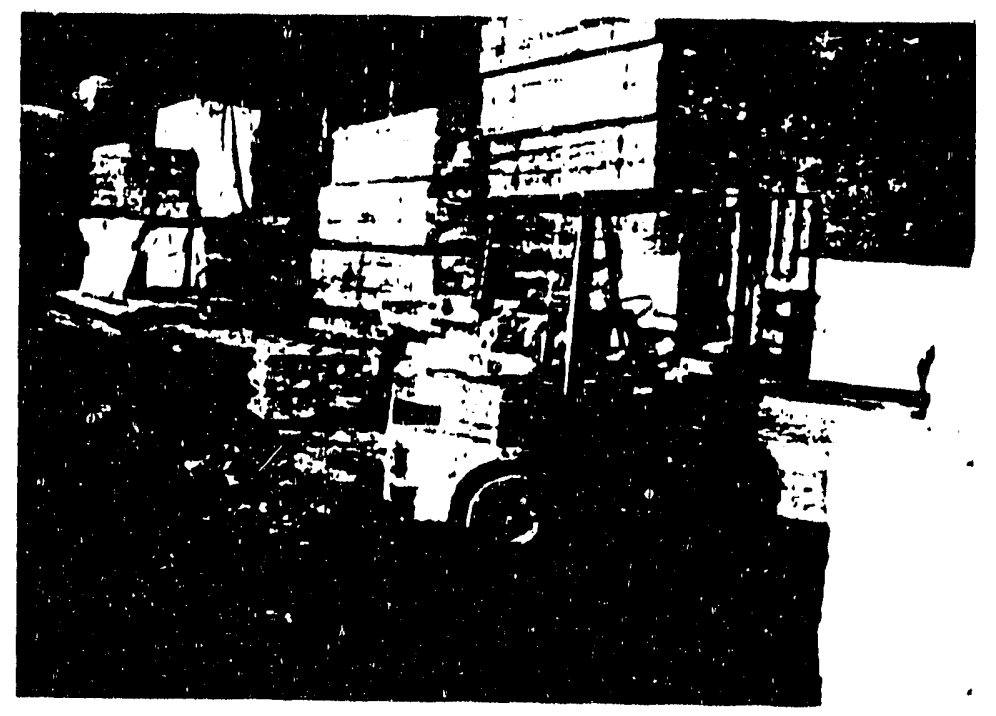

Figure 1. Forklift operating at the Main Warehouse.

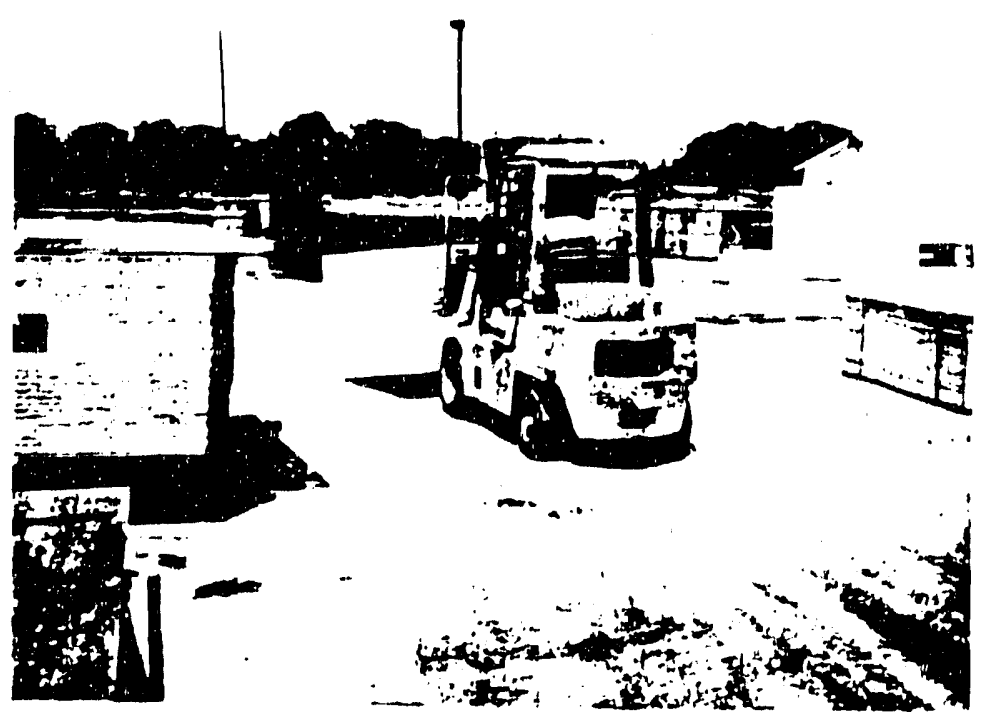

Figure 2 Forklif moving materials outside the plant. 


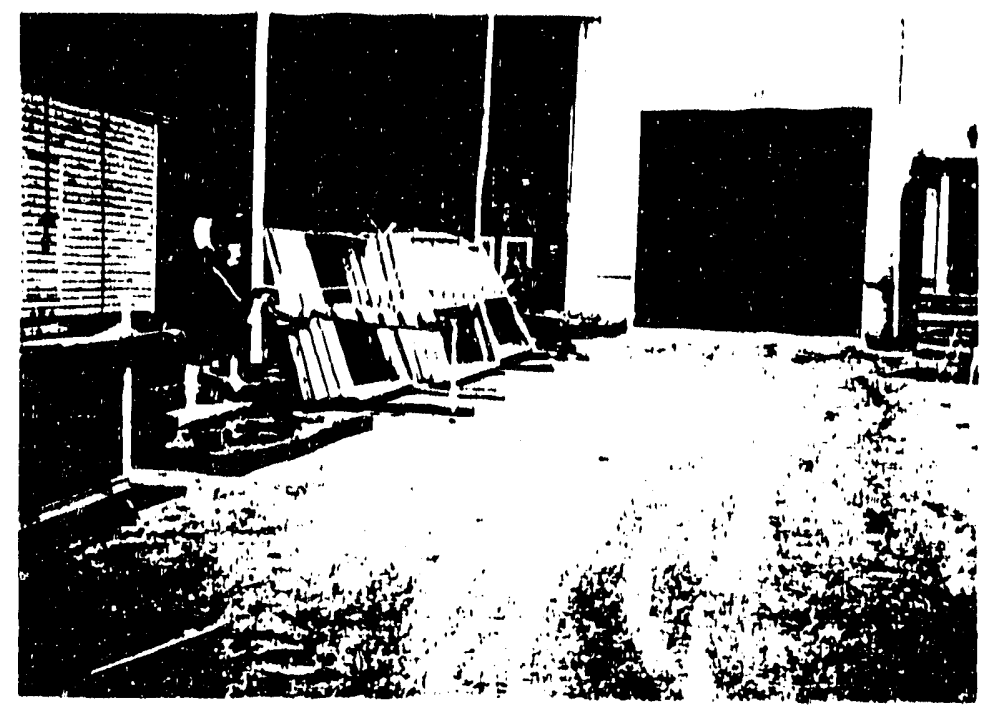

Figure 3. Windows stored outside.

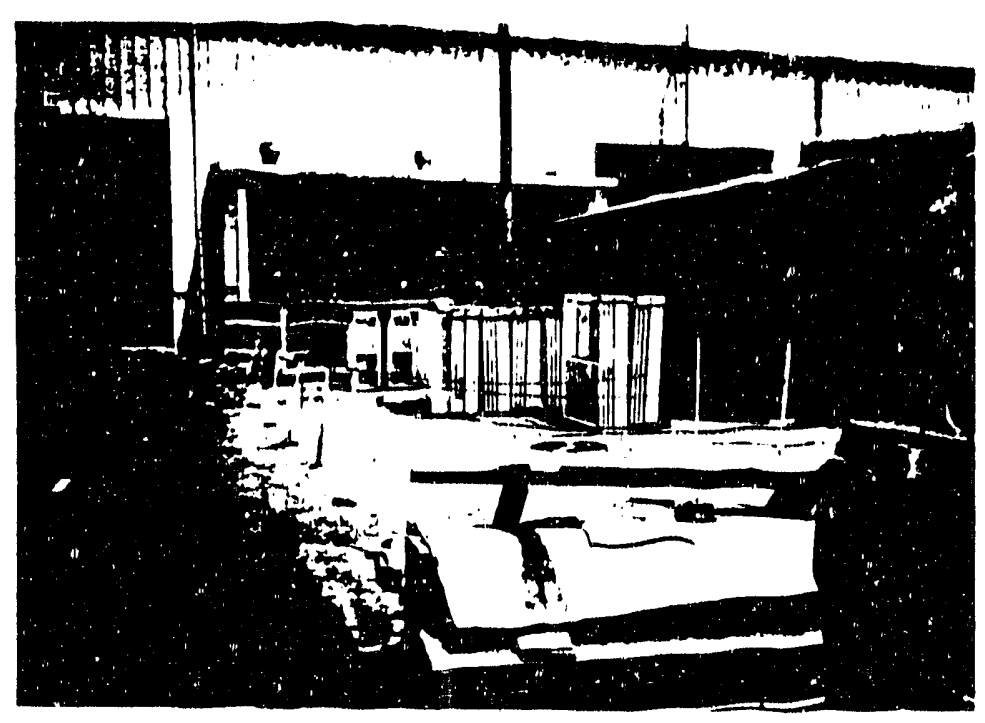

Figure 4. Glass doors stored outside. 

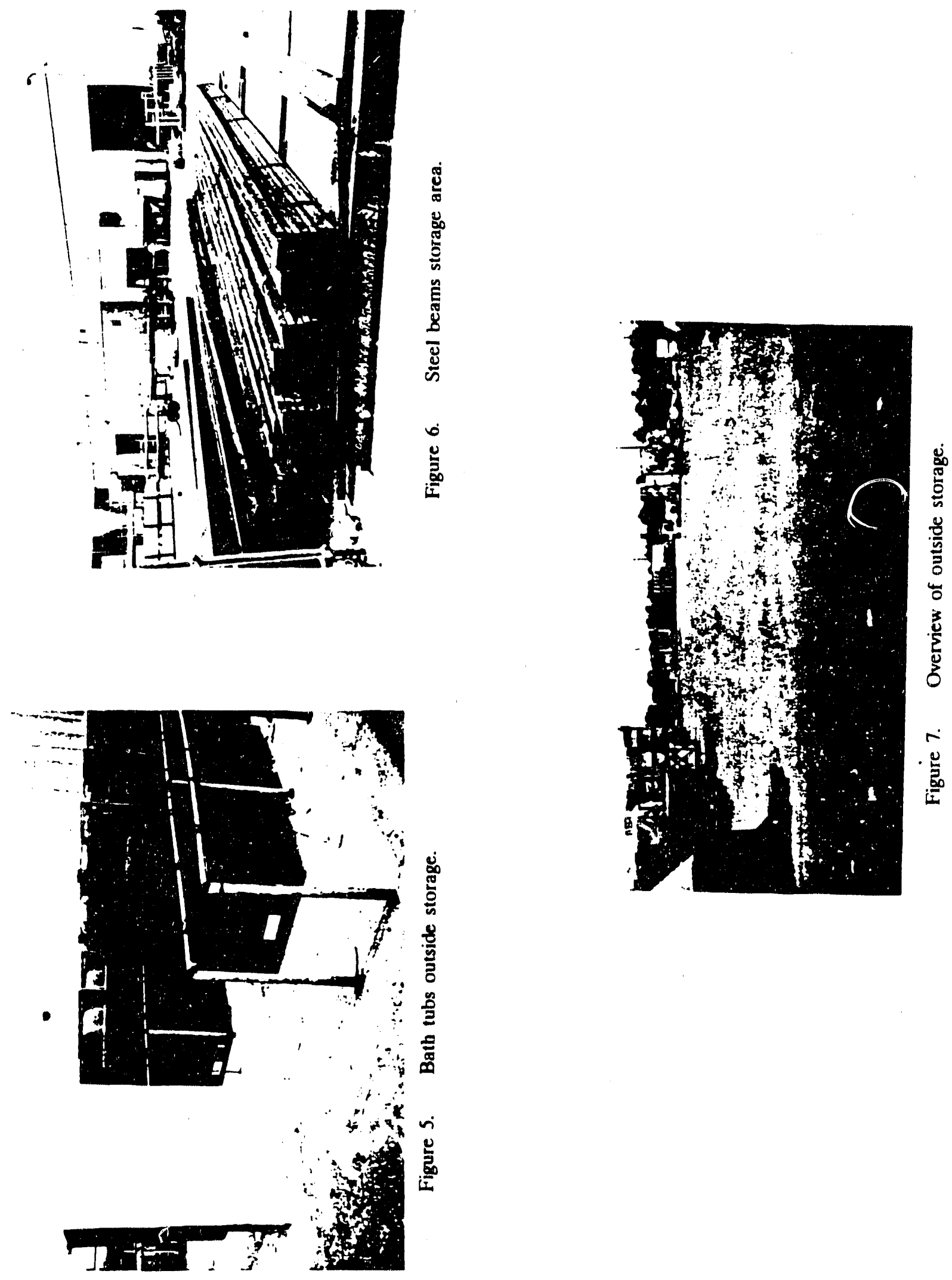

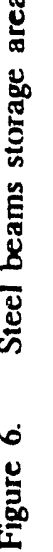




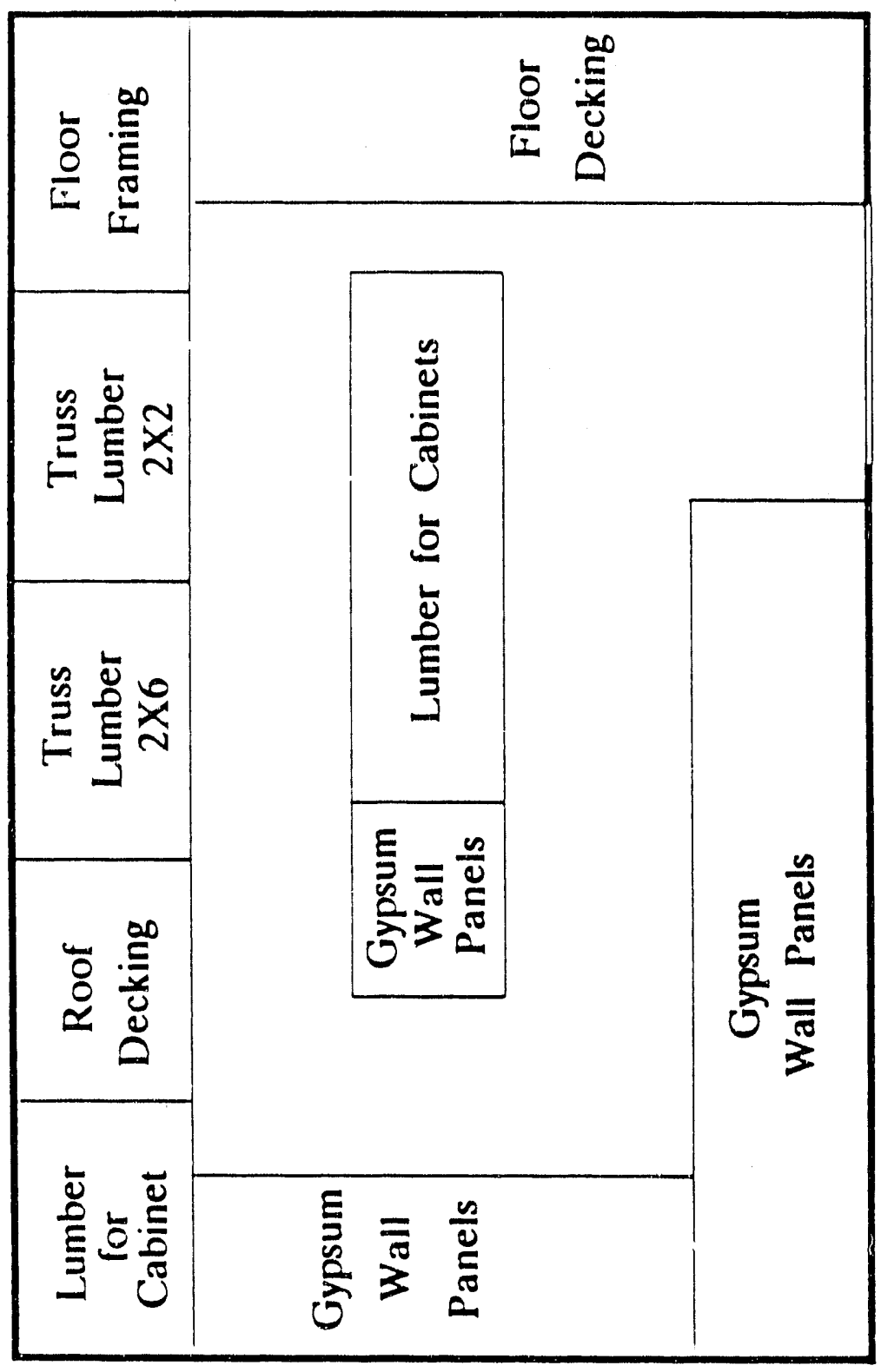

$\frac{11}{3}$
$\frac{1}{0}$
$\frac{1}{2}$
$\frac{1}{3}$
$\frac{3}{2}$ 


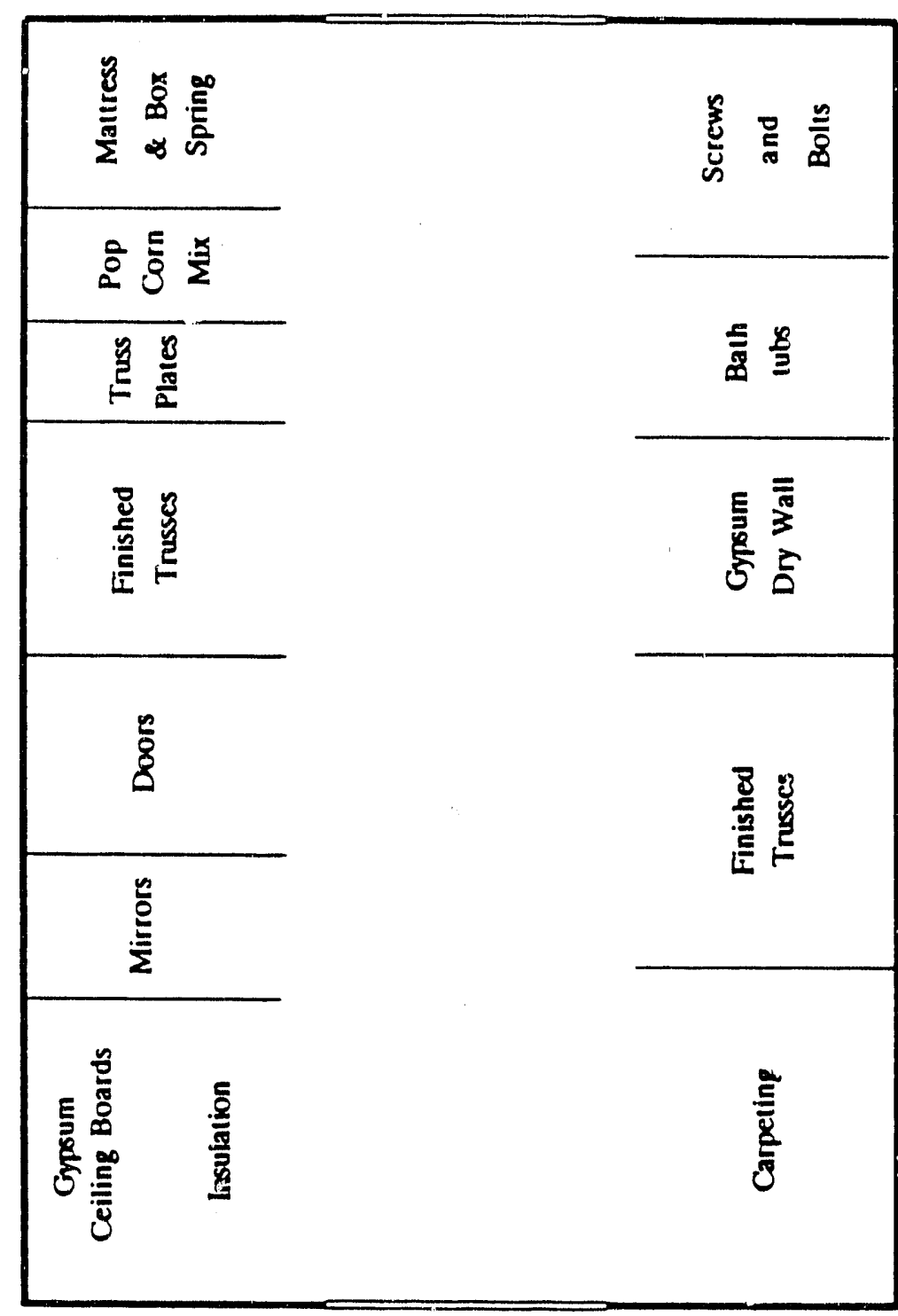

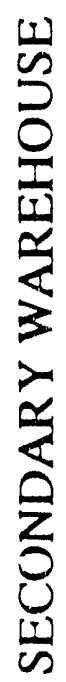




\section{TRUSS FABRICATION WORKSTATION}

\section{Process Description}

The truss assembly area is located outside of the main plant. Truss production supplies the Haines City plant as well as other facilities in Lakeland and Plant City, both aiso located in Florida.

Raw materials ( $2 \mathrm{ft} . \times 6 \mathrm{ft}$. studs) are stored in the warehouse on pallets. They are 1.oved to the first cutting workstation using a forklift truck and placed in carts (Figure 8). At this cutting station chords and webbing are reduced to 2'x 2'. pieces (Figure 9). Pieces are then moved to both angular (Figure 10) and small cut workstations (Figure 11). Good pieces are selected for assembly and defective pieces are sent back to a small cut off station.

Cut pieces are then moved to the assembly station, where pieces of different sizes and shapes are stored on top of the working area (Figure 12). Truss configuration is laid out and assembled using standard jigs, fixtures and a truss machine.

The following operations are performed at the assembly station:

- Place bottom plates.

o Layout truss configuration on top of the plates in fixtures.

o $\quad$ Flace plates on top of truss members.

o Insert assembly into press.

- Activate press machine for plate pressing.

- Remove finished truss and place it on a mobile dolly (Figure 1.3). 

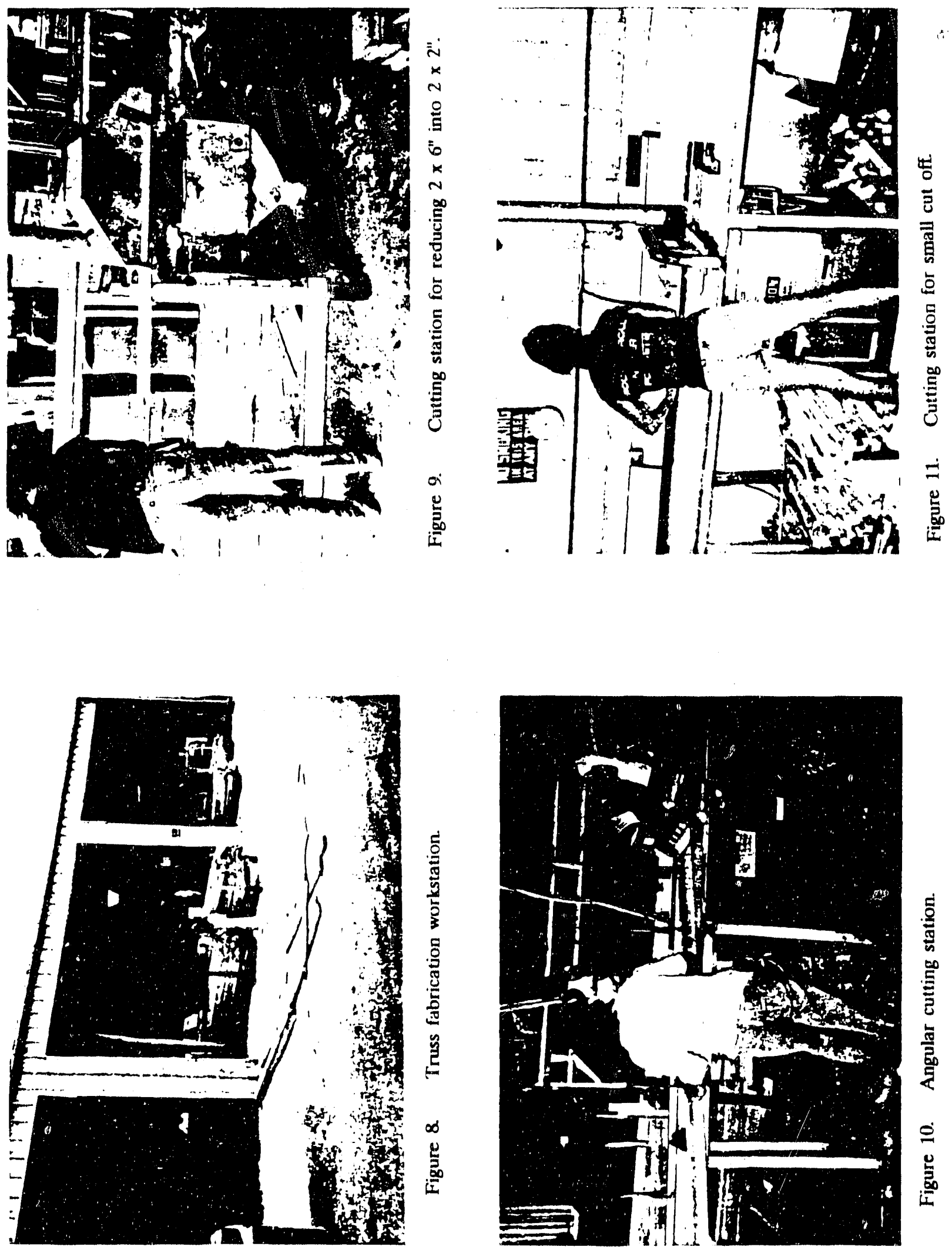


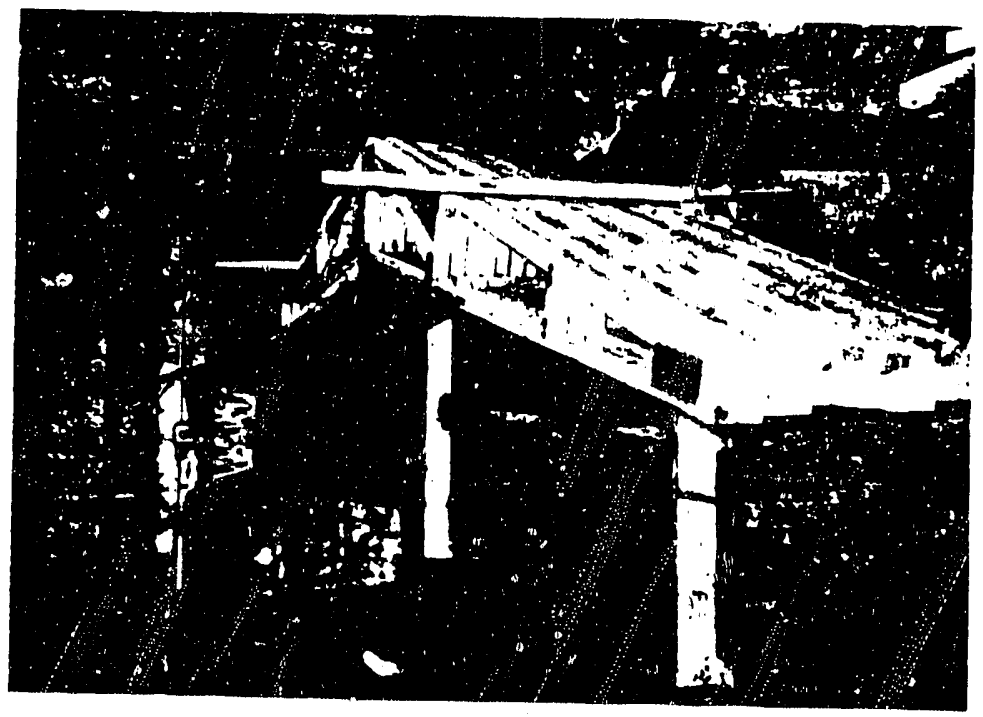

岛

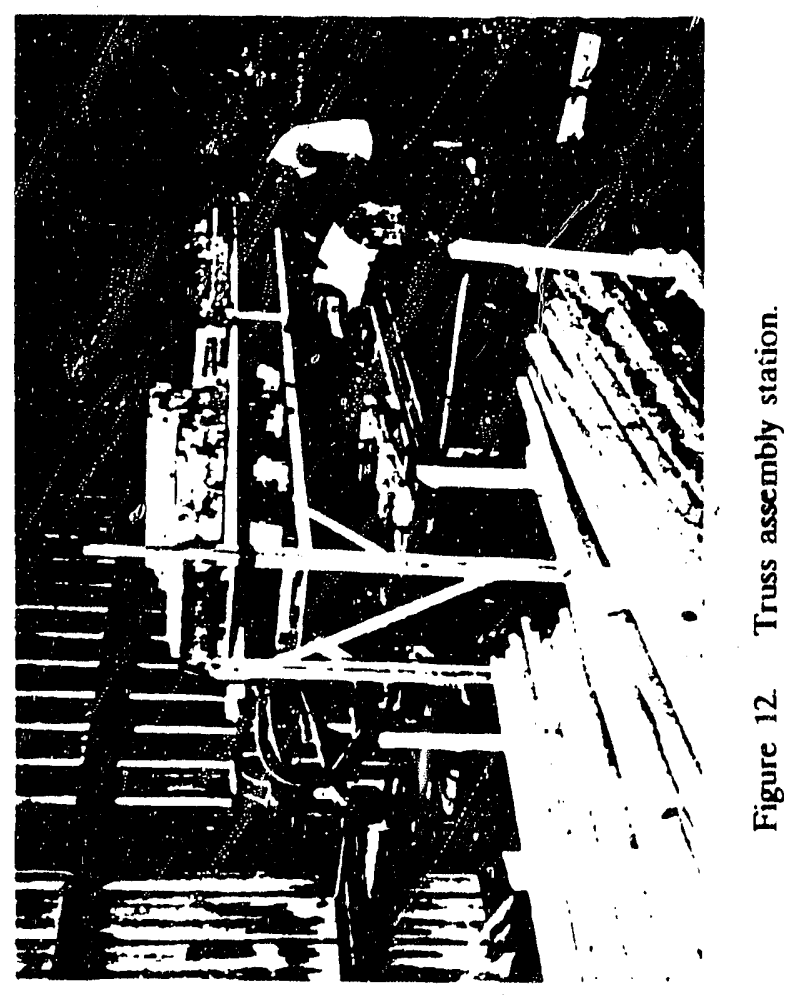


There are two truss assembly stations operating simultaneously. Finished trusses are stored in the secondary warehouse. Finished trusses can be shipped to other plants or moved to the roof assembly workstation.

\title{
Labor Utilization
}

A total of six workers are employed at this workstation. Two workers operate at each truss press while the other two perform cutting operations. An additional person is needed for materials handling within the work cell and to storage.

\section{Materials Handling}

Truss lumber is brought from warehouse to workstation by forklift. All stock is transported from operation to operation with roller carts. After truss has beer built it is then palletized and temporarily stored. Pallets are then transported to the secondary warehouse again using forklifts.

\section{Inspection}

There is visual inspection for defective pieces at the assembly station. Defective parts are sent to the second cutting station, where webbing can be reduced to smaller sizes.

\section{Equipment Description}

\author{
- Cutting: 1 table saw \\ 1 angular cut table saw \\ 1 radial arm saw.
}


- Assembly: 2 automatic truss presses.

- Jigs/Fixtures: 2 jig set ups.

- Materials Handling: 1 forklift and 2 roller carts.

\section{Recommendations}

It is recommended that the following suggestions be investigated:

1. Layout:

- Exchange the finished truss stock with the truss cord stock area.

- Expand workstation size to allow for more efficient flow of materials.

- Relocate workstation near the roof assembly area to potentially reduce transport time that exists with current location. Production balance between trusses used and trusses sent to other Fleetwood plants should be considered.

2 Labor:

- Labor utilization should be examined. This operation might possibly be performed with a smaller crew if adequate materials handling and cutting equipment are utilized.

- Truss machines exist that are capable of substantially higher production rates than current machines.

3. Process:

- Reasonably efficient Truss presses are adequate for required production volume.

- Cutting systems exist that are capable of straight and angular cuts on one machine, thus eliminating the need for two saws. An example 
of such systems is shown in Figure 14.

- Multi-head cutters are available that are capable of cutting multiple studs simultaneously. This production increase makes the possibility of using one man for cutting a feasible alternative. For a list of other available cutting equipment see Appendix $\mathrm{A}$.

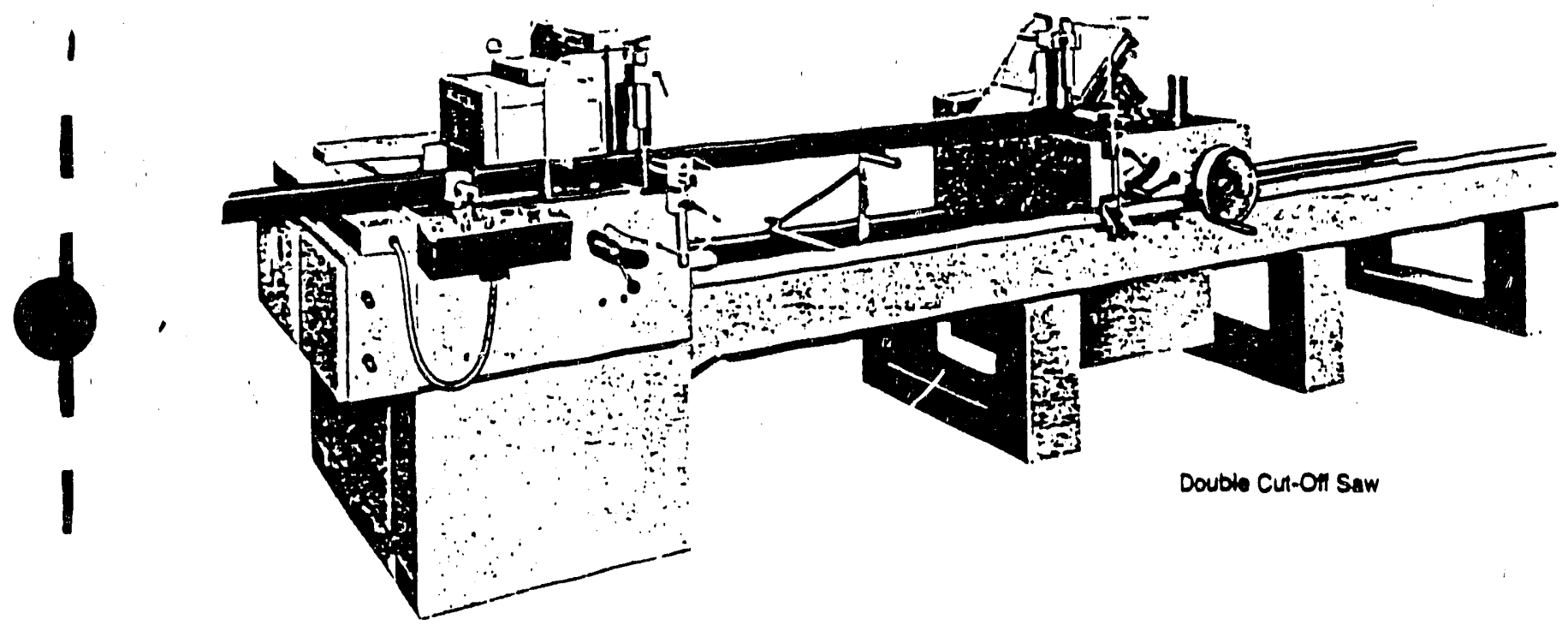

Figure 14 
4. Materials Handling:

- Replace roller carts with automatic conveyors such as the one shown in Figure 15 in order to eliminate the need for manual transporting of components within the work-cell.

- Reduce loading and unloading efforts. Automatic truss stackers are available that can perform automatic stacking and palletizing of finished trusses, thus reducing labor time. An example of such truss stackers is shown in Figure 16. For list of available equipment see Appendix A.

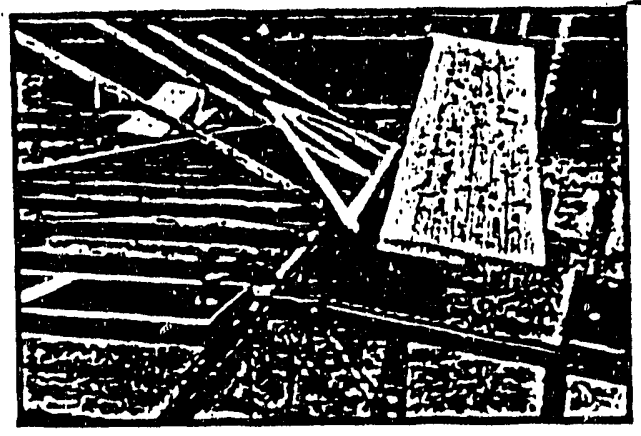

TRUSS STACKER

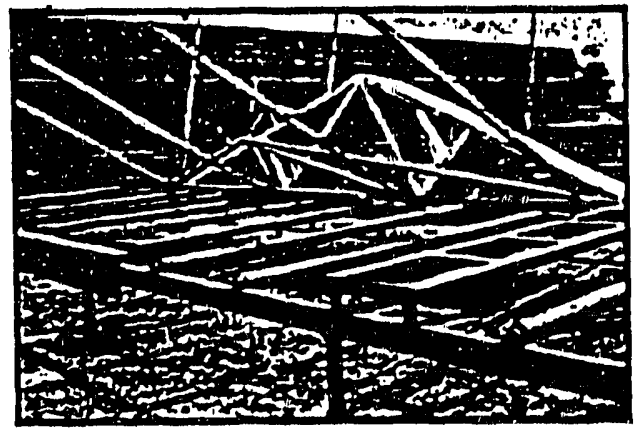

CONVEYOR

Figure 15

Figure 16 


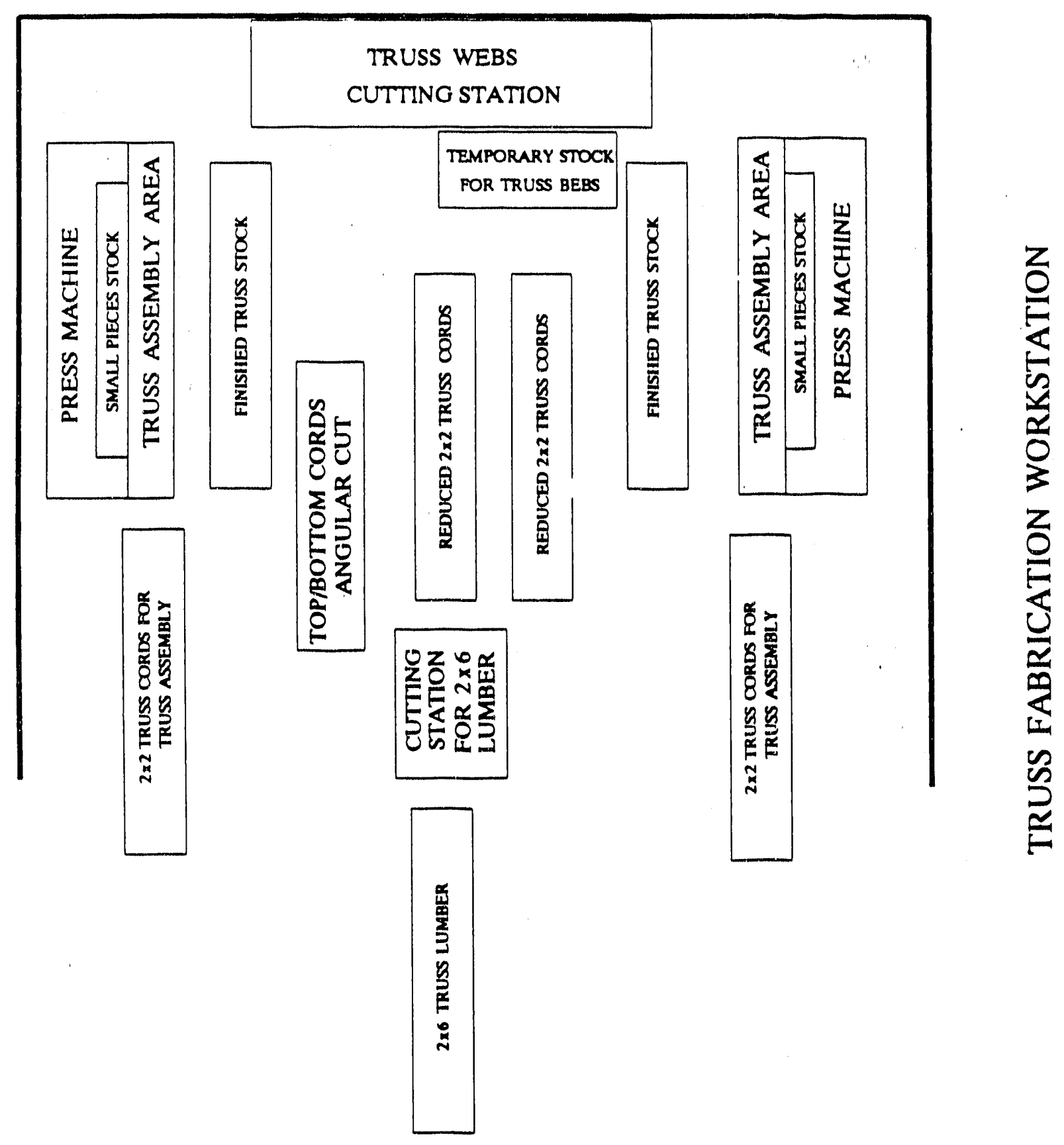




\section{TRUSS FABRICATION FLOW CHART}

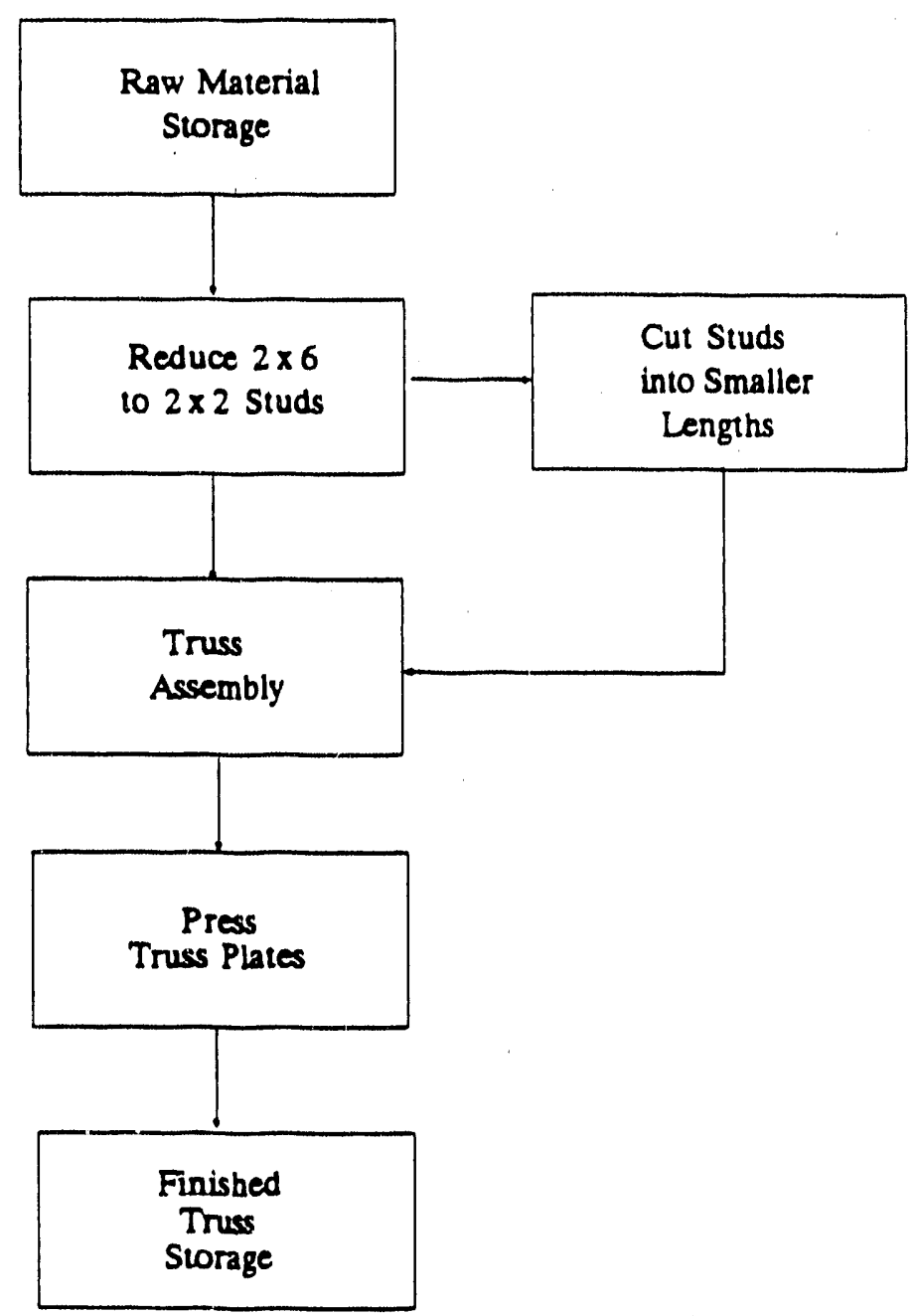




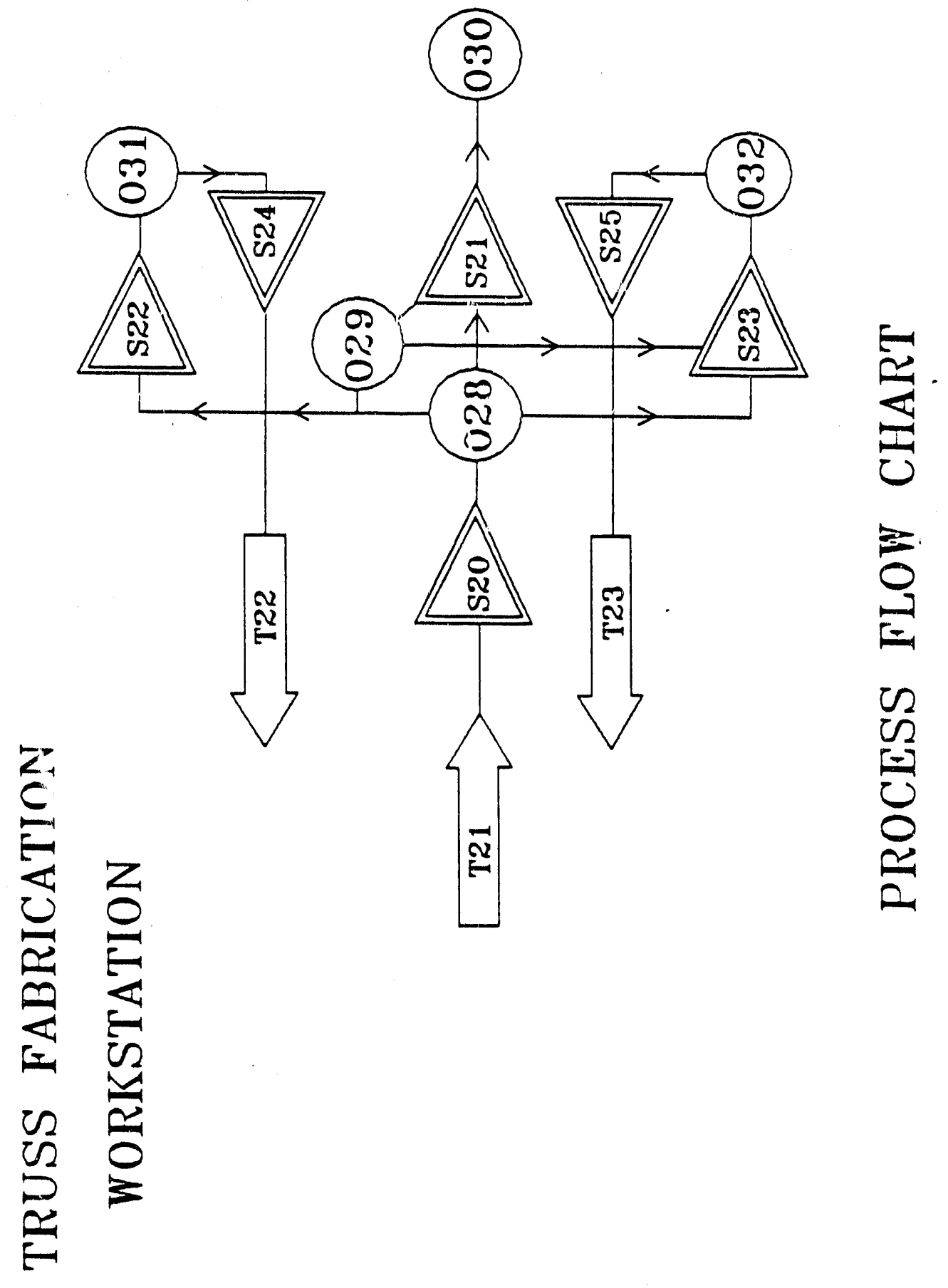


Truss Fabrication:

S20: Initial staging of $2 \times 6$ lumber waiting to be cut.

S21: Specific converted $2 \times 2$ pieces are waiting in process to be sent through an angular cutting process. Then they are sent to S22 \& S23 staging areas.

S22: Other converted $2 \times 2$ pieces not needing angular cuts are staged at this point before assembly.

S23: Same as S22 for other assembly station.

S24: Finished trusses are placed on pallets and staged.

S25: Same as S24.

O28: 2 X6 truss members are converted to $2 \times 2$ 's with a table saw.

O29: Angular cuts are made to small truss members as required.

O30: Web members are cut to size at this station.

O31: Metal plates and truss members are set up in standardized jigs and sent into a press for final assembly.

O32: Same operation as $\mathrm{O} 31$.

T21: Wood stock is brought in from main warehouse.

T22: Finished trusses are transported to storage.

T23: Same as T22. 


\section{TIME CHART \\ FOR \\ TRUSS FABRICATION}

Operation

No. of Operators

Total Time

Reduce lumber $(2 \times 6)$ to $(2 \times 2)$

1

Cut lumber $(2 \times 2)$ into smaller pieces

1

Assemble Truss (2 Workstation):

4

$30 \mathrm{sec}$

- Set metal plates and studs in jigs/fixtures

- Operate press machine

- Move truss to storage cart

Move Finished Trusses to Warehouse

Production Rate Analysis

Requirement:300 trusses/shift @30/unit

Cycle Time: $1 \mathrm{~min} . / \mathrm{truss} / \mathrm{machine}$

Production Rate: (1 truss $/ \mathrm{min} . \times 460 \mathrm{~min} . / \mathrm{shift} \times 2$ machines) $=920$ trusses $/ \mathrm{shift}$ 


\section{CHASSIS ASSEMBLY WORKSTATION}

\section{Process Description}

Raw materials are stocked outside the plant, such as beams, wheel axles and wheels.

Beams are placed on a chain driven conveyor, and then on a roller conveyor that wiil move them into the cutting station (Figure 17). Ilere beams are cut to length using an arm saw, and the residual part is welded to the next in-coming beam.

Cut beams are moved to the Chassis Frame Assembly workstation using a hoist (Figure 18) where the chassis frame is assembled by arc-welding. Welding machines are set up on an overhead rail (Figure 19) for moving purposes in the assembly area.

The chassis frame is inen moved to the final assembly area where the wheel axles and the hitch assembly are welded to the chassis support frame. Wheels are then attached to the axjes.

The finished chassis is then taken out of the plant to the paint workstation using a small tractor (Figures 20 and 21). A black rust resistant paint is applied to the chassis using an electrostatic paint system. The chassis is then moved to a drying area. After drying, it is brought to the front of the production line (Floor assembly workstation). 

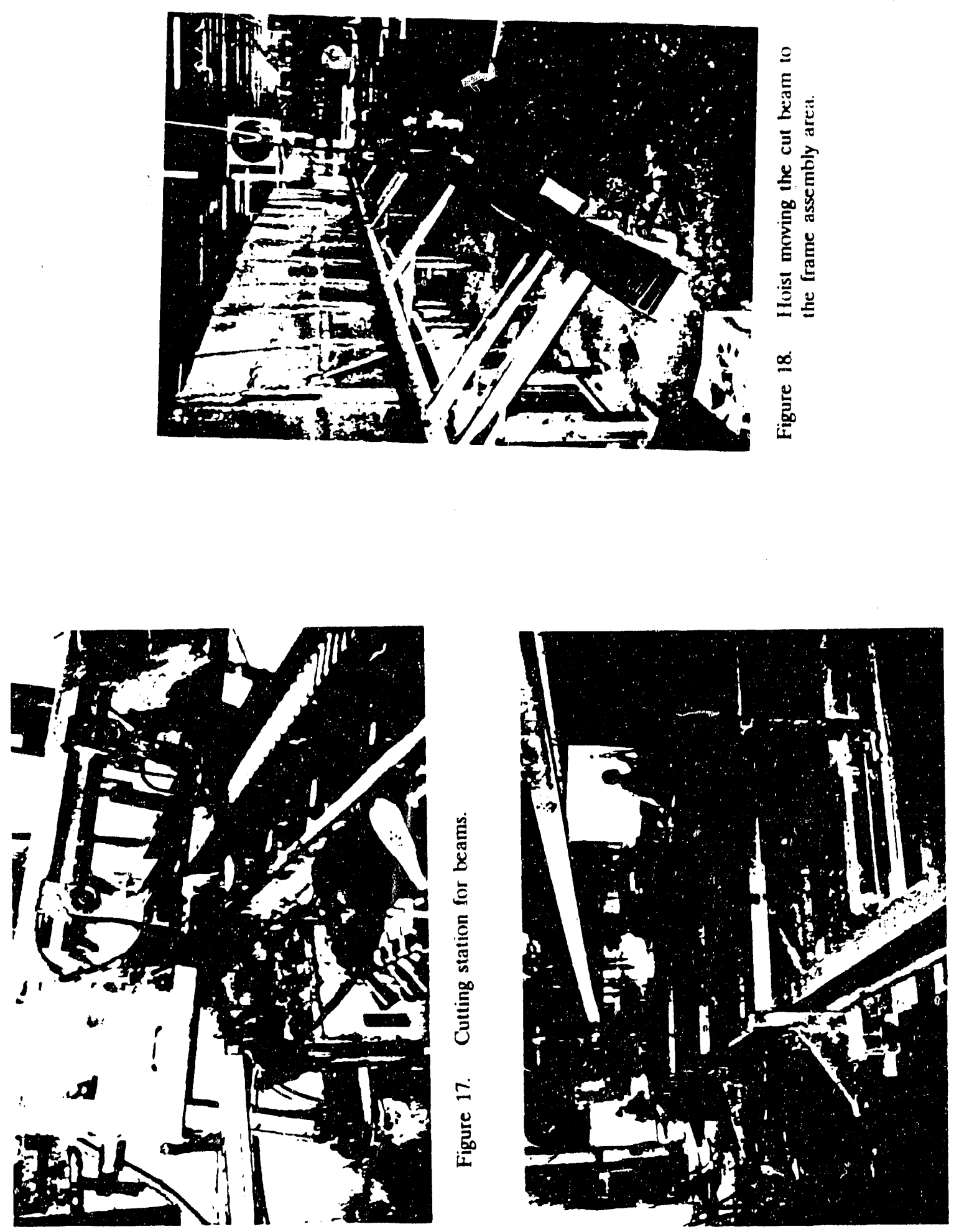

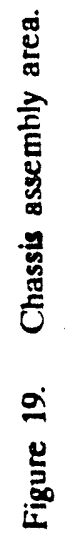




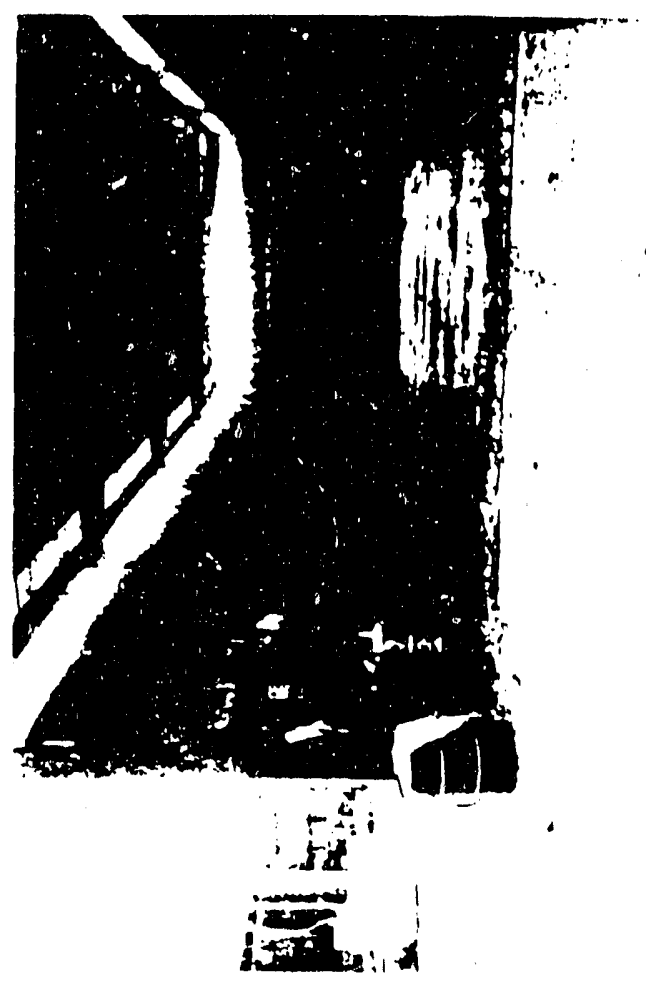

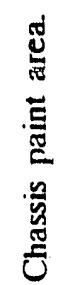

స్

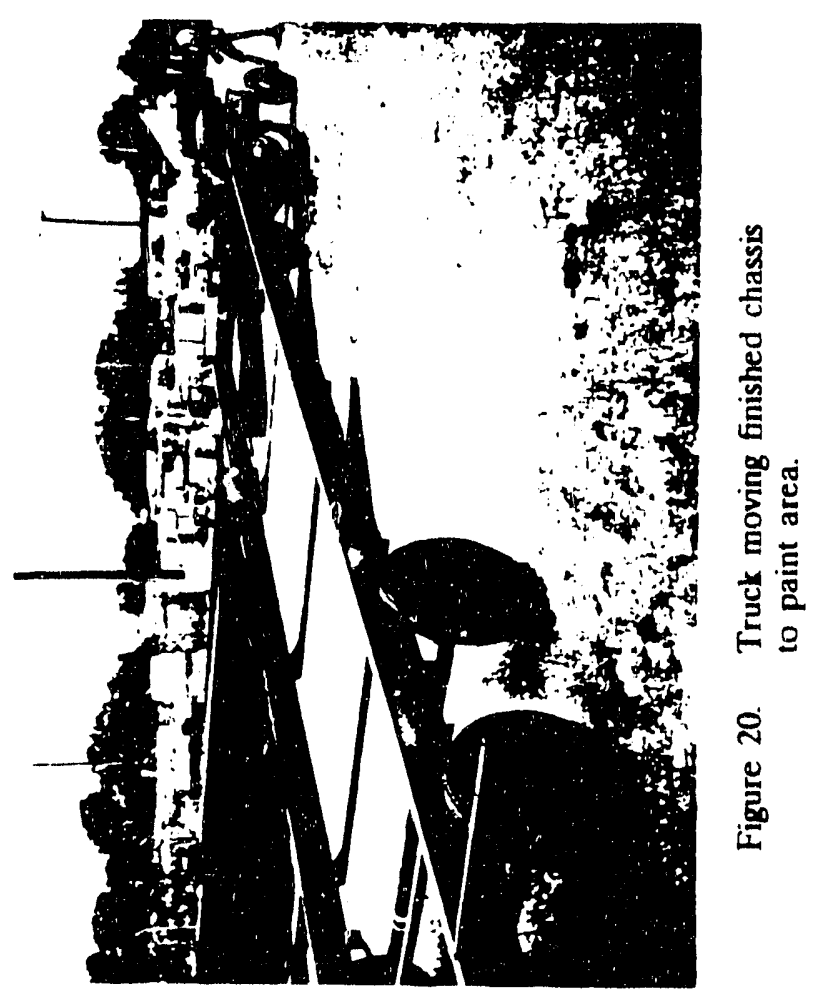




\section{Labor Utilization}

Three welders operate at the chassis frame assembly station, one of which is also responsible for cutting beams to size. Two other assemblers work in the final assembly area. There is one person in charge of the paint workstation. Another person is responsible for transporting the chassis to the paint area, and to the production line.

\section{Materials Handling}

Beam stock is transported by forklift to a chain conveyor outside of the building. It is then manually ( 2 workers) placed on a roller conveyor and brought into the building for cutting and arc welding. The beams are then crane transported to the next area for the chassis to be welded and assembled. An overhead crane hoist then lifts the frame and moves it to final assembly. A tractor is used for transporting the finished chassis to the next station.

\section{Inspection}

No inspection is performed at this workstation.

\section{Equipment Description}

- Cutting: 1 band saw

- Assembly: 6 arc welding machines and pneumatic screwdrivers

- Jigs/Fixtures: none

- Materials Handling: 1 chain driven conveyor, 1 roller conveyor, 4 ton overhead hoist, 1 tractor, and a forklift 


\section{Recommendations}

It is recommended that the following suggestions be investigated:

1. Layout:

- Relocate chassis workstation near the painting area. This will result in reducing material handling effort as well as creating floor space for other operations. The assembled chassis may then be moved to the production line as needed.

- An alternative is to set this station up in place of the warehouse area that is adjacent to the chassis painting station.

2. Labor:

- Cross train all chassis crew members for both painting and assembly operations in order to avoid overexposure to paint chemicals which constitute hazardous operating environments.

o Crews would operate on rotating shifts.

3. Pricess:

- Process is relatively efficient for this operation.

4. Material Handling:

none. 

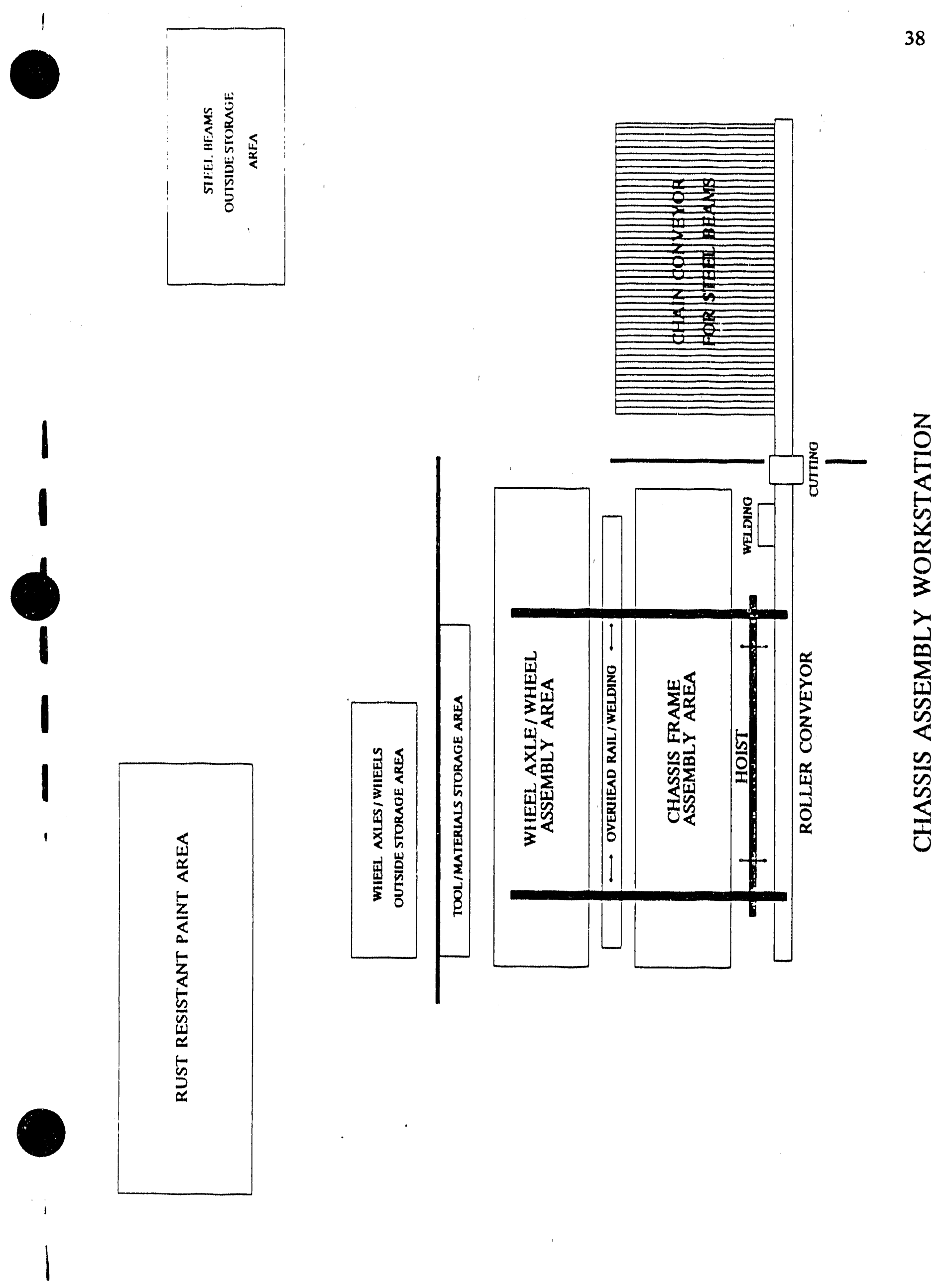


\section{CHASSIS ASSEMBLY FLOW CHART}

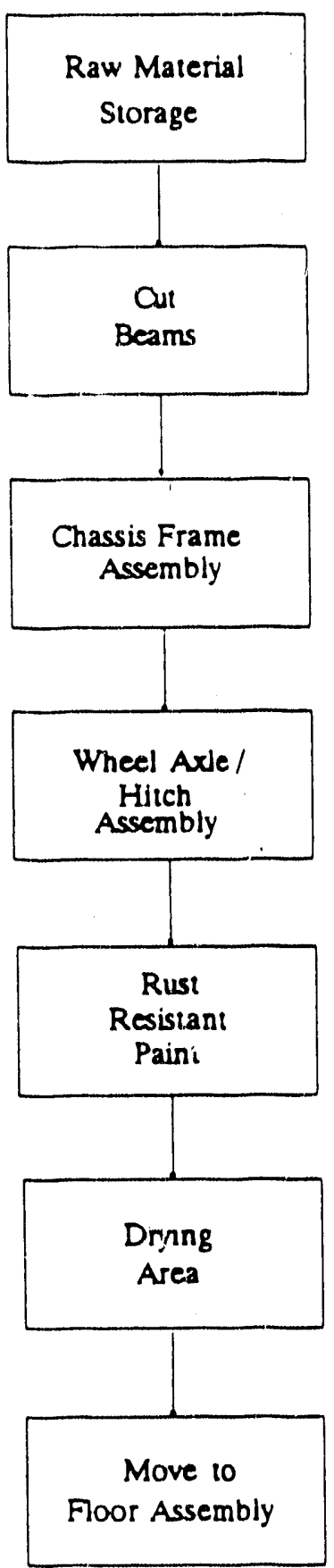



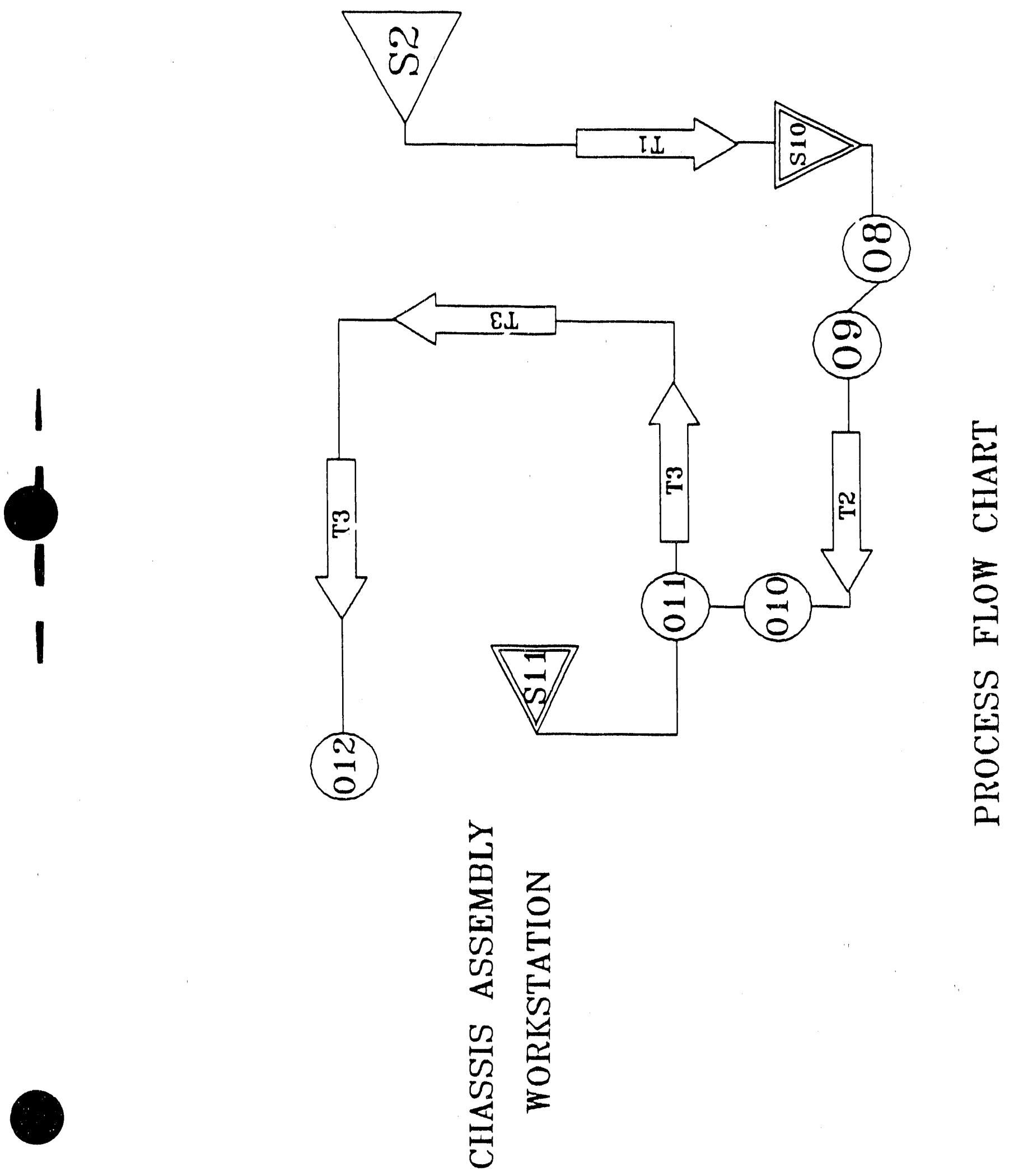


\section{Chassis Assembly:}

S2: Storage area for beam stock to be used for truss assembly.

S10: In-process staging conveyor where beams wait until ready for production.

S11: Storage area for axles and hitch assemblies.

O8: Beam cutting operation.

O9: Cut veams are welded together.

010: Chassis frame is assembled.

O11: Final assembly is performed including axle and hitch assemblies.

O12: Electrostatic painting of chassis.

T1: Beams are transported to staging area.

T2: Overhead crane system transports welded beams to assembly area. After the frame is assembled, crane lowers it down onto axles and the hitch is then installed.

T3: Chassis is tractor-pulled to the paint station. 
TIME CHIART

FOR

CHASSIS ASSEMBLY

Operation

Frame Assembly:

- Cut beam to size

- Weld small piece to next in-coming beam.

- Move beam to frame assembly area for welding

- Assemble chassis frame

- Move chassis to next workstation

Assemble Axje Wheels/Hitch

$20 \mathrm{~min}$

Move Chassis to Paint Area

Paint Chassis

Move Chassis to Drying Area

Move Chassis to Production Line
$5 \mathrm{~min}$

1

$20 \mathrm{~min}$

$5 \min$

$5 \min$
Total Time

$45 \mathrm{~min}$

* Note: Estimated maximum cycle time for chassis completion is 45 minute.

Production Rite Analysis

Requirement: 10 chassis/shift

Cycle Time: $45 \mathrm{~min}$./chassis

Production Rate: (1 chassis $/ 45 \mathrm{~min} . \times 460 \mathrm{~min} . / \mathrm{shift}$ ) $=10.2$ chassis $/ \mathrm{shift}$ 


\section{FLOOR ASSEMBLY WORKSTATION}

\section{Process Description}

Chassis is brought from paint area to the beginning of the production line. The chassis is placed on a dolly system, which is driven by a chain-pulled conveyor (Figure 22). The cutting station is located behind the assen.bly area and plumbing materials are brought from an adjacent workstation (Figures 23 and 24 ).

The following operations are performed at this workstation:

- Place scrim cloth over chassis. This protects insulation and seals bottom of the house.

- Lay down insulation (R-7 fiberglass).

- Layout underfloor electrical wiring and plumbing piping (Figures 25 and 26).

- Assemble floor framing using pneumatic nailers (Figure 27). Plywood decking is brought to the floor assembly workstation from a cutting station, which is located behind the workstation. See layout.

- Electrical wiring and plumbing piping are attached at the frame with tie wraps.

- Screw frame to Chassis (Figure 28).

The chassis is then pushed to the deck assembly area (Figure 29) where the following operations are performed:

- Finish underfloor electrical wiring and plumbing piping.

- Apply glue to frame (Figure 30 ). A glue hose is attached to the top of this workstation where it can be moved through the work area. 
o Lay sections of decking onto glue-coated frame and attach using pneumatic nailers (Figure 31). Normal deck panel size is $4^{\prime} \mathrm{x} 8^{\prime}$.

Floor opening cutting operations then take place at the next workstation where the following tasks are performed:

- Cut holes for toilets, electrical conduits, and plumbing. PVC connections are assembled in a workstation located to the right of the floor openings workstation.

- Reinspection, additional nails and screws are used where needed for floor support.

The following operations are performed at the next work area:

- Seal seams between decking panels (wood filler).

- Sand floor deck.

- Remove dust

- Place a foam padding onto deck for carpeting.

- Install carpet or vinyl.

- Cut off any excess carpet or vinyl.

- Cover carpet with plastic (Figure 32). 

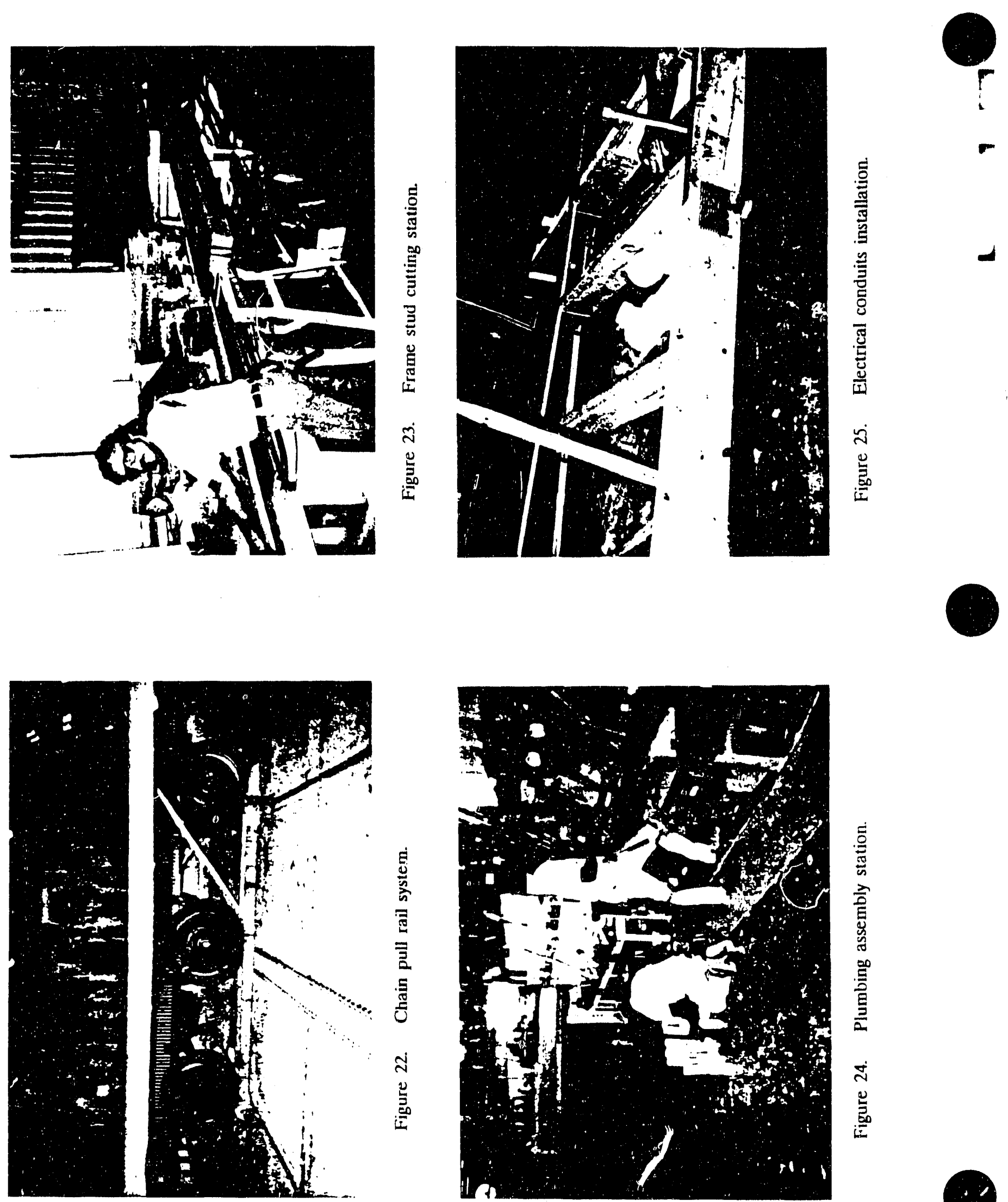

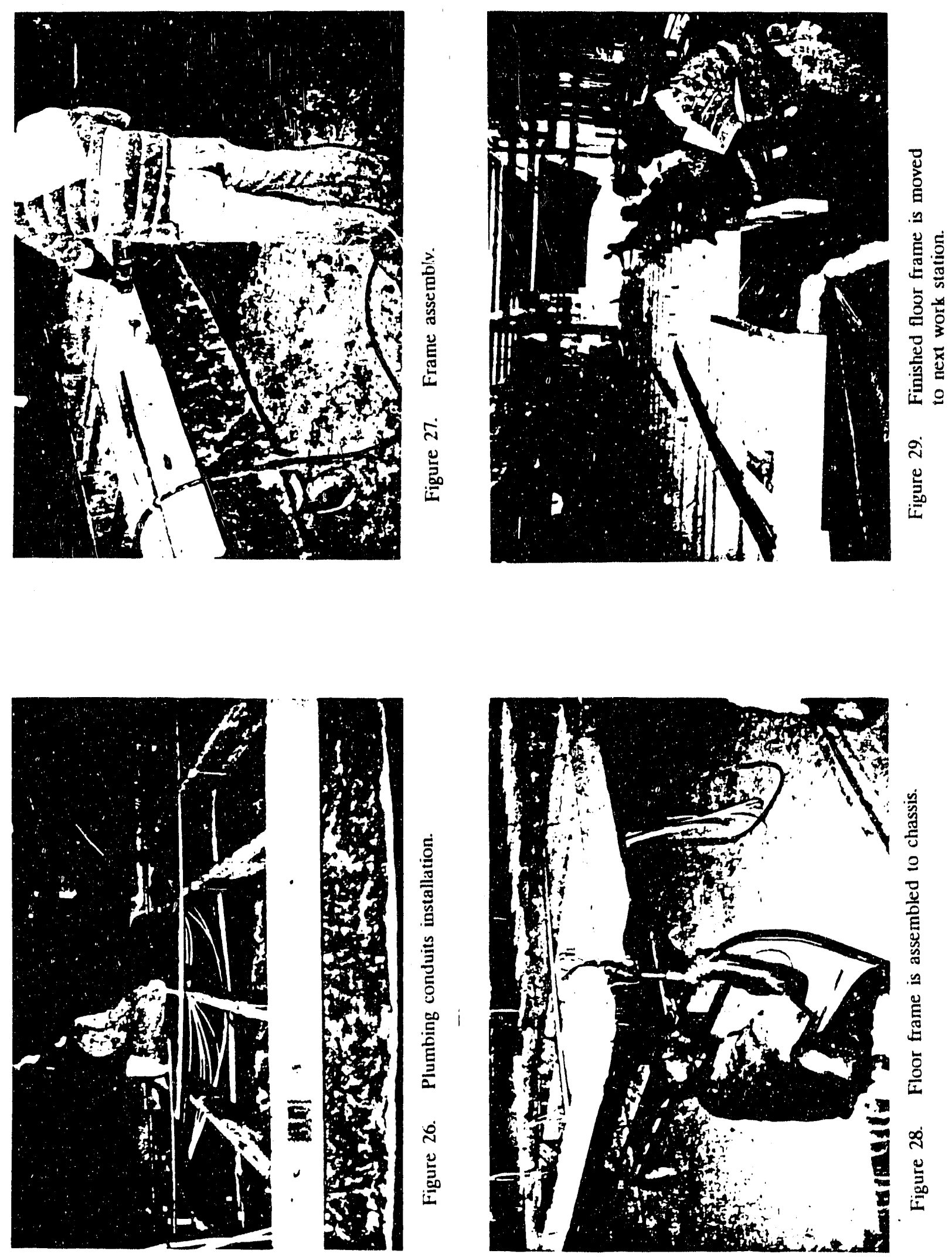


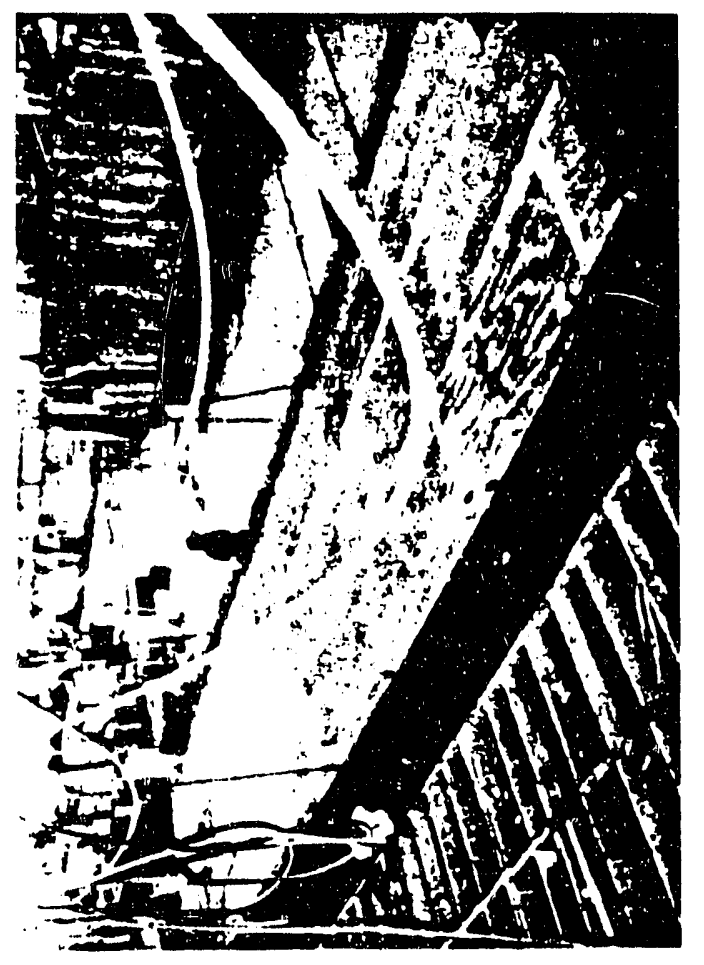

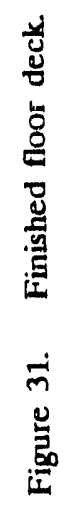
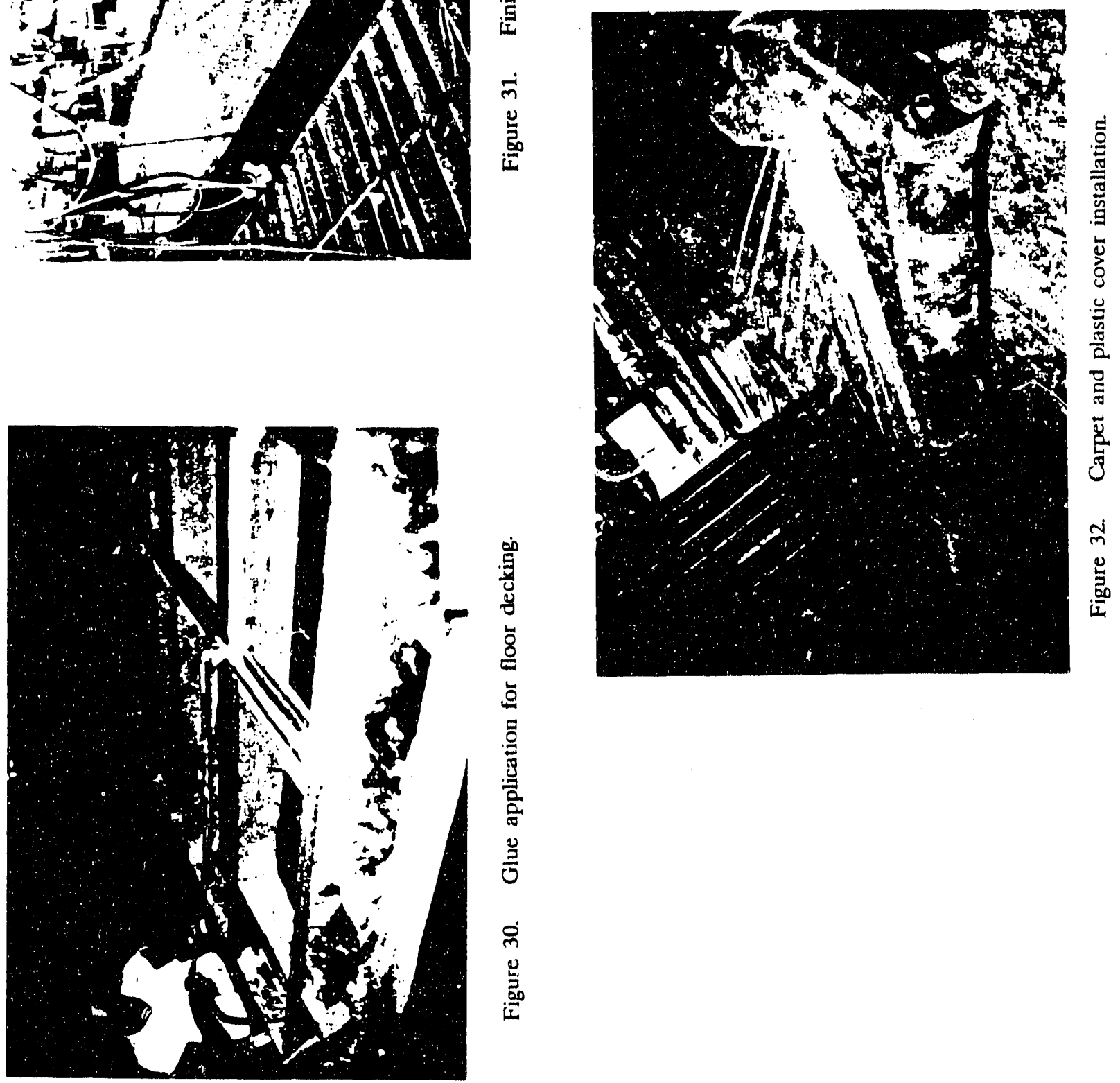


\section{Labor Utilization}

In the floor frame assembly workstation there are three assemblers, one of which is also responsible for cutting floor joists. Two additional assemblers operate in the deck assembly area. Four additional workers are utilized in the other two floor assembly areas.

\section{Materials Handling}

Chassis is brought onto production line by a tractor and placed on mobile pallet carts connected to a chain driven floor conveyor system. Floor frame materials are transported from warehouse by forklift to in process storage. Joists are manually put onto small conveyor on which they are notched and cut to length. The frame is then assembled on the top of the chassis. The finished floor frame is transported to the decking station by the chain conveyor system. Floor decking is brought to the workstation manually. After holes are cut for toilets and showers, toilet fixtures are hand carried to production line. Showers are also brought in manually and installed. The floor assembly is moved to the next workstation. Carpet and vinyl is brought in from secondary warehouse by forklift to be installed.

\section{Inspection}

Inspection is performed at this station to check for leaks in the plumbing piping as well as for any missed nailing in the floor deck. 
Equipment Description

o Cutting: 1 radial arm saw

1 circular hand saw

1 notching saw

1 jig saw

- Assembly: pneumatic nailers and screwdrivers

1 glue gun

1 electric floor sander

- Jigs/Fixtures: none.

- Materials Handling: Chain driven floor conveyor system

1 tractor

\section{Recommendations}

It is recommended that the following suggestions be irvestigated:

1. Layout:

- The installation carpet in the plant. This could the risk of damage to the material.

2 Process:

- Floor deck installation produces substantial amounts of scrap. This extra scrap could be eliminated by precision cutting. Computerized cutting systems are available to increase cutting speed and accuracy such as the one shown in Figure 33.

- Eliminate reinspection for missed nailing by the use of automatic panel staplers. Appendix A shows some available equipment for this 
purpose.

3. Labor:

- Manpower can possibly be reduced to six workers; two for framing, two for decking, one for sanding/floor openings and one for installing plumbing. Decking tables such as one shown in Figure 34 are available.

4. Materials Handling:

- Install an overhead storage \& retrieval system for bringing toilets and showers to the production line. 


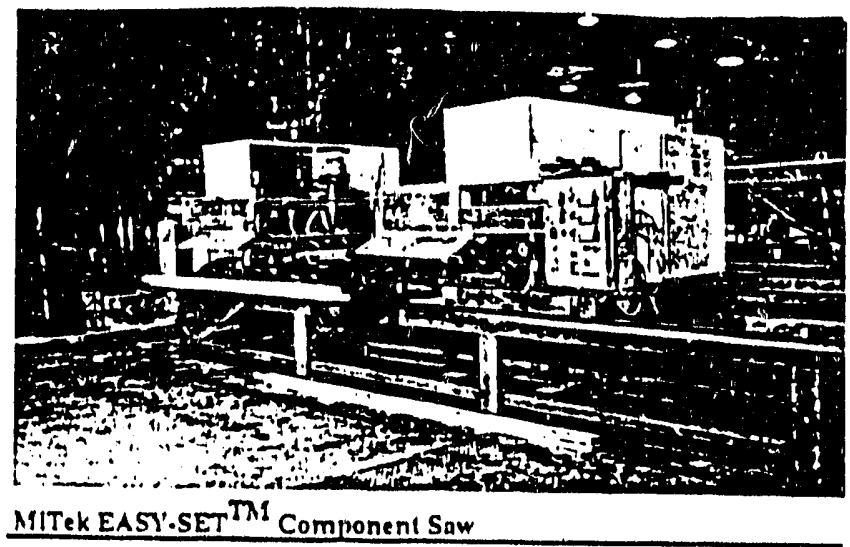

Figure 33

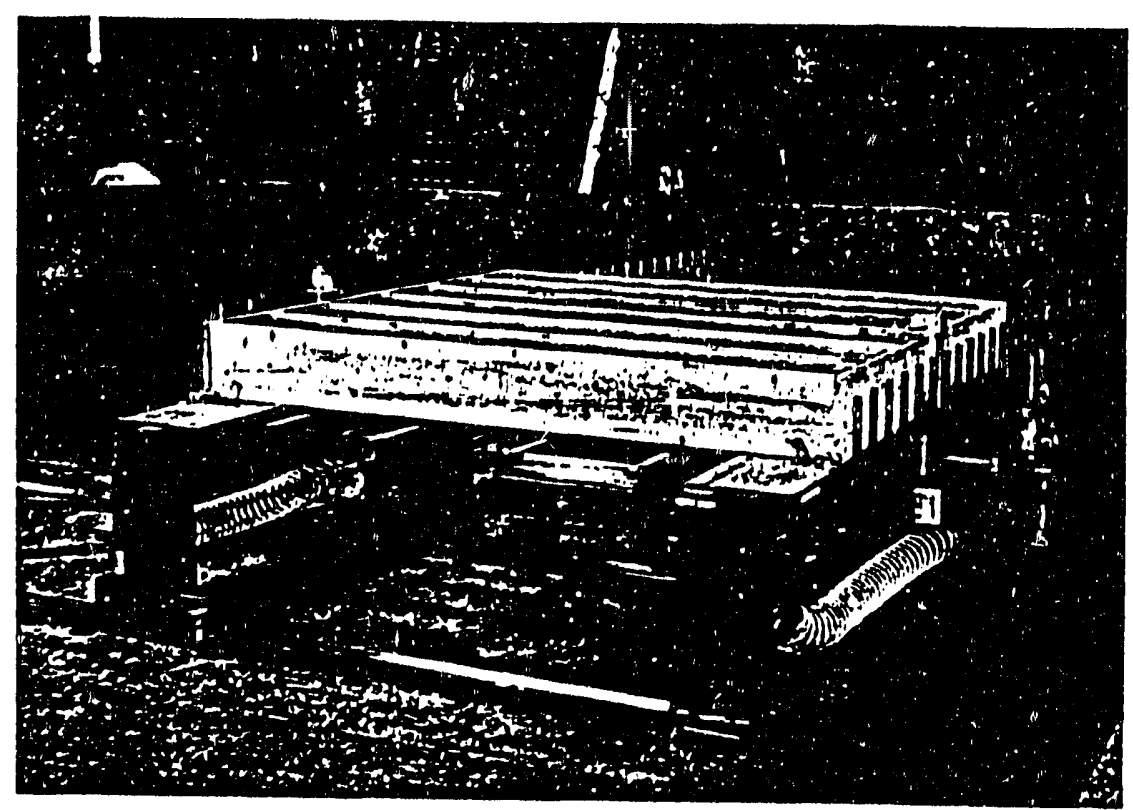

The Senco/Carlson Deching Table, Senco Products and Carlson Systems, is designed to bandle larger and heavier materials. The table clamps, squares and fastens lumber from $2 \times 3$ to $2 \times 12$ for hoor or deck modules up to $16^{\prime} \times 16^{\prime}$. The tool carriage is equipped with Senco SN4 pneumatic nallers and features full safety controls and an adjustable Pastener pattern. Retractable joist locators on 16" and $24^{\prime \prime}$ centers can bandle most designs. Hardened steel plate-clamp posts provide vertical and borizontal clamping to ensure square, tight-ntting floor modules. Fixed posts are used for $2 \times 3$ to $2 \times 6$ construc. ton; extended posts are used for joist material up to $2 \times 12$. Tuin ceater supports speed the loading of beavy joists and the deck removal system includes air powered lin rod
manual rollorf.

Figure 34 


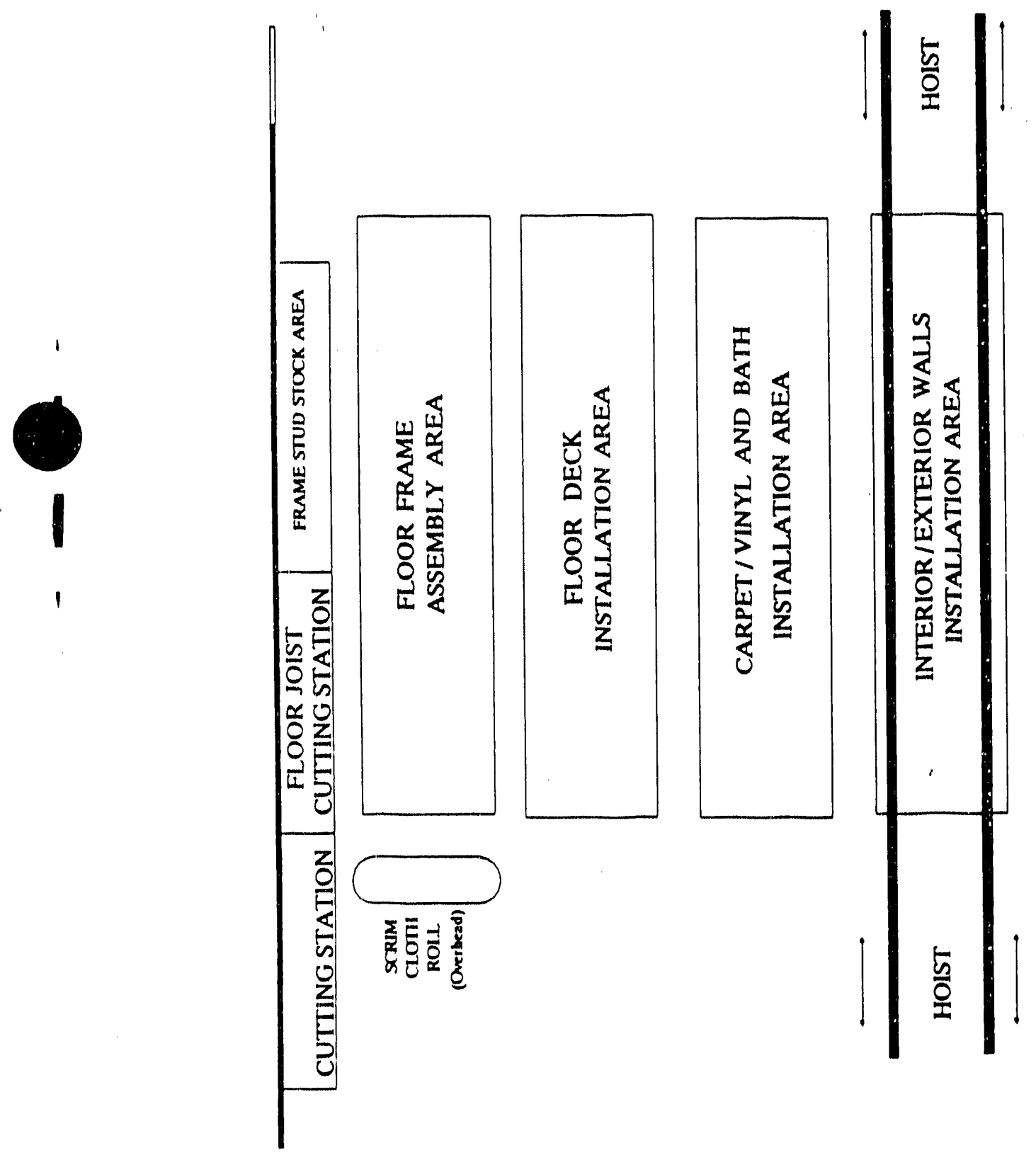

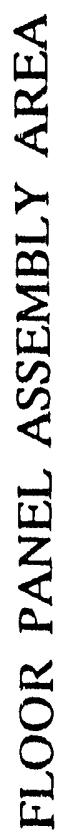




\section{FLOOR PANEL ASSEMBLY FLOW CHART}

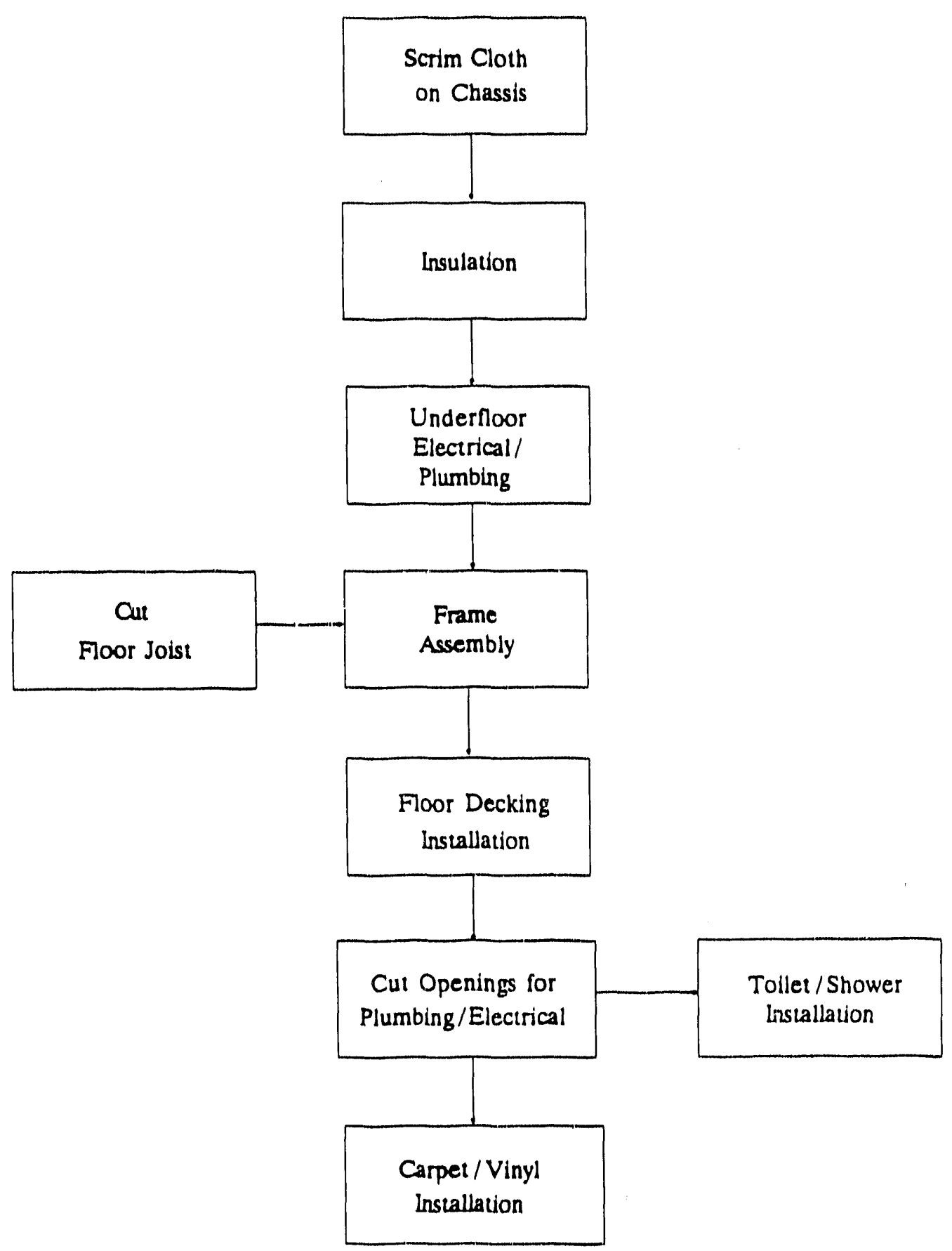




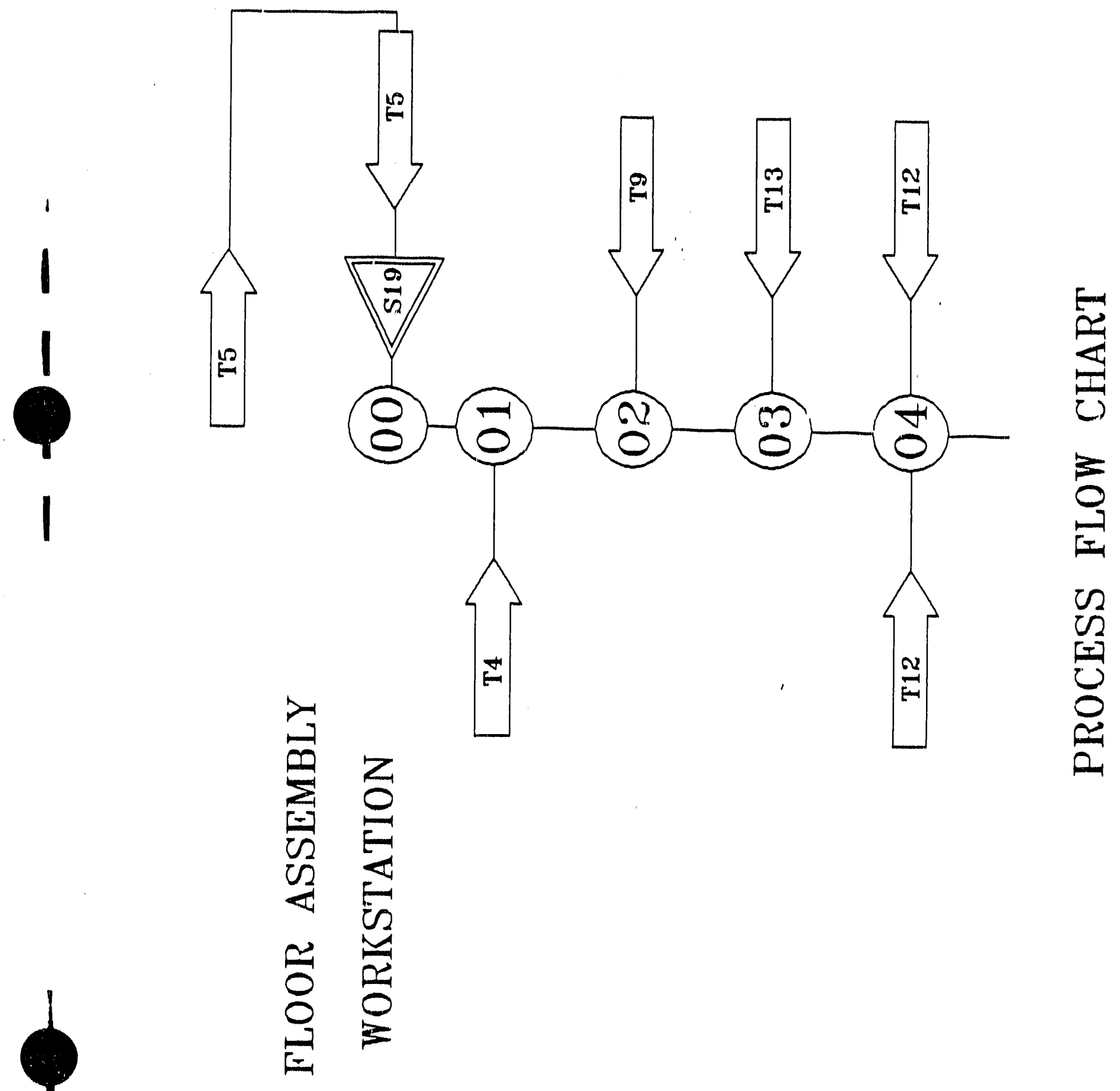


Floor Assembly:

S19: Temporary staging of floor frame stock.

O0: Floor frame is assembled.

O1: Floor deck is attached.

O2: Openings for tollets, showers, and plumbing are made and toilets and showers are installed.

O3: Carpet and vinyl installation.

04: Interior/exterior walls, and kitchen cabinets and counters are installed.

T4: Finished chassis is brought onto production line.

T5: Floor framing stock is transported from main warehouse.

T9: Previously defined.

T12: Previously defined.

T13: Previously defined. 
TAME CHART

FOR

FLOOR ASSEMBLY

Operation

No. of Operators

Total Time

Frame Assembly:

3

$45 \mathrm{~min}$

- Place scrim cloth on top of chassis

- Place insulation

- Place underfloor electrical wiring/plumbing piping

- Cut joists to size

- Assemble frame

- Move unit to next work area

Assemble Deck Floor:

$30 \mathrm{~min}$

- Apply glue to frame

- Attach floor decking

- Seal gaps between boards

- Move unit to next work area

Floor Openings

$20 \mathrm{~min}$

Carpet/Vinyl Installation:

$15 \mathrm{~min}$

- Sand floor deck

- Remove dust and apply protection coating

- Install foam padding/carpet or vinyl

- Cover carpet with plastic

- Move unit to next work area

\section{Production Rate Analysis}

Requirement: 10 floor units/shift @ 2 floors/home

Cycle Time: 45 min.//loor

Production Rate: (1 floor $/ 45 \mathrm{~min} . \times 460 \mathrm{~min} . / \mathrm{shift}$ ) $=10.2 \mathrm{assemblies} / \mathrm{shift}$ 


\section{EXTERIOR WALL ASSEMBLY WORKSTATION}

\section{Process Description}

Wall paneling and framing studs are cut to size in an area located behind the framing tables.

The following operations are performed at this workstation:

- Assemble wall frame, no jigs/fixtures are used (Figure 35).

- Install insulation (R-11 fiberglass).

- Apply glue to frame (Figure 36 ).

- Attach inside wall panel to frame using pneumatic staplers.

- Cut holes for windows and doors, electrical outlets and light switches (Figure 37).

- Move finished exterior wall to temporary staging rack (Figure 38).

- Move exterior wall to production line with an overhead hoist (Figures 39 and 40).

- A small working station for plumbing is located next to this workstation.

\section{Labor Utilization}

This workstation has two work tables, with crews of two at each table. There is also a small work table for end walls, in which there is only one worker. A similar work table is located next to the interior wall assembly area. Panels are cut 'jy the same workers. 

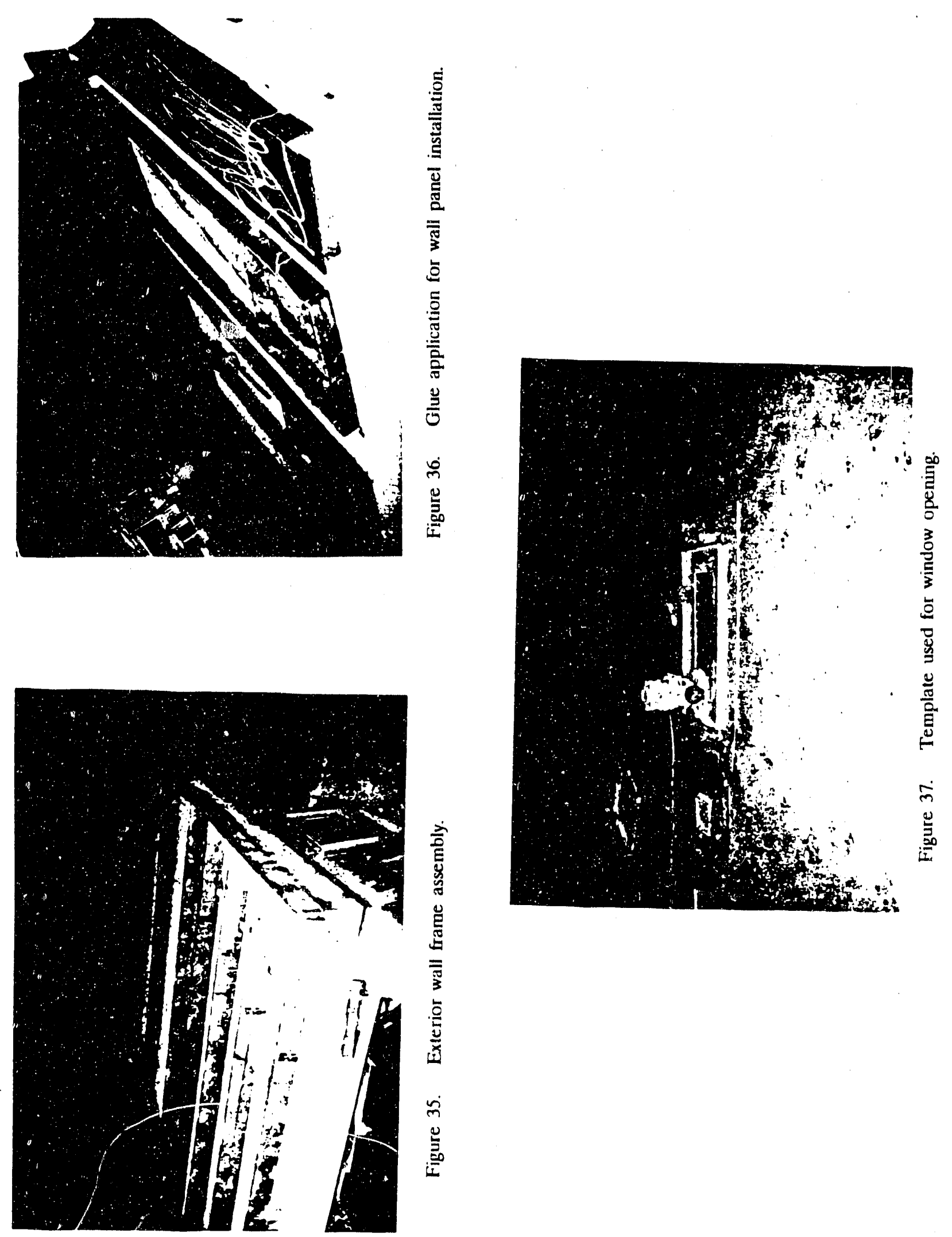


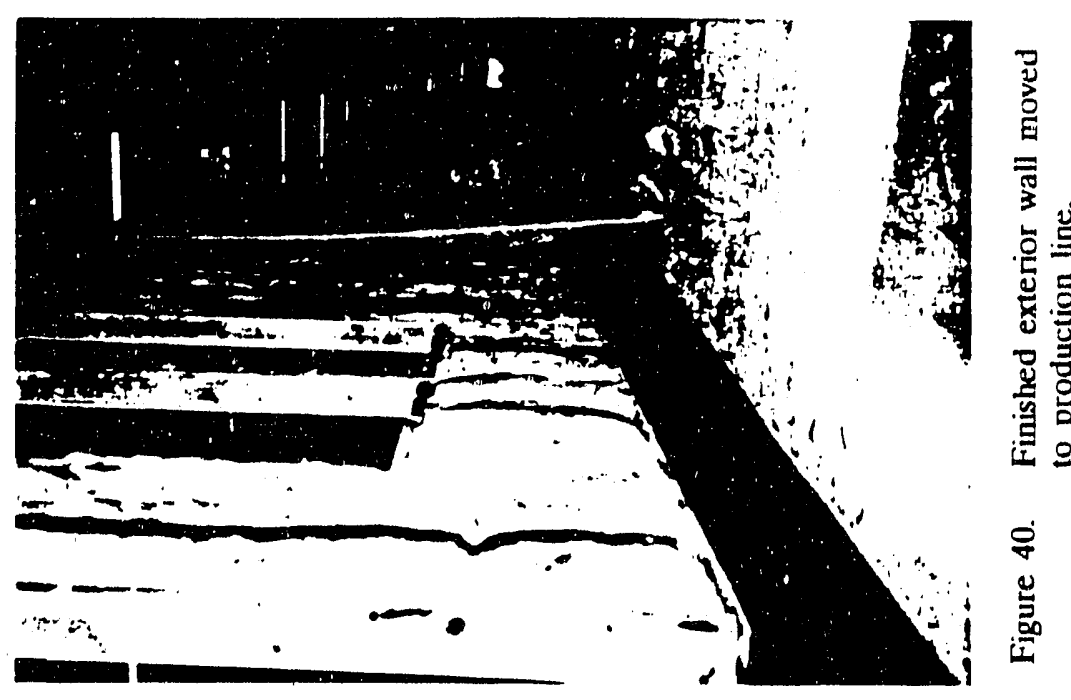

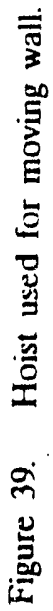

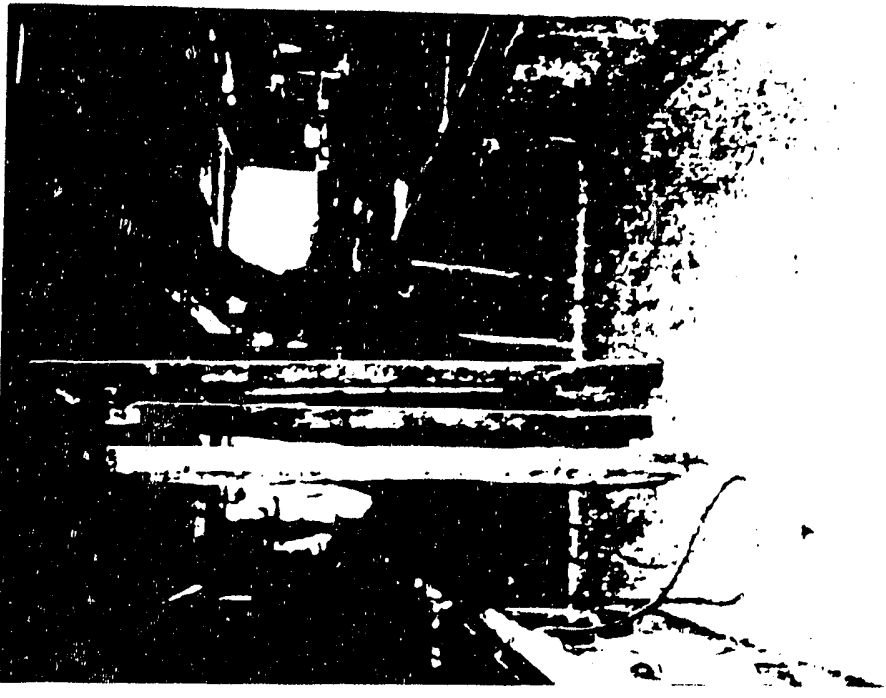

芒

$\infty$

选 


\section{Materials Handling}

Wall board, stud framing, and other building materials are brought to this station from the riaiai warehouse with forklifts. Materials are placed on pallets in temporary storage areas until needed. After cutting is performed materials are manually transported to assembly worktables. After completion, walls are manually placed in another temporary staging area. They are then taken to installation using the overhead crane hoist system.

Inspection

No inspection is performed at this station.

\section{Equipment Description}

- Cutting: 1 table saw and 1 radial arm saw.

o Assembly: pneumatic nail guns and hammers, drywall knives, 2 worktables.

o Jigs/Fixtures: none except for small templates used to cut openings for electrical boxes and light switches.

o Materials Handling: 2 forklifts, 1 overhead crane hoist, and 1 staging rack.

\section{Recommendations}

It is recommended that the following suggestions be investigated.

1. Layout: None. 
2. Process:

o Employ the use of jigs and fixtures for framing.

- Utilize automatic framers that can improve the speed, accuracy, and quality of the process. An example is shown in Figure 41.

- Use polyurethane foam for wall panel assembly rather than pneumatic nailers for fastening. It is believed that foam can produce a stronger, more level assembly, as well as increase the longevity of the wall panel. Additionally it reduces the need for glue and nails.

o A major consideration would be the cost of the foam as compared to current methods.

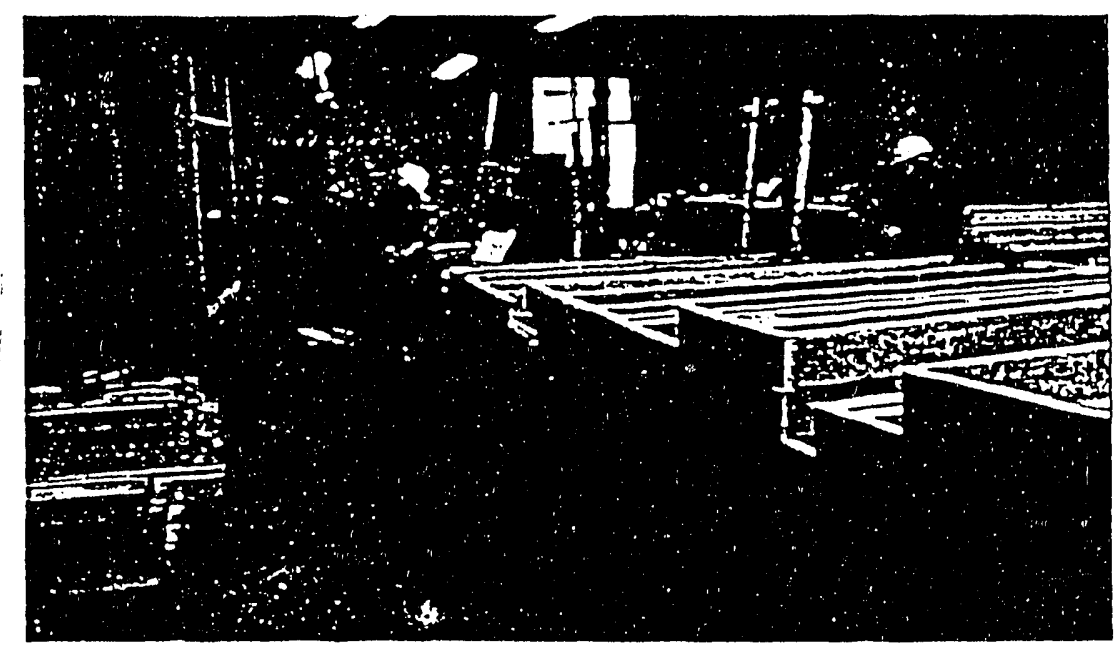

A PMIHI CREW assembles a $2 \times 6$ wall padel with a Diamond Quad Framer by Triadilerrick Machlne Co., equipped with Paslode aailing guns. PH.MI also builds $2 \times 4$ exierior walls. Window and door openings are (ramed al the head of the line (pole units standing on end) and sub-com. penents (jacks, lees, corners) are bullt al workstolion to the lesh (not shoun).

Figure 41 
3. Labor:

o Work is currently performed with crews of two at each table.

Additionally, there are two others building end panels bringing the total to six.

- Eliminate second framing and assembly crew. It is believed that this would not effect meeting production requirements because a sizeable storage buffer exists for finished panels. Manpower is then reduced to four.

- Remove cutting operations.

4. Materials Handling:

o Reduce the amount of handling time required by the workers. Automatic stacking and palletizing equipment, conveyors (see Figure 42), and vertical rollers (see Figure 43) exist that could perform these operations efficiently.

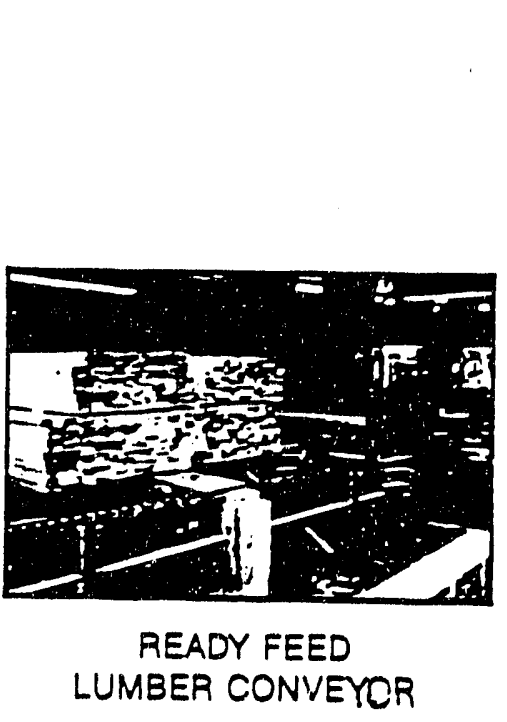

Figure 42

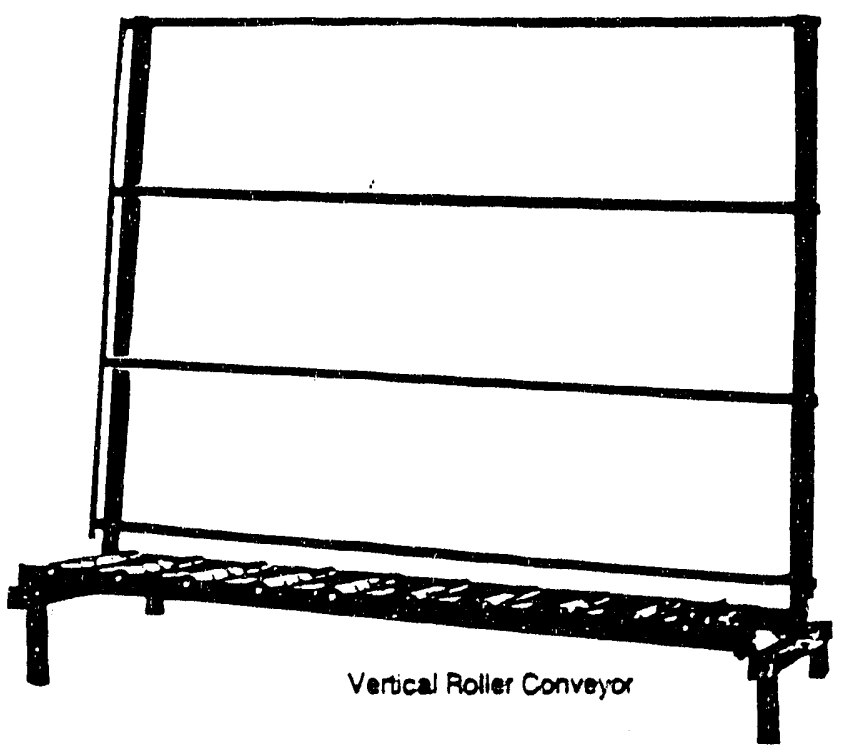

Figure 43 
o Plumbing stock, sinks, and toilets are transported from secondary warehouse into this workstation. Toilets are placed on elevated storage racks and wait to be sent for installation. Plumbing and PVC materials are placed in temporary storage until pipes and conduits have been cut and are ready for assembly which could be done on a work table like that shown in Figure 44. Plumbing items are manually transported to production for installation.

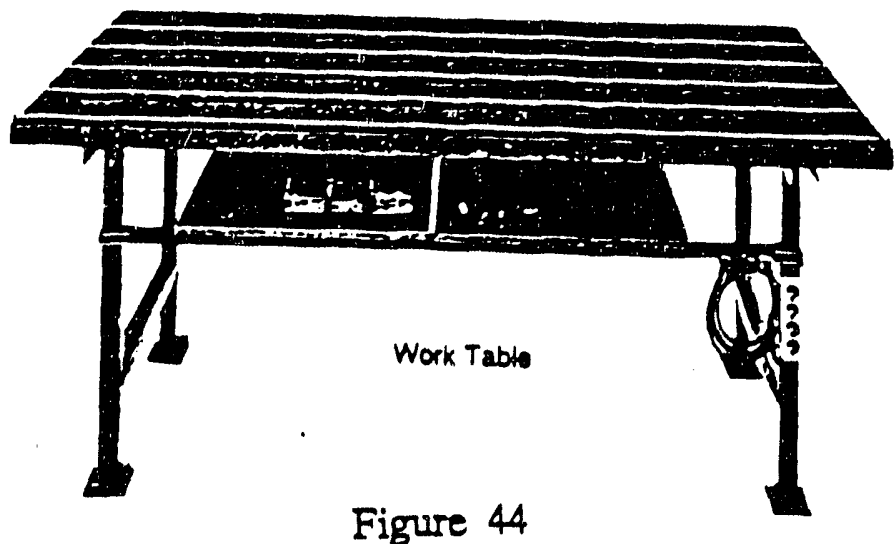

Figure 44 


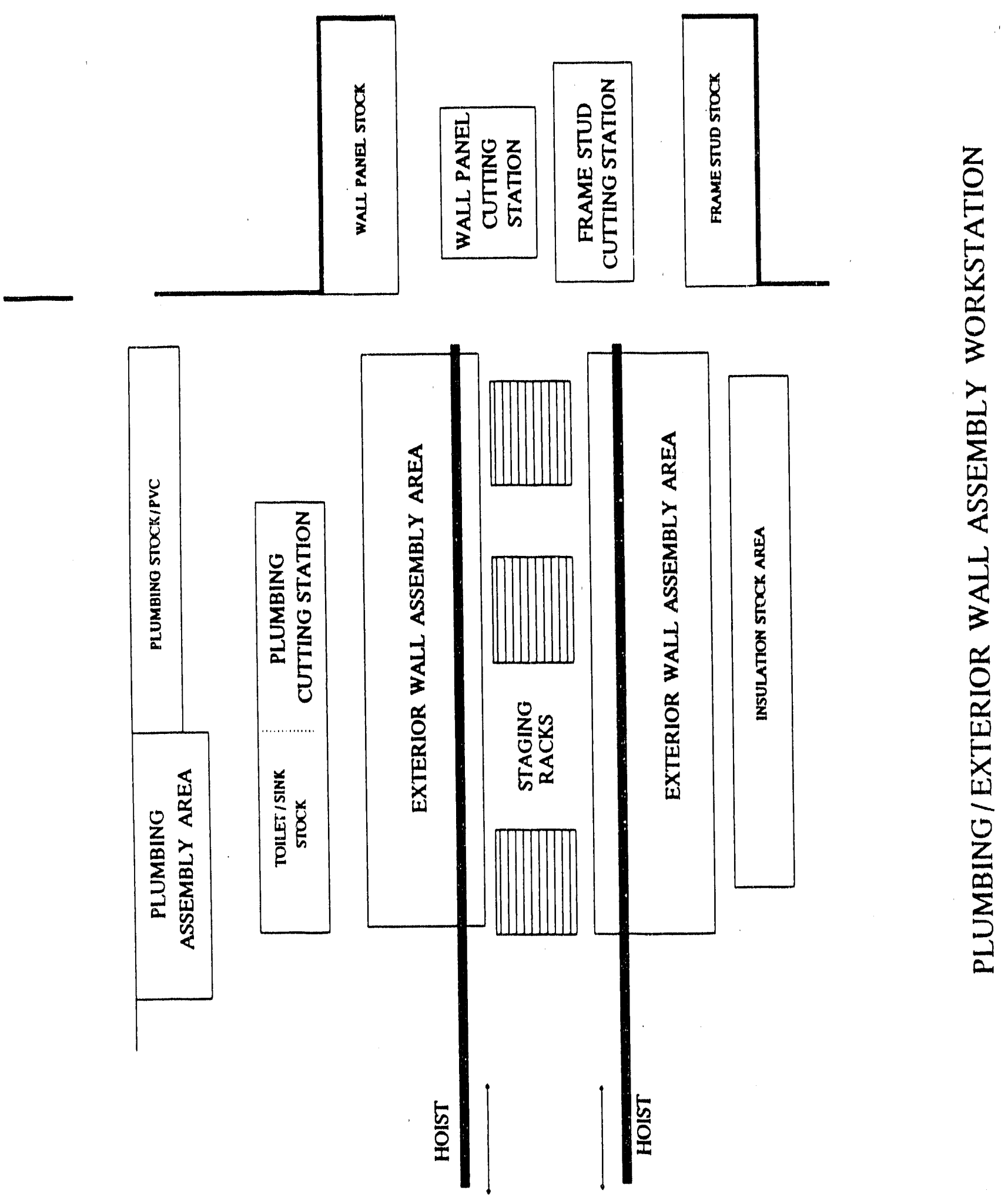




\section{EXTERIOR WALL ASSEMBLY FLOW CHART}

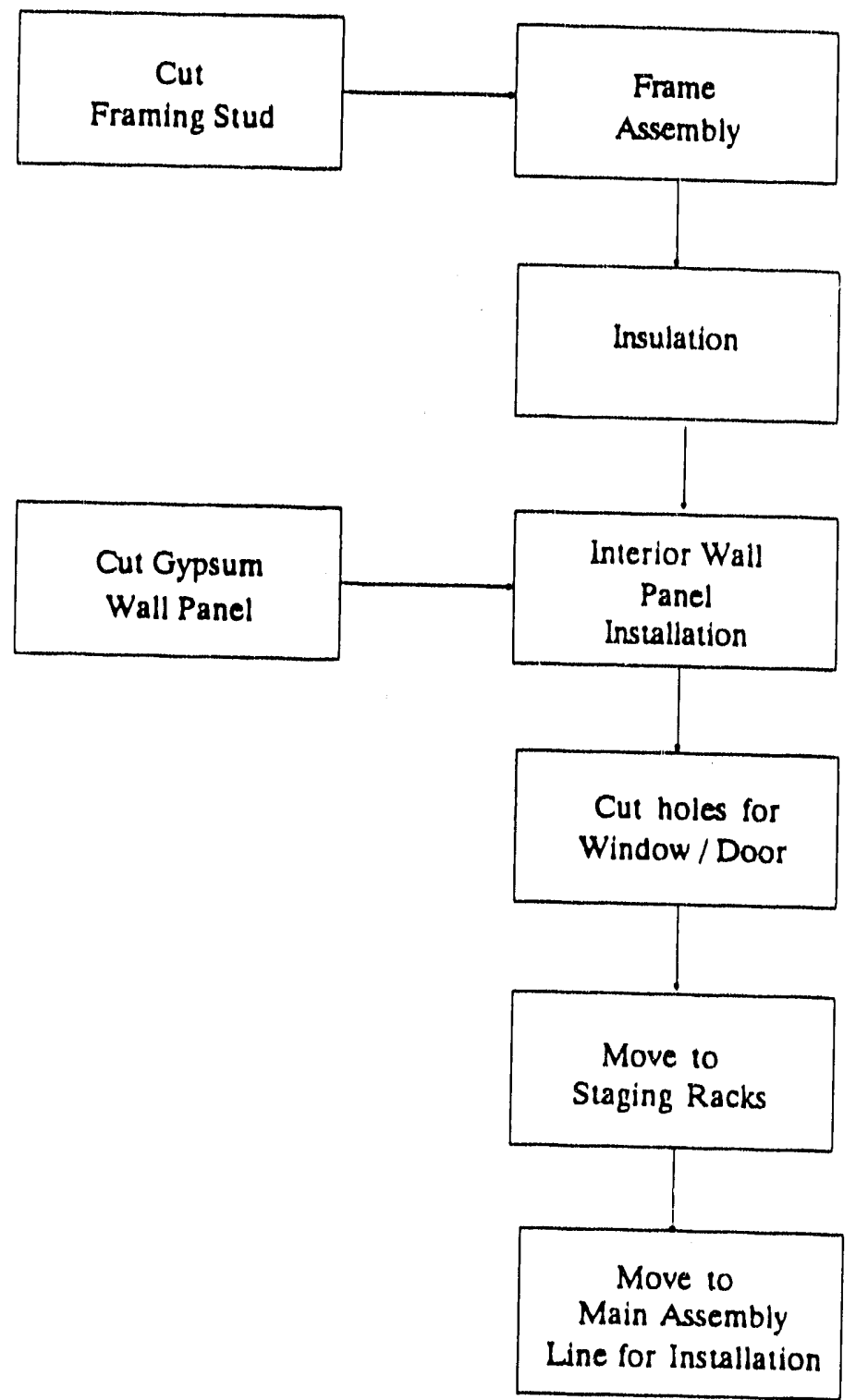



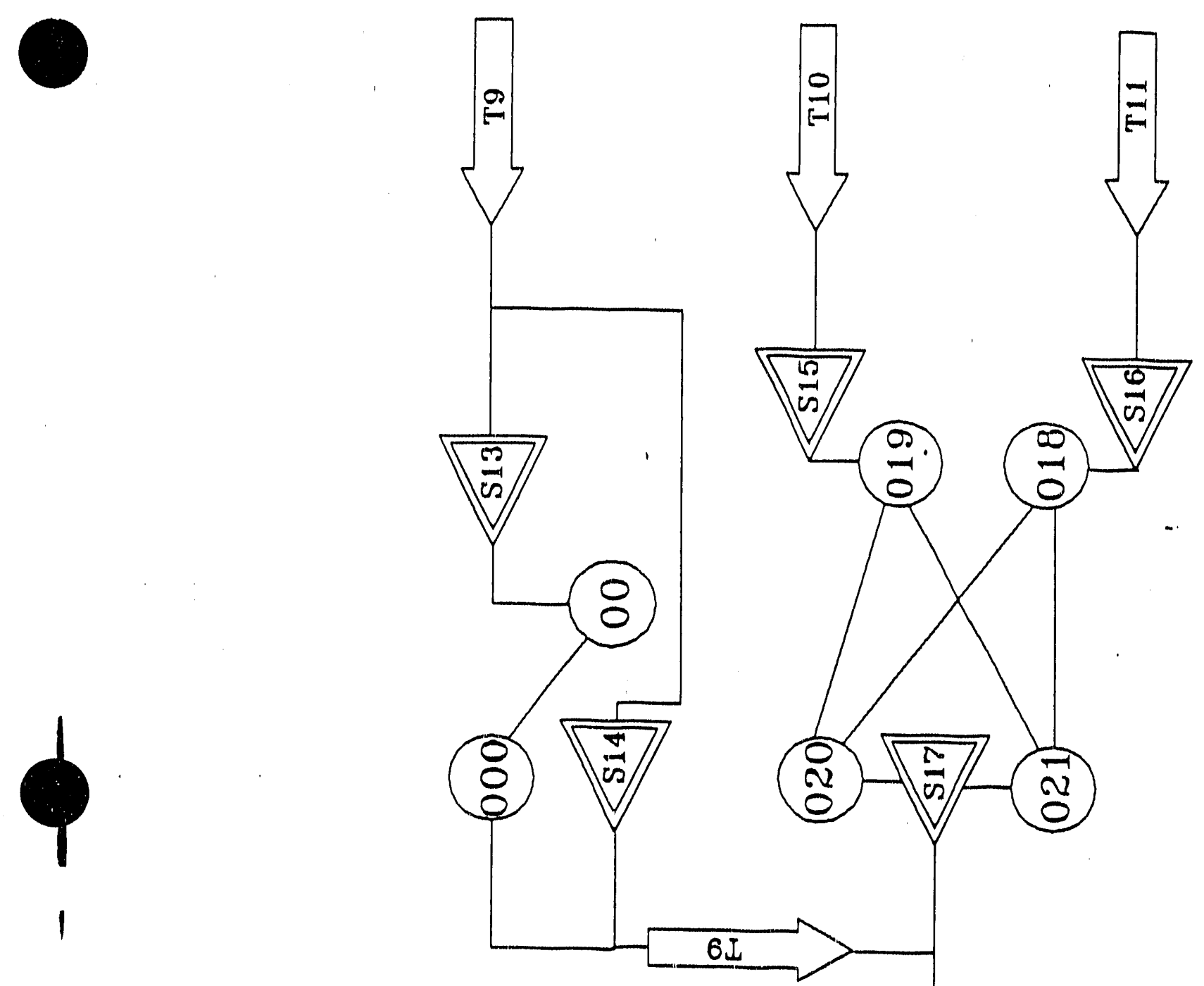

3
0
0
0
0
0
0
0
0
0
0

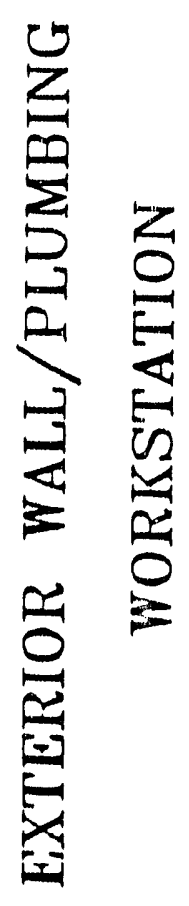


Exterior Wall/Plumbing Assembly:

S13: Plumbing and PVC stock are temporarily staged.

S14: Toilets and bathroom sinks are staged.

S15: Framing studs are temporarily stored.

S16: Drywall is temporarily stored.

S17: In-process storage for assembled exterior walls.

O0: Plumbing lines are cut to size.

O00: Plumbing items assembled.

O18: Drywall is cut to size.

O19: Framing studs are cut to length.

O20: Drywall to frame assembly is performed including installing insulation.

O21: Same as O20.

T9: Plumbing and PVC materials are brought from secondary warehouse.

T10: Framing stock is transported from main warehouse.

T11: Panel stock is transported from main warehouse.

T12: Exterior walls, toilets and sinks, and plumbing are transported to production line. 
TIME CHART

FOR

EXTERIOR WALL ASSEMBLY

Operation

Side wall Assembly:

- Cut studs to size

- Assemble framing

- Apply glue to framing

- Cut dry wall to size

- Attach dry wall

- Cut holes for window/door

- Move finished wall to staging racks

End wall Assembly:

- Same as side wall assembly

Move Exterior Wall to Production Line
Total Time

$25 \mathrm{~min}$

\section{Production Rate Analysis}

Requirement:30walls/shift @6walls/unit

Cycle Time: $50 \mathrm{~min} . / \mathrm{wall} / \mathrm{crew}$

Production Rate: ( 1 wall $/ 50$ min. $\times 460 \mathrm{~min} . / \mathrm{shift} \times 4 \mathrm{crews}$ ) $=36.8$ walls $/ \mathrm{shift}$ 


\section{INTERIOR WALL ASSEMBLY WORKSTATION}

\section{Process Description}

Two cutting stations, one for stud framing studs and one for paneling, are located behind and adjacent respectively, to the assembly tables (Figures 45 and 46 ).

The frame assembly consists of the following operations:

- Assemble wall framing with pneumatic nailers (Figure 47).

- Holes are drilled for electrical wiring.

- Install electrical wiring.

Finished frames are then placed in temporary storage where they wait to be moved to the gypsum drywall installation table adjacent to the framing table. The following operations are performed:

- Apply glue to frame (Figure 48).

o Install gypsum drywall. Adjustments are manually performed with tapes.

- Cut holes for electrical boxes, and openings for doors.

Finished interior wall is then manually transported to another staging rack (Figures 49 and 50) before it is taken to the production line with the hoist 

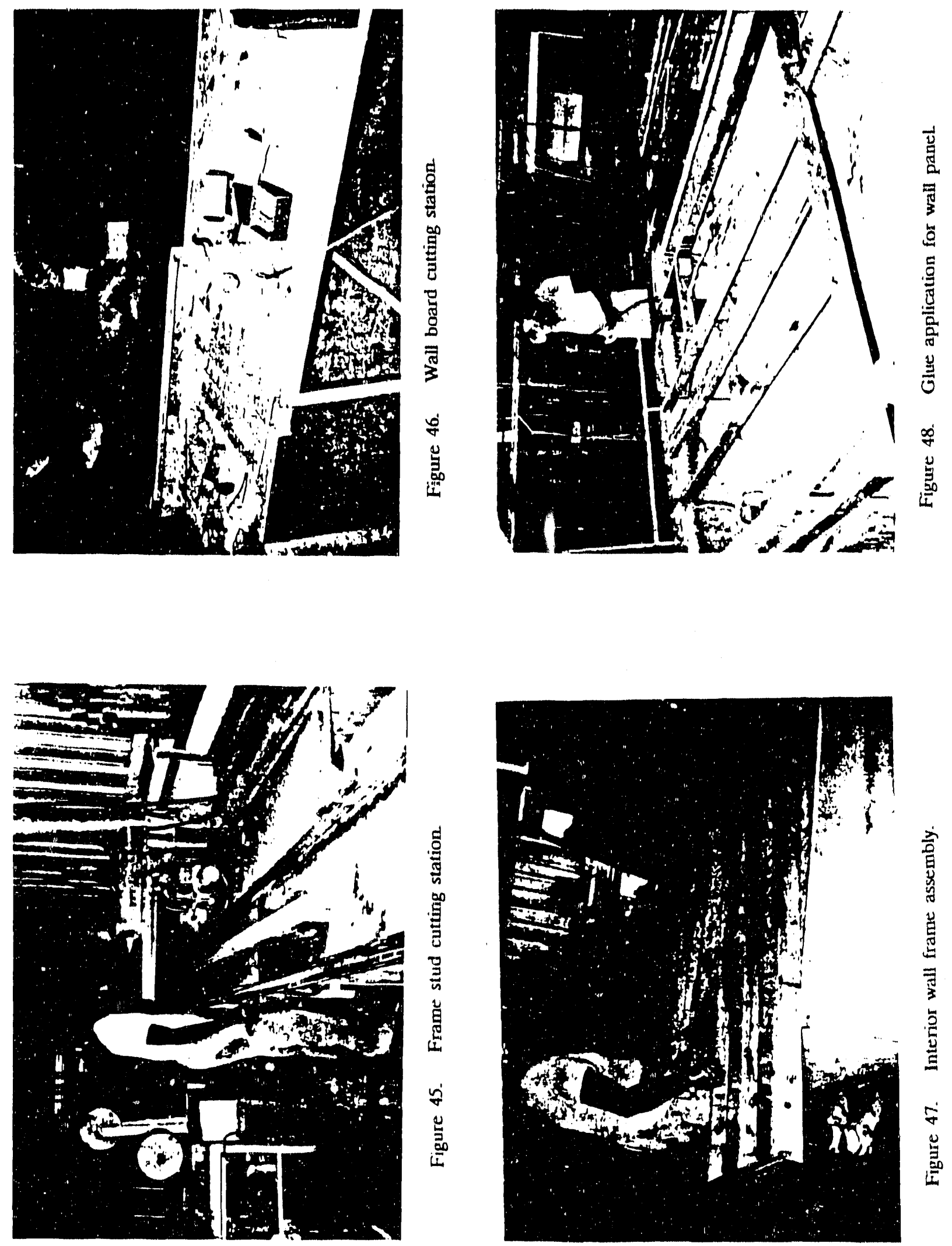

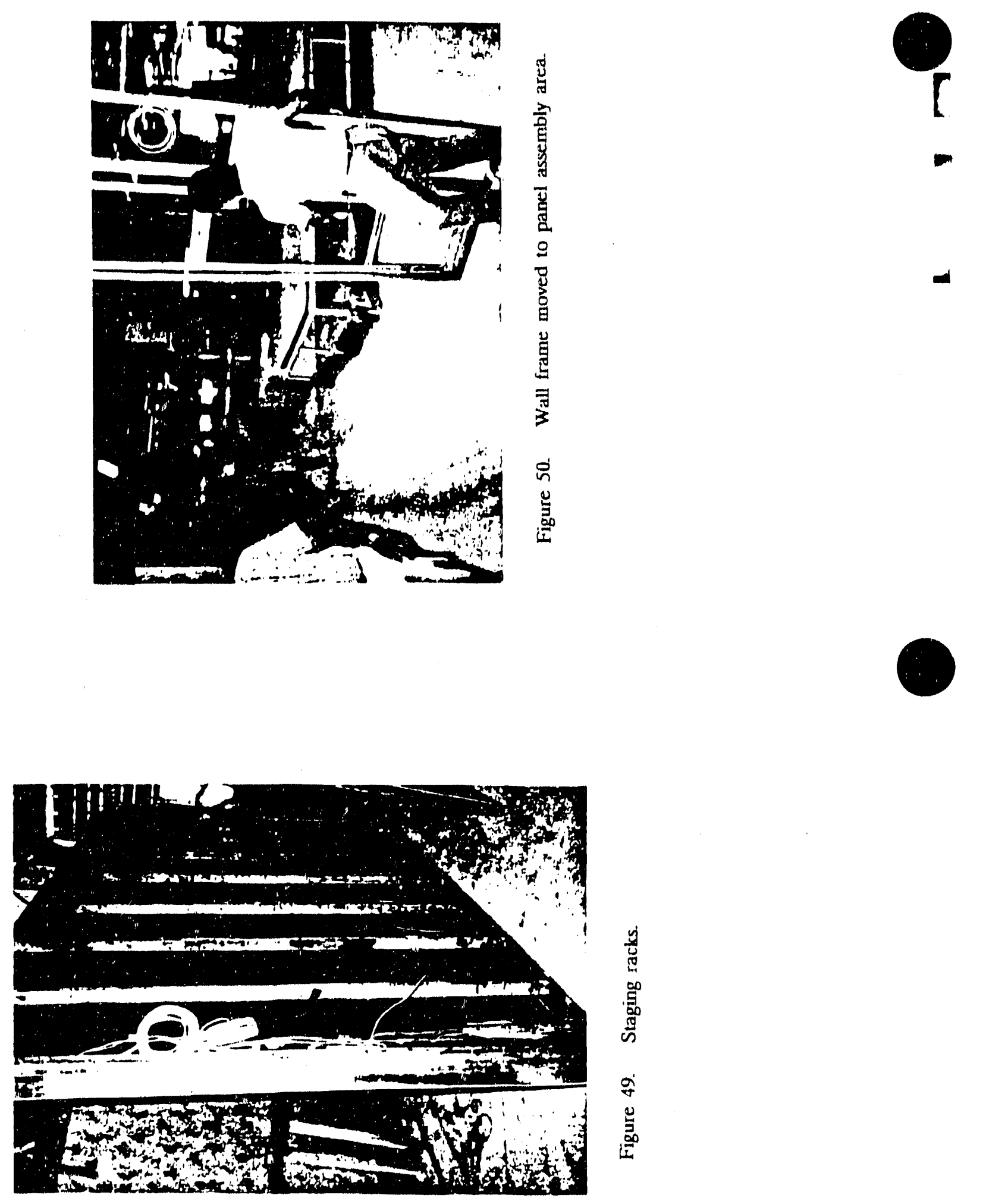


\title{
Labor Utilization
}

Total manpower utilized in both working areas is five. Studs for framing are cut by the same workers that assemble the frames. In a similar fashion the people that attach wall paneling will have to cut the panels at a station located next to the worktable and manually place them for attachment.

\section{Materials Handling}

Wallboard, framing studs, and other building materials are brought to this station from the main warehouse with forklifts and temporarily stored on pallets. Stock is then hand carried to cut stations. After cutting is performed materials are moved to framing table. Once the frame is completed, it is placed in temporary staging, then put on an assembly table for wall board attachment. Drywall sheets have also been hand carried to assembly table. After completion, walls are hand carried to another temporary staging area, from there they are taken to main assembly line for installation using an overhead crane hoist system.

\section{Inspection}

No inspection is performed at this station.

\section{Equipment Description}

\author{
- Cutting: 1 table saw \\ 1 radial arm saw \\ o Assembly: pneumatic nai! guns and hammers \\ 2 worktables
}


- Jigs/Fixtures: none

- Materials Handling: 2 forklifts

1 overhead crane hoist

\section{Recommendations}

It is recommended that the following suggestions be investigated:

1. Layout:

- Remove all cutting operations and dedicate this station to assembly only. Additionally, more floor space is created. See section on general recommendations.

2. Labor:

- With present system there are approximately six workers involved. This number could be reduced to five by employing same method 3 that used for exterior walls.

3. Process:

- Employ the use of jigs or fixtures for framing.

- Utilize automatic framers that can improve the speed, accuracy, and quality of the process (Figure 41).

- Use polyurethane foam for wall panel assembly rather than pneumatic nailers for fastening. It is believed that foam can produce a stronger, more level assembly, as well as increase the longevity of the wall panel. Additionally, it reduces the need for glue and nails.

- Perform entire operation on one table and have two tables operating at one time. Majoi considerations are if production requirements can be maintained and the cost of the foam as compared to current 
methods.

- Utilize layout tables with jigs that can effectively reduce the need for skilled framers.

- Utilize other equipment that are available such as framing tables (see Figure 51), component nailers (see Figure 52), and framing machines, and automatic panei staplers for assembly (see Figure 53).

This equipment can increase production rates, reduce labor, and ensure consistency, and improve quality. See Appendix A for additional equipment listings.

4. Materials Handling:

- Reduce the amount of handling time required by the workers. There is equipment available to accomplish this task. Automatic stacking and palletizing equipment such as the one shown in Figure 54 and conveyors exist that perform these operations efficiently and allow the workers to spend more time in productive operations. See Appendix A for additional listings of equipment. 


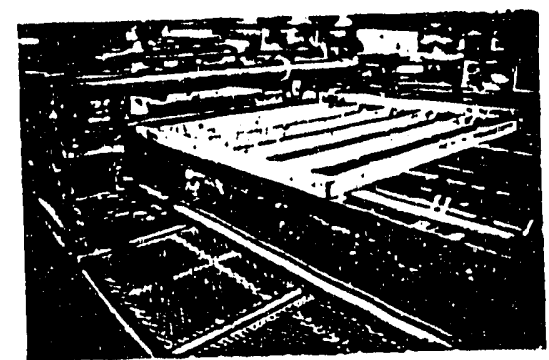

Trlad's New Heary Duty Framing Tnble with Slud Stitcher Bridge is custom-built from 12 to $80^{\prime}$ to fil vour needs. Adjusts from $3^{\prime} \cdot 6^{\prime \prime}$ to 10. '3" for different wall heights. Cast Iron stud localing Nippers 16 " and 24 "O.C ConIInuous squaring lip full length of the lable ISeary duly sicel rollen with roller bearlnes used to convey walls orr. Simple pusb bution tem. Tape Irack for laying In window and door openinges.

Figure 51

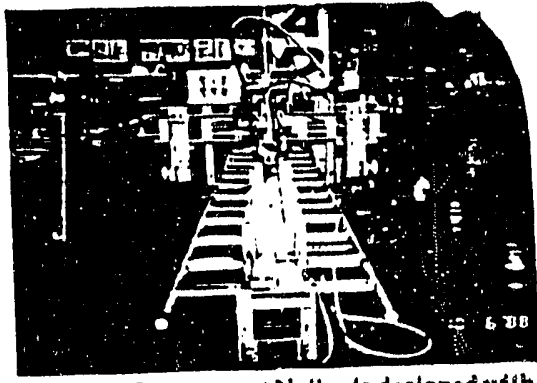

CN-4 Sub Component Naller is deslened with Trind's quitet qunlliy. The CNA can necom modale quenthing from a $2 \times 1$ 10 a $2 \times 12$. Tool can be mounted in the overhead position or can belo mides. anay squaring slop and on thelr sides. $A$ illities trom both clamping capabillies from both the sides and overhead straigbten out normally culled umber. One man operation and nith dual clamp butlons and dual fire bullons, the machine is enfe. Will bulld corners, headers, lees, ells, etc.

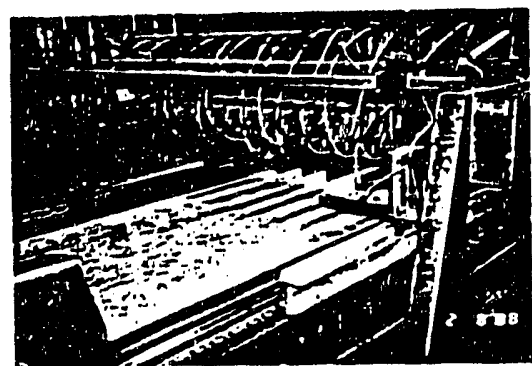

Panel Sloplet by Triad belps you coatrol loday's constructlon costs by bullding quality, square wills with fewer people. Be as. sured of aceurate anll and staple plocement 10 codes. Latest slate-of the-art Laser Polnier for Indleating slople end anll locations, elons with programmable controllers that control the functions of one bridge Space fire tools need to festen top and bottom plate. One men operallon with a simple control box make for bich production.
Figure 52

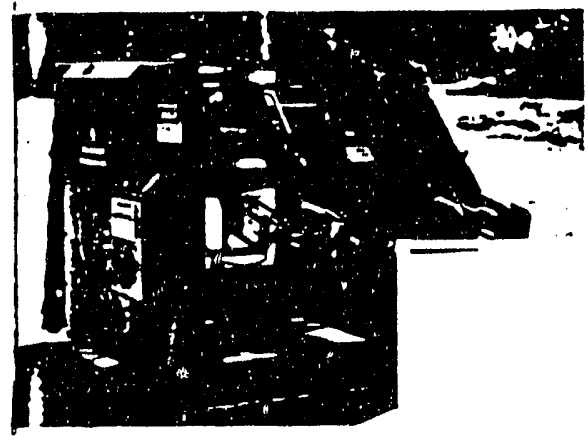

Figure 54
Figure 53

\section{Automatic}

Lumber Stacker

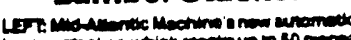

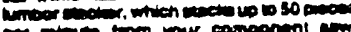

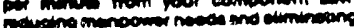

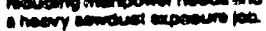




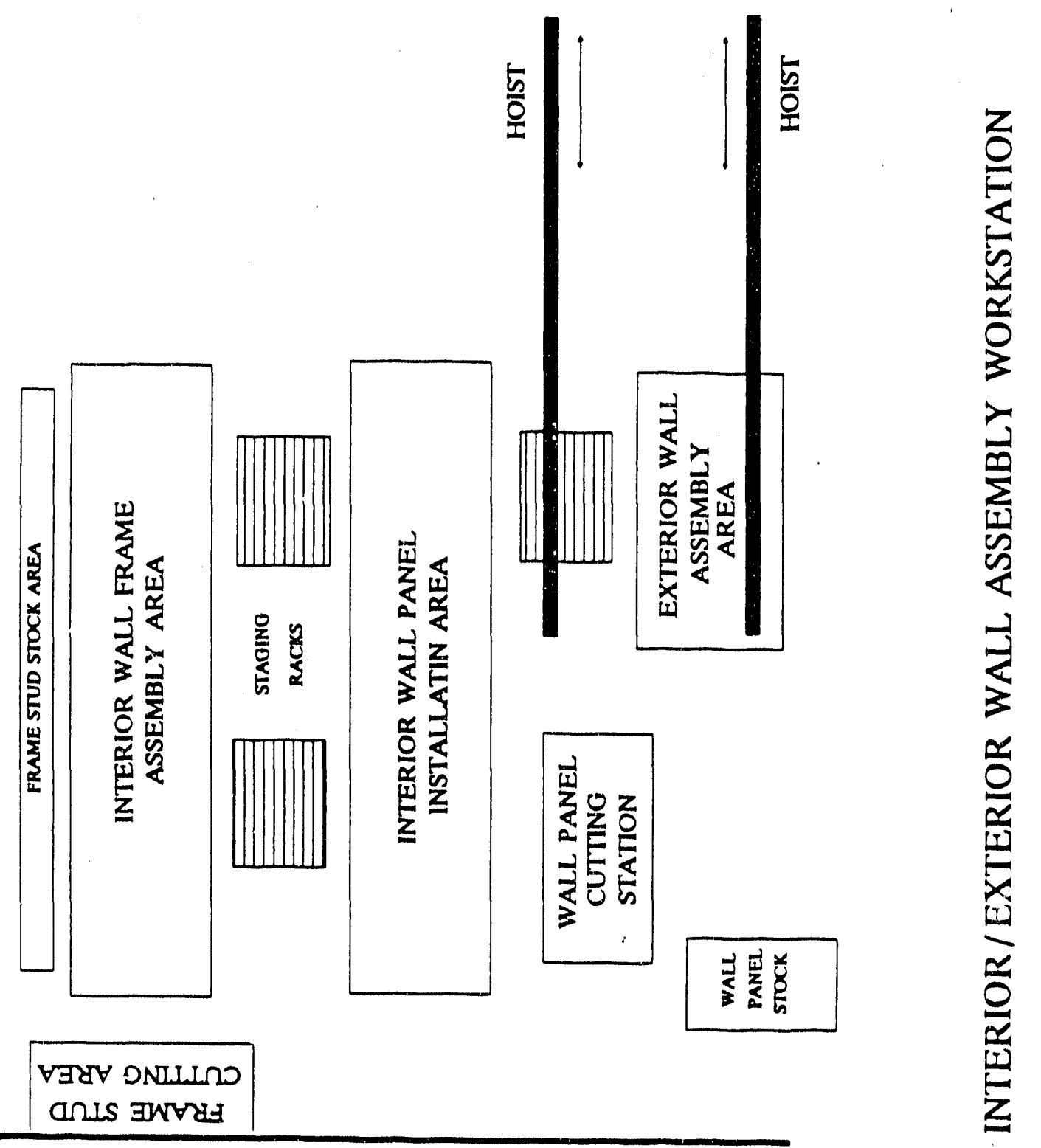


INTERIOR WALL ASSEMBLY FLOW CHART

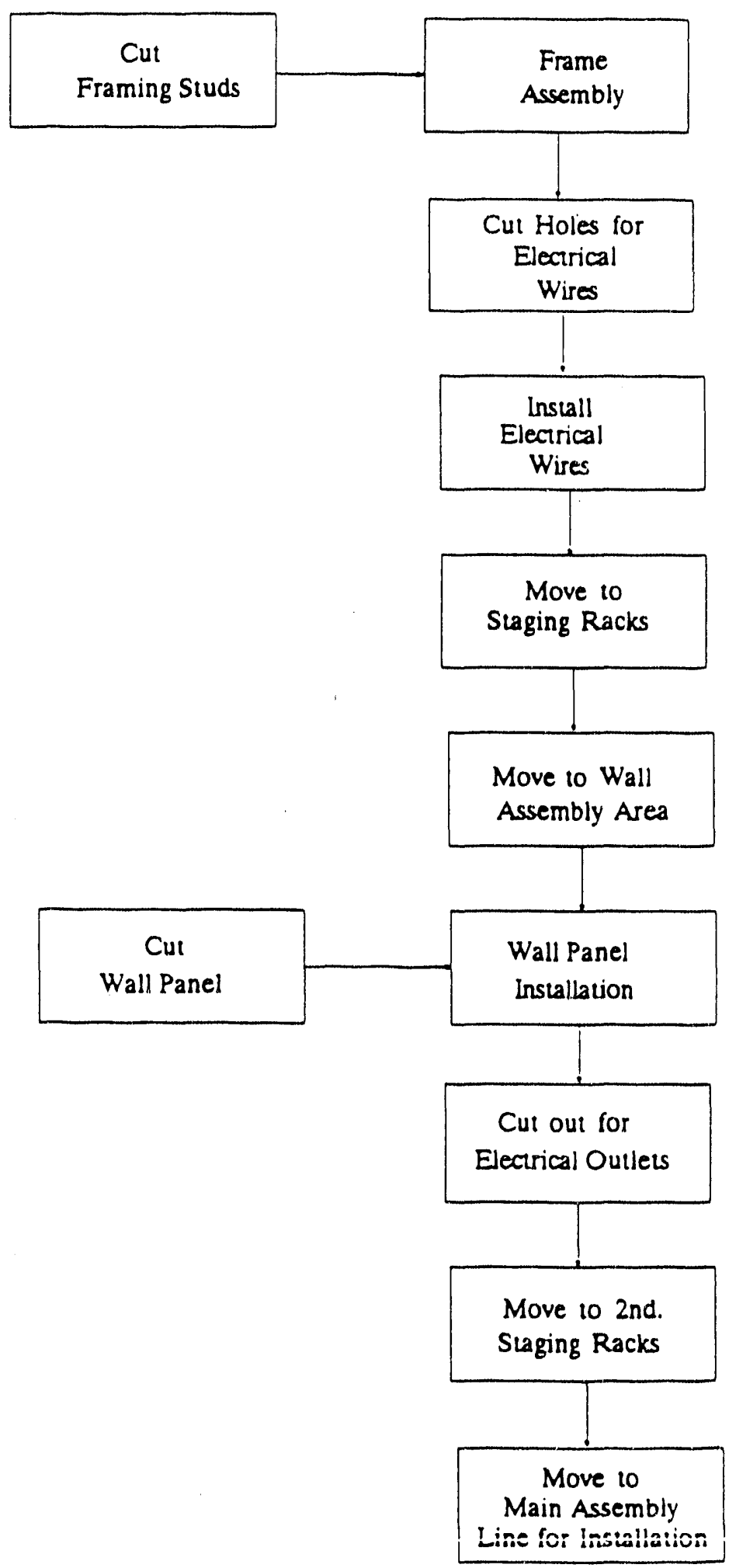



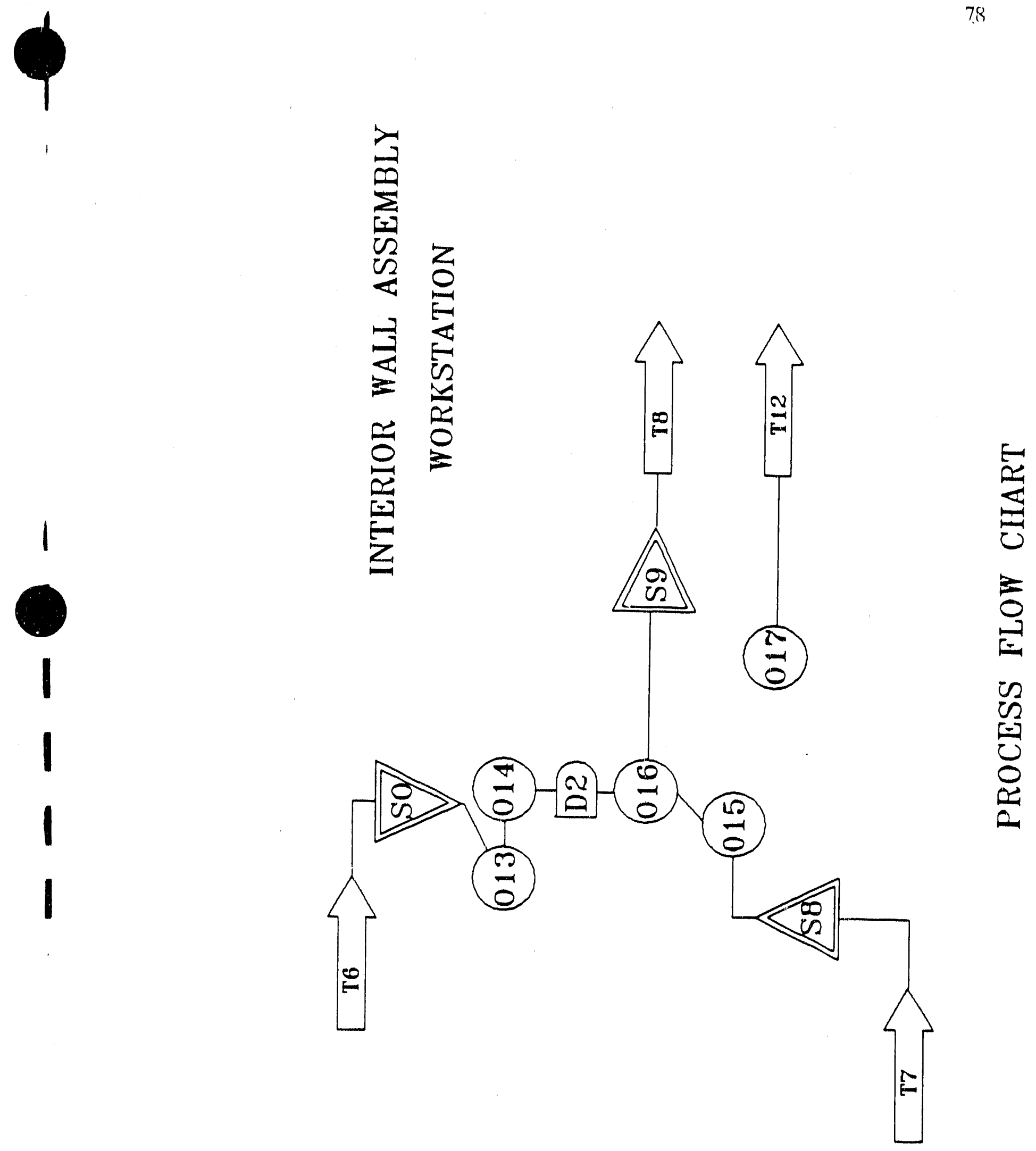
Interior Wall Assembly:

SO: Raw wood stock is temporarily stored before being cut for use.

S8: Drywall sheets are temporarily stored before being cut for use.

S9: In-process storage for assembled interior walls.

O13: Framing studs are cut to length.

O14: Studs are framed and electrical boxes are mounted.

O15: Drywall is cut to size.

O16: Drywall to frame assembly is performed.

O17: Exterior end wall assembly.

T6: Raw framing studs are transported to workstation from main warehouse.

T7: Drywall sheets transported to workstation from main warehouse.

T8: Interior wall assemblies are transported to production line.

T12: Exterior wall assemblies are transported to production line.

D2: Delay due to imbalance in production rate between frame assembly and wall assembly. 
TIME CHART

FOR

INTERIOR WALL ASSEMBLY

Operation

Frame Assembly:

- Cut studs to size

- Assemble framing

- Drill holes for electrical wiring

- Install electrical wiring

- Move frame wall to staging racks, then to next workstation

Attach Dry Wall to Framing:

- Cut dry wall to size

- Apply glue to framing

- Install dry wall

- Cut holes for electrical switches and boxes

- Move finished wall to staging racks

Move Interior Wall to Production Line

Production Rate Analysis

Requirement:55 walls/shift @ 6 walls/unit

Cycle Time: $8 \mathrm{~min} . /$ wall

Production Rate: (1 wall $/ 8 \mathrm{~min}$. $\times 460 \mathrm{~min} . / \mathrm{shift}$ ) $=57.5 \mathrm{walls} / \mathrm{shift}$
Total Time

$8 \mathrm{~min}$
$7 \min$ 


\section{INTERIOR/EXTERIOR WALL INSTALLATION AREA}

\section{Process Description}

Interior/Exterior walls are moved from both wall assembly workstations using an overhead hoist (Figure 55). A caulking strip is first installed between the wall and the floor deck. The wall is held up until it is screwed and nailed to the floor deck by overhead crane (Figures 56 through 58). While connecting walls to the floor, a pneumatic clamp is used to pull wall assembly down while they are being nailed/screwed together (Figures 59 and 60), after which the clamp is removed.

Exterior electrical wiring is installed (Figures 61 and 62), a metal plate is used to protect wiring in exterior wall studs from nails (Figure 63). Kitchen cabinets are also installed at this workstation.

\section{Labor Utilization}

There are four workers installing both interior and exterior walls, two installing the kitchen cabinets and two performing electrical wiring.

\section{Materials Handling}

Interior and exterior walls are brought onto the line using overhead hoist system and lowered onto floor deck and installed. Cabinets, counters, and other items are hand carried and then installed. 

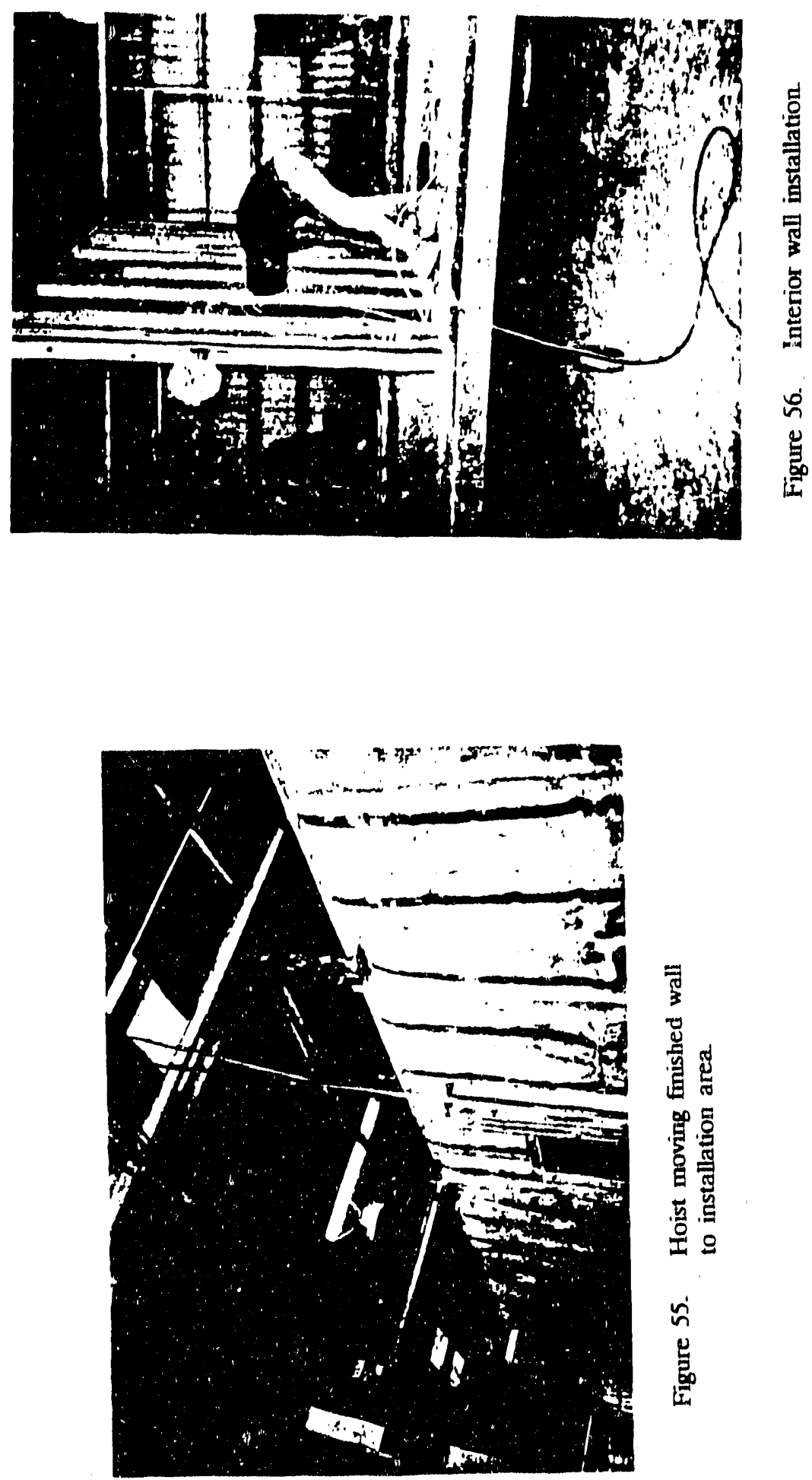


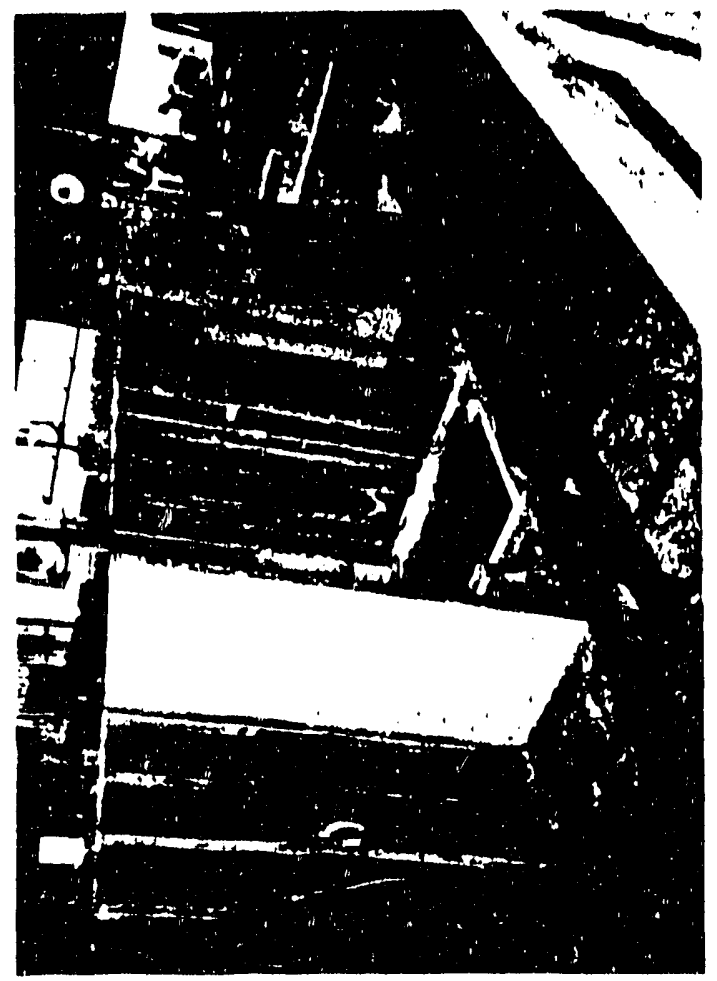

通

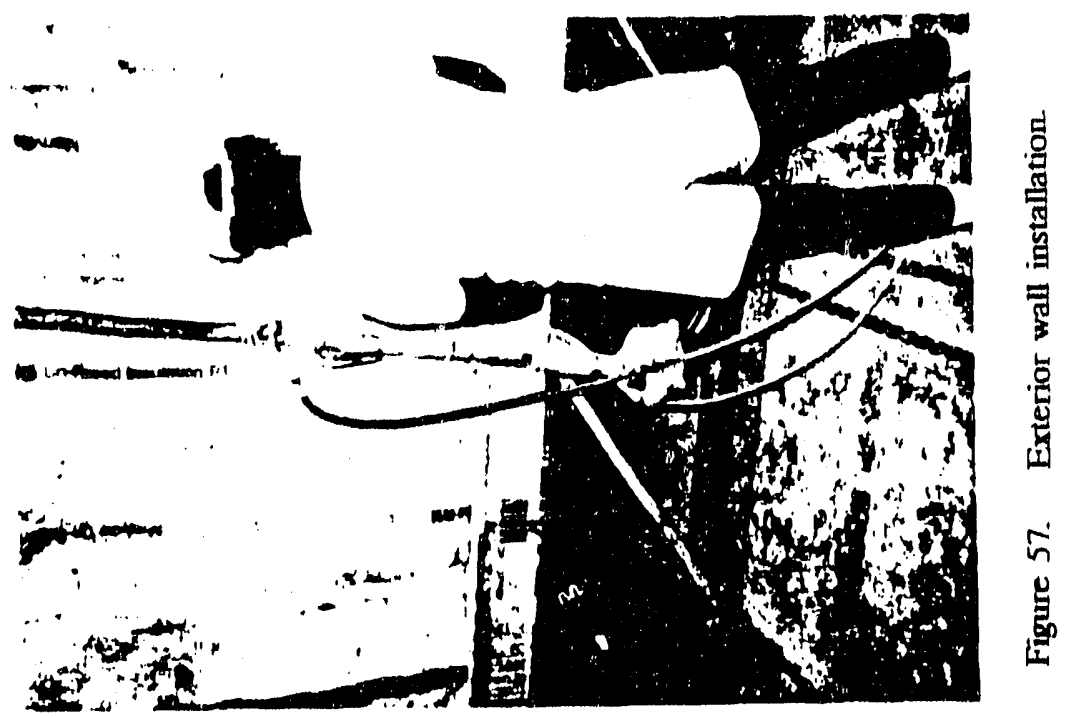



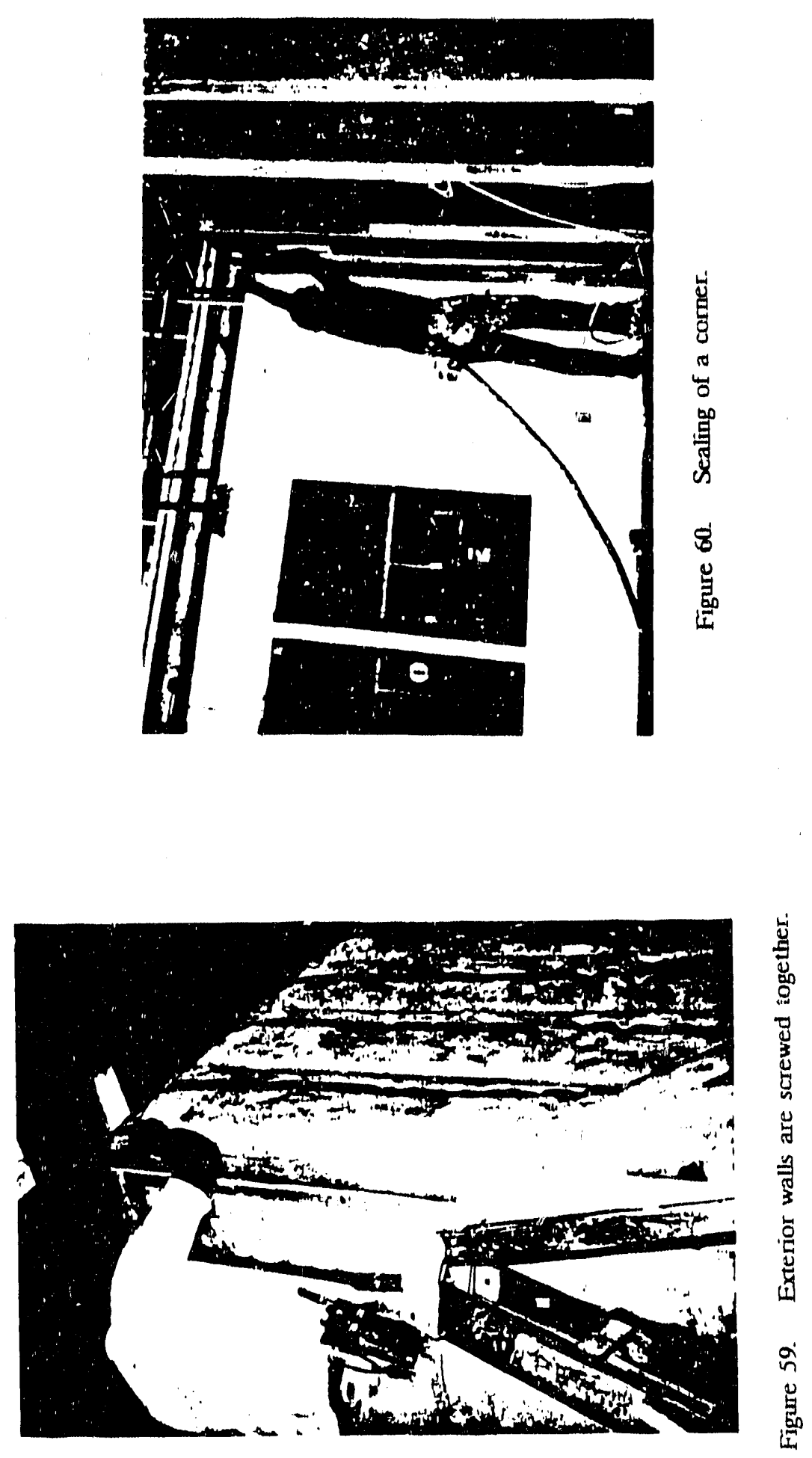

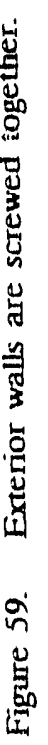




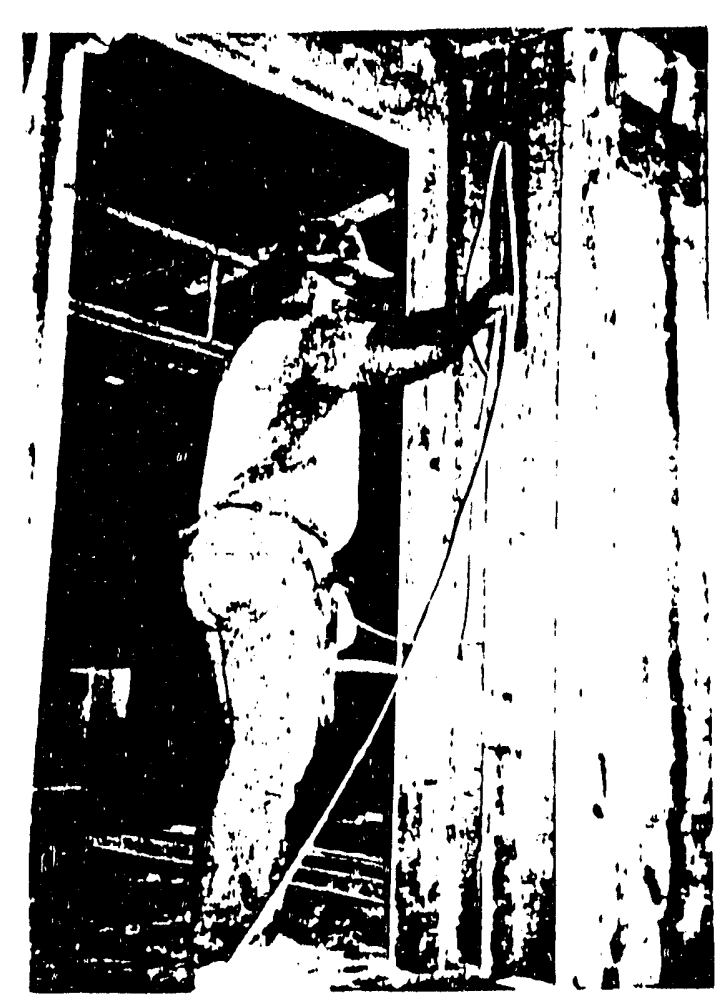

Figure 61. Electrical wiring installation.

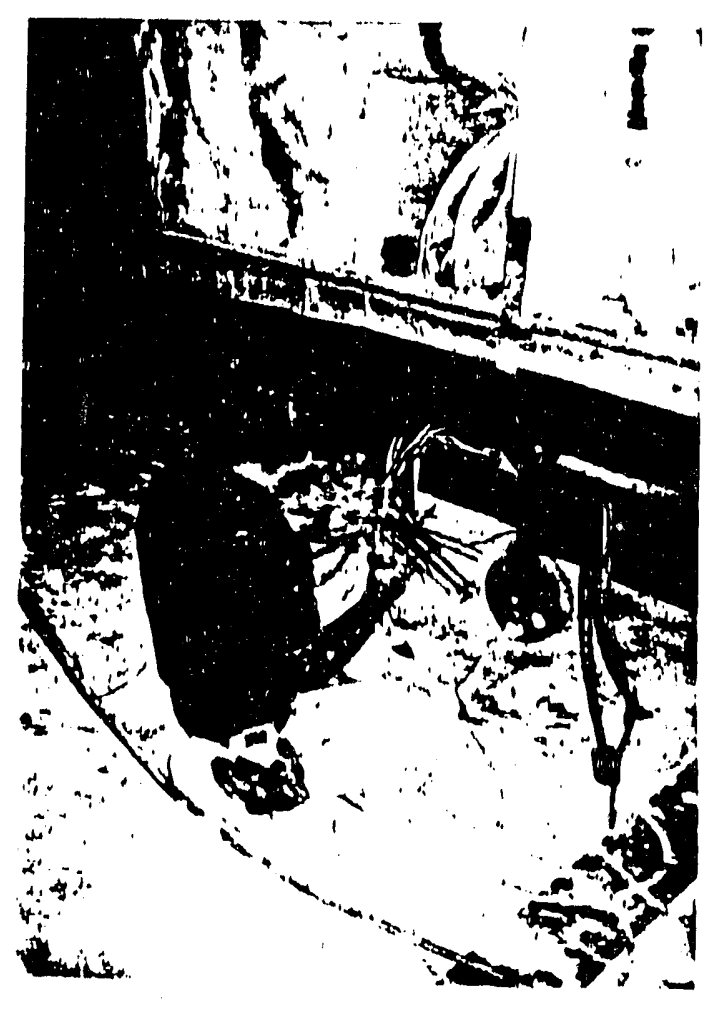

Figure 62 Electrical wiring installation.

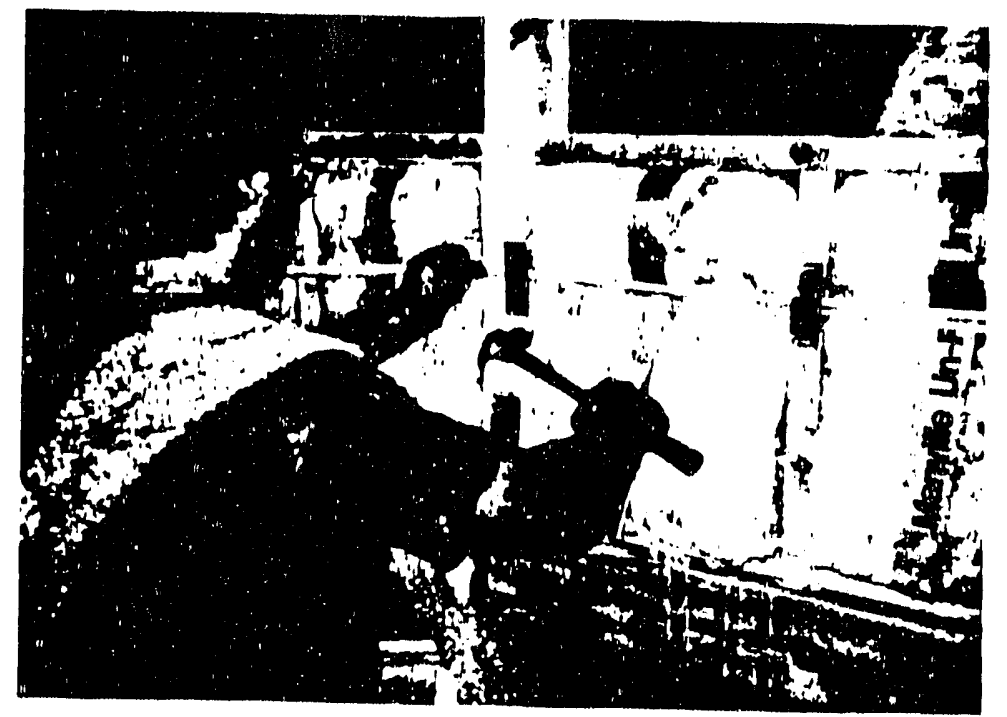

Figure 63. Metal plate used for wiring support. 
Inspection

Inspection consists of manual checking to insure that walls are securely fastened.

\section{Equipment Description}

- Cutting: electric hand saws

- Assembly: wall clamps and supports

pneumatic nailers and screw guns

- Jigs/Fixtures: none

- Materials Handling: 2 overhead crane hoists and ?

\section{Recommendations}

It is recommended that the following suggestions be investigated.

1. Layout: None.

2 Labor:

- Manpower possibly could be reduced to six: two for setting walls; two for installing bathrooms and kitchen cabinets; and two for electrical wiring,one inside and one outside. Required production rate must be considered.

3. Process:

- Automatic fastening systems and self feeding screwdrivers (Figure 64) are available to reduce installation time. An example of such equipment is shown in Figure 64. For additional equipment listings see Appendix A. 
4. Materials Handling:

- Utilize overhead storage \& retrieval systems to transport cabinets and counters to the production line.

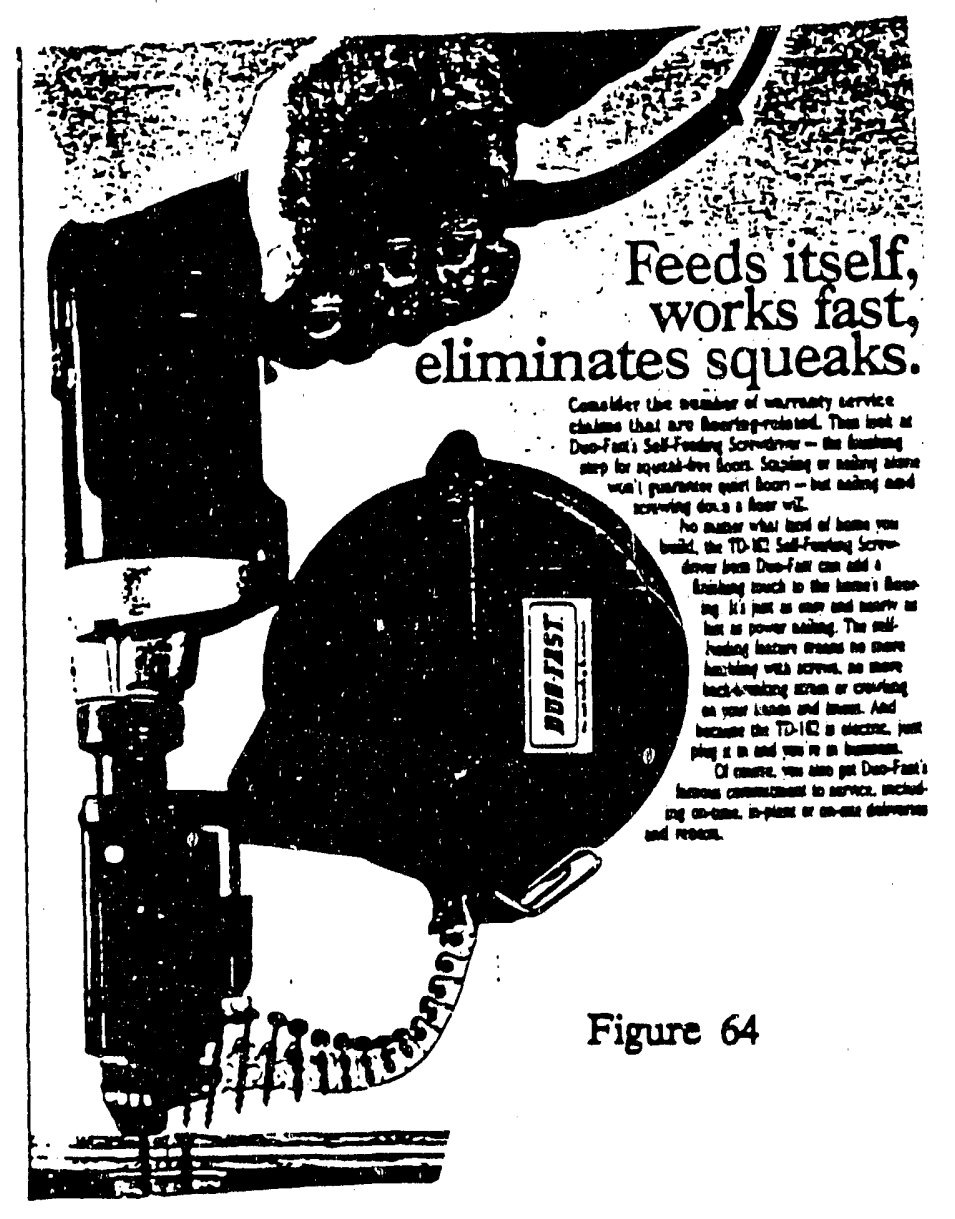




\section{INTERIOR / EXTERIOR WALL INSTALLATION FLOW CHART}

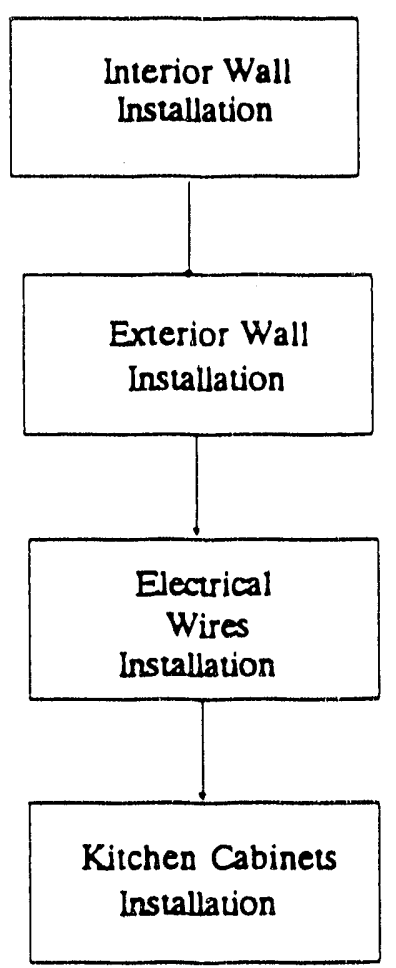




\section{TIME CHART \\ FOR \\ EXTERIORINTERIOR WALIS INSTALLATION}

\section{Operation}

Exterior walls installation:

- Move exterior wall from assembly area

- Install wall (screw to floor deck)

Interior walls installation:

- Move interior vall from assembly area.

- Install wall (screw to floor deck)

Electrical wiring installation

Kitchen cabinets installation

\section{No. of Operators}

2

Total Time

$45 \mathrm{~min}$

2

$30 \mathrm{~min}$

2

2
$30 \mathrm{~min}$

$20 \mathrm{~min}$

- Note: Interior and exterior wall installation operations are performed simultaneously. Approximate time for combined operations is 45 minutes.

Production Rate Analusis

Requirement:1/module@2/nome

Cycle Time: 45 min./installment

Production Rate: (1 installment $/ 45 \mathrm{~min} . \times 460 \mathrm{~min} . / \mathrm{shift})=10.2 \mathrm{installments} / \mathrm{shift}$ 


\section{ROOF FRAME ASSEMBLY WORKSTATION}

\section{Process Description}

Ceiling drywall is brought to this workstation from the warehouse using forklift trucks. It is stored at the workstation and manually placed on a mobile pallet.

Panels are stacked on this mobile pallet which traverses the length of the table overhead. The ceiling of the roof system consists of 4 'x12' gypsum board panels which are laid out face down on the worktable adjacent to one another. Seams between panels are taped and trusses are set onto ceiling panels (Figure 65).

A front perimeter frame is laid along the edge of the ceiling and nailed to the end of the truss (Figure 66). The frame is made of $1^{\prime} \times 2^{\prime}$ boards and is attached to the truss using pneumatics nail guns. A similar operation is used for the rear perimeter frame which is laid along back edge of the ceiling and nailed to the large end of the trusses. These frames are made on a worktable adjacent to the assembly deck.

Polyurethane foam is sprayed along the edge of truss bottom cord to cornect trusses to paneling (Figures 67 and 68 ). The foam is instantly setting and with sufficient strength to preslude additional fasteners, and provides a lével ceiling surface. 2 'x 4' studs are installed for roof truss bracing. HVAC ducts are also installed at this workstation. From this workstation, roof is lifted with a 4-ton hoist system and transported to the adjacent finishing workstation (Figures 69 and 70).

The following operations are performed at this station:

- Seams between wallboard are taped.

- Wallboard are finished with a drywall mud which is applied in two layers. 
- Cut holes for HVAC registers, lighting, etc. (Figure 71). A pneumatic jig saw is used for this purpose.

The roof is then transported to the ceiling texture workstation where the textured finish is sprayed onto the ceiling (Figure 72). A mixer is located outside the building (Figure 73). HVAC registers are installed at this workstation (Figure 74). After the roof assembly is finished it is moved to the production line using a hoist (Figure 75).

\section{Labor Utilization}

Eight workers; one is responsible for bringing raw materials into the assembly area; four men work in assembly; and three at the finishing and pop corn areas. 

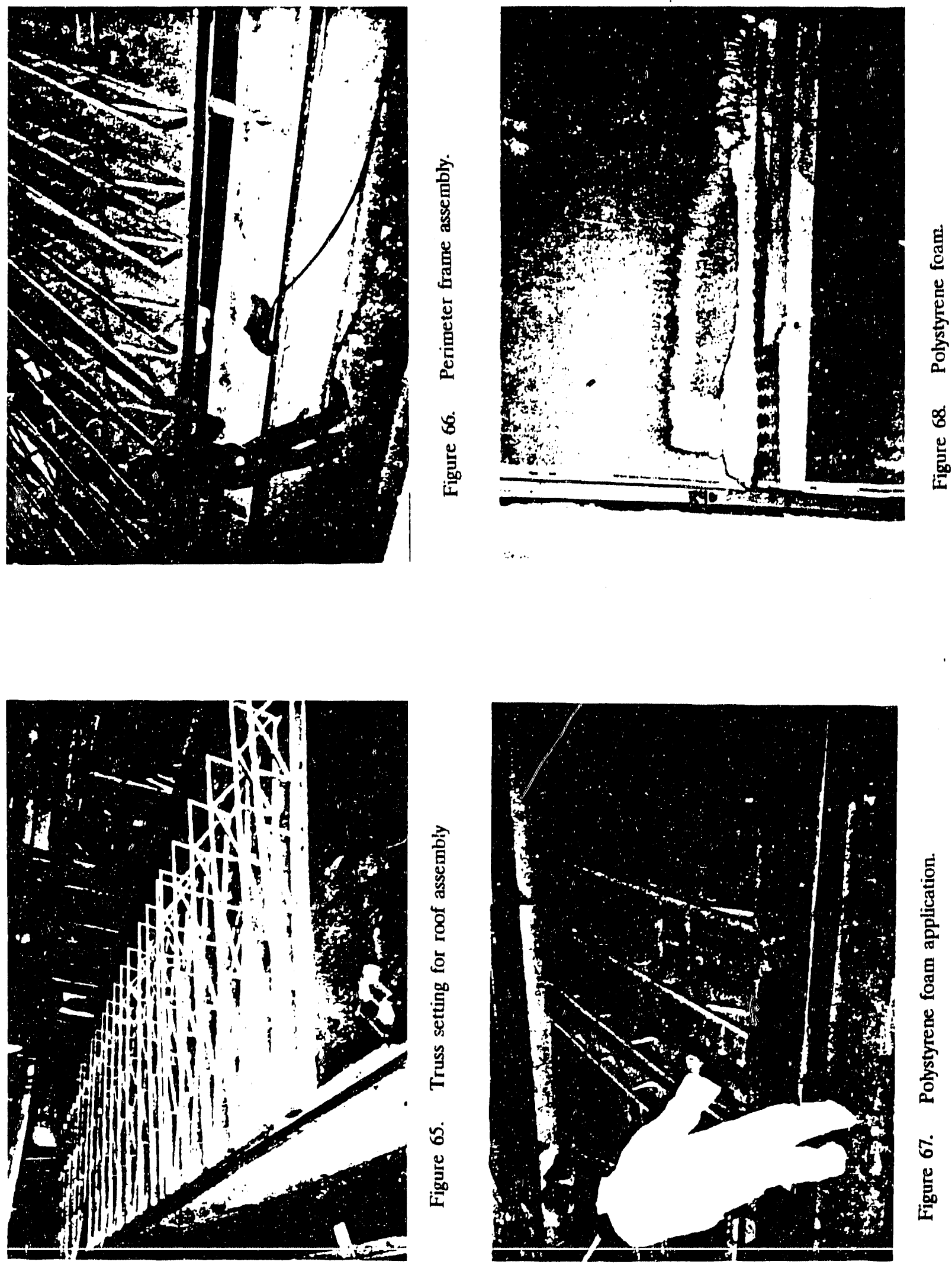

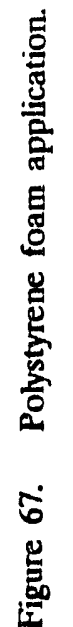



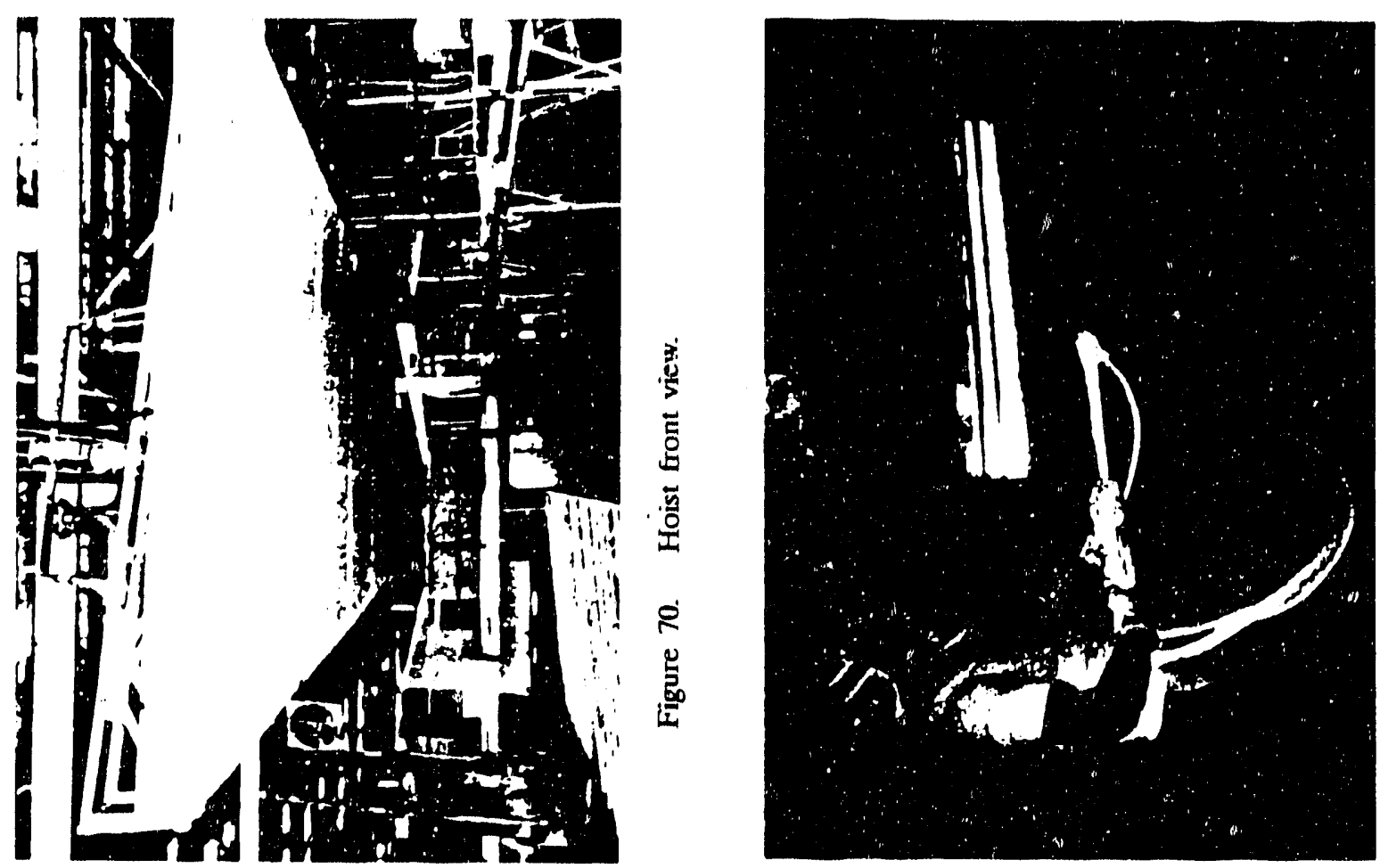

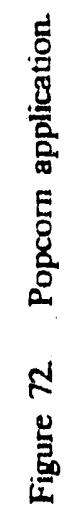
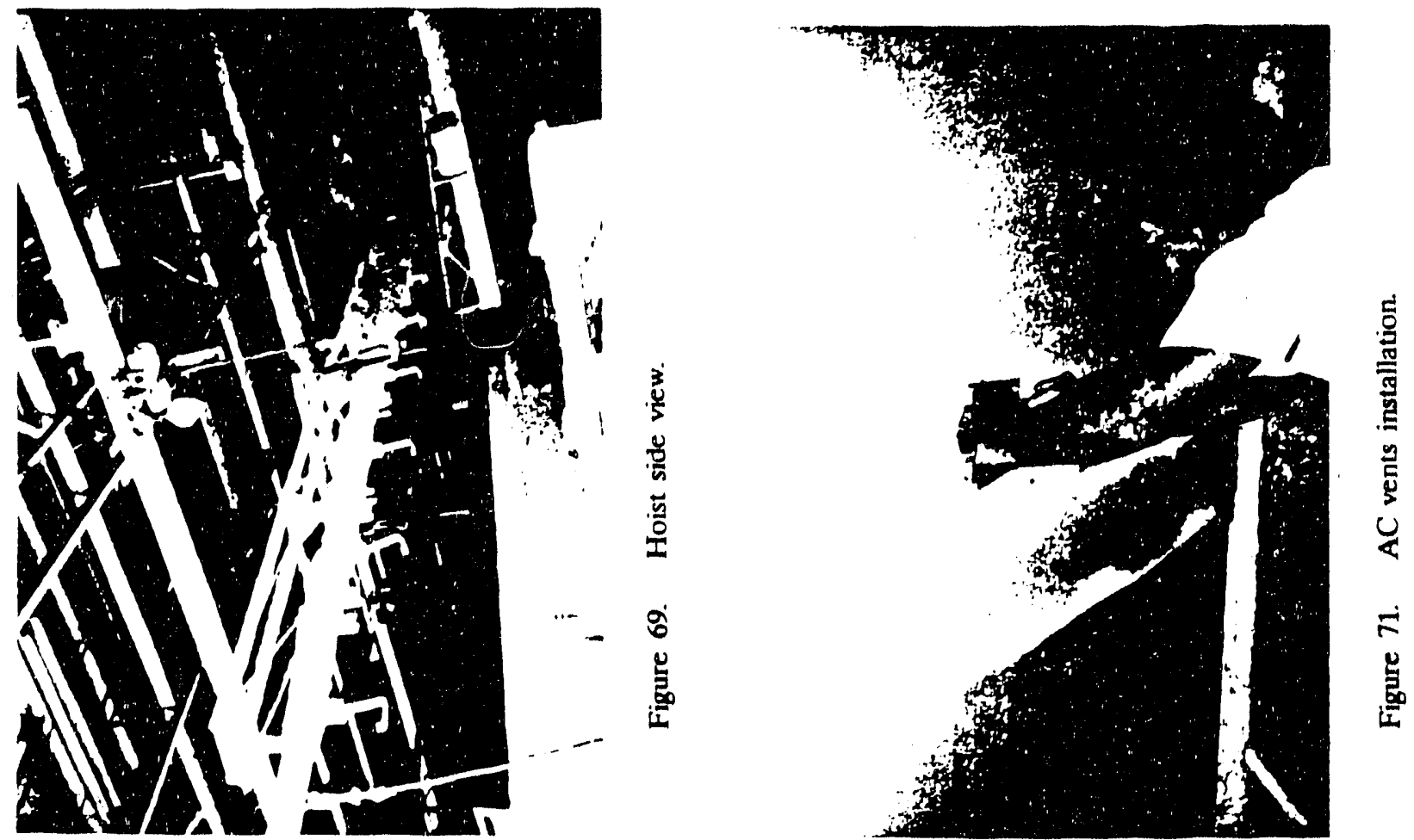

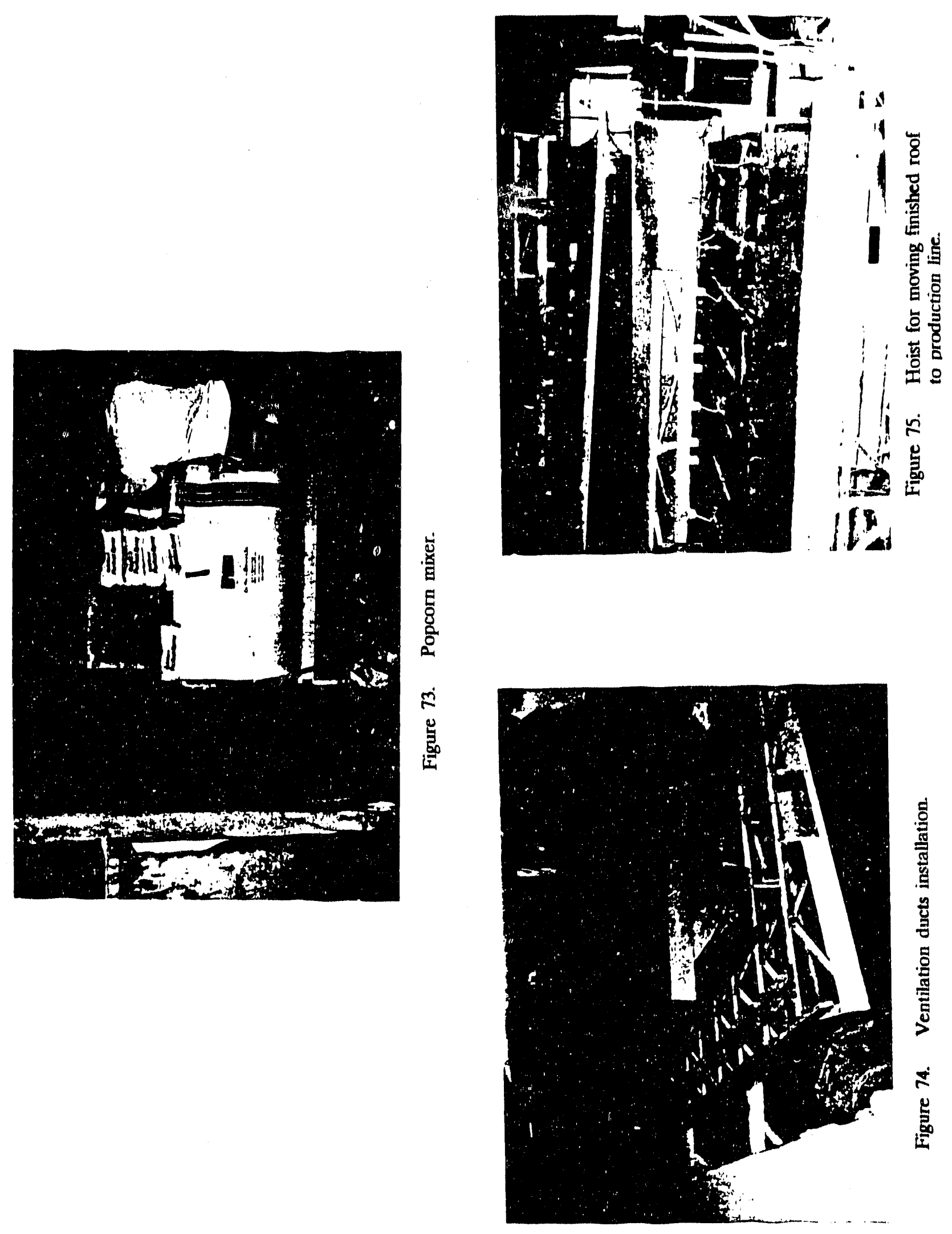


\section{Materials Handling}

Trusses and ceiling panels are brought to assembly station by forklifts. Truss stock is staged outside the station. Panels are stacked on a mobile pallet mounted over the worktable. Trusses are manually brought in and placed on panels. Other frame materials are cut and again manually brought to assembly table. After roof truss is assembled, an overhead hoist lifts it and transports it to the finishing station where it remains suspended during operation. Crane system then moves to the next station for spraying. After this, the roof truss/ceiling assembly is moved to the main assembly line for installation on top of walls.

\section{Inspection}

No inspection is performed at this station.

\section{Equipment Description}

- Cutting: 1 radial arm saw

1 jig saw

- Assembly: pneumatic nailers

2 airless sprayers

1 worktable

- Jigs/Fixtures: none

- Materials Handling:

1 overhead crane hoist

1 mobile pallet

1 scaffolding 


\section{Recommendations}

It is recommended that the following suggestions be investigated.

1. Layout: None.

2. Labor:

- A balance problem exists between assembly and finishing due primarily to a lack of manpower for finishing creating a potential bottleneck during high production runs. Though one person can perform the finishing operations, he cannot keep pace with assembly. Also, too much time is used up walking back and forth for tool changes, hand washing, etc.

- The assembly station has a crew of four. It is recommended that one worker be shifted to finishing in order to reduce the imbalance.

3. Process:

0 The assembly of the roof truss system is good.

- The insulation as well as the roof decking could be installed at this workstation, primarily because men can work more efficiently on the ground than at a height on a slanted roof. Additionally, risk of injury is reduced. One drawback is that this might create a material handling and floor space problem. Currently these materials are stored on the second level.

4. Materials Handling: None. 


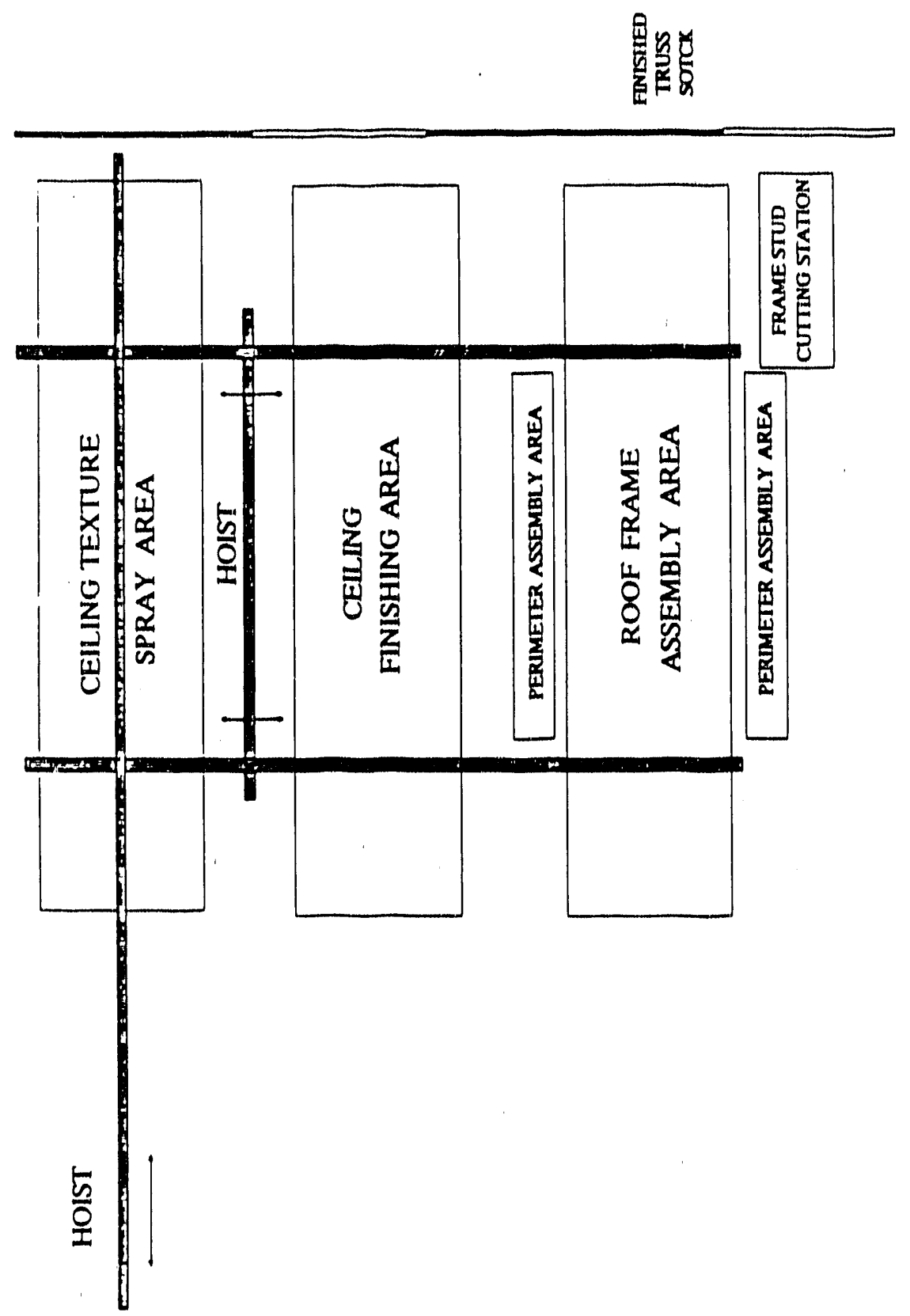

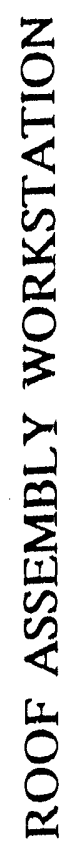




\section{ROOF ASSEMBLY FLOW CHART}

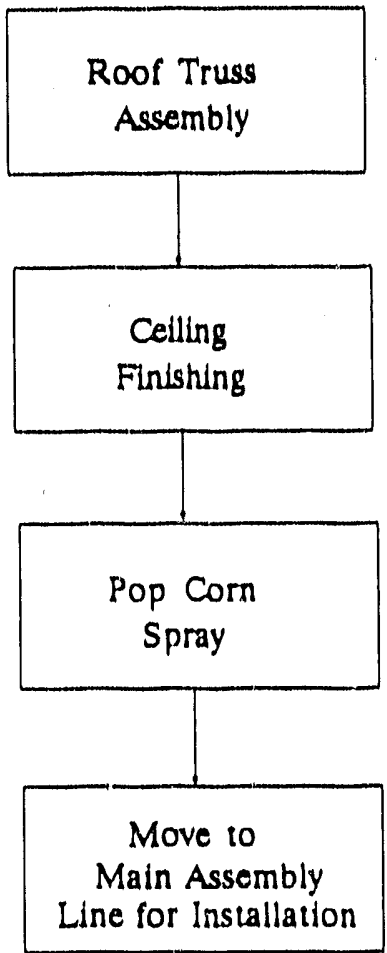


Z

$\sum_{01}^{20}$

5

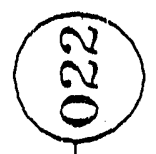

N

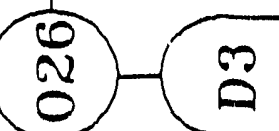

용

$\frac{n}{n}$

$\{y$

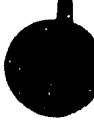

2

$\sqrt{v_{u}^{n}}$

$\sum_{-1}^{2}$

2

(1)

บ

0

- 
Roof Frame Assembly:

S18: Trusses are temporarily staged before being used.

O22: Finishing mud and ceiling texture materials are mixed.

O23: $1 \times 12$ board stock is cut to size for roof truss end framing.

024: Boards are glued together in layers of three in preparation for assembly.

O25: Truss assembly is performed.

O26: Ceiling is taped and finished.

O27: Ceiling is sprayed with popcorn coating.

T14: Ceiling panels are brought from main warehouse.

T15: Trusses ard other framing materials are brought from storage.

T16: Finished roof assembly is transported to production line.

D3: Delay between assembly and finishing. 
TIME CHART

FOR

ROOF FRAME ASSEMBLY
Operation

Bring Dry Wall Panels and

Finished Trusses from Warehouse
No. of Operators

1

Roof Assembly:

- Layout dry wall

- Assemble perimeter framing

- Set trusses on dry wall

- Spray foam

- Install HVAC ducts

- Move roof assembly to next workstation

Roof Finishing: 1

$30 \mathrm{~min}$

- Tape seams between boards

- Apply drywall mud

- Cut holes for registers

- Move roof to next workstation

Spray "Popcorn" Texture 2

$10 \min$

Move Finished Roof Assembly to Production Line

\section{Production Rate Analysis}

Requirement:10/shift @1/module

Cycle Time: $40 \mathrm{~min} . / \mathrm{roof}$

Production Rate: (1 roof $/ 40 \mathrm{~min} . \times 460 \mathrm{~min} . / \mathrm{shift})=11.5 \mathrm{roofs} / \mathrm{shift}$ 


\section{ROOF INSTALLATION AREA}

\section{Process Description}

The roof truss assembly is transported by a chain hoist to the production line and lowered onto the shell (Figures 76). Before it is secured, a caulking strip is applied to the top of the wall frame around the perimeter for insulation purposes (Figure 77 and 78). The roof assembly is then fastened to the exterior wall framing (Figures 79 and 80 ). Additional framing is screwed to the roof borders where fascia is later installed (Figure 81). A metal strap is then attached to tie the roof system to the exterior walls (Figure 82). An overview of the finished roof installed is shown in Figure 83.

Rock wool insulation material is applied by using a high pressure blower (Figures 84 and 85 ). The roof decking is laid and fastened to truss assembly. The paneling used for the roof decking is oriented strand board. The decking is stored in containers supported on a overhead mounted track which extends across the work area (Figure 86). Decking is attached using pneumatic nailers. Metal clips are utilized between panels. Measurements are made using a tape to mark where cuts are to be made on the decking. These cuts are made by a powered hand saw (Figure 87). Then the fascia is installed (Figure 88).

After installing the roof decking, a layer of black asphaltic sealant is applied at all edges of the roof decking (Figure 89). A waterproofing cover of roofing paper is rolled over the roof (Figure 90). Adjustments and alignments are performed manually. Excess material around the edges is cut with a knife. The roofing paper is then stapled to the roof decking. Shingles are then placed on top of this cover and stapled (Figure 91). 

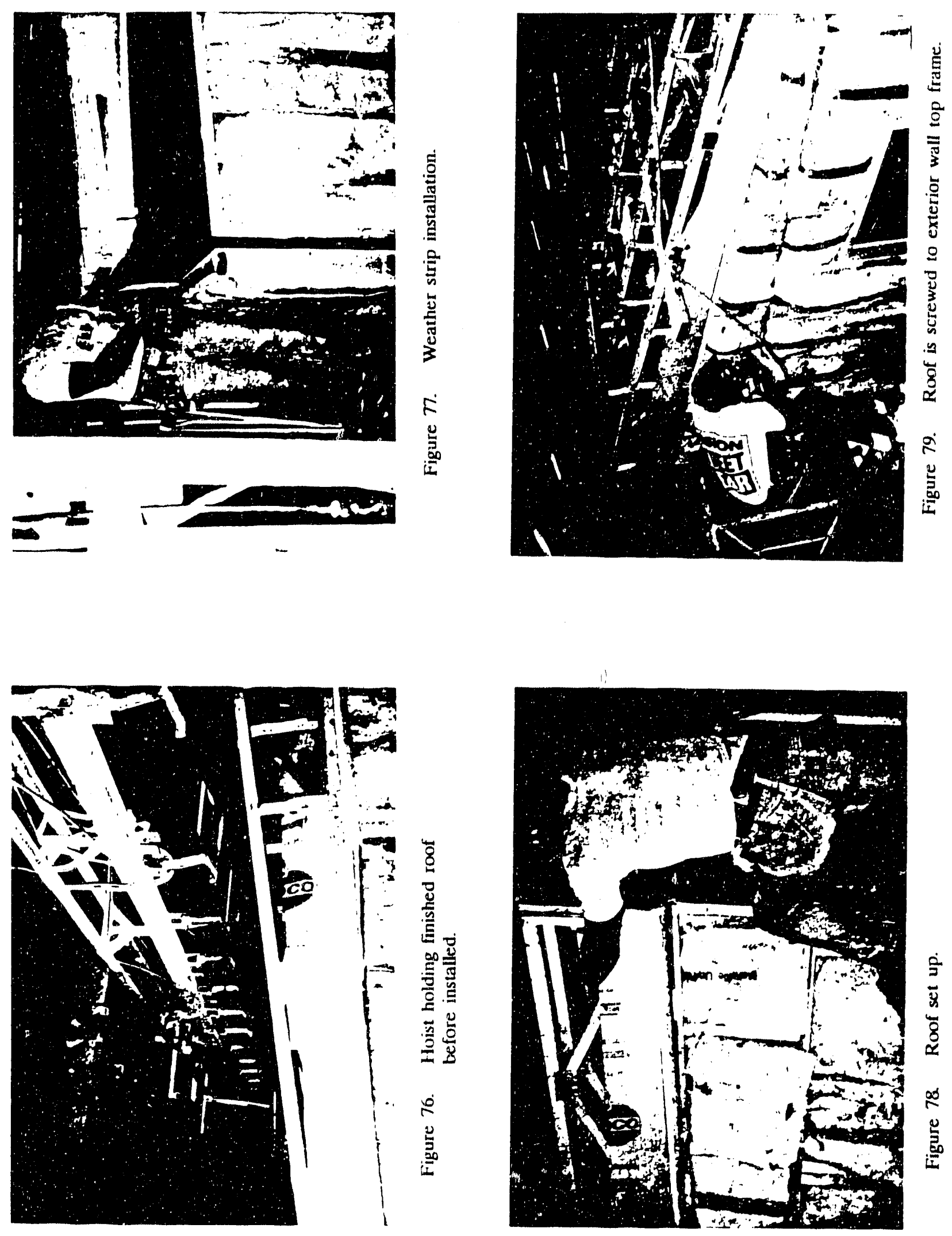

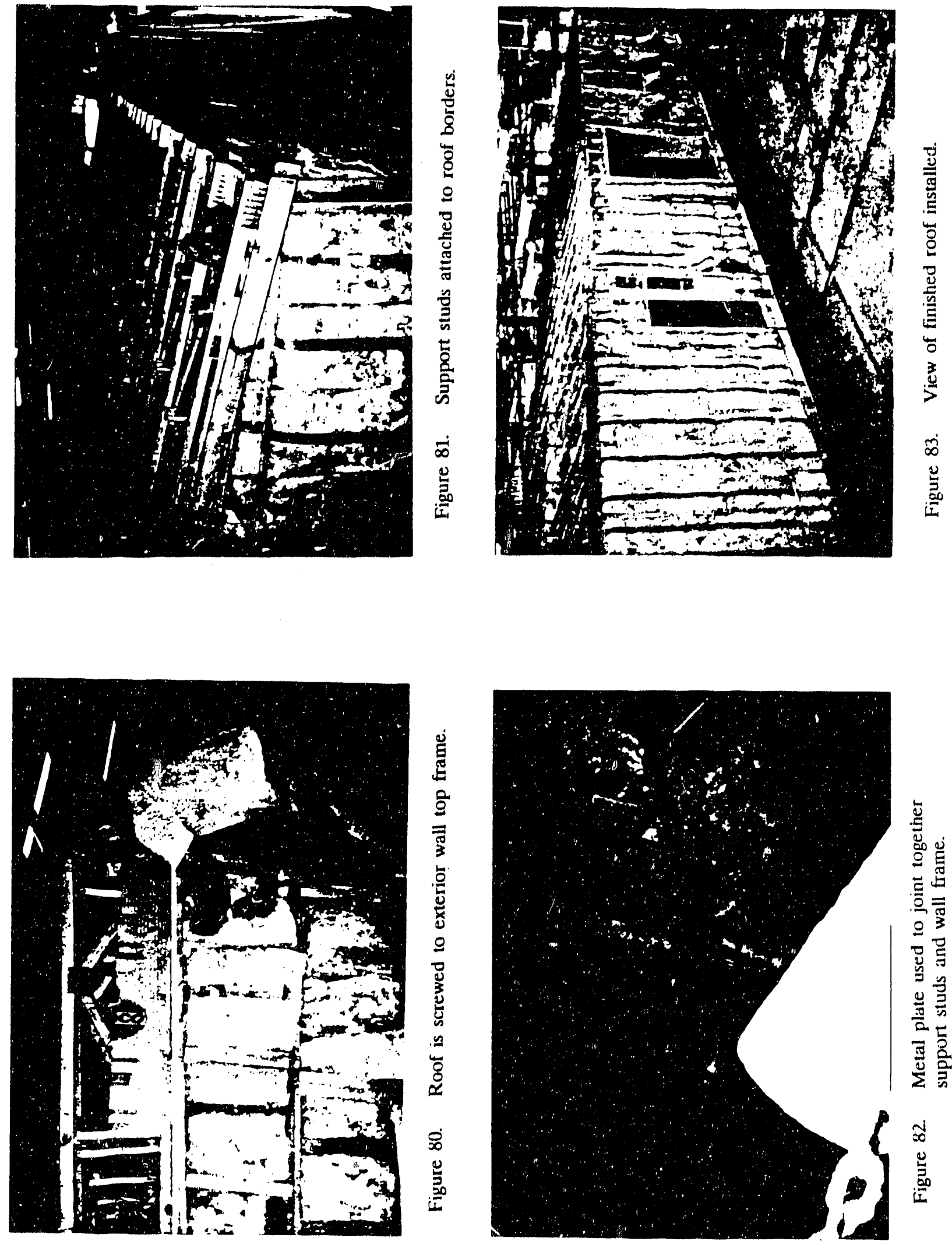

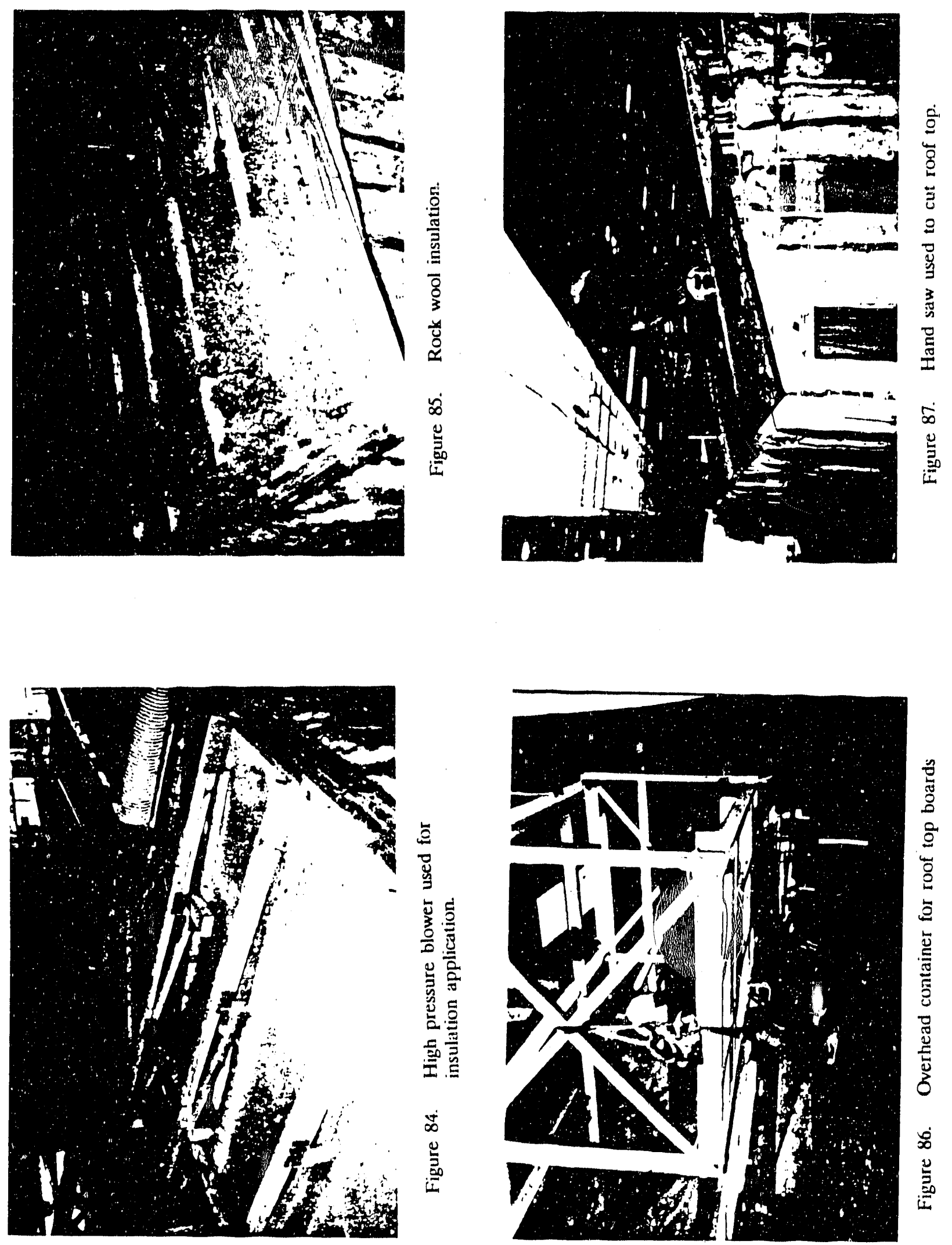

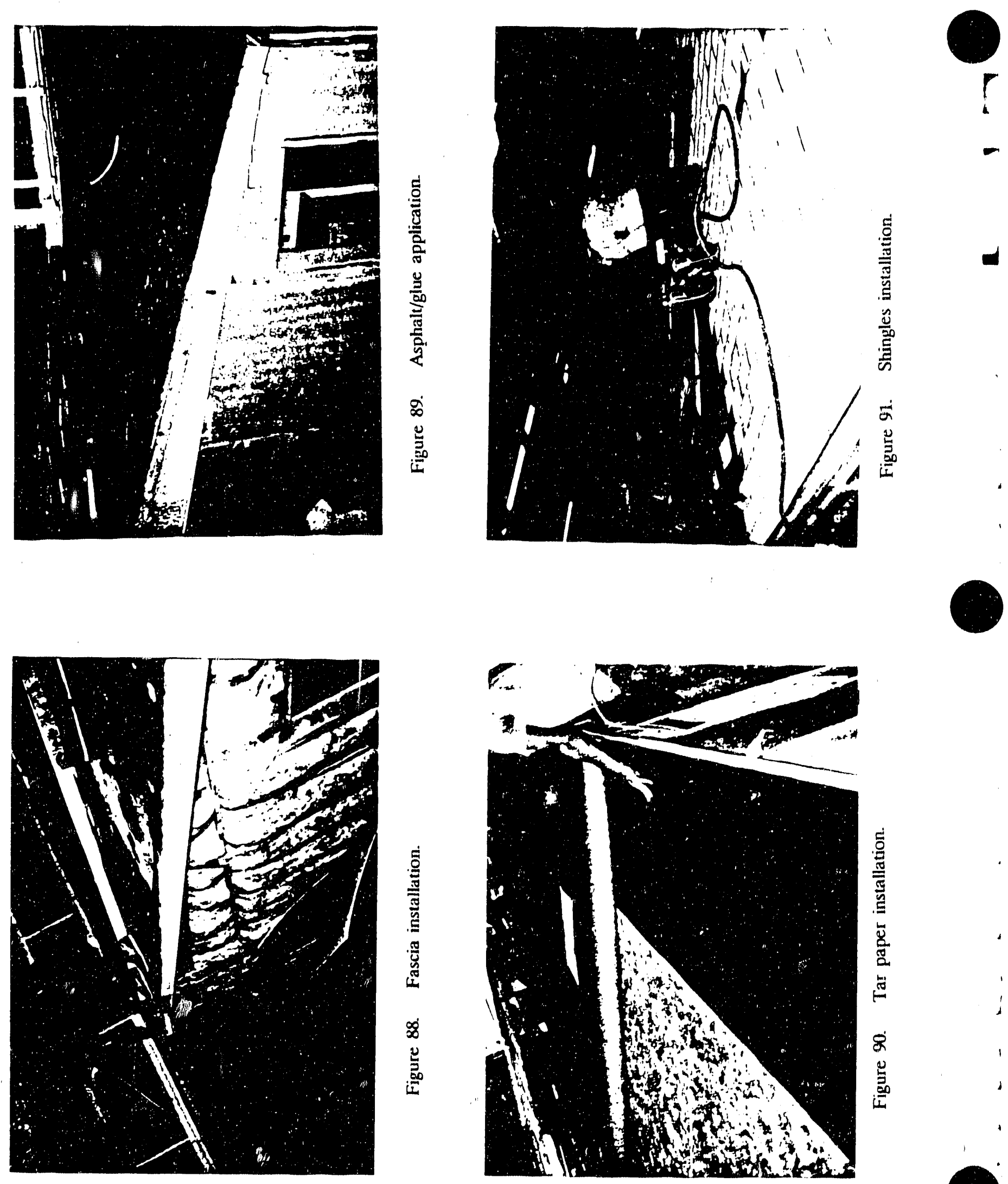


\section{Labor Utilization}

Total man power utilized in this working area is 11, duties of workers are described in the time chart for roof installation.

\section{Materials Handling}

Roof truss assembly is brought to the line using the hoist system and lowered onto the walls. Roof decking is stored in overhead pallets and manually placed onto the roof assembly. Shingles, roof paper, and fascia are also stored above and manually retrieved for use.

Inspection

Inspection is performed to ensure that the roof is properly assembled.

\section{Equipment Description}

- Cutting: 2 electric hand saws

- Assembly: 1 air compressed blower and pneumatic nail and screw guns

- Jigs/Fixtures: none

- Materials Handling:

1 overhead hoist crane

1 scaffolding

2 overhead containers 
Recommendations

1. Layout: None.

2. Labor: None.

3. Process:

- Investigate the possibility of eliminating the roof de from this station.

o Only roof attachment to the walls, fascia installation, waterproofing paper and shingles need to be installed at this point. This could also lead to a reduction in manpower.

- Automatic framing nailers exist that are faster than pneumatics now used. Installation time could be decreased. For a listing of available equipment see Appendix A

4. Materials Handling:

- Automatic storage and handling equipments are available such as materials handling bridges (see Figure 92 that can be used for placing roof panels rather than performing it manually. This could reduce the risk of injury and hazardous operations.

Figure 92

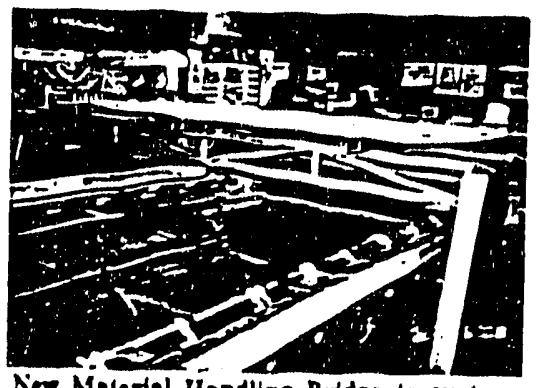

New Malerial liandling Bridge is curlom. bulll to hi your peeds. Heany duly sicel con. struetion with rarlable speed IS ILP. DC drtre for 0.60 FPM travel speed Tharee maln

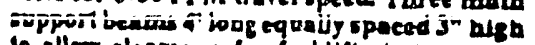
to allow clenrapce for forkulf auto return aner malestal is lald oul Designed and bull 10 necomodale your malerial Eeslly adapt. able to extstlog Iriad linees. 


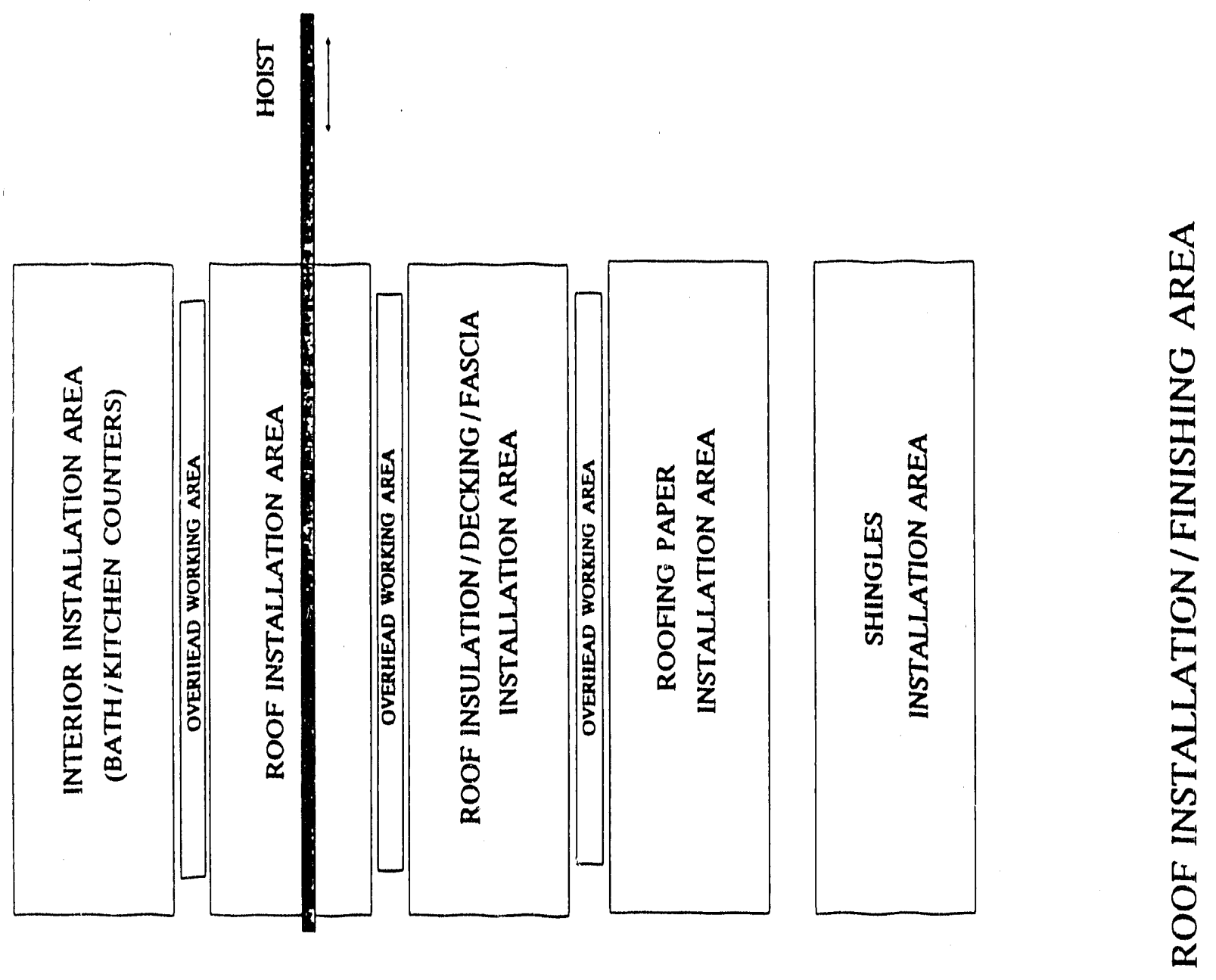


ROOF INSTALLATION FLOW CHART

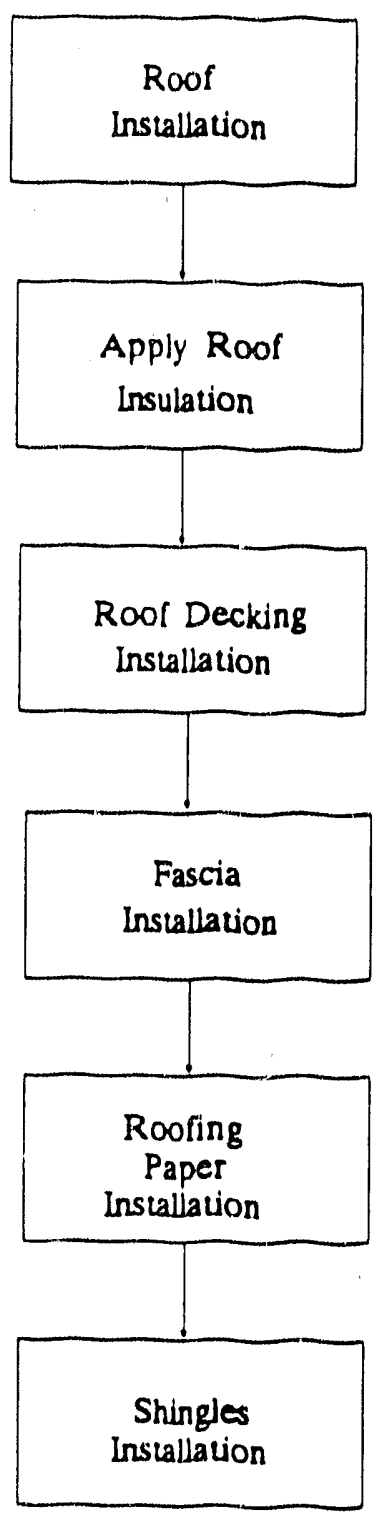




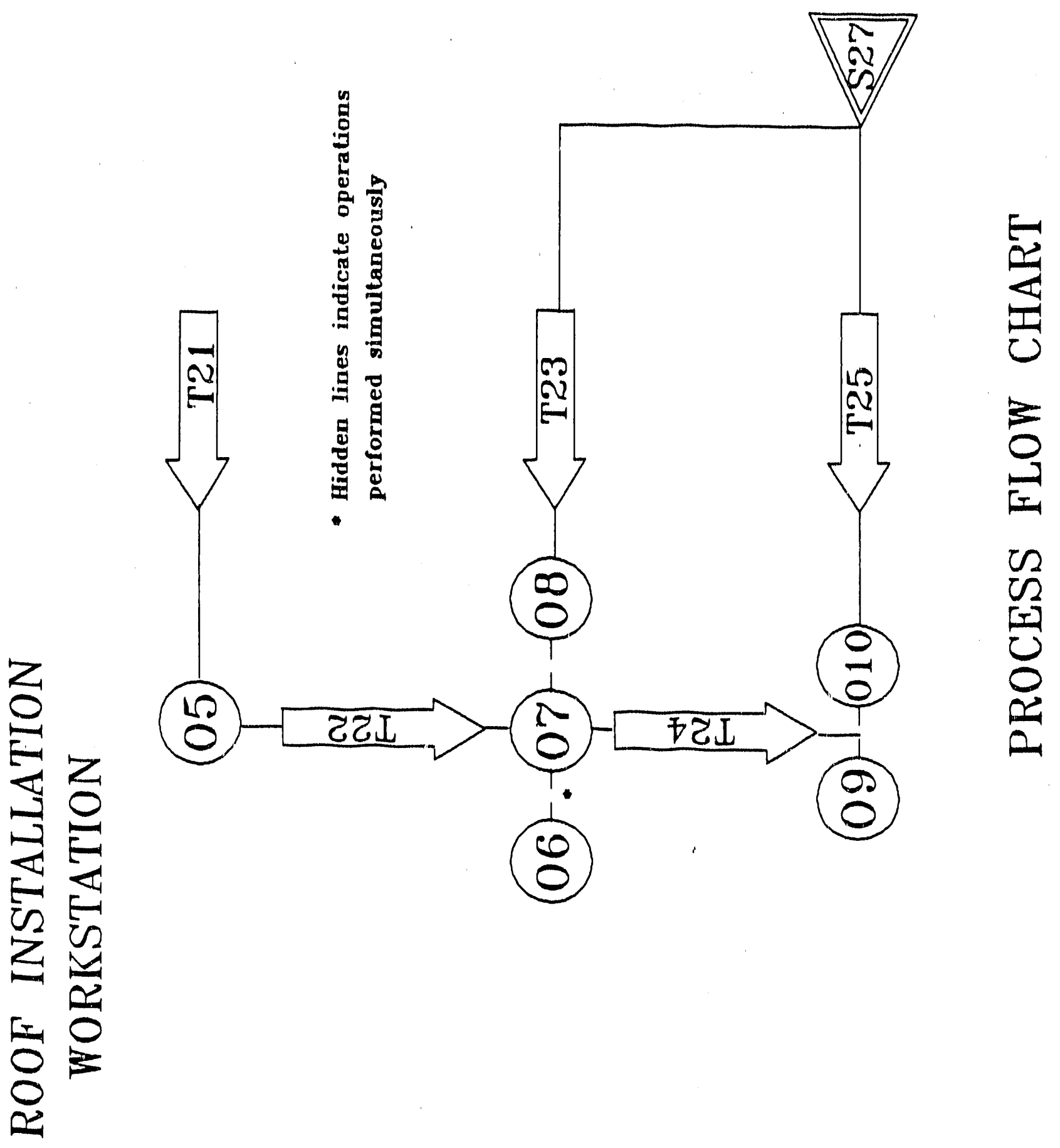


Roof Installation:

S27: Roof decking, tar paper, shingles stock.

O5: Roof installation (set up).

O6: Roof insulation application.

O7: Roof decking installation.

O8: Fascia installation.

O9: Tar paper installation.

O10: Shingles installation.

T21: Finished roof is transported to the roof installation area.

T22: Assembly is moved to next workstation (Roof insulation/top/fascia).

T23: Roof decking is transported from overhead container to installation area.

T24: Assembly is moved to next workstation (Tar paper installation/shingles).

T25: Tar paper and shingles are moved to installation area. 


\section{TIME CHART \\ FOR \\ ROOF INSTALLATION}

Operation

No. of Operators

Install Finished Roof Assembly

Total Time

Move Unit to Next Workstation

Blow-in Insulation

Install Roof Decking and Fascia

Move Unit to Next Workstation

Install Roofing Paper

Install Shingles

Inspection
3

1

2

$25 \mathrm{~min}$

$45 \mathrm{~min}$

2

2

$50 \mathrm{~min}$

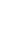

1

\section{Roof Installation Production Analysis}

Requirement:10 roof/shift @ 1 roof/unit

Cycle Time: $50 \mathrm{~min}$./installment

Production Rate: (1 installment $/ 50 \mathrm{~min} . \times 460 \mathrm{~min} . / \mathrm{shift}$ ) $=9.2$ installments $/ \mathrm{shift}$ *

* Production rate is less than requirements. More detail time study is needed in this area, first bottleneck may occur at this point (Finished roof frame installation). 


\section{EXTERICR FINISHWNG AREA}

\section{Process Description}

Outside insulation is installed on exterior walls and sidings. This includes the installation of Extruded Polyurethane Insulation boards which are stapled to the exterior wall frame (Figure 93). The exterior siding is attached and stapled to the exterior wall insulation board (Figures 94 and 95). Sidings are hand cut to fit smaller spaces, such as between windows and doors.

Window and door frames are installed in exterior wails (Figures 96 through 99). A weather strip is also used to provide infiltration barrier. Windows and doors are then installed in a clam shell fashion.

Once siding, windows, and doors are installed, the exterior electrical wiring is connected, such as lights, switches, and electrical boxes. A plastic cover is used to protect the open side of the trailer (Figure 100).

\section{Labor Utilization}

There are four workers installing the insulation panels and the siding (one for ends and two for sides). For the window and door installations there are five operators. Also one person is responsible for installing the plastic cover. There are two additional workers installing the outside lighting. 

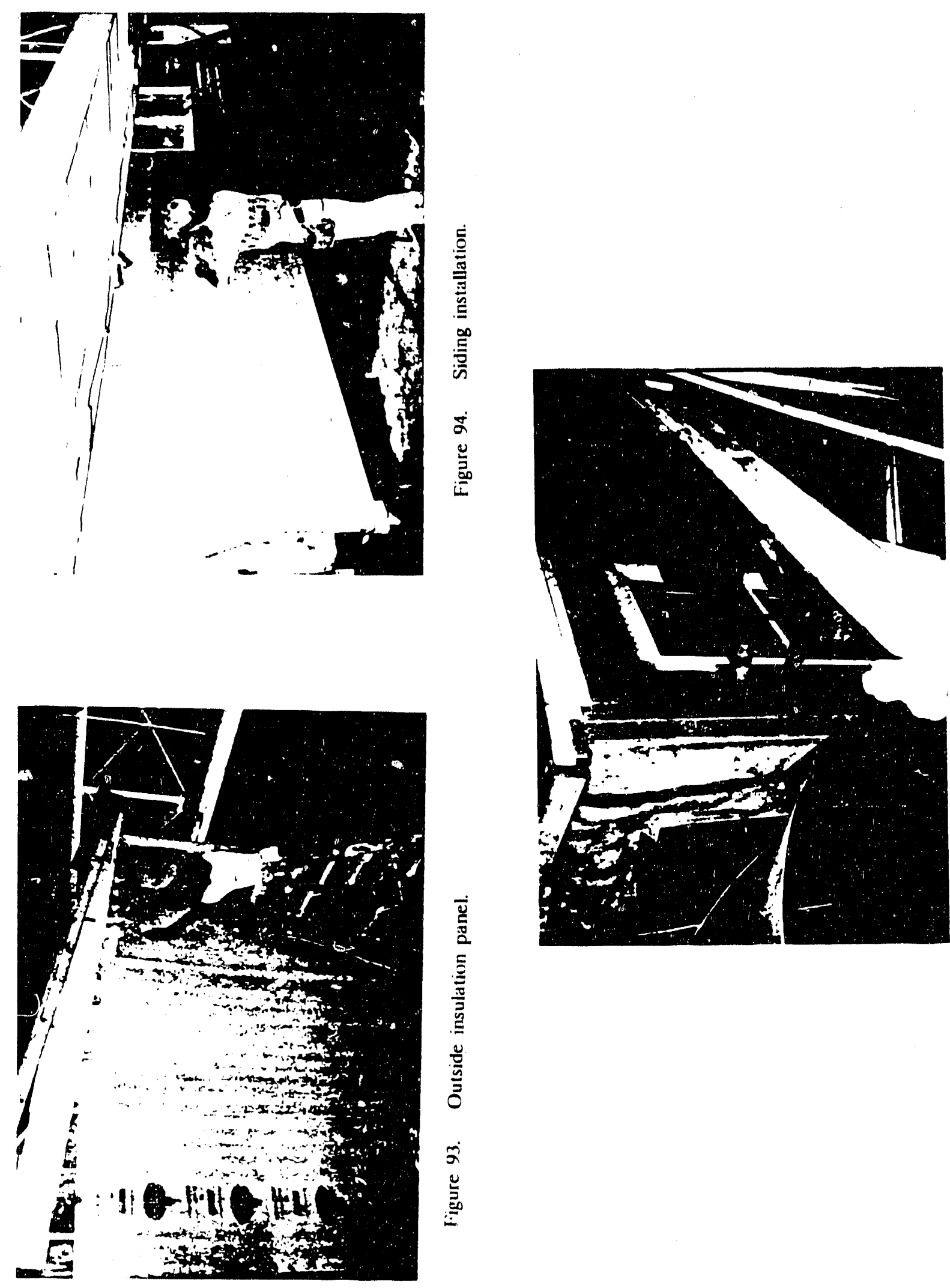

竭

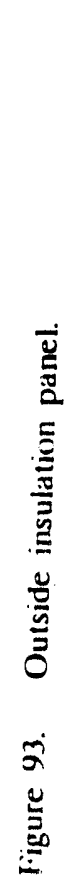



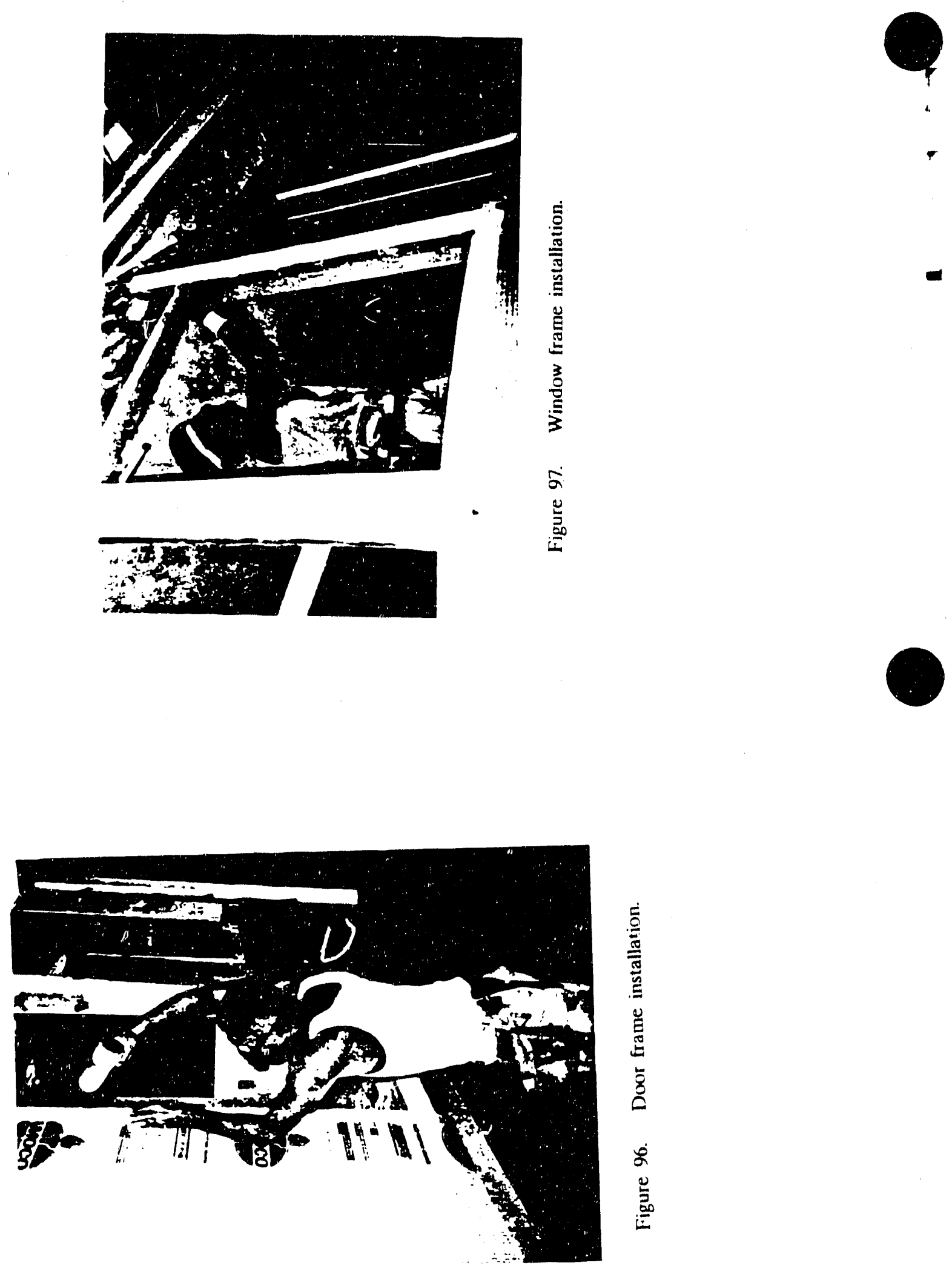

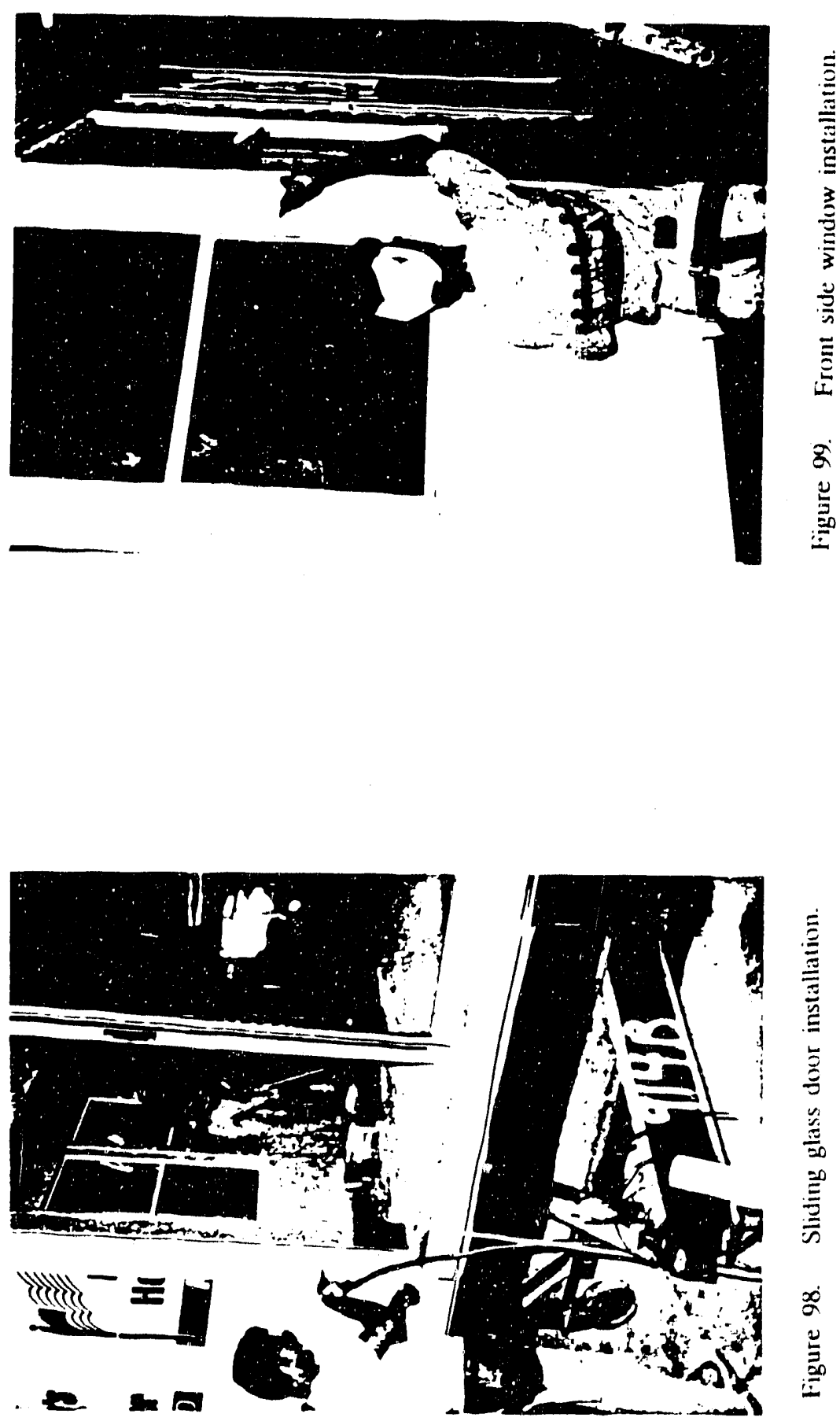

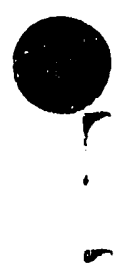

-

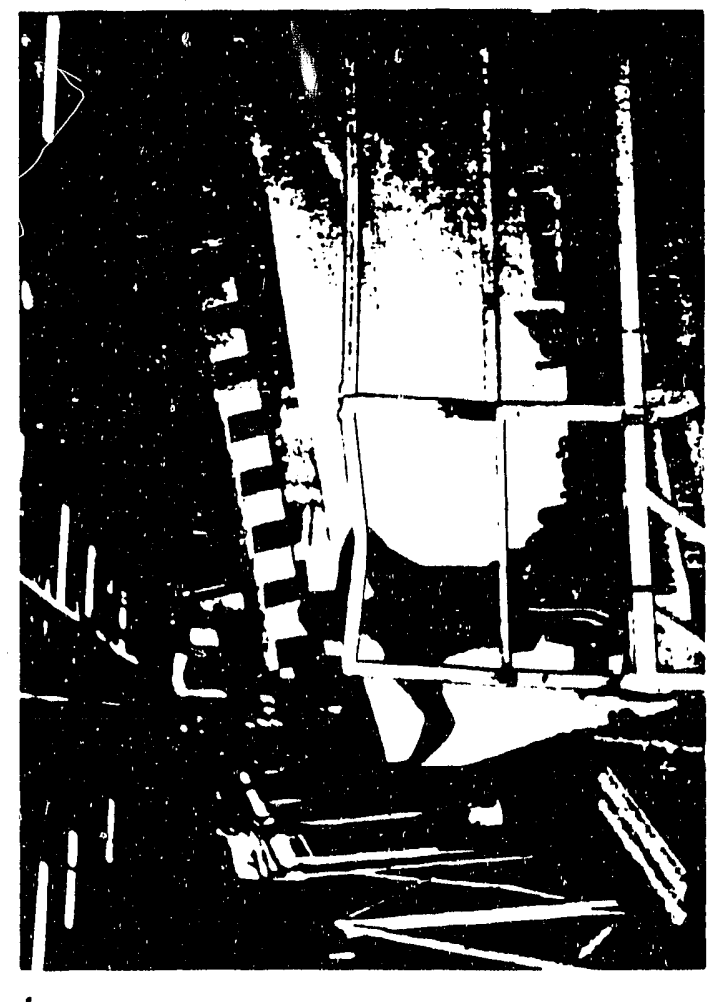

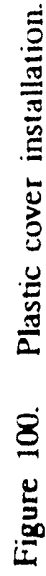




\section{Materials Handling}

Windows and doors are brought from a small storage area to a temporary staging near this workstation. When needed for installation, they are manually brought to station and installed. Vinyl siding and soffits are inhouse stored, then brought to a small cut station for odd size pieces. These materials are then taken to the production line to be installed.

\section{Inspection}

No inspection is performed at this station.

\section{Equipment Description}
- Cutting: 1 radial arm saw
- Assembly: pneumatic nail and screw guns
o Jigs/Fixtures: none
- Materials Handling: none

\section{Recommendations}

It is recommended that the following suggestions be investigated.

1. Layout: None.

2. Labor: None.

3. Process: None.

4. Materials Handling:

- Utilize storage carts to transport materials to the production such as the storage cart shown in Figure 101. 
- Transpon cars could be used for storing and transporting windows and doors to the production line. An example of such carts is shown in Figure 102. This would reduce unnecessary time for retrieving materials.

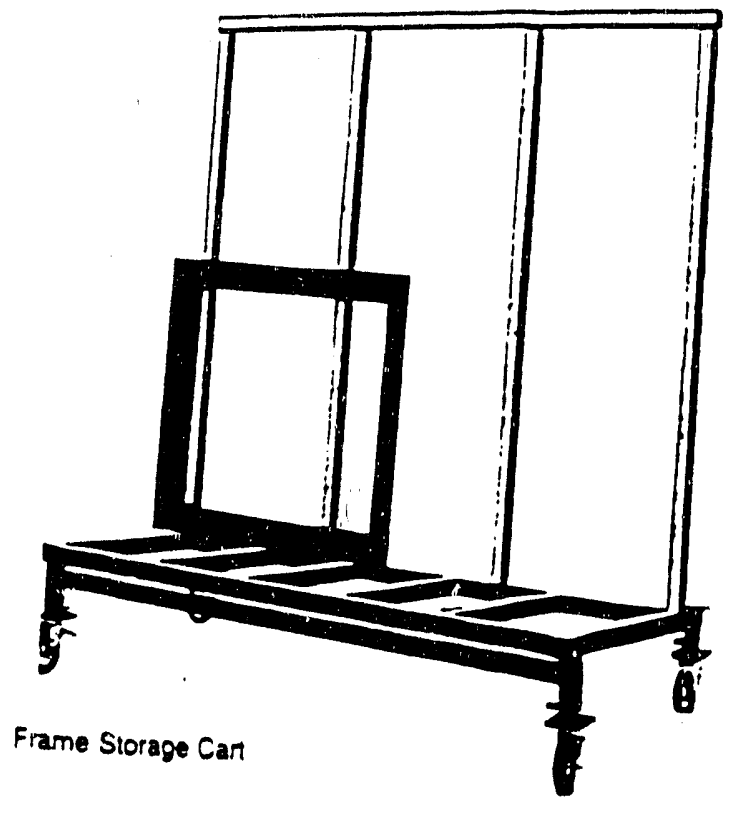

Figure 101

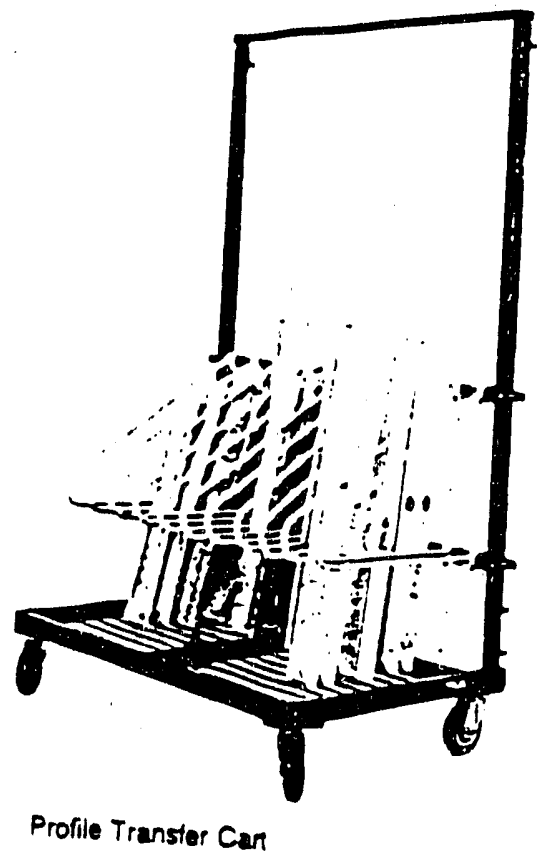

Figure 102 


\section{EXTERIOR FINISHING FLOW CHART}

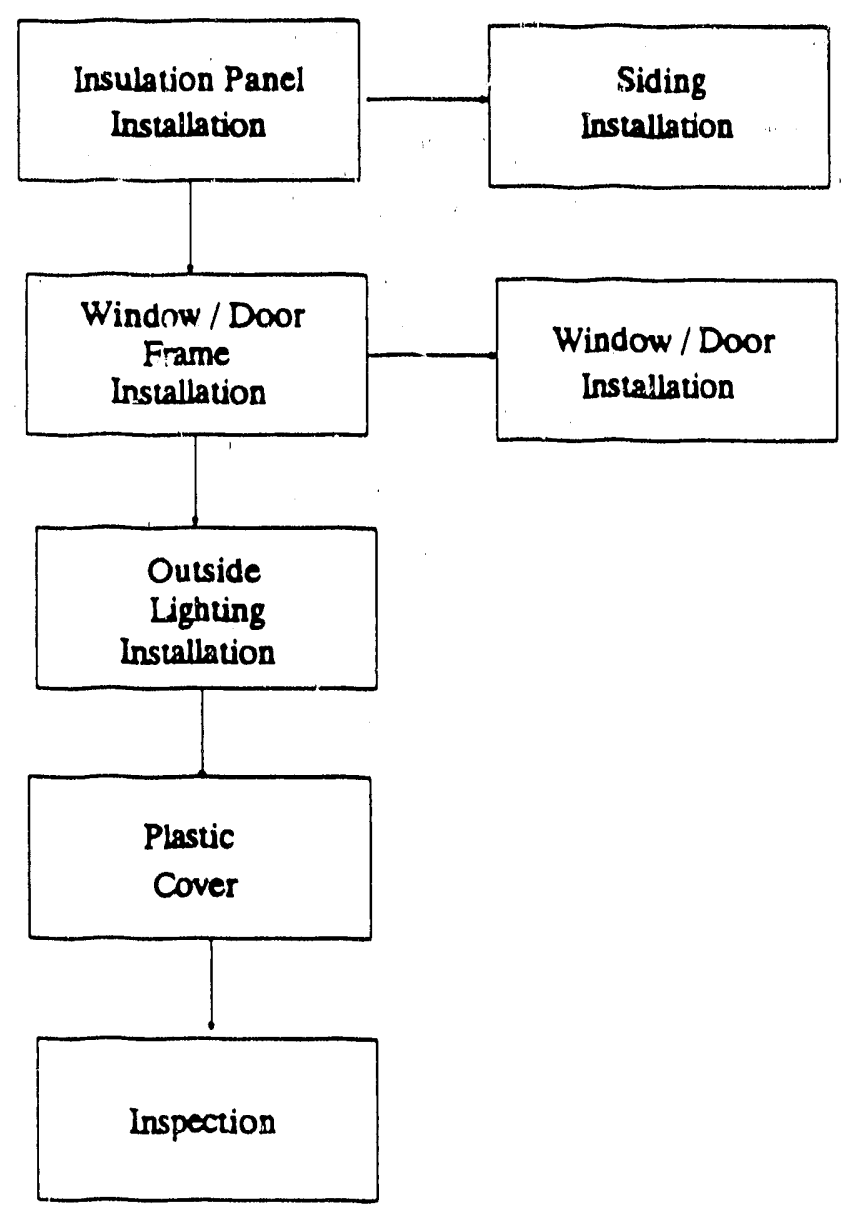




\section{TIME CHART \\ FOR \\ EXTERIOR FINISHING}

\section{Operation}

Atta 'h Panel Insulation

Install Siding:

- End

- Side

Install Windows/Doors

Install Outside Lighting

Attach Plastic Cover
No. of Operators

1

1

2

5

2

1
Total Time

$10 \mathrm{~min}$

$50 \mathrm{~min}$

$60 \mathrm{~min}$

$25 \mathrm{~min}$

$20 \mathrm{~min}$

$10 \mathrm{~min}$

- Note: Some of this operation may not be finished in one workstation, for example siding installation will be completed in two workstation. Estimated longest time in one work station is 45 minutes.

\section{Production Rate Analysis}

Requirement:10/shift @1/module

Cycle Time: $45 \mathrm{~min} . /$ assembly

Production Rate: (1 assembly $/ 45 \mathrm{~min}$. x $460 \mathrm{~min} . / \mathrm{shift})=10.2$ assemblies $/ \mathrm{shift}$ 


\section{INTERIOR INSTALUATION/FINISHING AREA}

\section{Process Description}

Interior installations consist of the following operations:

- Bathroom and kitchen counters installation (Figures 103 through 113).

- Living room cabinets (Figures 114 and 115).

- Bedroom closets.

Dry wall boards are cut to size for interior wall panels, then moved to the production line where they are stapled to the wall frame (Figure 116). Electrical wiring is installed inside the house which includes electrical switches and boxes.

Sealing of walls and cabinets is performed before the house is cleaned and moved to the inspection area. A molding strip is installed to cover exposed edges or seams between walls and roof (Figure 117). Also curtains/mini-blinds may be installed in this workstation (Figures 118 and 119). Kitchen appliances and interior lighting is also installed.

There is a final inspection, usually visual, performed by a supervisor of the finished operations. Inspection may include electrical testing for switches, connections, lighting, etc. (Figure 120).

\section{Labor Utilization}

Operations and duties of workers are described in the time chart for interior finishing. 

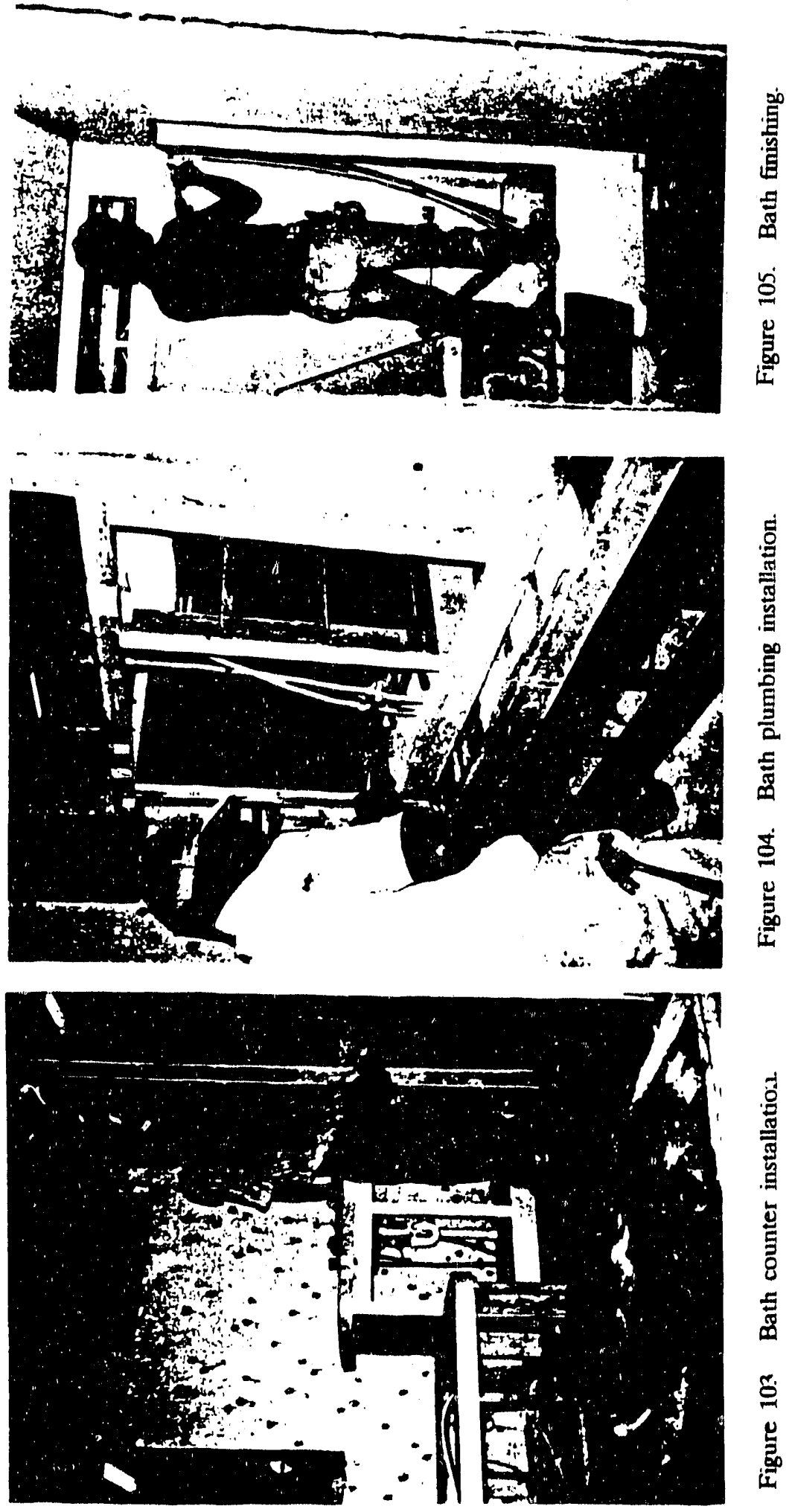

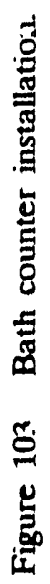



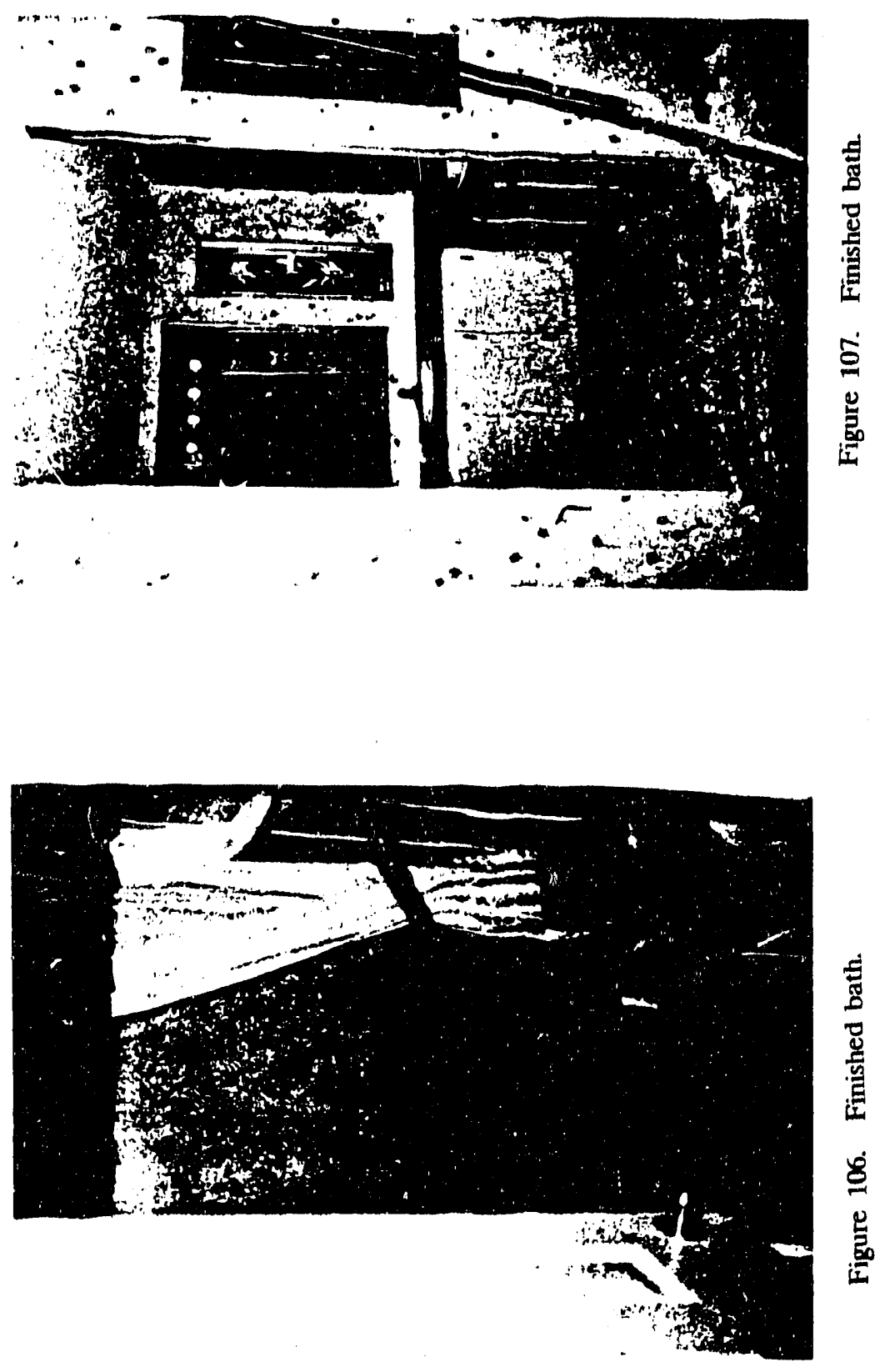

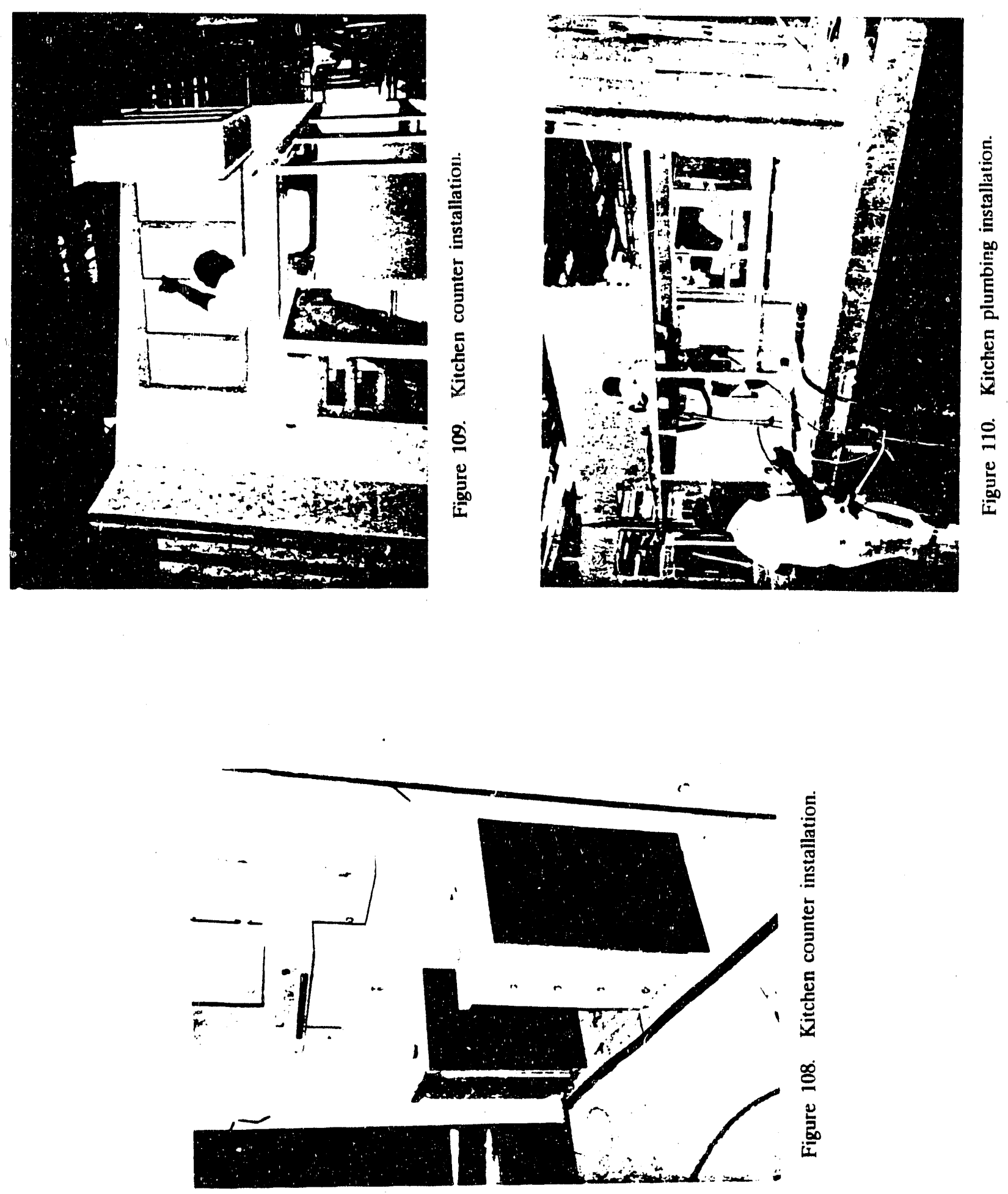

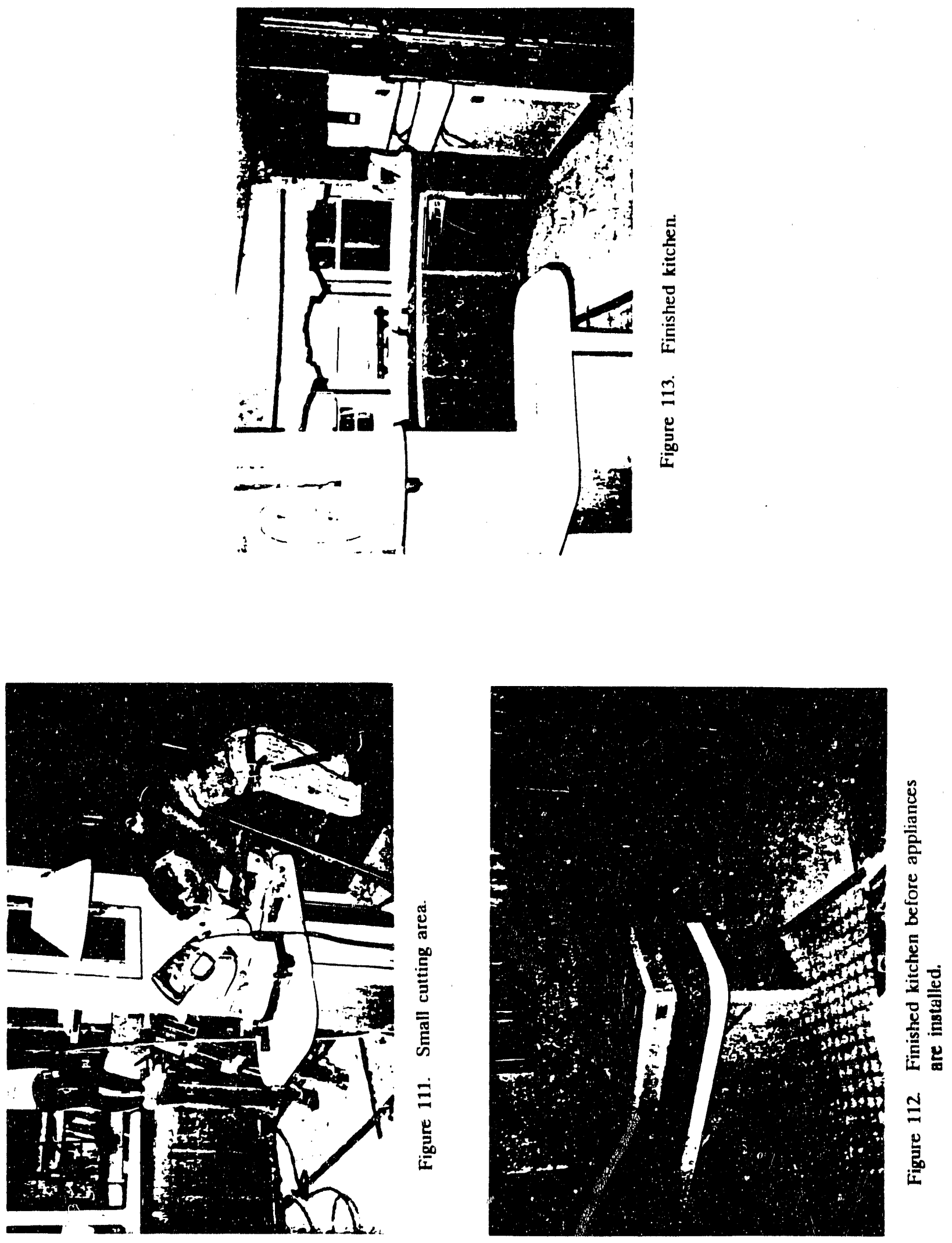


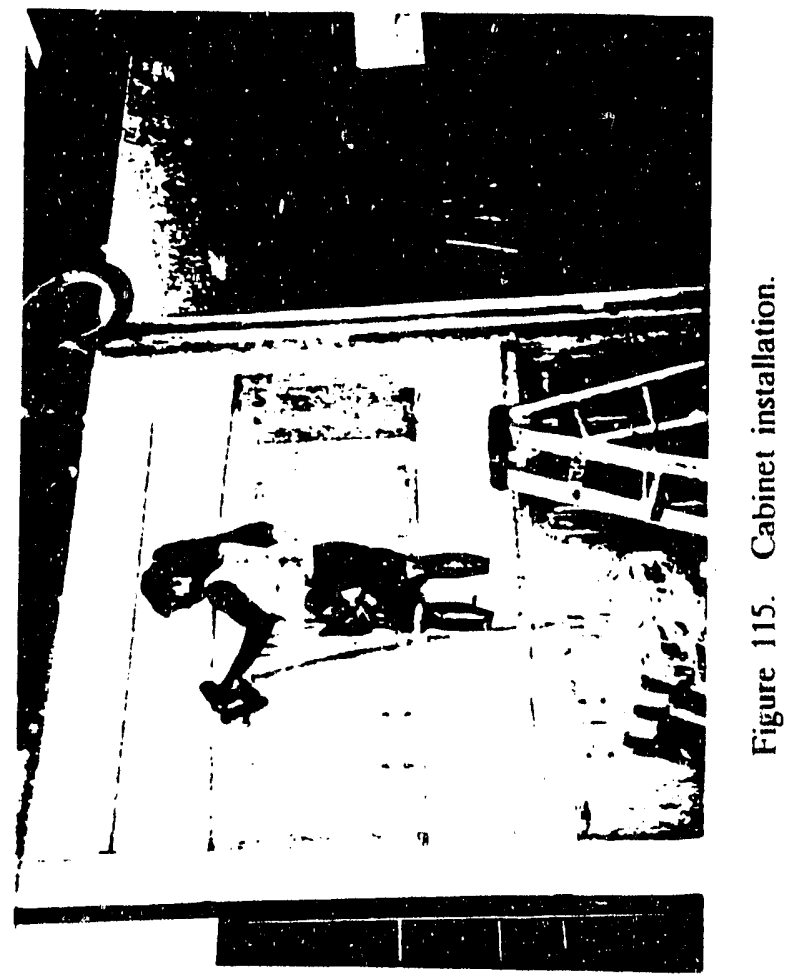

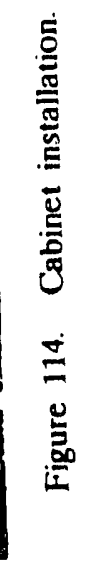



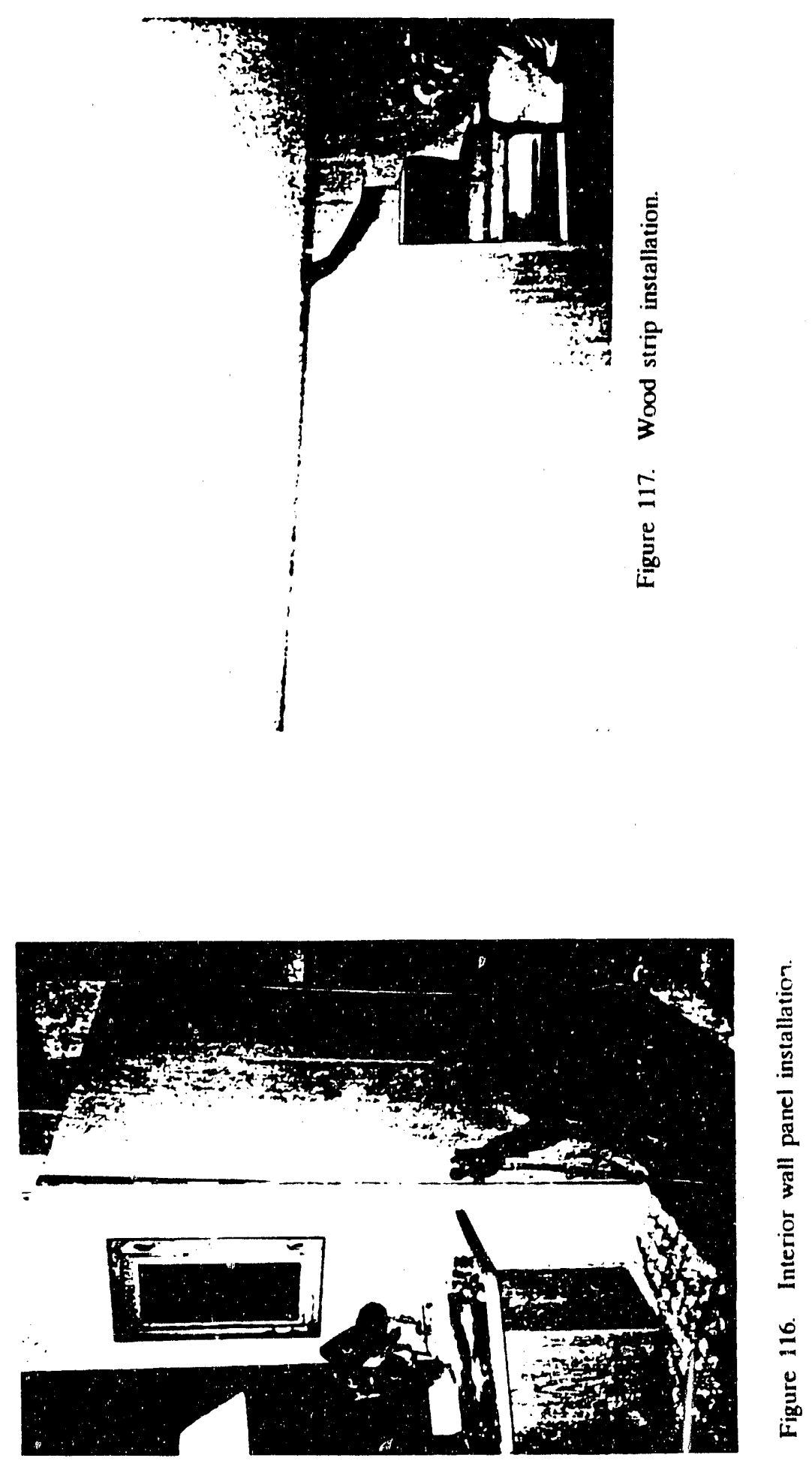

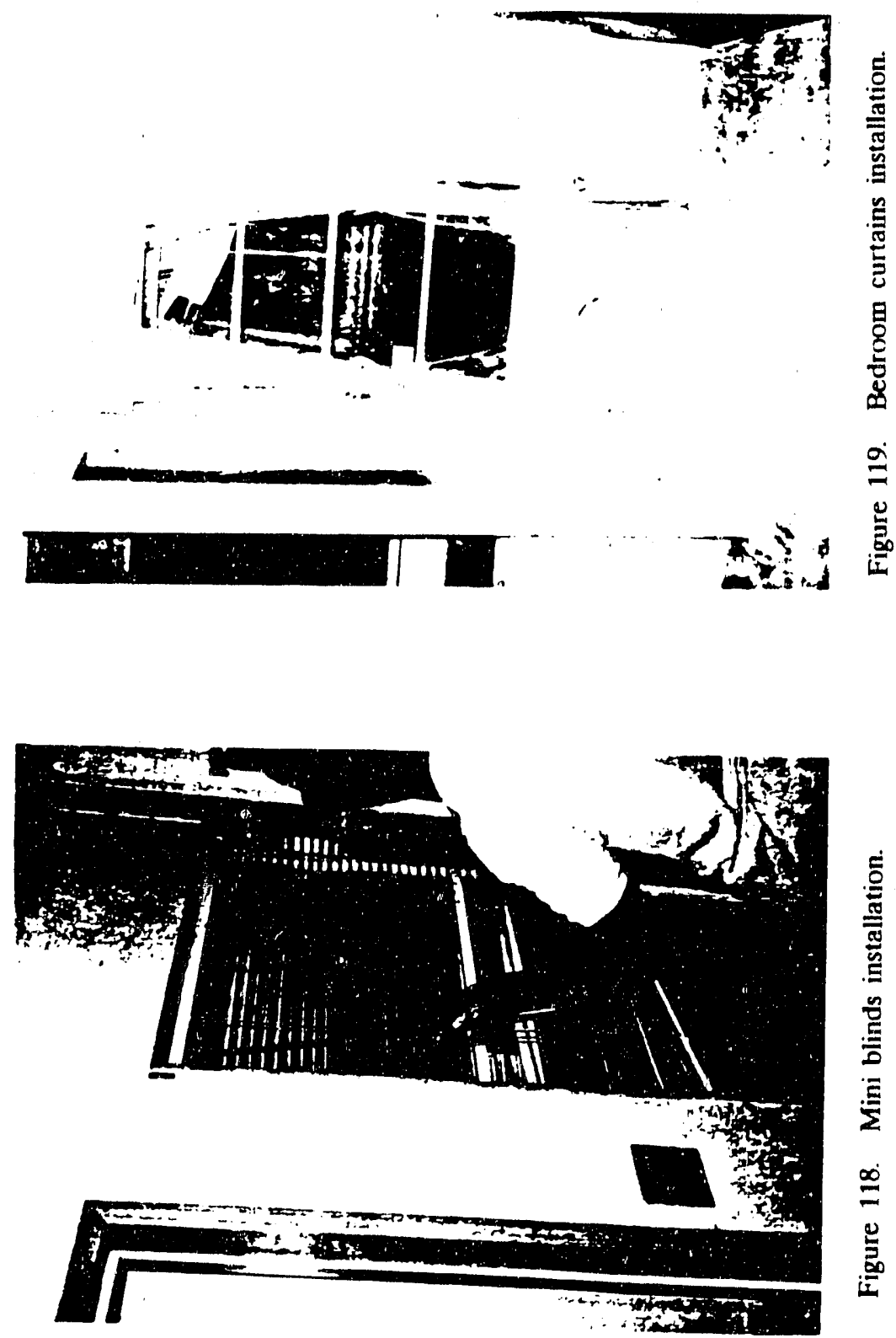

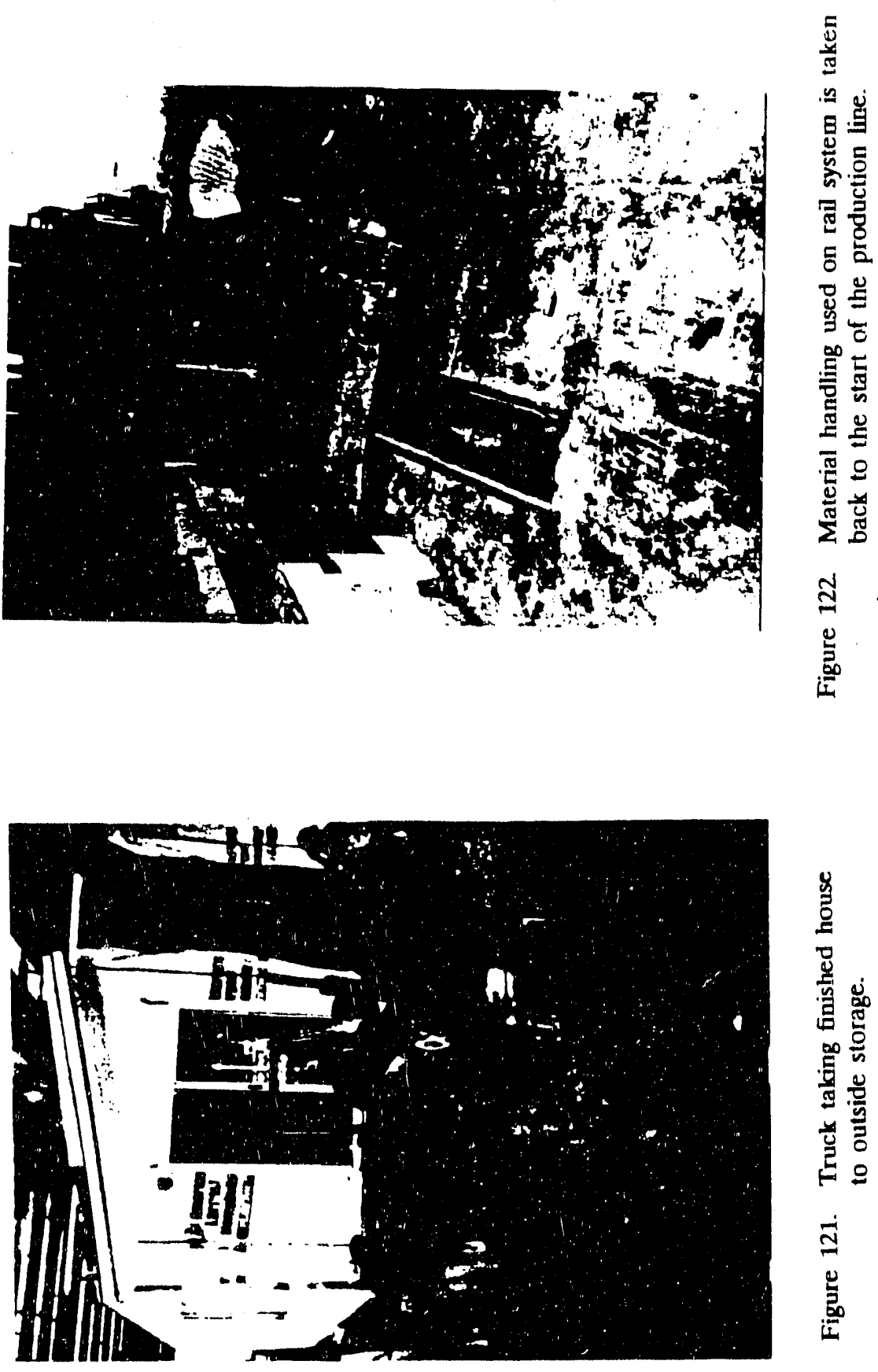

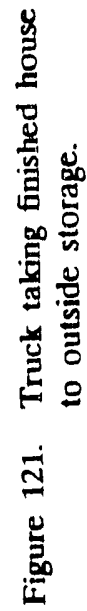




\section{Materials Handling}

Other cabinets are manually brought to the line for installation from an in-process storage area. Trim for windows, doors, baseboard, etc. is brought from an outside storage area to be installed. Curtains, blinds, etc. are manually brought from an in-house storage area to workstation. Finally, appliances are transported from an in-house storage area to the line using hand carts.

\section{Inspection}

No inspection is performed at this station.

\section{Equipment Description}

- Cutting: 1 radial arm saw

- Assembly: Basic hand tools

pneumatic nailers

screw guns

- Jigs/Fixtures: none

- Materials Handling: manual 
INTERIOR INSTALLATION / FINISHING FLOW CHART

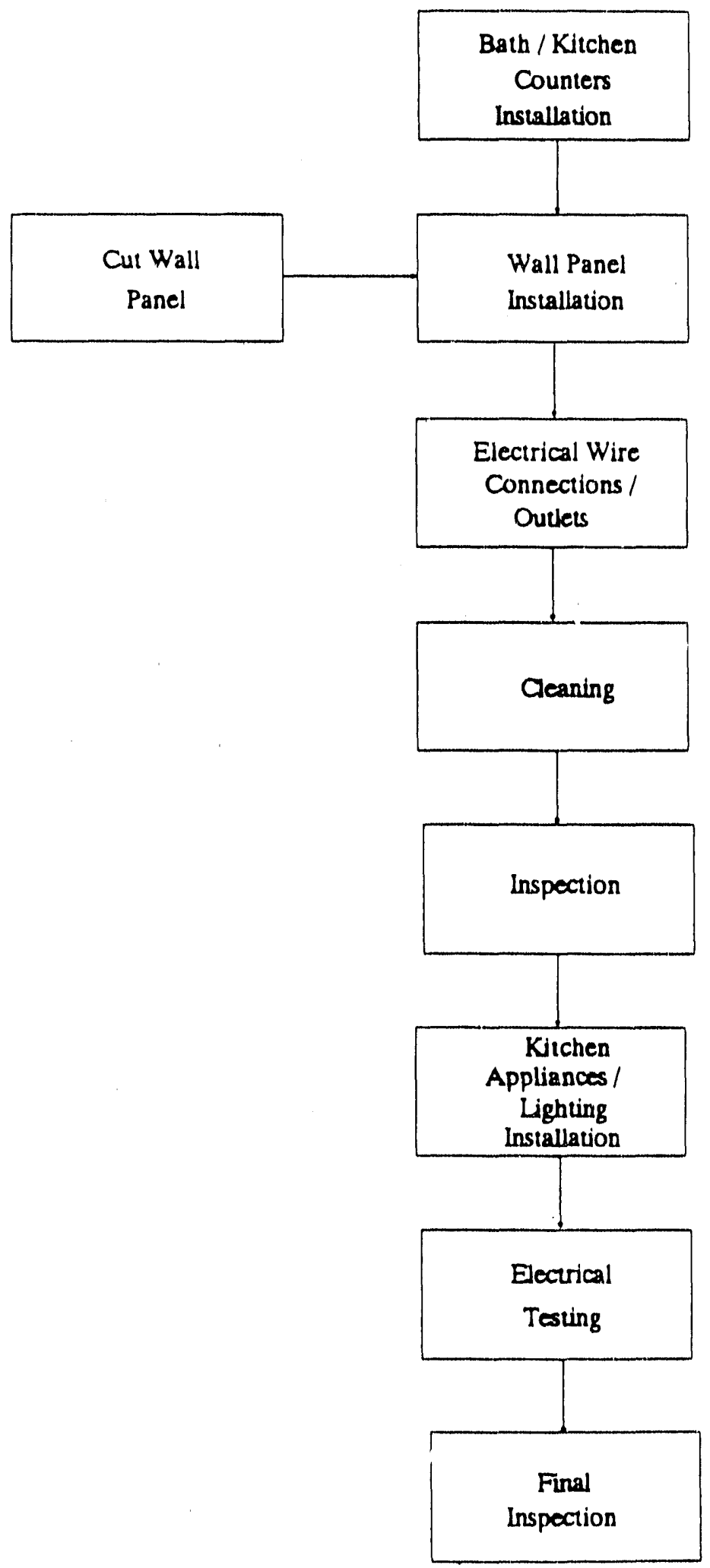



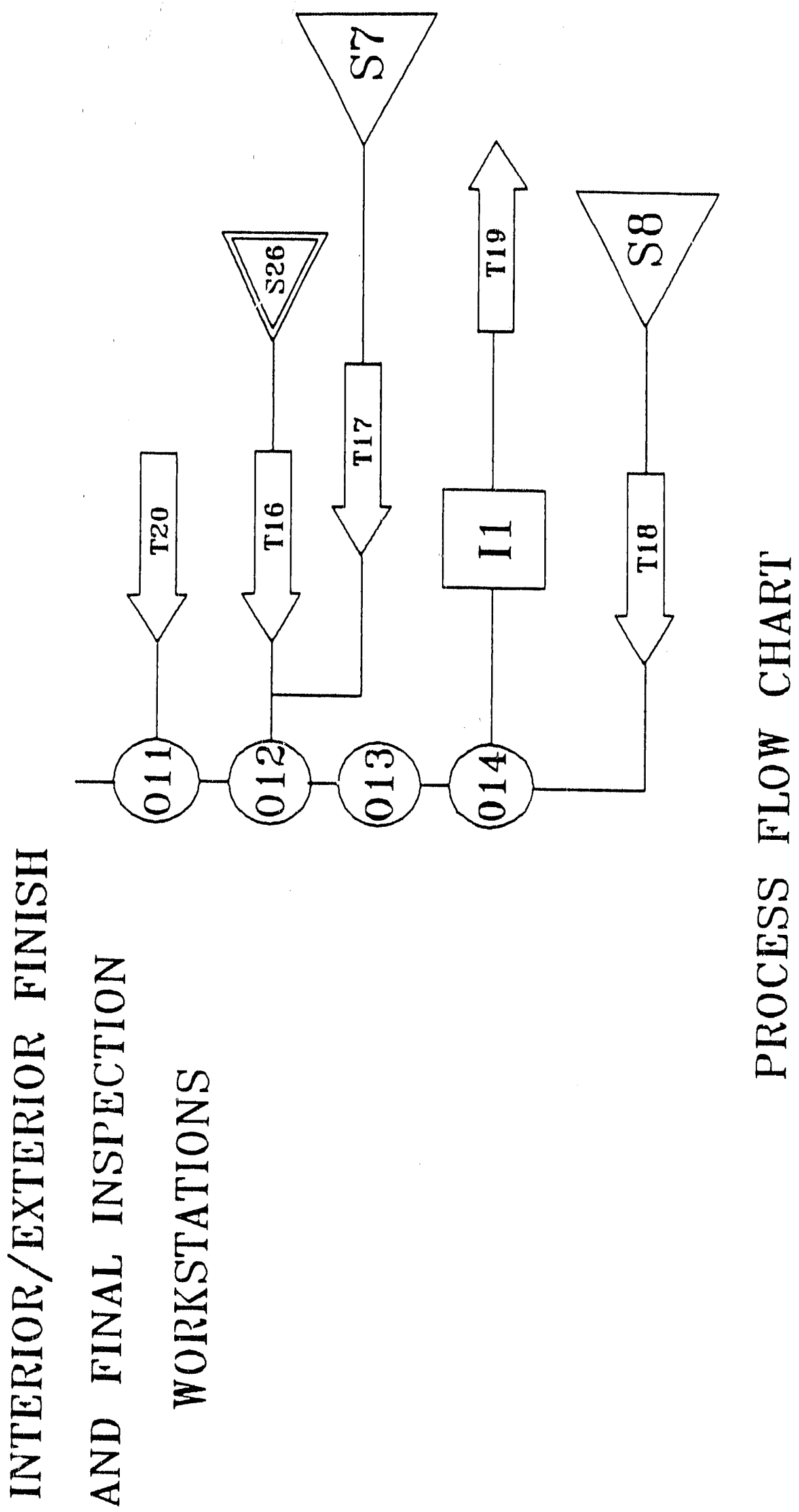

$\pi$
$U$
0
0
0
0
0 
Interior/Exterior Finishing and Fingl Inspection:

S7: Window and door stock.

S8: Kitchen appliance stock.

S26: Exterior siding and soffits are stocked.

O11: Roof top is assembled and finished.

O12: Exterior siding, windows, doors, and aluminum soffits are installed.

O13: Interior trim, lighting, and other accessories are installed.

014: Appliances are installed.

1 I1: Final testing and inspection are conducted.

T16: Siding is brought in for installation.

T17: Window and door stock is transported from storage to production line.

T18: Kitchen appliances are transported to production line.

T19: Finished house is transported out of production and into temporary storage. 


\section{TIME CHART \\ FOR \\ INTERIOR FINISHING}

Operation

Counters Installation

Closet/Cabinets Installation

Wall Panel Installation

Wiring Connections

Cleaning

Kitchen Appliances/Lighting

Installation

Electrical Testing/

Inspection
No. of Operators

3

3

2

2

2

4

3

\section{Total Time}

$40 \mathrm{~min}$

$45 \mathrm{~min}$

$30 \mathrm{~min}$

$35 \mathrm{~min}$

$20 \mathrm{~min}$

$30 \mathrm{~min}$

- Note: Most of these operations are performed simultaneously, estimated total time for Interior Finishing is 45 minutes.

\section{Production Rate Analysis}

Requirement:10/shift @1/module

Cycle Time: $45 \mathrm{~min}$./assembly

Production Rate: (1 assembly/45 min. $\times 460 \mathrm{~min} . / \mathrm{shift}$ ) $=10.2$ assemblies $/ \mathrm{shift}$ 


\section{WORKSTATION SUMMMARY \\ FOR \\ INSPECTION}

\section{Materials Fiandling}

No handling involved other than managing test equipment which is done manually. After inspection is completed, house is transported out and placed in finished storage (Figures 121 and 122).

\section{Inspection}

A final inspection is performed to ensure that components are securely assembled and installed, and house is checked for any missing or out of specification elements. Electrical testing is performed to ensure that all lighting, plumbing, and appliances are working properly.

\section{Equipment Description}

Inspection is visual, and testing is done with electrical diagnostic equipment. 


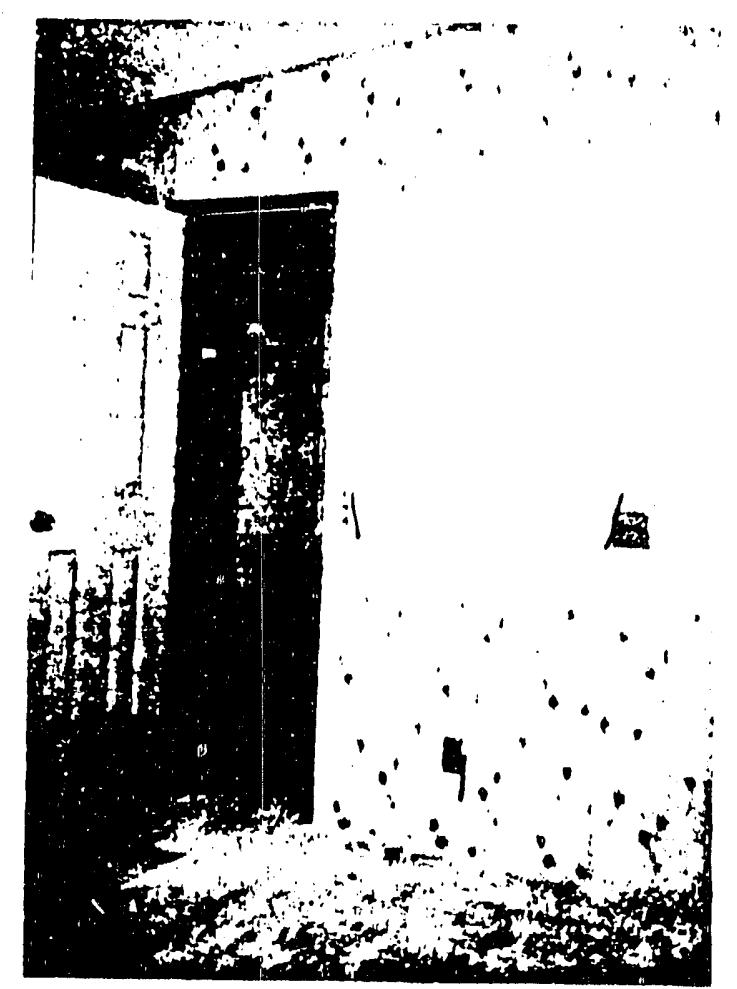

Figure 120. Inspection marks for electrical testing. 


\section{OTHER POTENTIAL DMPROVEMENT OPPORTUNITIES}

The following recommendations should be investigated.

Centralize Cutting

- Centralize cutting for all structural components as well as gypsum board and plywood paneling. Every workstation has its own cutting section. Assemblers often have to perform their own cutting which slows down production time. The area created by the removal of chassis assembly could be utilized for this operation. The crew would consist of 3 to 4 workers sumplied from those taken off other processes that are over supplied.

- The use of computerized sawing machinery capable of precision cutting at substantially higher cut rates could prove beneficial when considering production volume. Figure 123 shows an example of automated computer-controlled cutting systems. See Appendix A for additional listings of available cutting machinery.

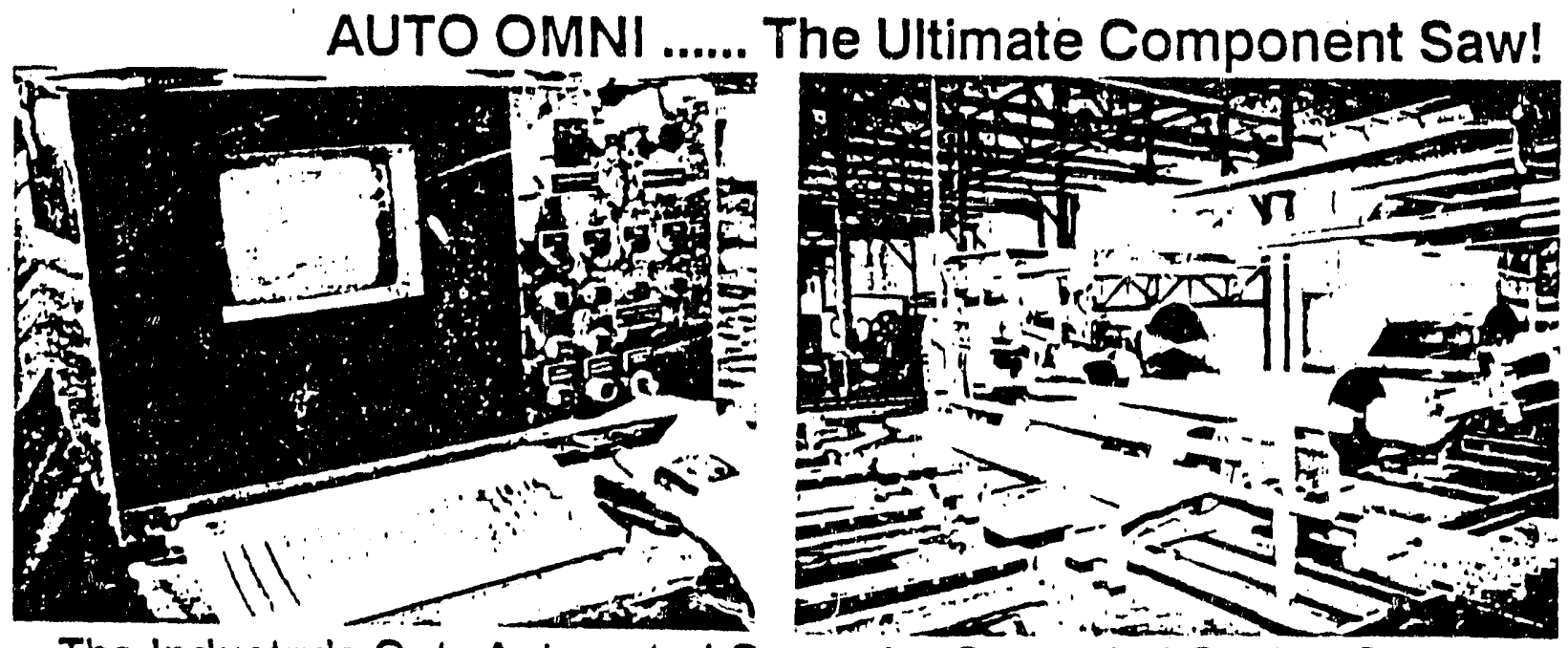

The Industry's Only Automated Computer-Controlled Cutting System

- Cunting lisis are downloaded from your in-house corn. puter directly to the saw's control console and stored until you are ready to produce the component

- The desired component appears on the IBM PC screen at your command

Fig are 123

- 15 to 20 seconds later you aro cutting lumber ... wthout running test pieces

- Indusiry leaders like Truswal, On-Line Data, Bemax and Hydro-Air can now provide sotwware to download direally 10 the Auto Omni 
Reduce Inventory

- Warehouse always contains substantial amounts of stock. The holding costs could be substantial for both materials and finished products. Inventory control procedures such as materials requirements planning, could be adopted to help optimize desired inventories.

o Developing a structured system will aid in improved planning and scheduling. If excess inventory does exist as suspected.

- Schedule and purchase materials only to fill customer orders. This change can only be considered after determining what the stock turnover rate is.

\section{Improve Materisl Handling System}

- Overhead cranes work very well for transport of heavy materials such as building components, but there is still a large amount of manual handling of heavy items, which increases likelihood of injury.

- The use of small conveyors, vertical roller carts, automatic lifts and conveyors, pallet tables, and autonatic lumber stackers (see Figure 124 for example) should be considered for both production. Appendix $\mathrm{A}$ has additional listing of available materials handling equipinent.

Figure 124

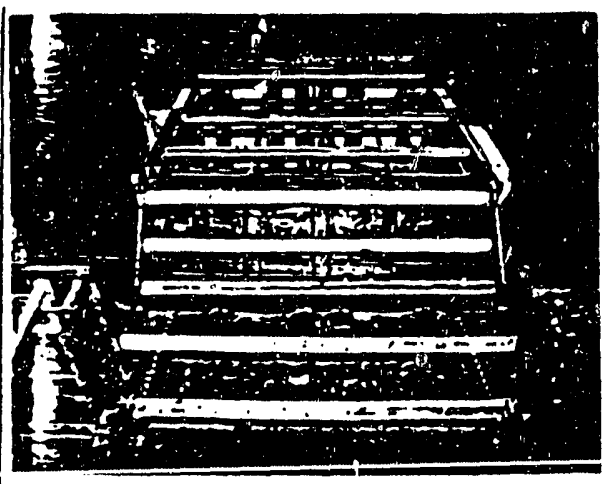

MAK-STACKER stacks lumber on the off-feed side of component 
Provide More Inspection

o Very little inspection is performed other than inspection of finished products. More stringent criteria of selection should be used for raw material acceptance. Inspection of cuts, joints, pro iesses can lead to a higher degree of quality for the overall product.

Jigs and Fixtures

- Currently the use of these tools is scarce. Only for truss fabrication are they employed extensively. For assemblies such as interior/exterior wall frames and floor frames, workers lay them out from memory and by sheer repetition have gotten very proficient at this operation. It is doubtful that jigs and fixtures could substantially improve the process over the current methods used.

o This is true as long as skilled workers are performing the operations, but when new people must be trained the operation is slowed considerably, making jigs a more attractive alternative. Additionally, the quality of the product would be improved.

- Adopting the use of jigs and fixtures (see Figure 125) would effectively eliminate the need for skilled workers to perform these operations and thus reduce labor costs. It is believed that these tools can offset the loss of production time caused by the use of less skilled people.

Figure 125

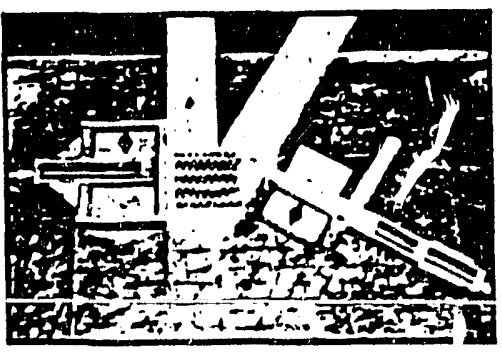

STEEL TABLE JIGGING HARDWARE

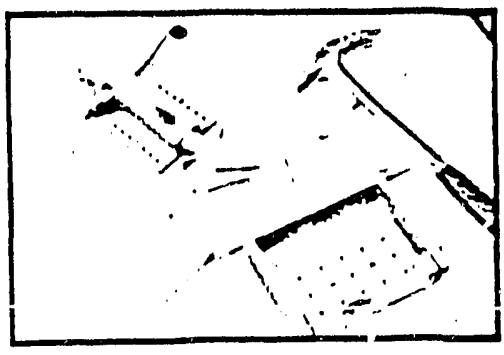

WOOD TOP JIGGING HARDWARE 
- They could also be used in cutting operations which would save time now used for measuring. Additionally, more consistent and precise cuts would be made improving quality.

- Layout tables with jigs are commercially available. See Appendix A for listings of available equipment.

- Only consideration would be the trade off between labor savings and the cost of building the jigs.

- Another alternative would be to develop templates for the various configurations that are used. This would be less expensive than making jigs and fixtures, as well as ease handling efforts. 
APPENDIX A

Listings of Available

Equipment 


\section{LIST OF POTENTIAL EQUIPMENT}

\section{Cutting Machinery}

1. Clary Multi-Purpose Component Cutter (Clary Corp.)

2. AutoOmni Programmable cutting system (Engineering Services Co.)

3. Whirlwind Cut-OFF Saw machine (Whirlwind Inc.)

4. Linear and Miter Notching Saws (Sampson Corp.)

5. Cut-o ff Saws (Sampson Corp.)

6. Speed Shop 'A' turntable cufting system (Speed Cut Inc.)

7. Timber Mill 6-20C muti-head cutting system (Speed Cut Inc.)

8. Timber Mill 5-20 High volume cutting system (Speed Cut Inc.)

9. TC-8 Turntable cutting system (Speed Cut Inc.)

10. Mobile Speed Builder mobile cutting station (Speed Cut Inc.)

11. Mobile Framer (Speed Cut Inc.)

12. Mobile Little Framer (Speed Cur Inc.)

13. MiTek Easy-Set component saw machinery (Gang Nail Systems Inc.) 

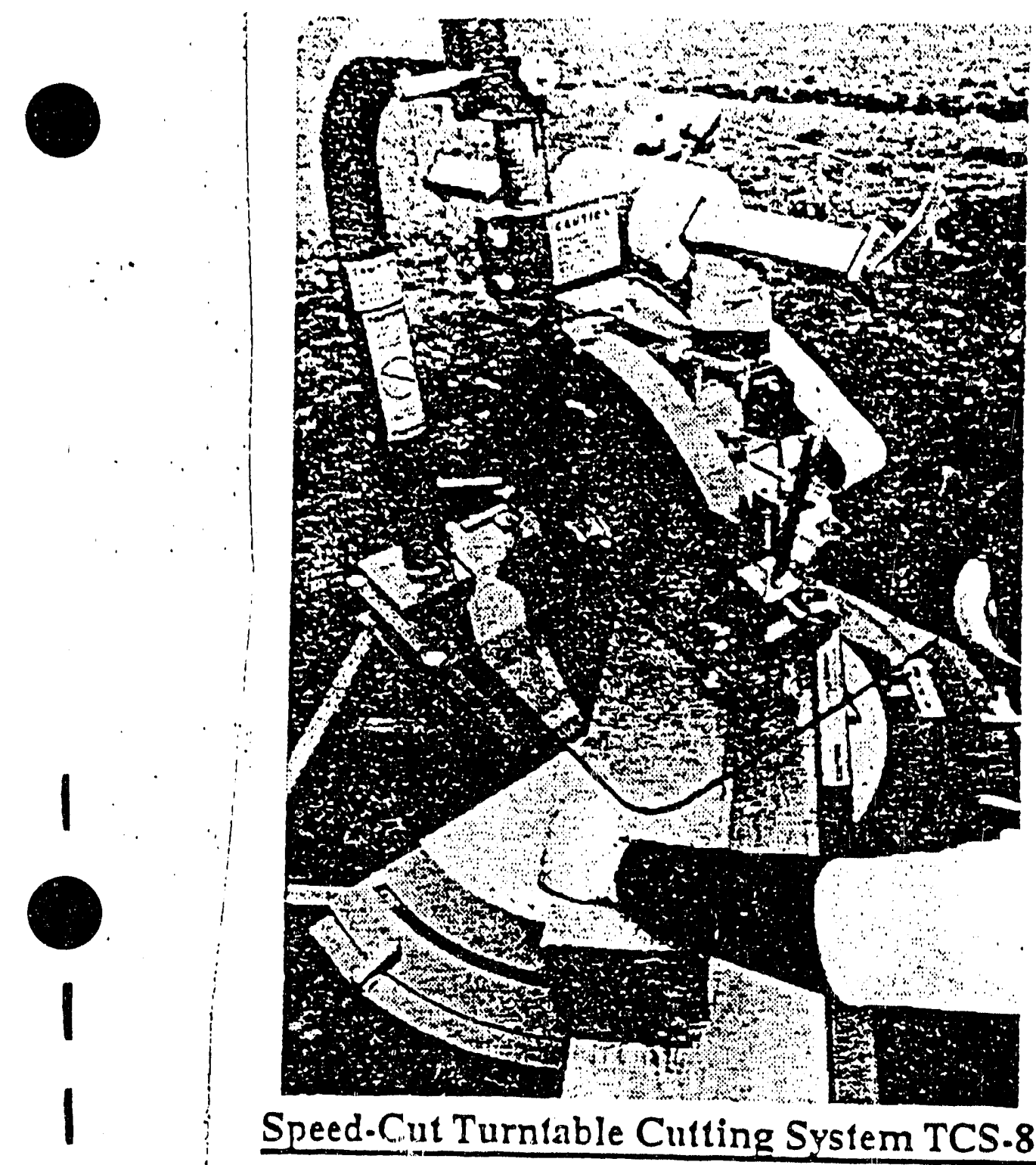

Speed-Cut Turntable Cutting System TCS.8

The Turntable Cutting System Model TCS-8, Speed Cut Inc., features a 22' carbide-tipped blade with an 8" depth of cut designed especially for the log home builder. Easy angle selection and depth of cut capacity allow the builder to quickly and accurately cut gable end components, large open beam ceiling framing timbers or other members. Support components bave been specially modified to handle heavier log and timber frame members. 


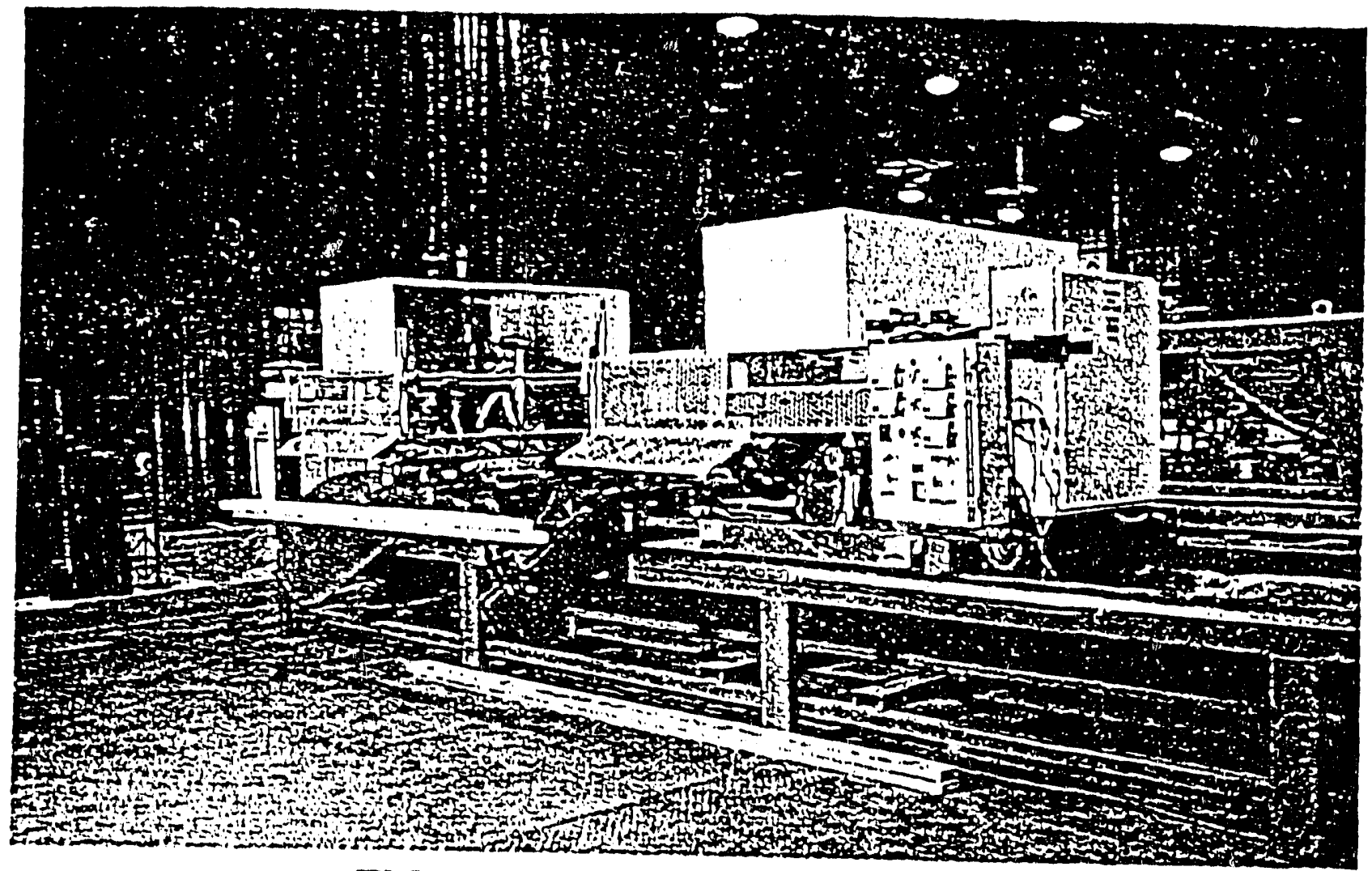

\section{MiTek EASY.SET ${ }^{\text {TM }}$ Component Saw}

the most advanced safety and guarding systems available in the industry, with both cable and push button shut-offs, air brakes, expanded guarding and manual backups. EASY-SET will be sold through Gang-Nail Systems Inc., Miami FL, (John Hurder, (800) 288-4264 or circle No. 98; and Hydro-Air Engineering Inc, St. Louis, MO, (Ken Klasing, (800) 325-8075 


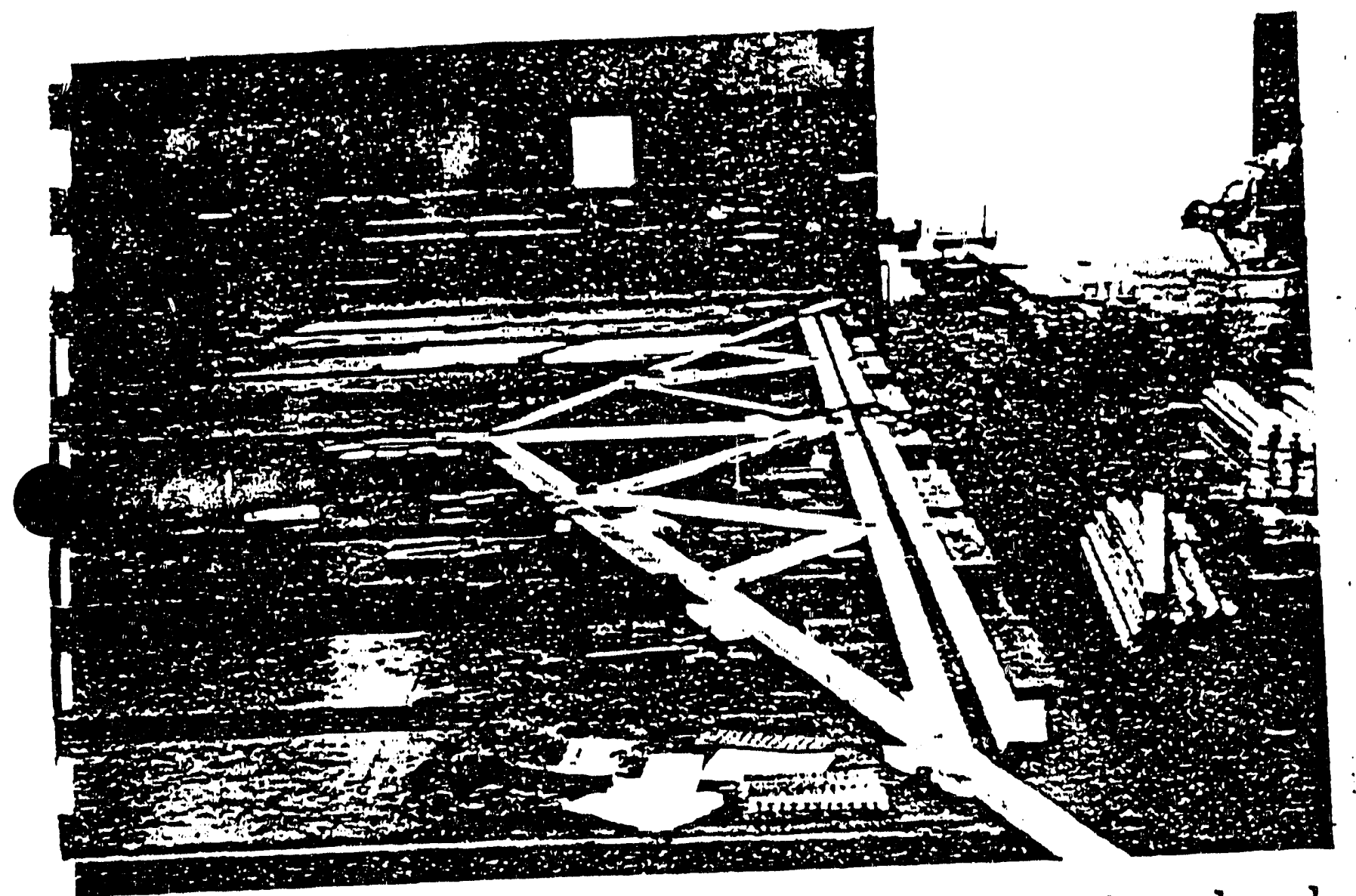

A new line of competitive truss machines has been introduced Jy Commercial Machinery Fabricators Inc., including this gantry plus roller press with $15 \mathrm{hp}$ drive performance. Also in the line zre layout tables with w'ood or steel tops, jigs, liftouts, conveyors : and truss stackers. 


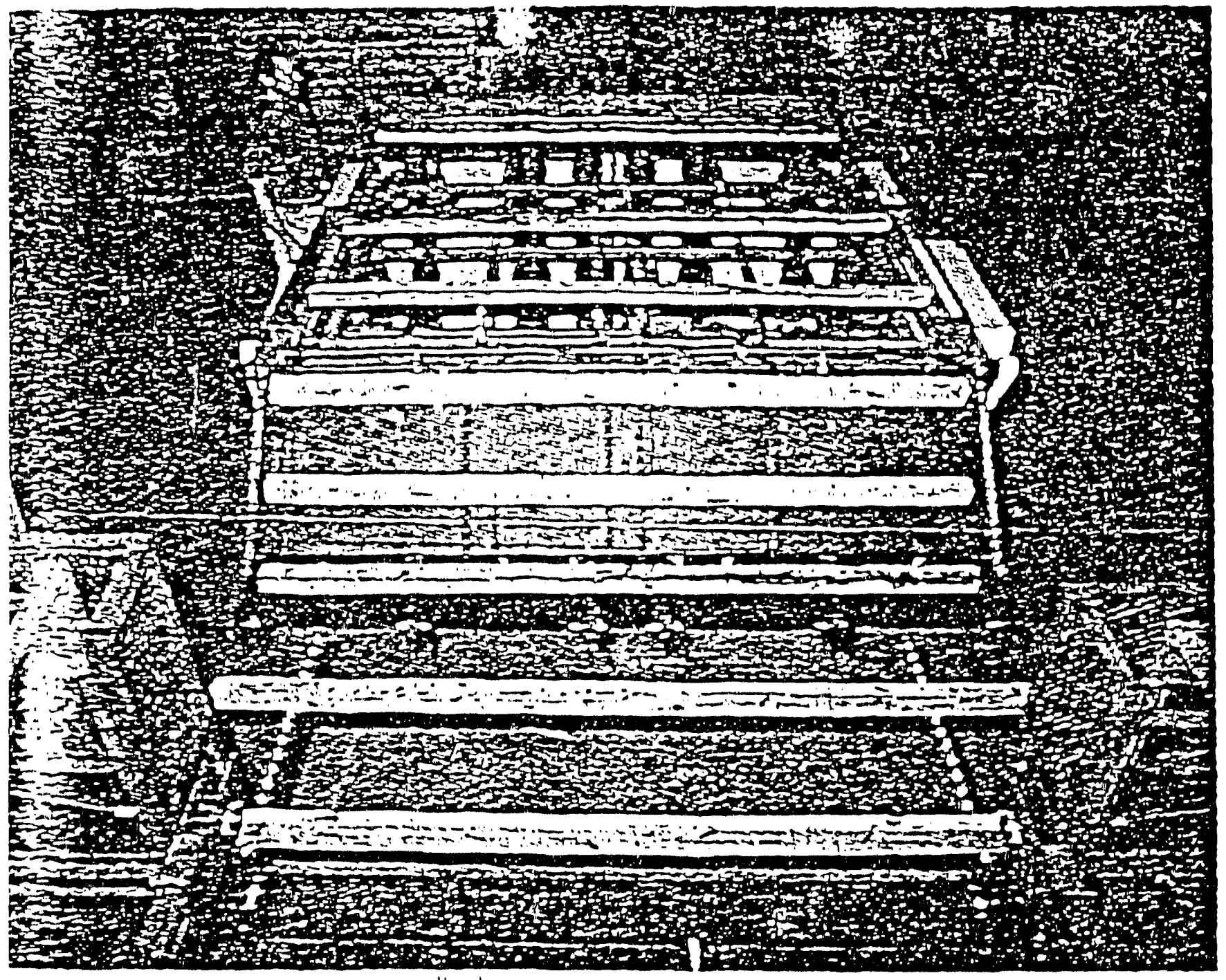
MAK-STACKER stacks lumber
on the off-feed side of component cutters replacing off-bearers. SC Inc. 


\section{Turnkey Production Programs}

\section{Technology}

Responsibility for achieving production goals is shared be. tween the product manufacturer and the machinery supplier. Both of these parties must be familiar with the product and the equip. ment and jointy work together to develop a "plant layout" that utilizes available floor space and manpower so as 10 maximize production volume and achieve efficient material flow. It is then the responsibility of the supplier to provide the required machinery and equipment as well as the nec. essary training and startup as. sistance to the manufacturer. The end result is a "turnkey" inmulacturing program that takes into account both current and huture requirements.

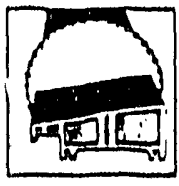

CUTTING

- Single Cul.OH Saws

- Double Cut.Off Saws

- Double Miter/Notching Saws

- Aulomatic Feed and

Cut.OH Saws

- Measuring Cauges

- Saw Blades

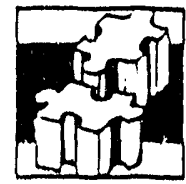

ASSEMBLY

- Vinyl Welders

- Comer Crimpers

- Assembly Tables

- Weld Clearing Machinery

- Hand Toois
47

FABRICATION

- Hydraulic Punch Presses

- End Mills

- Copy Roulers

- Tool \& Die Work

- Drill Units

- M lltiprocessing

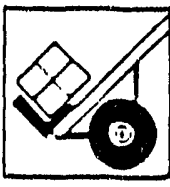

HANDLING

- Tables

- Carts

- Racks

- Rolvers

- Transier Units

- Test Units

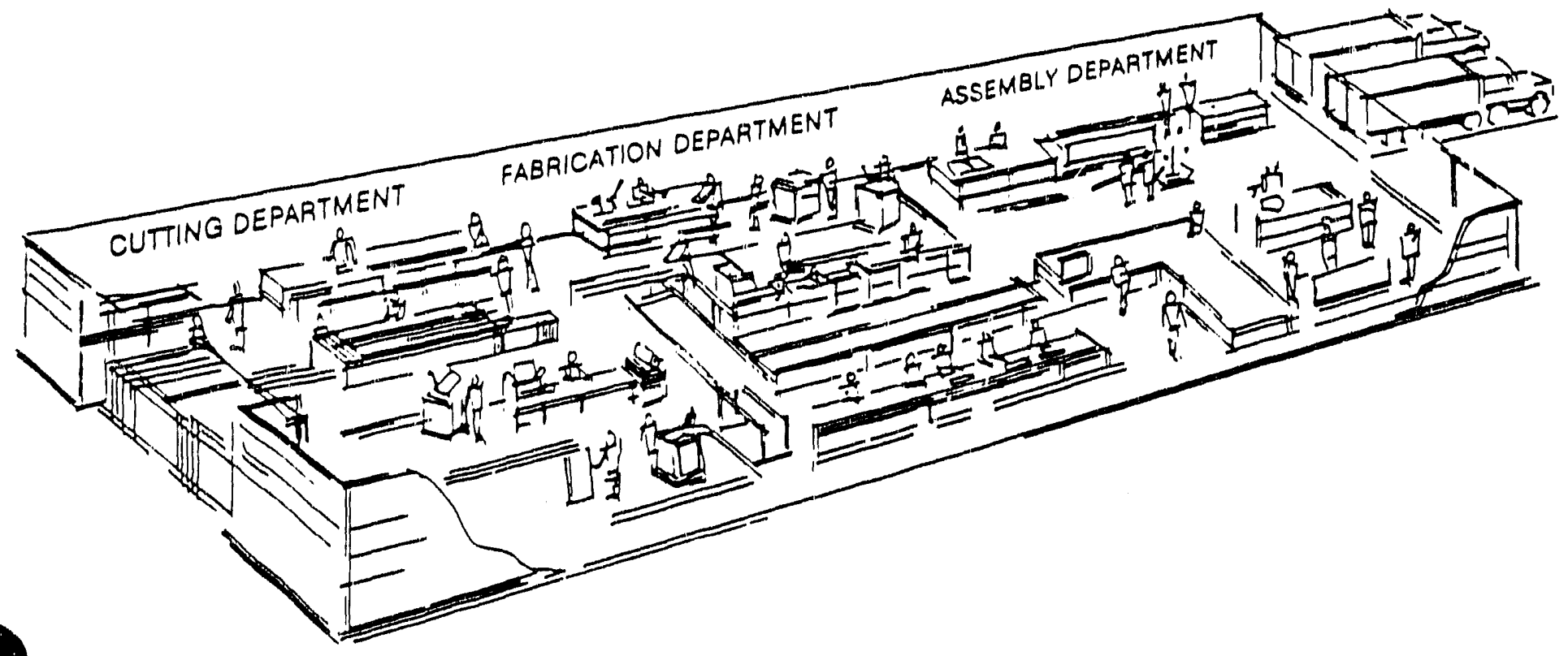




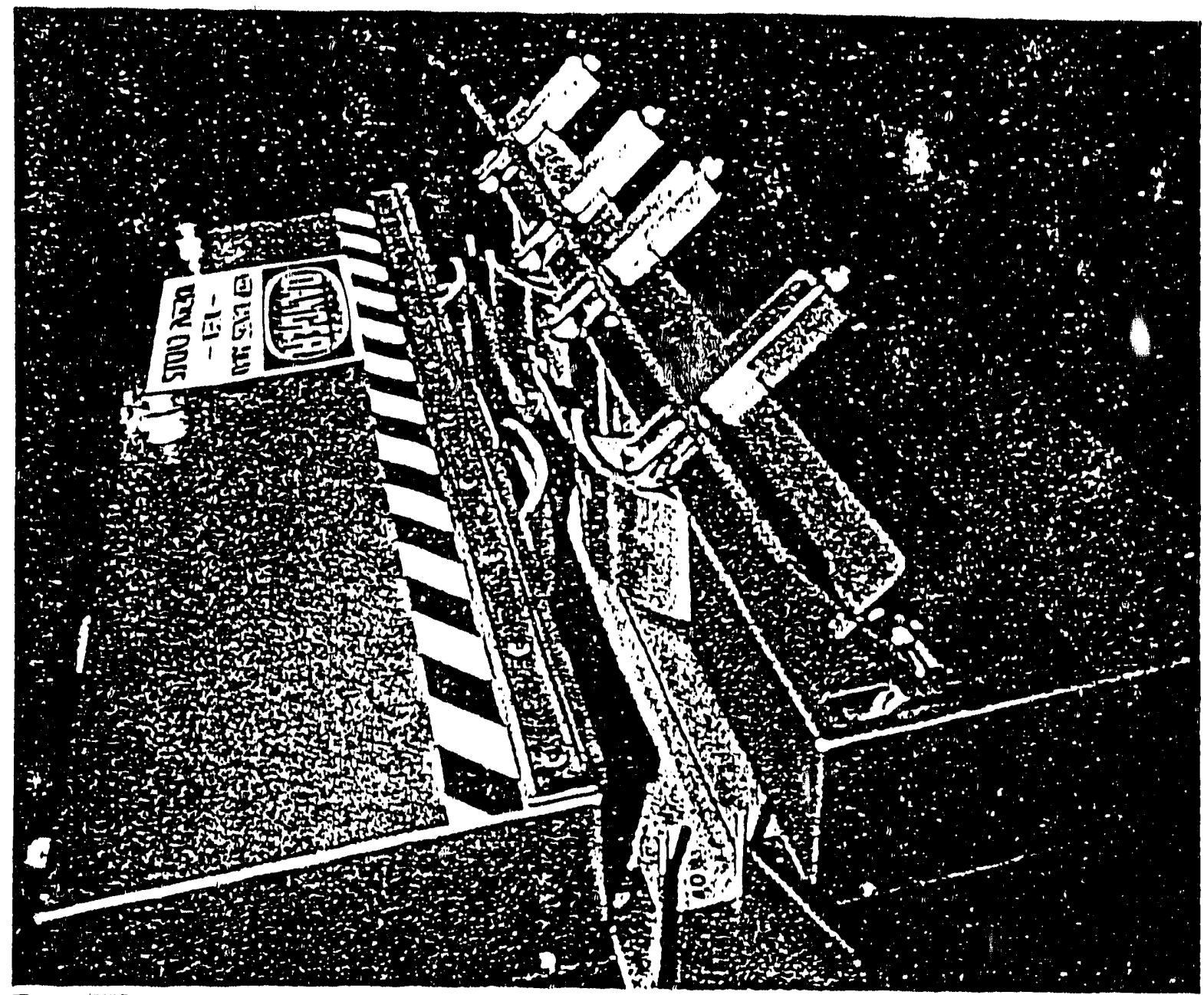

TrusWal Systems' "C" Clamp Truss Assembler

The Gantry "C" Clamp truss assembler, Truswal Systems Corp., (not sictured) allow's simultaneous assembly If several different truss styles without ime consuming set-ups. The machine is :asily expanded as production grors by tdding additional tixtures or complete igs as required. The assembler can also ve configured for or later converted to angnetic hold-dorns. 


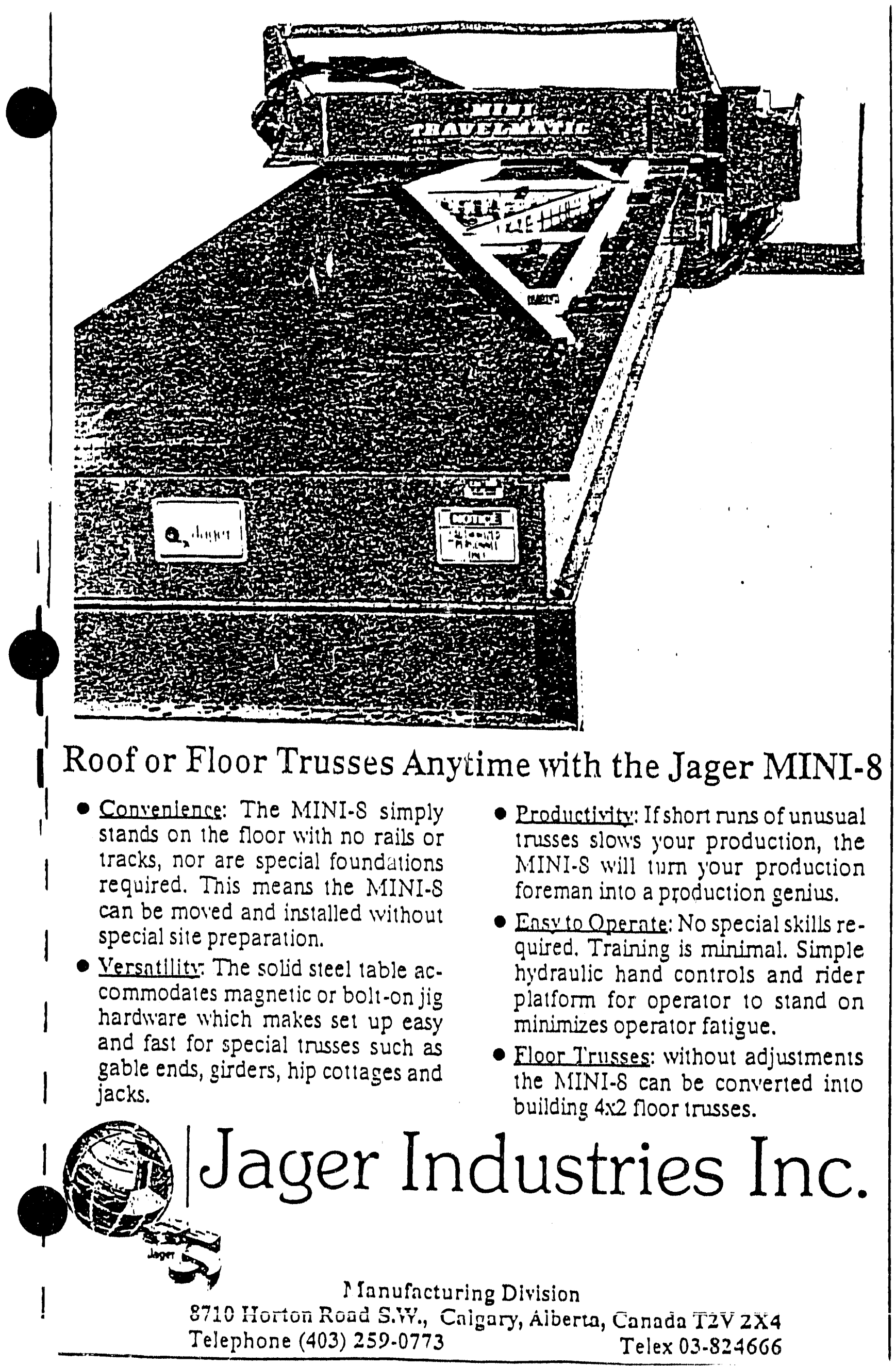




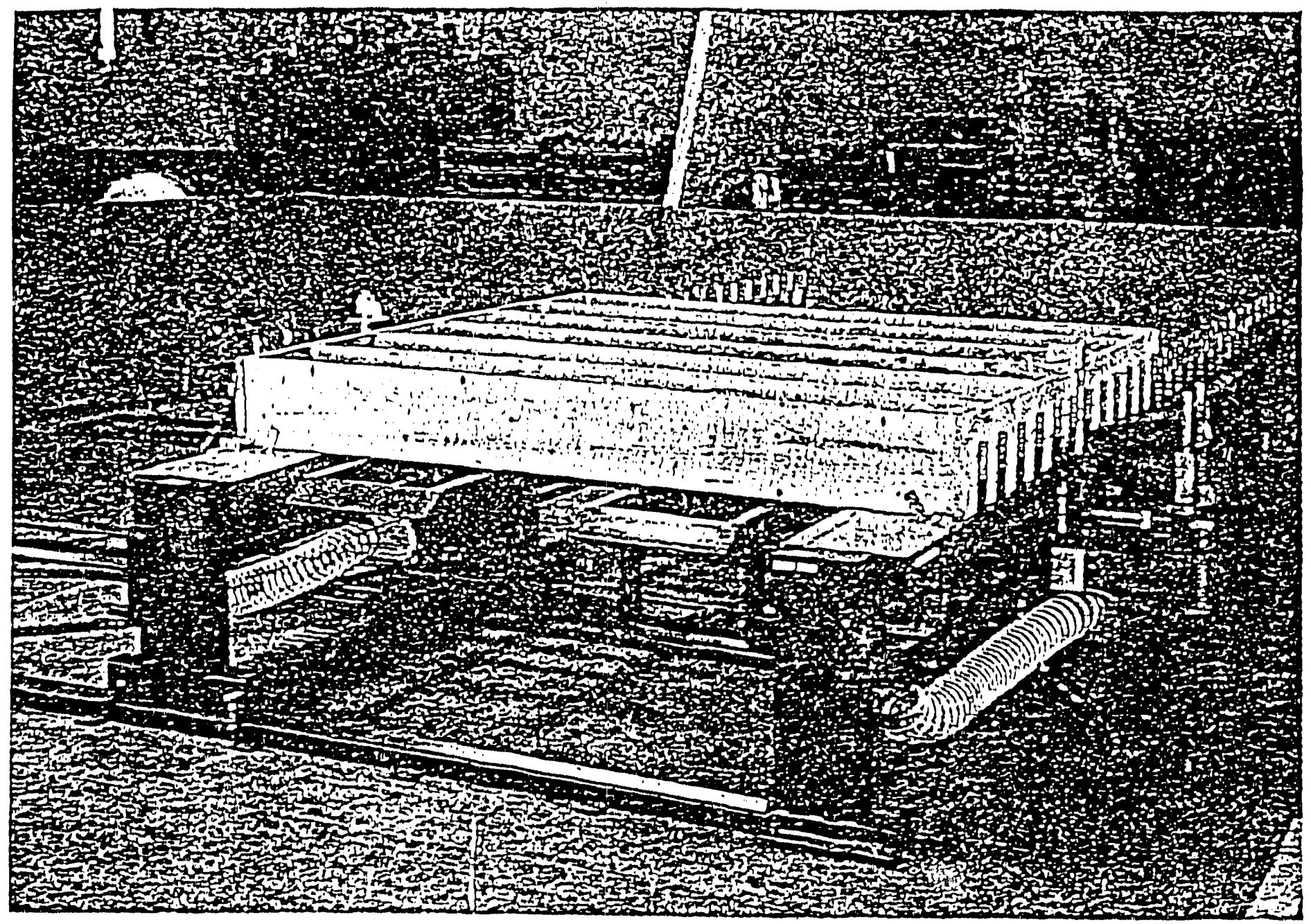

The Senco/Carlson Deching Table, Senco Prodtrtsand Carlson Sjstems, is designed to handle larger and beavier materials. The table clamps, squares and fastens lumber from $2 \times 3$ to $2 \times 12$ for floor or deck modules up to $16^{\prime} \times 16^{\prime}$. The tool carriage is equipped with Senco SNA pneumitic nailers and features full safety controls and an adjustable fastener patterp. Retractable joist locators on 16" and $24^{\prime \prime}$ centers can handle most designs. Hardened steel plate-clamp posts provide vertical and horizontal clamping to ensure square, tight-fitting floor modules. Fixed posts are used for $2 \times 3$ to $2 \times 6$ construction; extended posts are used for joist material up to $2 \times 12$. Thin center supports speed the loading of heary joists and the deck removal system includes air portered lift and manual rolloff. Deck lenghts of over 16' are available in I'increments up to any practical size. 


\section{Heavy-Duty 24" Dia. ROLLER PRESS Only $\$ 15,250$ !}

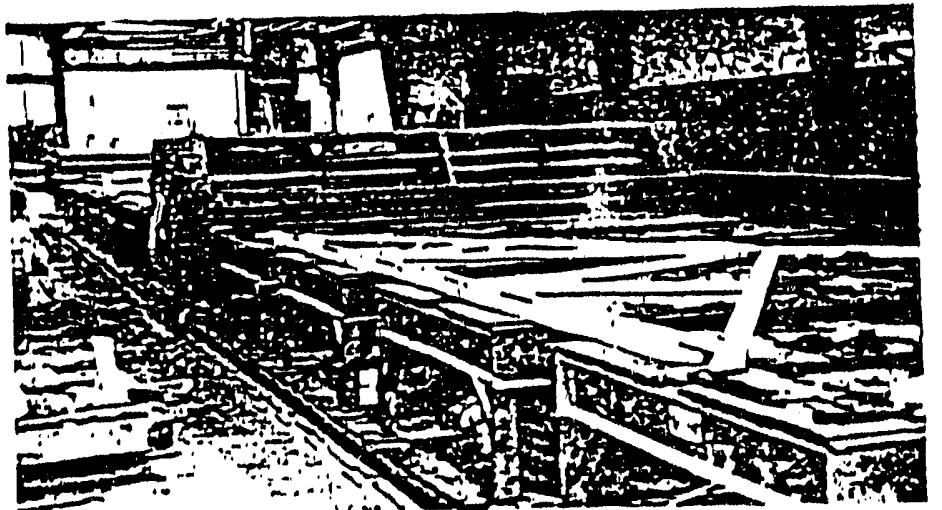

Also-Full Set of Axles and 16 Bogie Wheels for Any Gantry Unit : Only $\$ 1,250$ (A \$1,600 Value).

Commercial Machinery offers the component industry a complete line of machine tools and equipment at prices considered to be the MOST COMPETITIVE IN THE BUSINESS!

Check Us Out For:

- Gantry Plus Roller Presses with 15 h.p. Drive Performance

- Layout Tables With Wood or Steel Tops-Plus Jigs

- Liftouts \& Conveyors

- Truss Stackers

- No 'Extras' To Buy-All Equipment Complete with Air \& Electric Lines \& Hardware

CALL TODAY-Ask for Ed Joseph

Commercial Machinery

Fabricators, Inc.

3530 Josette Lane, Lansing, Ml 48906 Phone: 517-374-6845

Fax: $517-321-1283$ 


\section{You Need MUSCLE In A Wall Panel Machinge!}

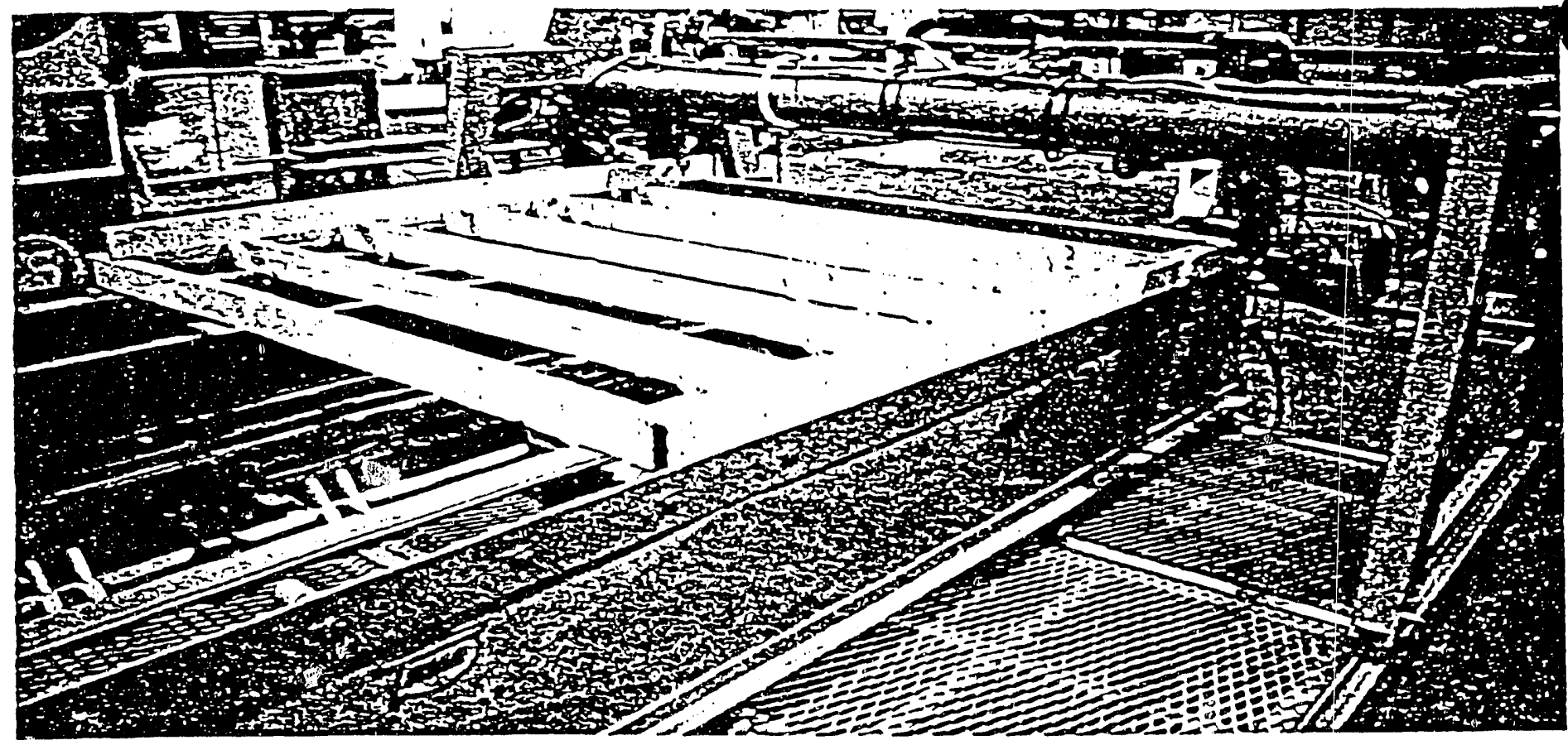

ONLY TRIAD HAS IT. ONLY TRIAD CAN GIVE YOU ...

\section{THE HEAVY DUTY "Neus Generation" WALL PANEL MACHINERY}

We have the following machinery available:

- Framing Tables

- Squaring Tables

- Sheathing Tables

- Handle Bar Routers

- Sub-Component Machines

- Panel Lift (PL 1000)

- Wind Brace Saws
- Material Handling Carts

- Material Bridges

- Router Bridges

- Stud Stitchers

- Screw Bridges

- Complete Wall Builders

- Complete Floor Builders

YOUR MACHINE IS TAILOR-MADE FOR YOUR SPECIFIC PLANT

P.O. BOX 130

A.Ida, NE 68810

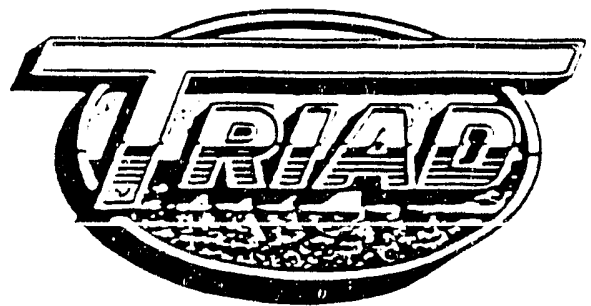

Merrick Machine Co.
CALL TODAY

FAX: (308) 384-1657 PH: (308) 384-1780 


\section{Curt-Off Sanars}

Below is a representation of commonly used saws for various angular cutting applications.
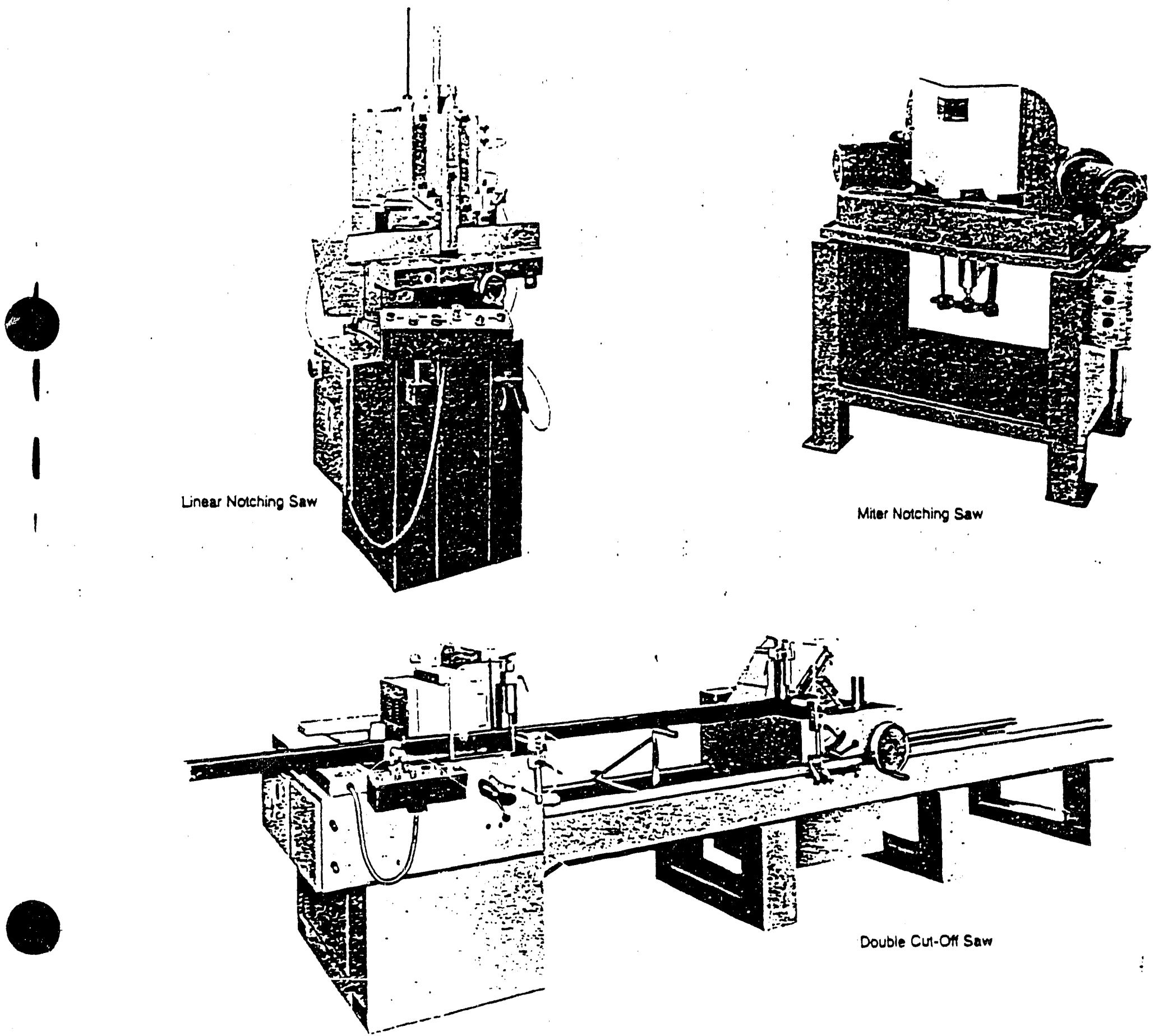


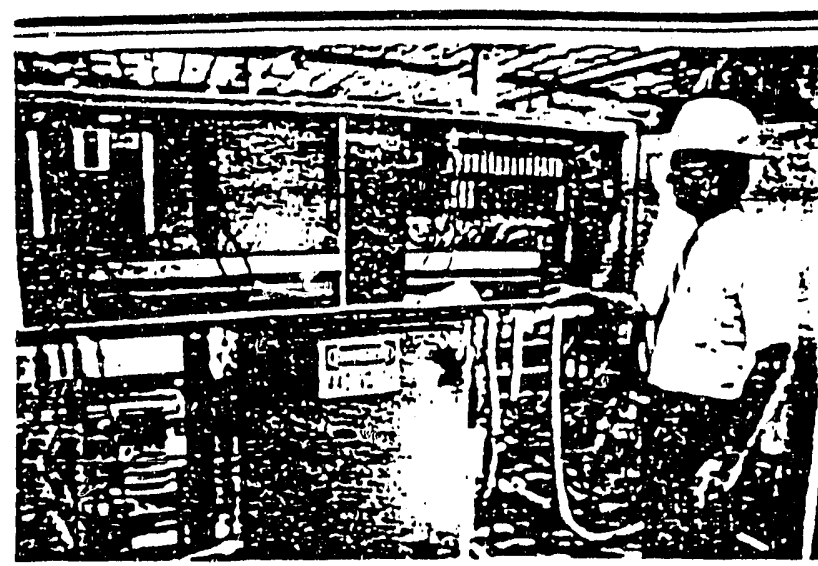

BOB THOMPSON checks over computer controls and w is. ins panel for Cardinal's new noor extruder machine which iuras out a 12' $\lambda^{\prime} 24^{\prime}$ framed and sheathed deck in seven minuies.

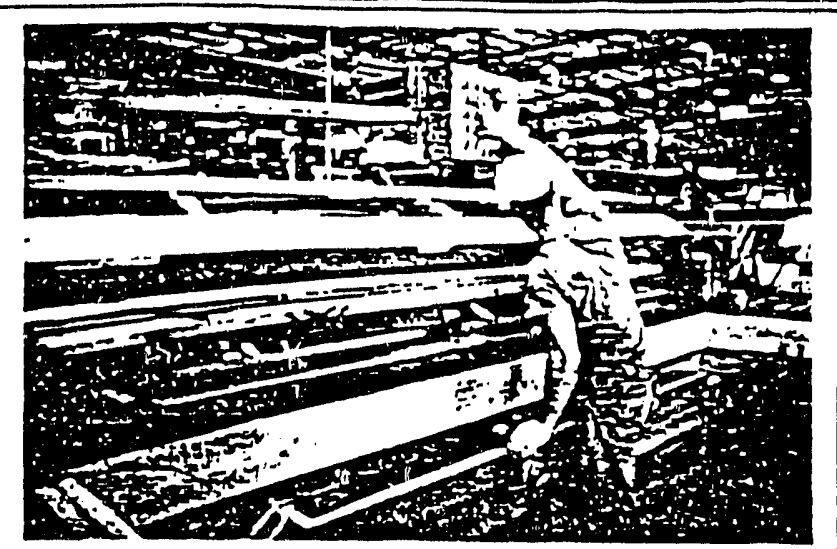

PADDLE WHEEL mechanism drops cross joists into posi. tion 10 be fed between perimeter joists at the head end of unit. Note push button controls for one.man operation.

\section{Improves Quality, Saves Nails \& Adhesive: Cardinal's New Floor Deck Extruder Cuts Time $88 \%$}

\begin{abstract}
A NEW AUTONATED FLOOR DECK exiruder machine at Cardinal Industries, Reynoldsburg, OH, has slasbed $12 \times 24^{\prime}$ deck assembly time from 60 io only seven man-minutes. 2л 88 í improvement.

Designed and developed for Cardin. al's Broad Sireet plani, the machine iniproves quality by eliminating the possibiliry of missed nails, saves about S3 per deck on nail corts and applies exactly the right amount of conaruction adhesive with no k'aste.

Bab Thompson, corporate manager of manufacturing engineering for Casoinal, explains that the machine, angineered and iabricated at a cost of aproximately 5500,000 , is one of पTre Eิrst major accomplishments of Cardinal's new cost reduction team
\end{abstract}

headed by Ron Guyer, vice president manufaciuring, and various Cardinal engineers.

The machine, is approximatily $26^{\circ}$ wide and 70' long. In operation it feeds in single or double rim joists, handies the framing nailing, automa. tically applies adhesive on the top edges of the cross and longitudinal members, lifis and positions 8'X12' sheets of Haferboard decking, then precisely. nails the decking to the cross and perimeter joists.

Buidds Floor in 7 Afinutes

"This machine arill fabricate our stancard 12'X=4" noor deck for our modular units in about seven min. vites," say's Bod. "That compares 10 our previous method of iw'o men using pneumatic nailers 10 assemble a noor deck in a jig which required 60 man mirutes."

Bob explains that the machine uses custom made nails, about 5\%" long. The bulk nails are fed by a hopper iray (w'hich cy'cles up and dow'n), through four plastic iubes into the driving mechanism. Similar to the old Morgan nailing machine, the four nails are hydraulieally pushed through the perimeter joists inio each cross member. While missed nails are extremely rase, if one should be missed, the computer con. trol immediately advises ine operator with a signal so a correction can be made.

"Even though we are using custom. made nails," say's Bob, "h'e figure w'e are saving about $S 3$ on nails per deck

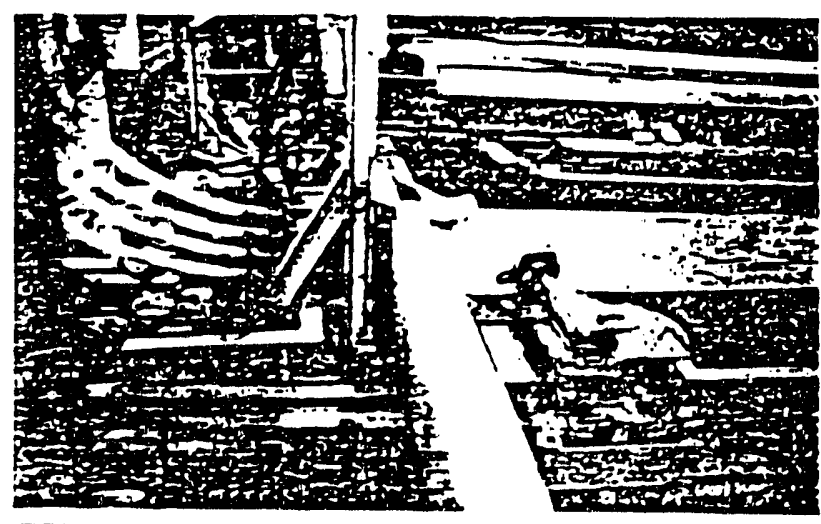

FOLR NAlls are fed through rubes and hydraulically driven through double perimeles joisis inlo cross io ists. clote bocking mechanisms which hold joisis in squared position.

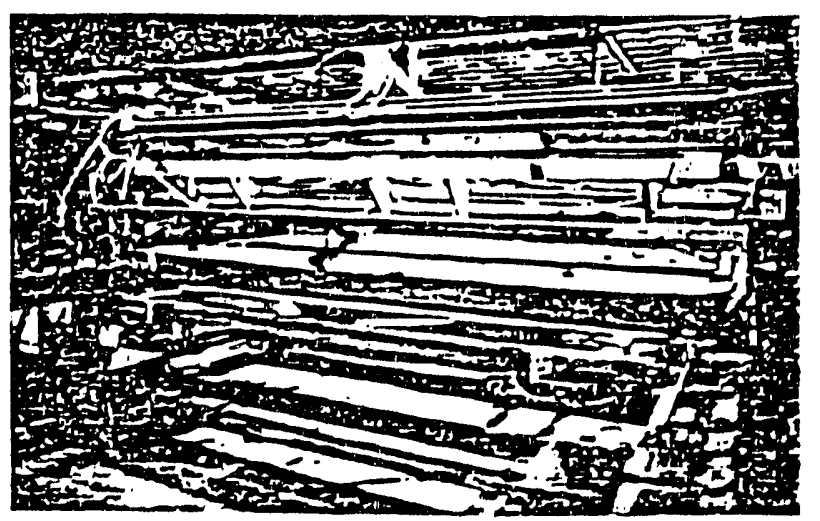

SEXSORS detect positions of all joist edges and construc. lion adhesive bead is applied to lop edges of all members as deck moves through the mechine. 


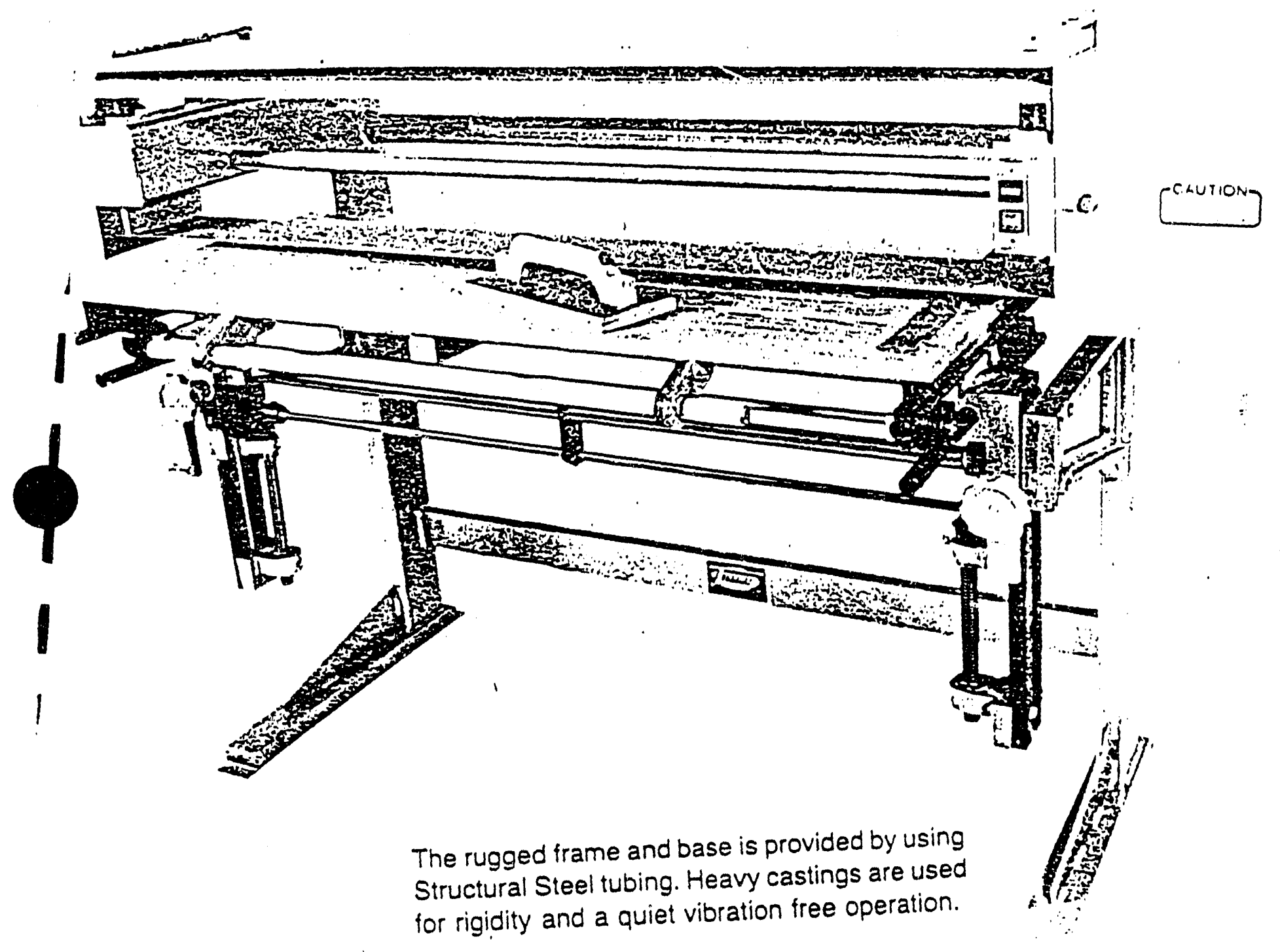




\section{MODEL FN FRAME NAILER}

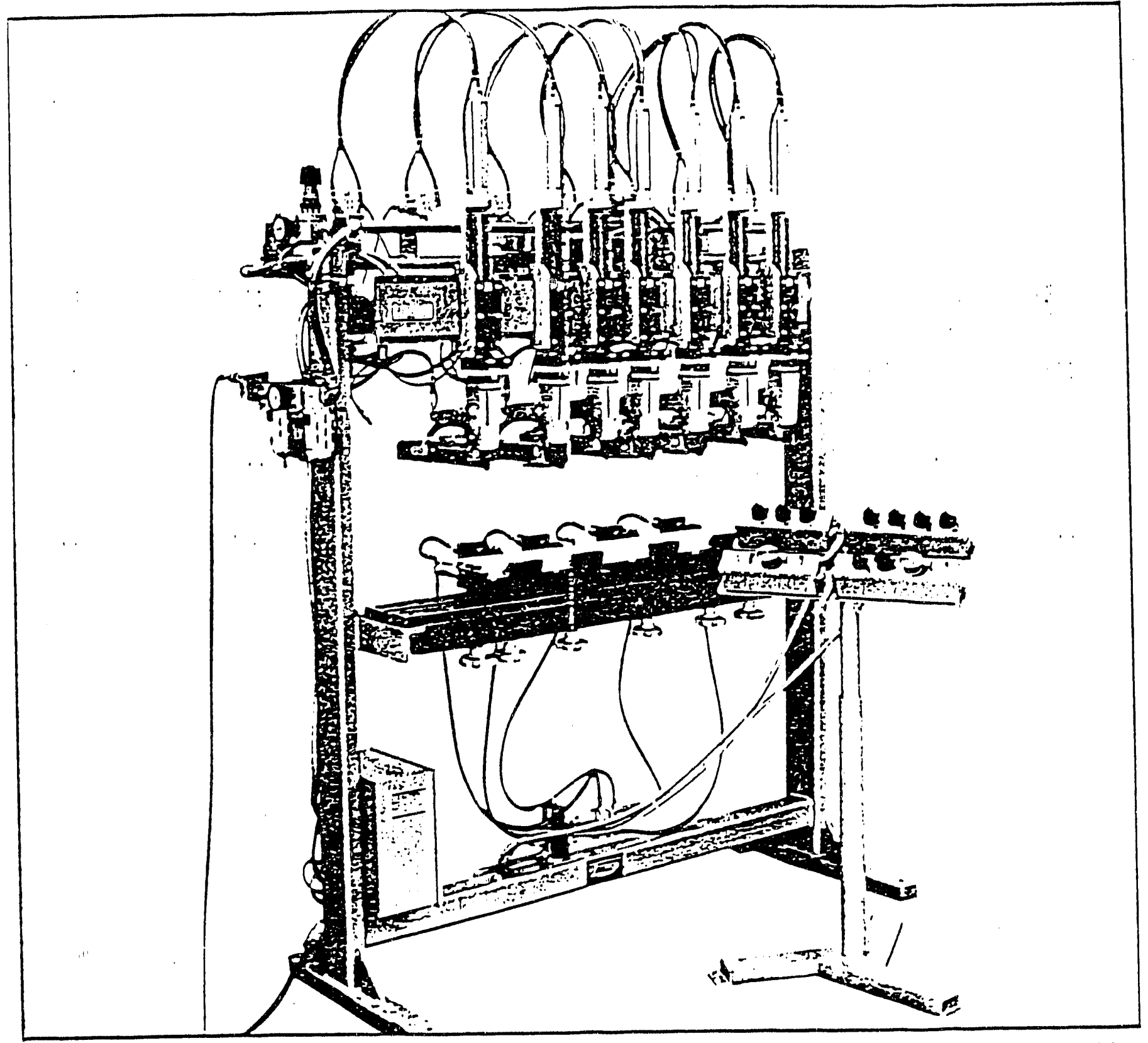

The Triad Frame Nailer is a rugged machine designed 10 provide fast, efficient, reliable assembly. The machine eliminates mis-alignment of parts and use of dangerous hand tools. All air systems have adjustable air cushions where needed to protect the equipment and the product. Mufflered exhaust ports reduce noise and add to general safety. Guaranteed consistancy of product even with mixed runs. Machine adapts quickly to produce todays frame styles from clad frames to sun roots. All components are precision machined for lorger life, reliable accuracy and the finest quality avallable. Solid steel tool bar provides a rigid straight line with each 1001 holder individually mounted on adjustable castings. The machine requires only periodic lubrication and adjustments, as stated in the maintenance manual. Oil cups and grease fittings are located for easy accessibility.:

$$
=0
$$




\section{NINDOWS}

3RICK MOLD

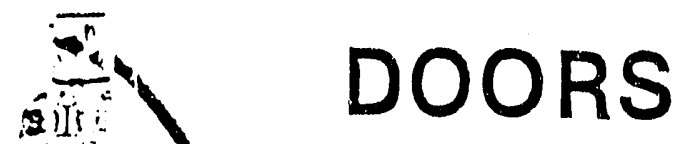

IAMB

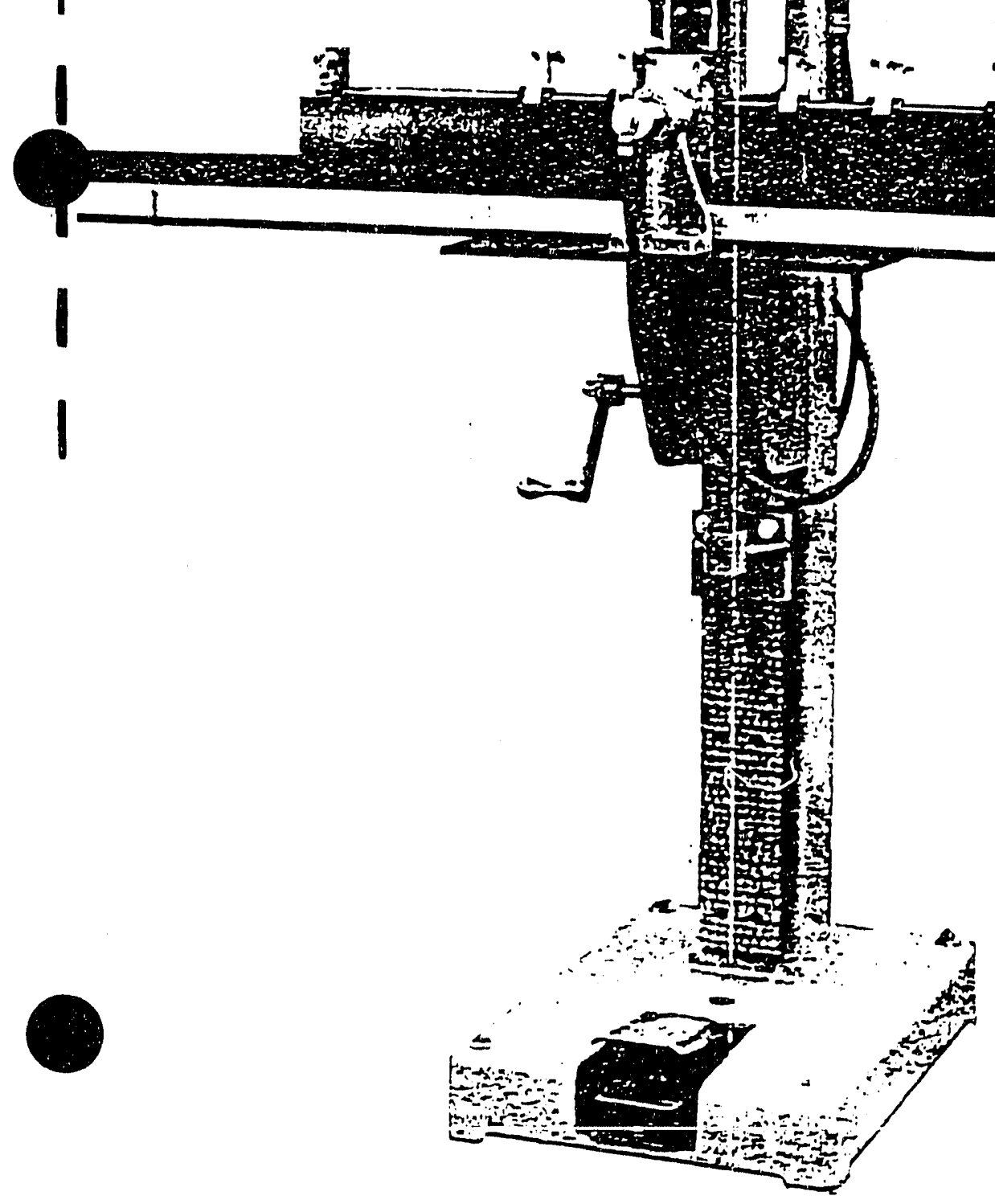


TRIAD'S

Practical, versatlle and rugged, yet priced to make modest runs as pro. PALLET TABLE

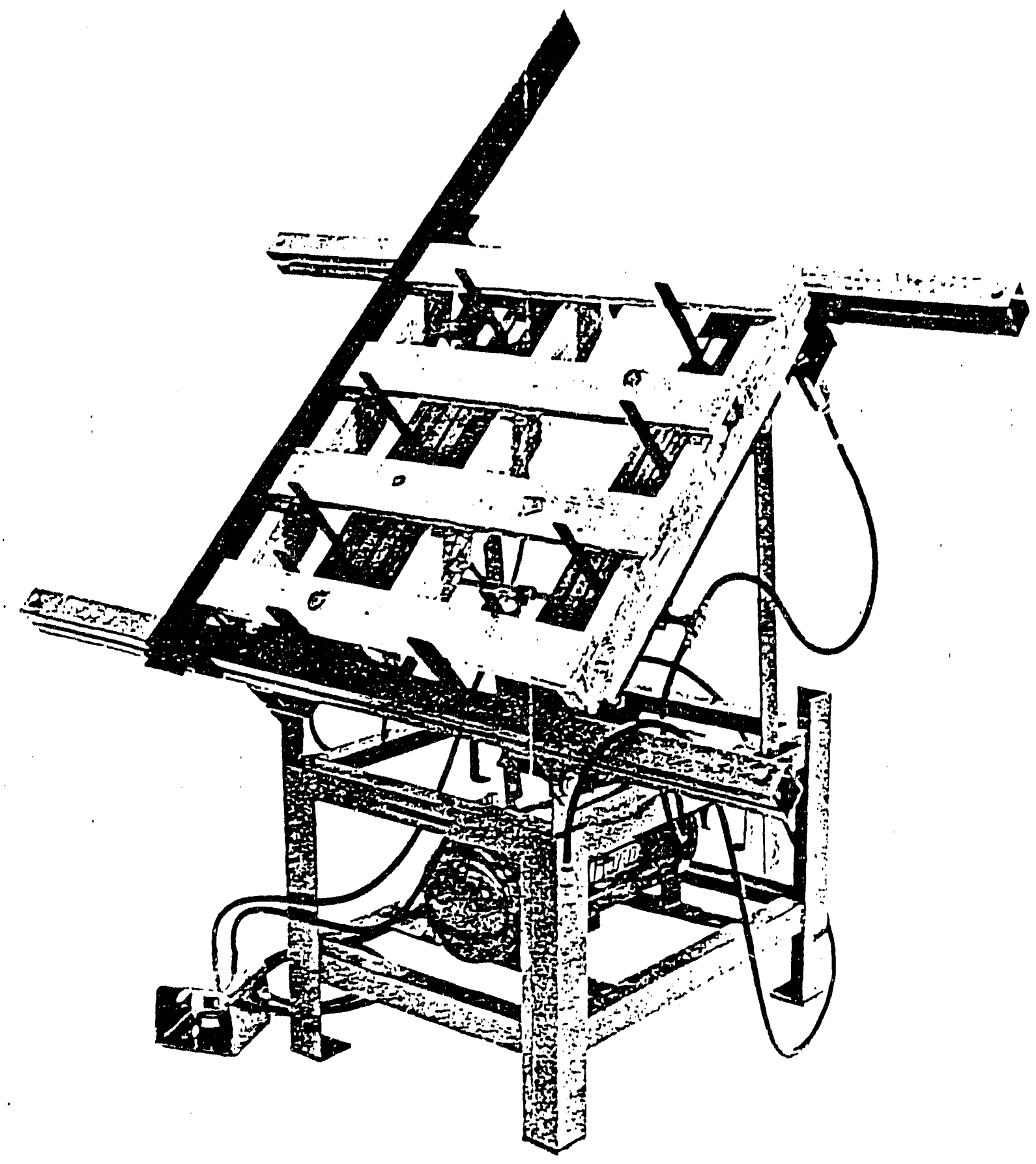

The Triad Pallet Table is designed for low volume "in house" production as well as multiple, unit high speed, high volurne: commercial production. Comes with quick disconnect..air outlet for pneumatic naller or stapler. Deluxe model is equipped with ASME air storage tank, manifoid, air reguiatioi and safety valve. The Triad Pallet Table makes quality pallets in far less time than other methrods. 
At Shelter Systems In New Jersey:

From 100 To 180 Set-ups Per Shift!

From 3,000 To 5,000 Cut Pieces Per Shift!

\section{Auto-Omni}

\section{Truly the Ultimate Component Saw!}

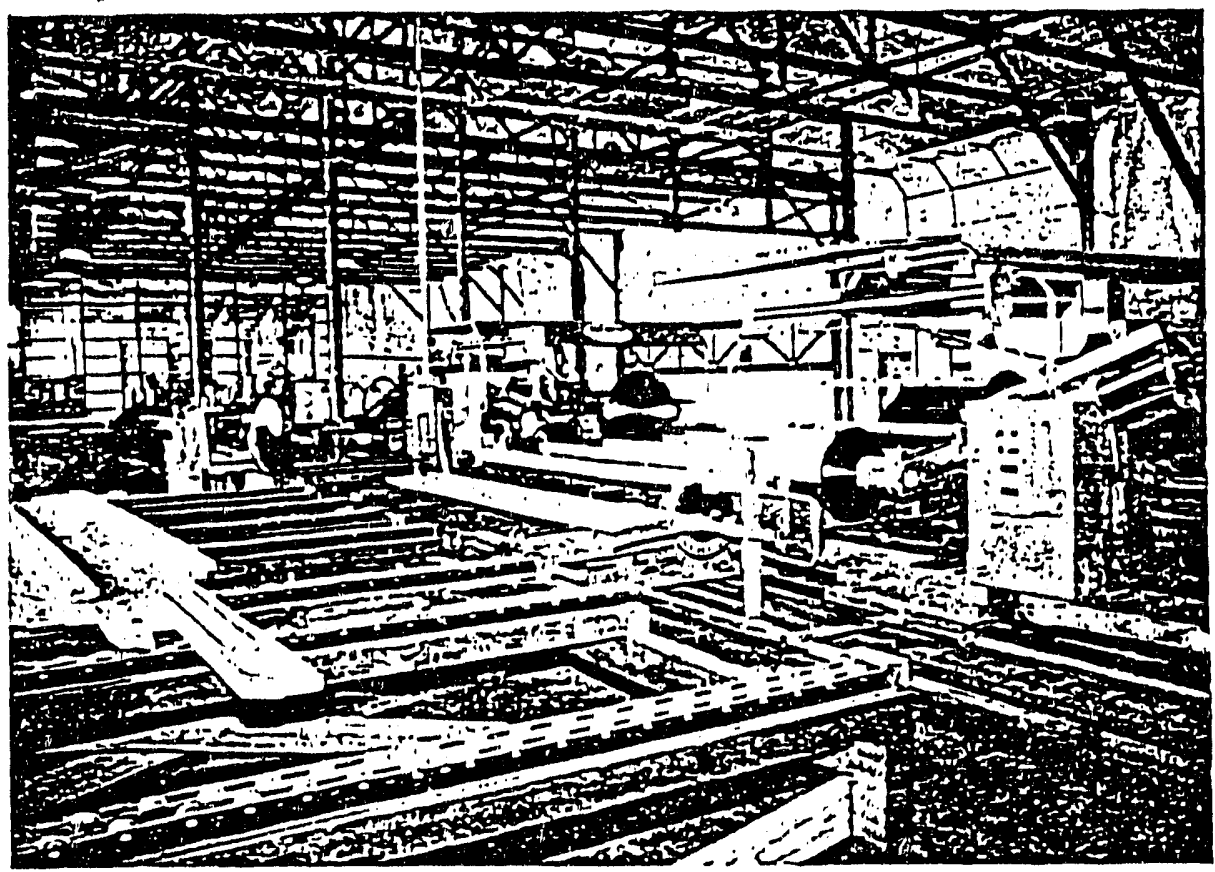

Auto-Omni Component Cutter above is similar to the machine instailed at the Shelter Systems New Jersey plant. Saw's performance at SSG has led to an order for eight more ... believed to be the first $\$ 1$ million equipment order in the component industry.

Check Your Advantages:

- Only Fully Automated Cutter

- Only Computer-Controlled Set-Ups

- Computer Screen At Sawyer's Elbow Shows The Part, Keeps The Count

- Robotically Controlled Arms Position Blades To 1/1000th of An Inch
- Set-Ups In 10 To 20 Seconds

- Why not join the growing list of industry leaders who have the Auto-Omni -- Shelter Systems; Villaume; Midwest Manufacturing; All-Fab; Load-Star; Thurndale Roof Sy'stems; Kent Truss; and others.

\section{CALL TODAY \\ Engineering Services Company \\ P.O. Box 696 \\ Rochester, MN 55903 \\ (507) 286-9209 or (507) 288-4741}




\section{Tons Of Lumber At Your Sawyer's Fingertips WITEHN 30 SECONDS!}

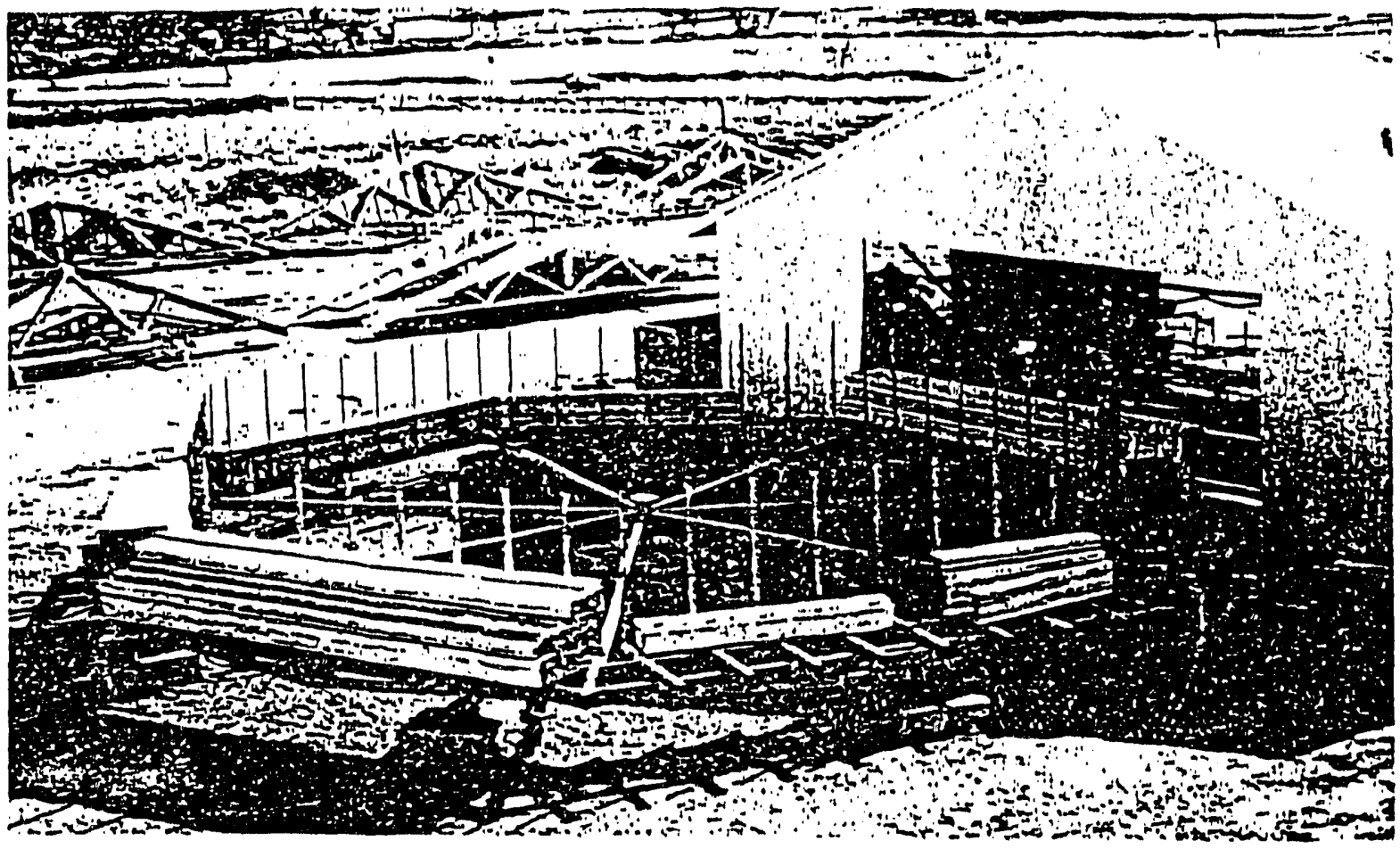

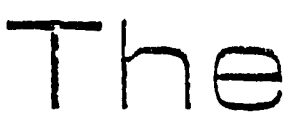

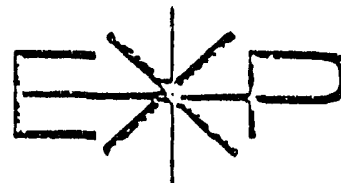

Pictured above is the 50' model of the EXPEDITER lumber bandling system. It brings a seleccion of lumber leagths right to the sauryer in as little as 30 seconds from its wost remote bay. It frees up the fork lif to work more time in the plant or tbe yard on ouber duties.

What's more important, the EXPEDITER can in. crease the componeat saw's producuivity by as much as $25 \%$.

There are three models 10 choose from: 30', 40' and 50' diameter. The EX 50 model bas seven bay's and will bold lumber up $1024^{\prime}$ long. The EX 70 model also has

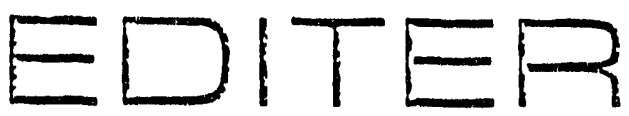

seven bays and will bold lumber up to 14' long. The EX 30 bas seven bays and bolds lumber for a $12^{\prime}$ n'eb saw.

With the bydraulically powered rollers there is no track 10 clog so stickers or chips can't jam the machine. No slab is Decessary since the Expediter can be installed on any surface.

The EXPEDIIER is the most advanced material bandling system of its kind available. Leara bow your plant can get tbe MOST out of your componeat saw. Call us today and find out why w'e call it the EX. PEDITER. A videotape is arailable.

\section{Call \\ TOLL-FREE 1-800- $877-5151$}

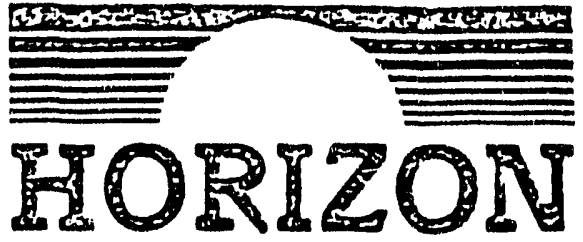

Equipment Manufacturing, Ine. Manulociurer of the Espediter

1701 Dowell Road, Grants Pass, Oregon 97527 (503) 479-5264 


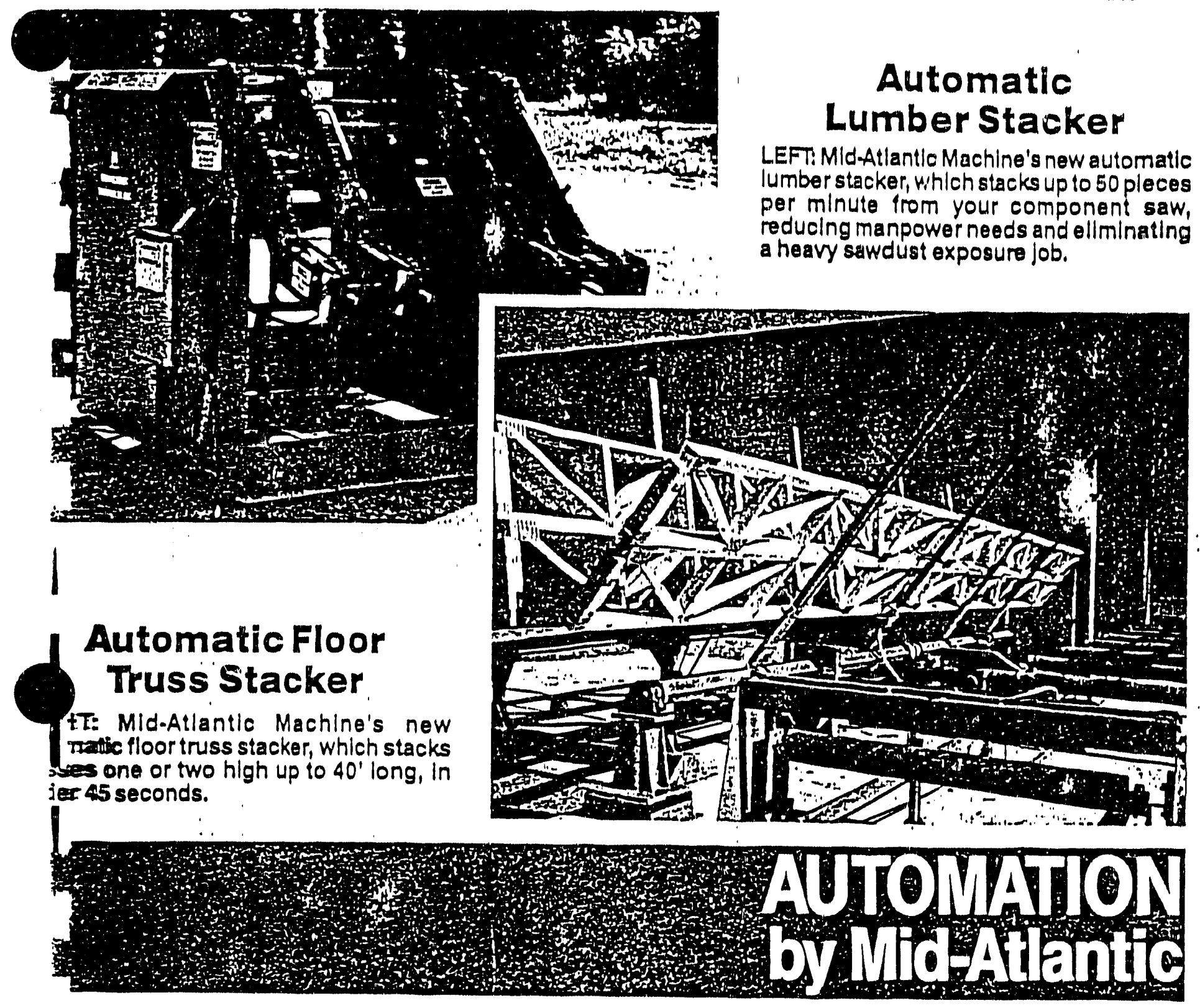

MidAtlantic is the expert's choice for plant The new automatic floor truss stacker Fumatic lumber stacker join our other proven II-sering, high-production equipment:

Tre Trussmaker Automated roller gantry roof "Fstem with 18" or 24" diameter gantry heads. ure Floor Thussmaker Roller gantry foor system zuring a 24" diameter embedment roll and matic depth set-up.

"Trussmaker Final Roller With 24" diameter i

- Roof Truss Stacker Automatic handling f for trusses up to 80' in. length.

cus help increase your productivity and reduce mower requirements.

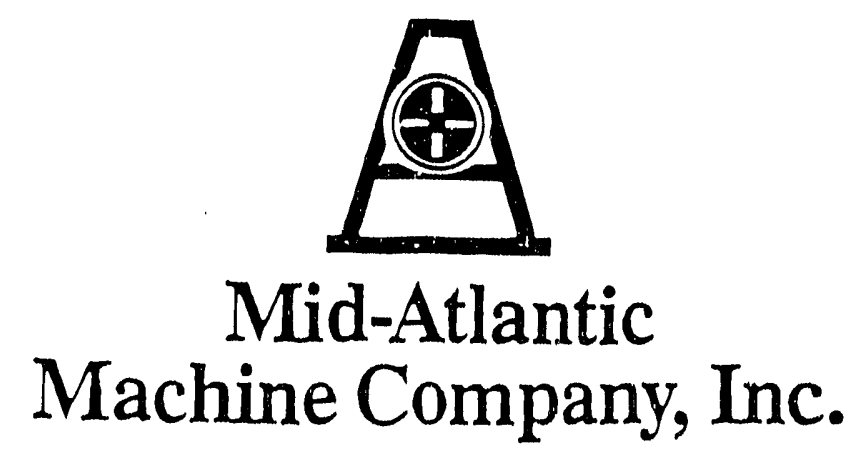

AUTOMATION SPECIALISTS P.O. BOX 585 EDENTON, NC 27932 $919-482-2178$ 


\section{OUR FINEST EFFORT... THE CLARY MASTER}
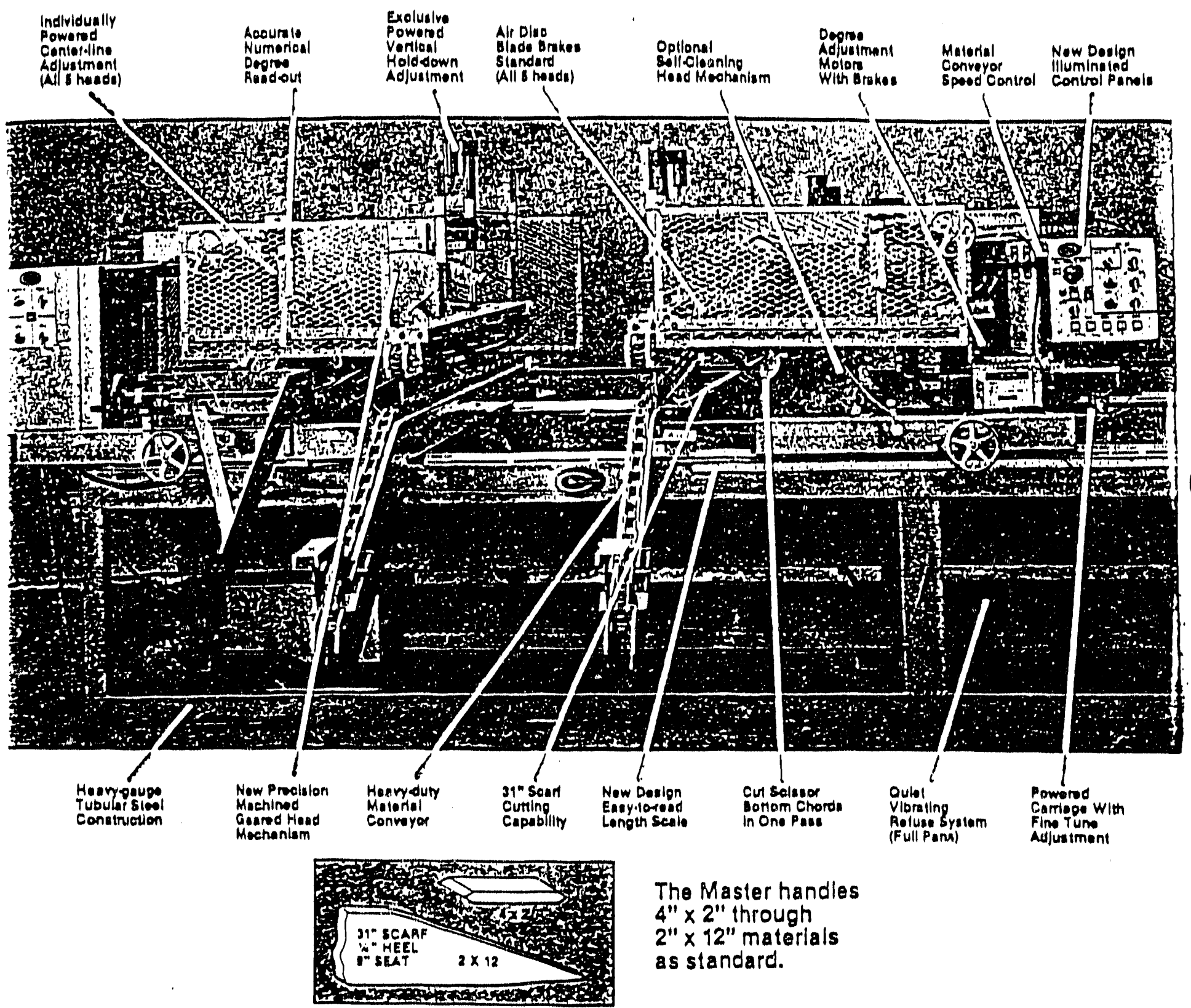

The Master handles

$4^{\prime \prime} \times 2$ " through

$2^{\prime \prime} \times 12^{\prime \prime}$ materials

as standard.

Don't miss seeing the new Clary Master in action... ORDER OUR NEW VIDEO TODAY.

For complete information contact:

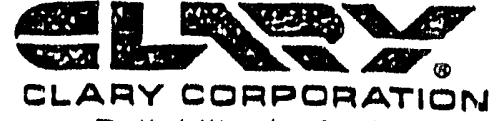

Rel!ab!!lty !n Act!on

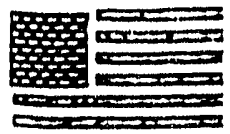

2
First Name

in American Made

Component Cutters

1801 South Great Southwest Parkway - Grand Prairle. Texas 75051 


\section{aterial Handling}

\section{Transfer and storage Carts}
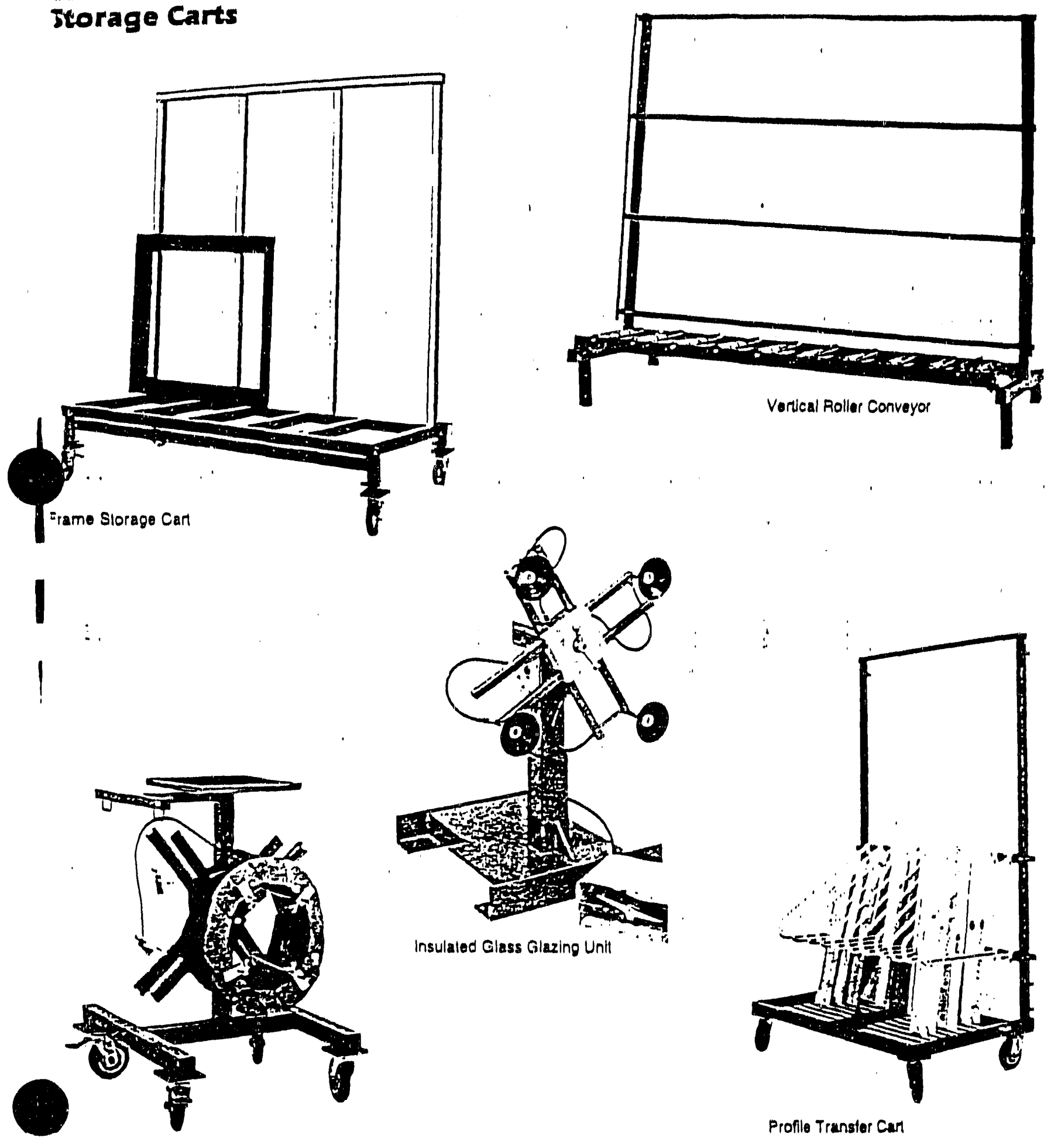

Nool Pllo Can 


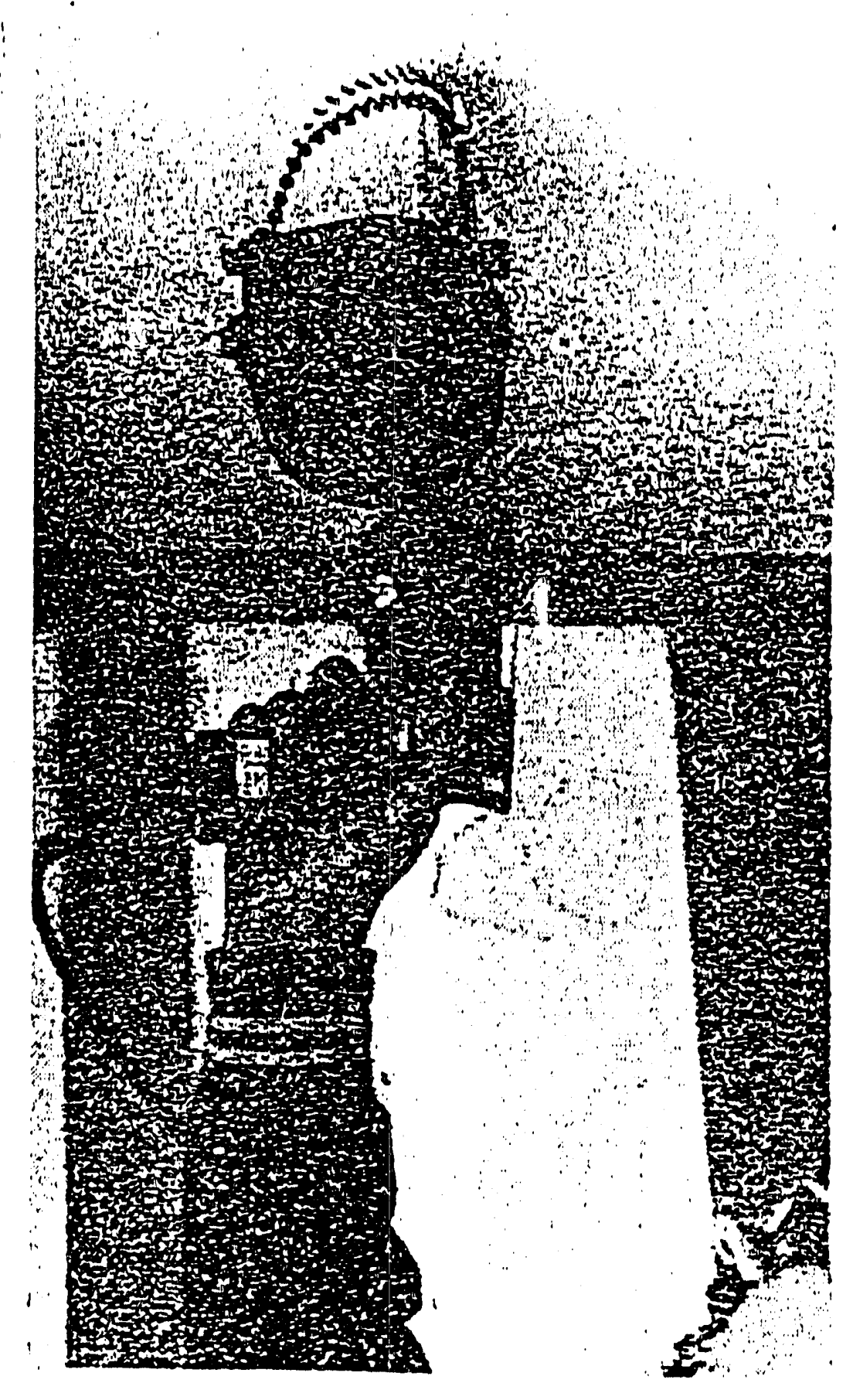

Quik Drive Fastening System, Quik Drive, Port Sydney, Ontario, converts mostair-powered and electric screw guns into coil-fed drivers for installing subflooring, drywall and panel assembly. 

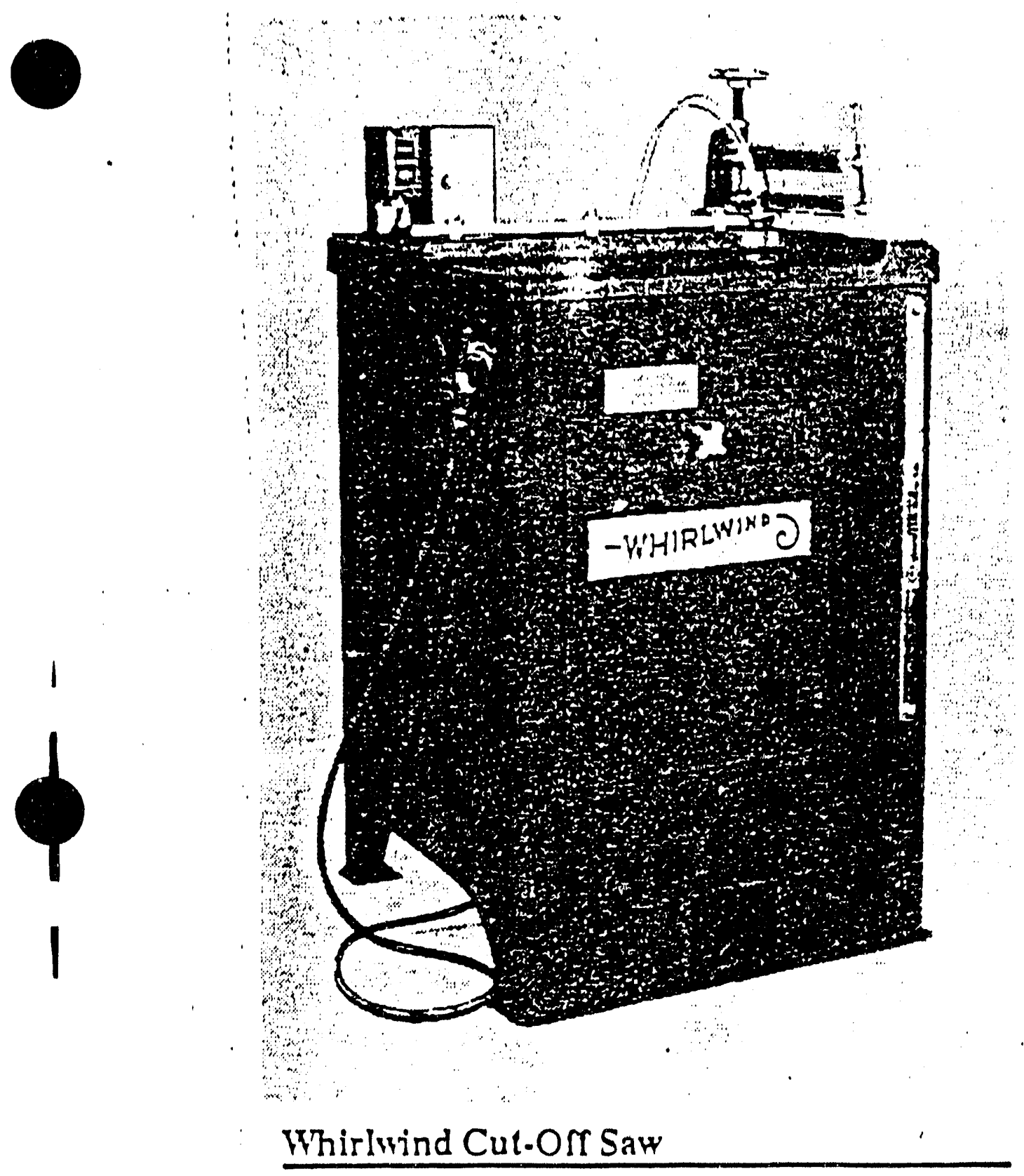

Whirlwind Cut-Off Saw, Whirlwind Inc, delivers cutting speeds of up to 90 cuts per minute, automatic clamping, accuracy and reliability. Each saw is tested under power for 4.5 hours and double checked for quality and squareness of the saw cut before shipment. One-day shipment of repair parts is guaranteed or Whlrlwind pays the frelght charges. $P$-ices start at $\$ 2,760$ FOB. 


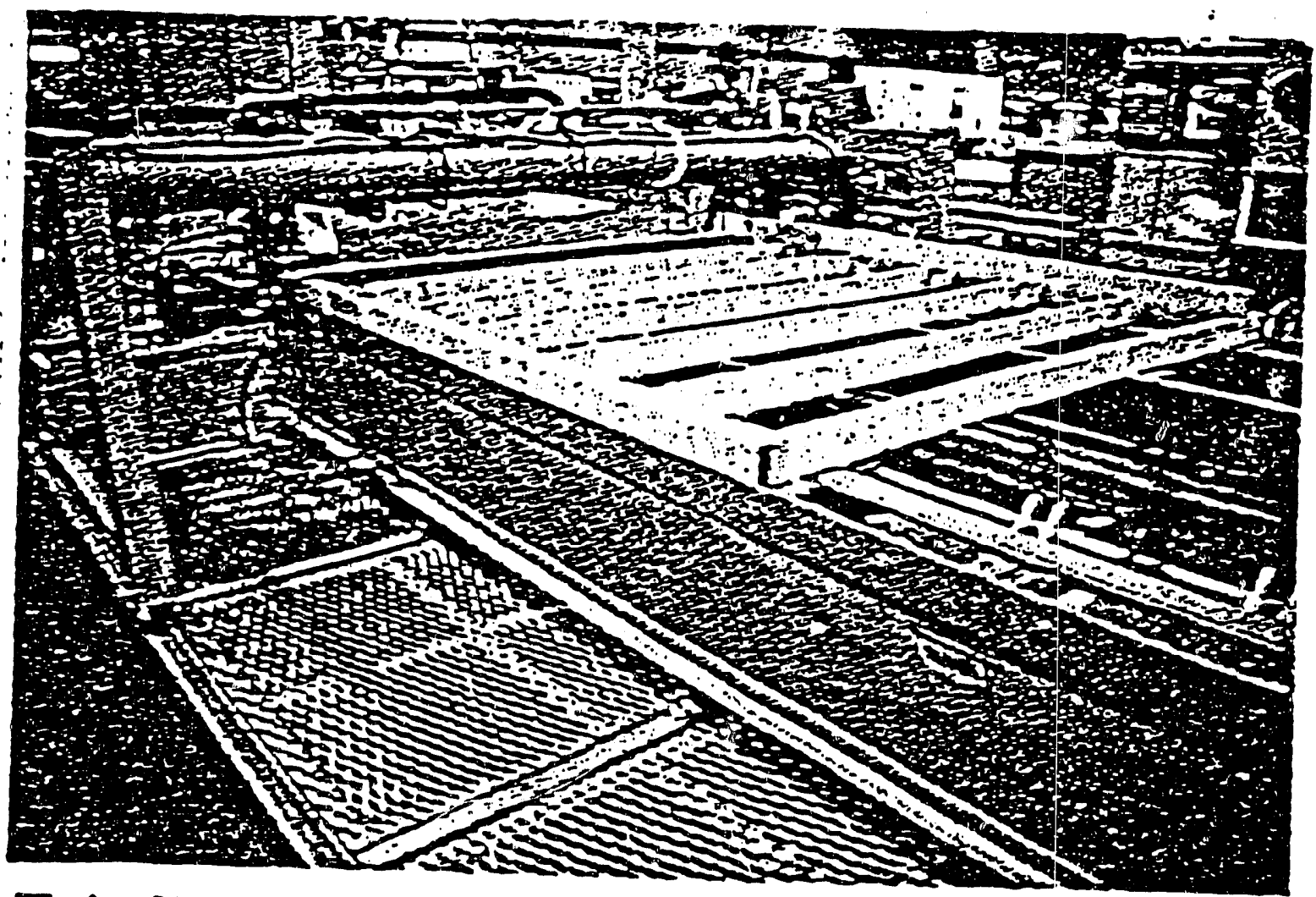

Triad's New Heary Duty Franing Table with Stud Stitcher Bridge is custon-built from 12' to 80 ' to fit your nceds. Adjusts from 3'-6" to 10.'3" for different wall heights. Cast iron stud locating flippers 16" and 24" O.C. Con. tinuous squaring lip full length of the table. Heary duty stcel rollers with roller bearings used to convey walls off. Simple push bution controls opcrate table and roller control system. Tape track for laying in window and door openings. Table rails accommodate Stud Stitcher. 


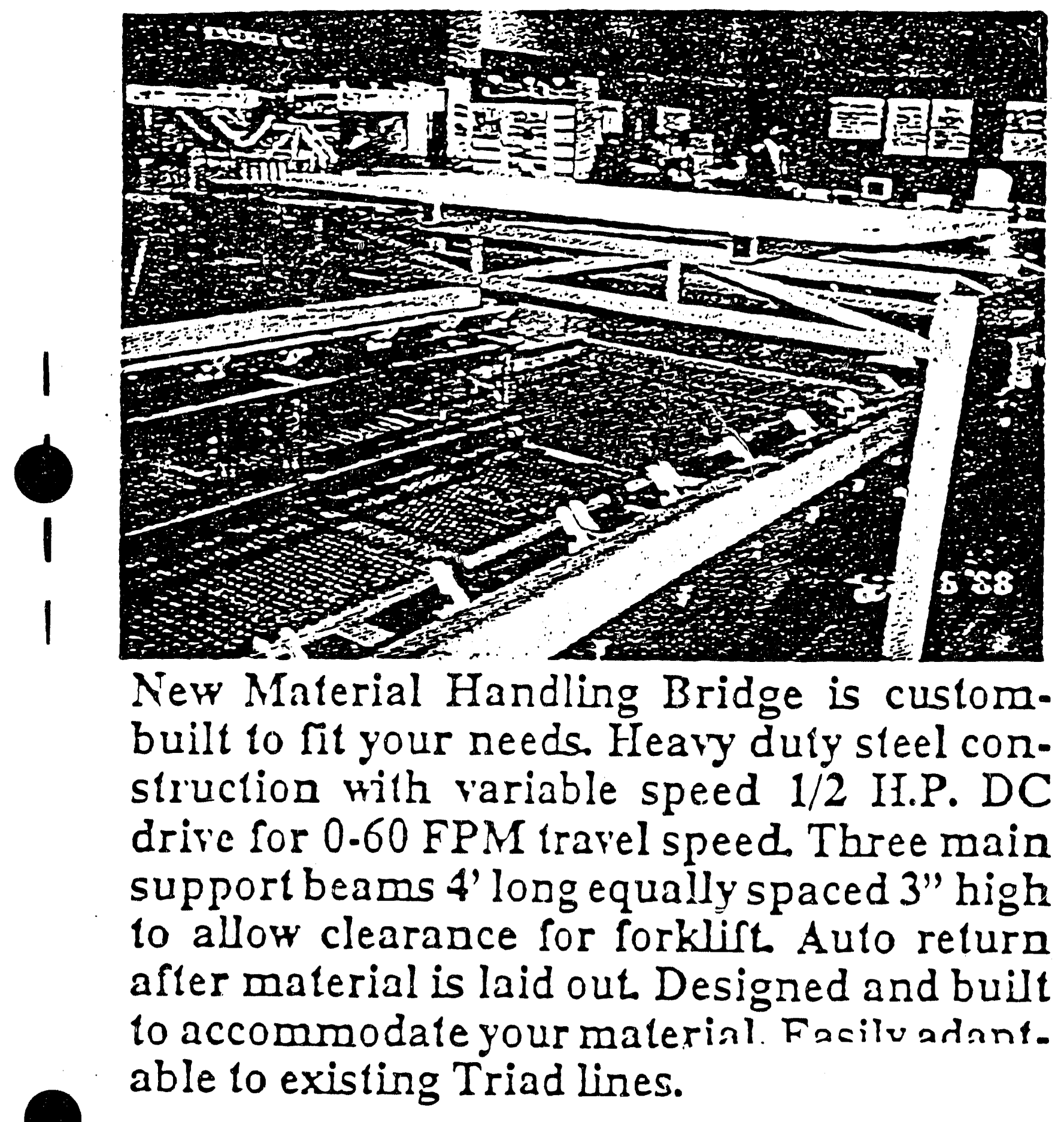




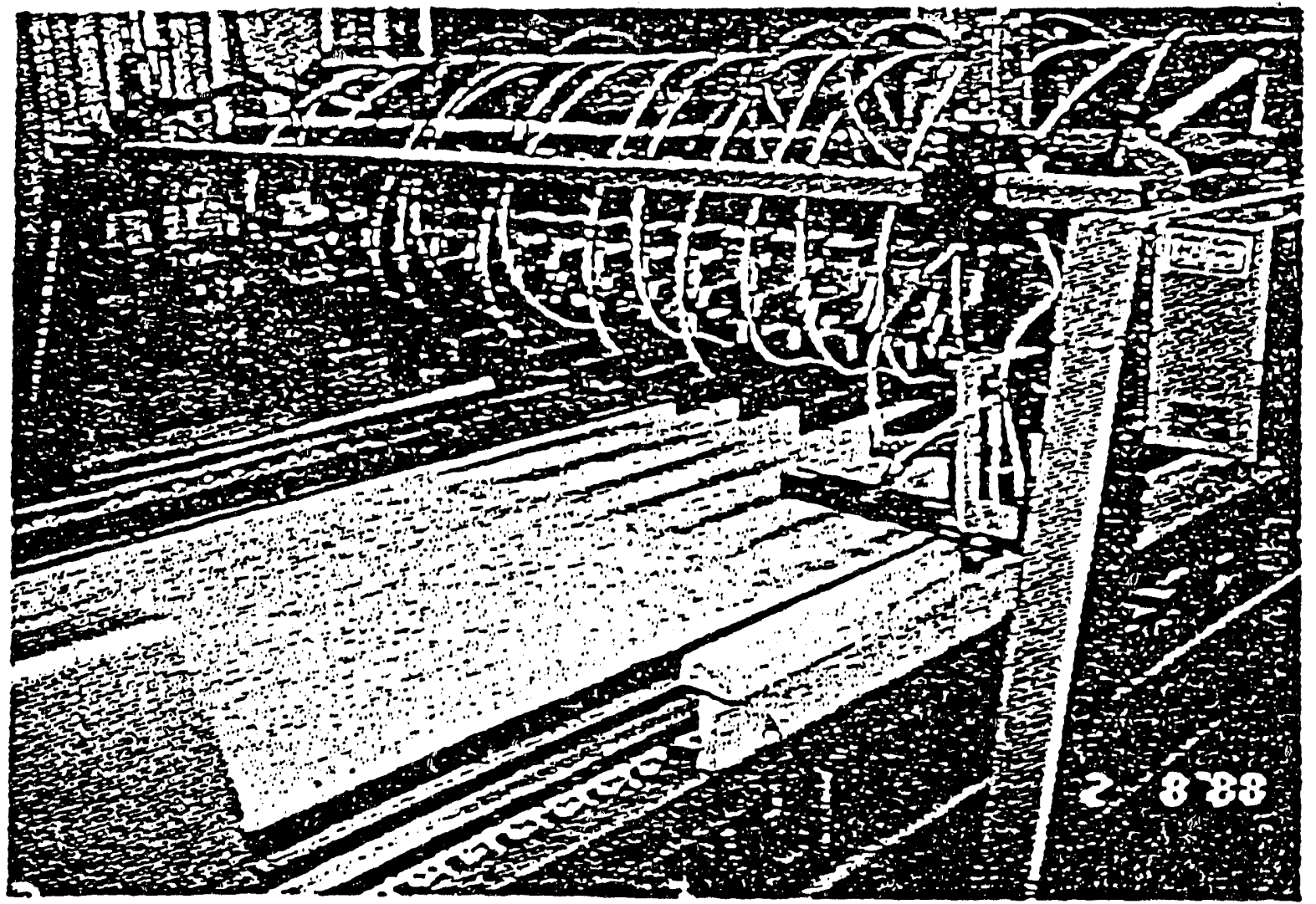

Panel Stapler by Triad helps you control today's construction costs by building quality, square walls with fewer people. Be assured of accurate nail and staple placement to codes. Latest state-of-the-art Laser Pointer for indicating staple and nail locations, along with programmable controllers that control the functions of one bridge. Space fire tools used to fasten top and bollom plate. One man operation with a simple control box make for high production. 


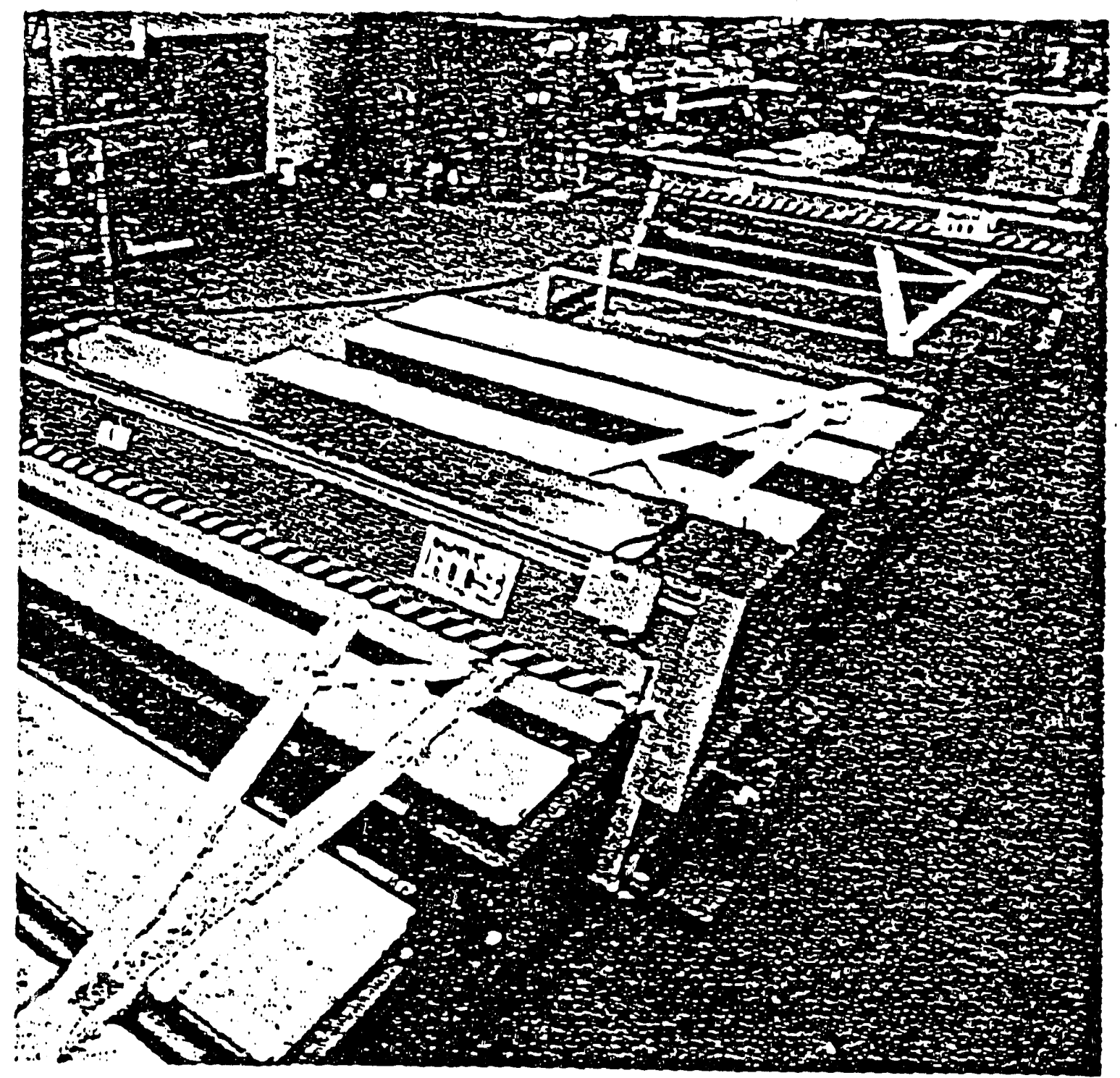

The new RTS (Rapid Truss System) combines truss assembly with material handling for high rolume, costîñ̂̃ective production and fast operation. 
APPENDIX B

List of Equipment Manufacturers 


\section{LIST OF MANUFACTURERS}

\section{Company}

ADVANCED AUTOMATION SYSTEMS

Enterprise Corp. Towers,

1 Corporate Drive, Suite 404

Shelton, CT 06484

(203) 925.0332

ALPHA \& OMEGA INTEGRATED

CONTROL SYSTEMS, INC.

3244 Washington Rd.

Suite 240

McMurray, PA 15317

(412) 941-3205 (Steve Latterman)

ASSEMBLY AUTOMATION INC.

1858-T Business Center Dr.

Duarte, CA 91010

(818) $303-2777$

AUTOMATIC SALES, INC.

P.O. Box 411

Col., MO. 65205

1-(800) 333.8758

BLAN-KNOX EQUIPMENT

P.O. Box 11450-T

Pittsburgh, PA 15238

1-(800) 253.2000

BUCK'S MACHINERY, INC.

Star Route 63 Bux 95

Guntersville, AL 35976

(205) $582-2133$

CLARY CORP.

1801 S. Great S.W. Pkwy.

Franklin Park, IL 60131-2176

1-(800) $527-6621$
Products

Industrial Engineering/Manufacturing Consultants

Layout Equipment \& Systemization

Automatic Screw

Feeding and Driving Systems

Truss \& Wall Panel

Trailers

Material Handling

Lifting Equipment

Machine Tools

Lathes

Mills

Saws, etc.

Componet Cutter 
CONSTRUCTION AUTOMATION

EQUIPMENT CO.

727 Deep Valley Dr.

Palos Verdes, CA 90274

CYBERMATION, INC.

5457 Aerospace Rd.

Roanoke, VA 24014

(703) $982-2641$

DUO FAST CORP.

3702 River Rd.

Franklin Park, IL 60131-2176

1-800-752-5207

GANG-NAIL SYSTEMS, INC.

P.O. Box 59-2037 AMF

Miami, FL 33159-2037

1-800-752-5207

GENERAL AUTOMATION

8585.T Commerce Ave.

San Diego, CA 92121

(619) $578-3033$

HERCULES MANUFACTURING CO.

P.O. Box 263269

Escondido, CA.

HIAB GRAVES \& LOODERS, INC.

34 Blevins Dr., Suite 10

New Castle, DE 19720

(302) $328-5100$

JOGER INDUSTRIES, INC.

8710 Horton Rd. S.W.

Calgary, Alberto, CANADA

T2V $2 X 4$

(403) $254-0773$

JOHN W. PORTER, INC.

$23 \mathrm{~N}$. Bluff Rd.

Chesapeake City, MD 21915

(310) $885-5233$
Cutting Machinery

Material Handling Equipment

Assembly Tools

Mobile Robot Systems

Material Handling

Tool Changes

Inventory Retrieval etc.

Self-Feeding

Screwdrivers

Truss Machines

Assembly Machines, Parts

Handlings Inspection

Systems, Pnuematic Tools

Non-Automated Pick \&

Place Lifting Equipment

Cranes \& Loading Equipment

Roof \& Floor Truss

Machinery

Automated Construction

Machinery; Trusses, Panels

Doors, Windows, etc. 
KAL-TECH CORP.

35-T James Way

Eatontown, NJ 07724

(201) $389-2500$

KALTENBACH, INC.

6775 Inwood Dr.

P.O. Box 1629

Columbus, IN 47202

(812) $342-4471$

KANT-SAG (UNITED STEEL PRODUCTS CO.) Truss Hangers

703 Rodgers Dr.

Montgomery, MN 56069

1.800-KANT-SAG

MARK V TOOL CORP.

36 Race St.

Bristol, CT 06010

(203) 582.7437

MERRICK MACHINE CO.

P.O. Box 130

Alda, NB 68810

(308) $384-1780$

METRIGUARD

P.O. BOX 411

Pullman, WA 99163

(509) $332-7526$

METRIX INDUSTRIES

P.O. Box 886

691 St. Paul St. (Dept. 501)

Rochester, NY 14603

(716) 232.4530

MUNCK AUTOMATION TECH., INC.

P.O. Box 6677

Newport News, VA 23606

(804) $838-6010$
Custom Automated Equipment

Cutting Equipment

Jigs, Fixtures

Tools, CNC, etc.

Sub Assembly Nailers,

Pallet Tables, Automated Machinery, etc.

Production Line Test

Equipment

Inventory Systems

Tooling

Inspection Systems

Auto/Manual Storage

\& Retrieval Systems,

Load/Unload Machines 
NASA MACHINE TOOLS

8-T Industrial Rd.

Pequannock, NJ 07440

(201) 633-5200, Ext. 9

OMNI LIFT, INC.

332 W. 1700 South, Dept. 86,

Salt Lake City, UT 84115

(801) $486-3776$

OMNI PLASTICS OF CANADA

22 Weneil Dr.

Freelton, Ontario

CANADA LOR $1 \mathrm{KO}$

1-800-344-7788

OMNITOOL, INC.

3502 48th Ave. N.

Minneapolis, MN 55429

(612) $535-4240$

OMNIITRON TOOLING \& ENGINEERING

P.O. Drawer 4402

Euchart, IN 46514

(219) $262-2083$

OMNITEK COMPUTER SYSTEMS

Bay 3, 2115w 27 th Ave.

N.E. Calgary, Alberta

CANADA T2E 7E4

(403) $291-2988$

O'NEILL MANUFACTURING CO.

Dept. TR, P.O. Box 949

Rome, GA 30161

(404) 295-1414

ONSRUD CUTTER MANUFACTURING CO.

800-T Liberty Dr.

Libertyville, IL 60048

(312) $362-1560$

ORANGE TOOL CO.

1733-T Monrowia, Unit "L"

Corta Mesa, CA 92627

(714) $548-7616$
CNC Tools

CAD/CAM Systems

Material Handling:

Conveyors

Loaders/Unloaders

Etc.

Plastics, Molding

Port Fabrication

High Precision Machine

Parts Tools \& Dies

Conveyor Systems

Data Acquisition

\& Control Systems

Lumber \& Millwork

Cutting Equipment

Tool Design, Jig,

Fixtures, Dies, etc 
ORANGEVILLE MANUFACTURING CO.

507 Main St. Box 2150

Orangeville, PA 17859

(717) $683-5113$

PANEL PROCESSING OF ILLINOIS, INC. 2600-TS Emerald Ave.

Chicago, IL 60616-2598

(312) $842-0330$

PENDU, INC.

R.D. 1, Box AB-425

New Holland, PA 17557

(717) $354-4348$

PENTALIFT EQUIPMENT CORP.

1552 Hertel Ave. Suite 901-T

Buffalo, NY 14216

(519) $763-3625$

POSTALUCK CORP.

P.O. Box 24

Windsor, VT

QSOURCE ENGINEERING, INC.

228 Byers Rd.

Miamisburg, OH 45342

1-800-356-9039

ROBOPAC

5933-A Peachtree Industrial Blvd.

Norcross, GA 30092

(404) $448-1120$

ROYAL INDUSTRIAL STORAGE SYSTEMS

Atkins Center

P.O. Box 2844-T

Spartanburg, SC 29304-2844

(803) $574-5931$

SAFETY SPEED CUT MANUFACTURING CO. 13462 N. Hwy. 65

Anoka, MN 55304

(612) 755-1600 Ext. 12
Automated Factory

Warehouse Equipment

Hardboard, Particleboard, etc.

Cutting Equipment, Gang Saws, Auto-Stackers, etc.

Elevating Docks

Lift Tables

Joint Trimmers

Miters

Industrial Engineering/Manufacturing.

Consultants

Mobile Pallet

Wrapper

Sideloaders for

Pallets, Materials

Fixtures, etc.
Panel Saws, Vertical/Horizontal panel Routers 
SAILRAIL ENTERPRISES, INC. 1935.D Dilk Industrial Blvd.

Marietta, GA 30067

(404) 952.8377

SAMPSON AUTOMATION CO., INC. 140 Commerce Dr.

Hanppauge, NY 11788

(516) $231-1900$

SHUTTLELIFT, INC.

49 E. Y'ew St.

Sturgeon Bay, WI 54235

(414) 743.8650

SPEED CUT, INC.

P.O. Box 1125

Corvallis, OR 97339

(503) $928-1281$

STANDARD TOOL \& MANUFACTURING CO. 710 Schuyler Ave.

Lyndhurst, NJ 07071

(201) $939-5500$

STERLING TOOL \& MANUFACTURING CO. Jigs, Fixtures, Dies

No. 60 W22700

Silverspring Dr. Dept. TR

Sussex, WI 53089

(414) $246-6246$

SUBNER INDUSTRIAL PRODUCTS CO.

P.O. Drawer A

Highway 411 South/Subner Dr.

Rome, GA 30162-1234

(404) $235-8046$

TYLER MACHINERY CO., INC.

654 S. Detroit St.

Warsaw, IN 46580

(219) 267.3530

VERSATRON CORP.

103 Plaza St

Healdsburg, CA 95448

(707) $433-8244$
Conveyor Systems

Storage \& Retrieval Systems

Stacker Machines

Extrusion, Cutting, Fabrication Machinery, Assembly Machines, Material Handling Equipment, etc.

Mobile Straddle Hoist

Mobile Frames

Mobile Cutters
Automation Production Machinery Assembly Systems, Transfer Equipment, FMS, etc.

Drilling Equipment

Cutting Equipment

Factory Automation Systems 
VESTIL MANUFACTURING CO.

P.O. Box 507.A

Angola, IN 46703

1.800-348-0868

WHITNEY SYSTEMS

53 Parkhurst St.

Chelmsford, MA 01824

(508) $937-7444$
Lifting Equipment

Factory Automated Equipment 

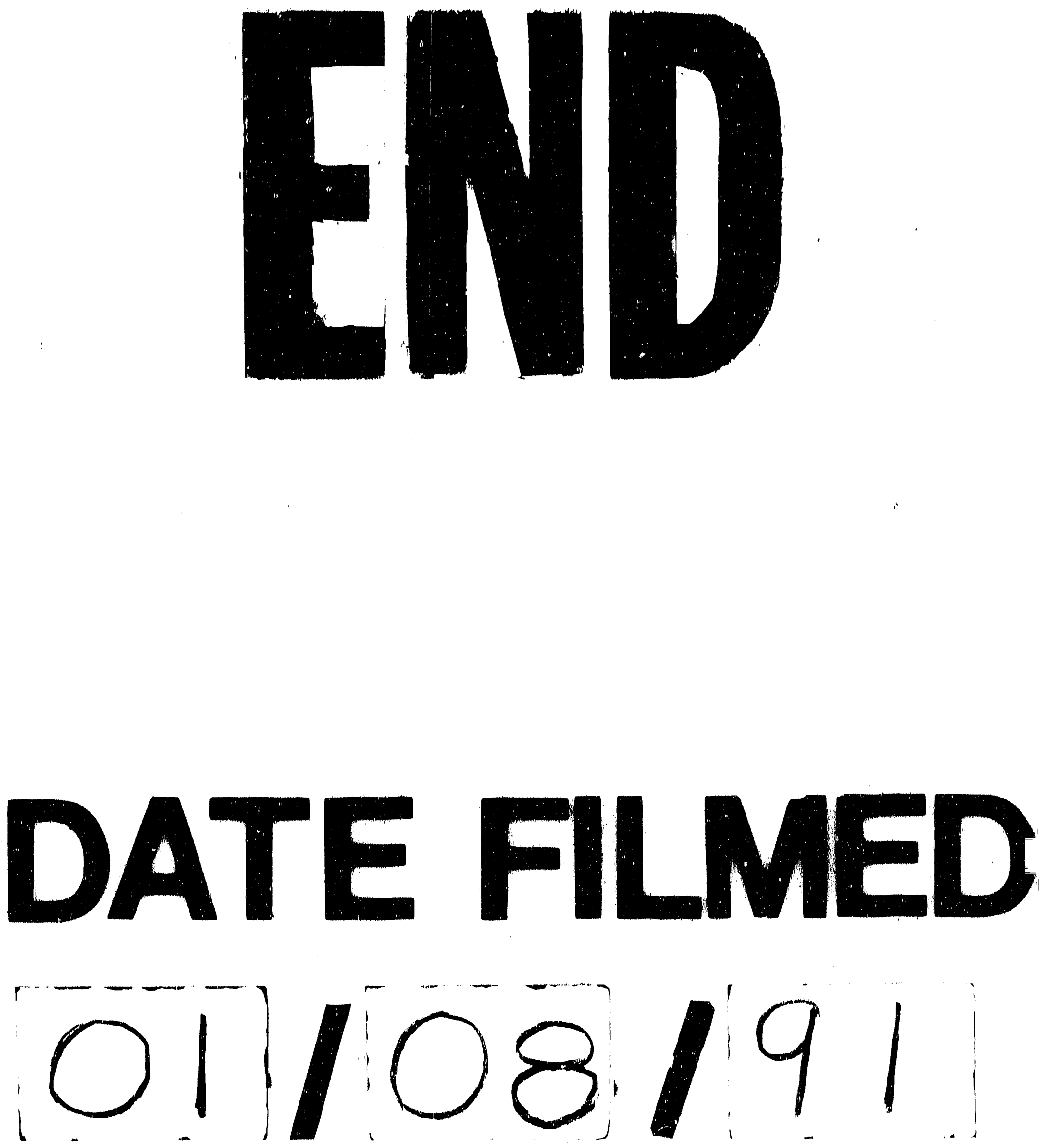
